\title{
Graphical user interface for three-dimensional FE modeling of composite steel bridges
}

\author{
Aditya Vuchi \\ West Virginia University
}

Follow this and additional works at: https://researchrepository.wvu.edu/etd

\section{Recommended Citation}

Vuchi, Aditya, "Graphical user interface for three-dimensional FE modeling of composite steel bridges" (2005). Graduate Theses, Dissertations, and Problem Reports. 1689.

https://researchrepository.wvu.edu/etd/1689

This Thesis is protected by copyright and/or related rights. It has been brought to you by the The Research Repository @ WVU with permission from the rights-holder(s). You are free to use this Thesis in any way that is permitted by the copyright and related rights legislation that applies to your use. For other uses you must obtain permission from the rights-holder(s) directly, unless additional rights are indicated by a Creative Commons license in the record and/ or on the work itself. This Thesis has been accepted for inclusion in WVU Graduate Theses, Dissertations, and Problem Reports collection by an authorized administrator of The Research Repository @ WVU. For more information, please contact researchrepository@mail.wvu.edu. 


\title{
GRAPHICAL USER INTERFACE FOR THREE- DIMENSIONAL FE MODELING OF COMPOSITE STEEL BRIDGES
}

\author{
Aditya Vuchi \\ Thesis submitted to the \\ College of Engineering and Mineral Resources at \\ West Virginia University in \\ partial fulfillment of the requirements \\ for the degree of
}

\section{Master of Science}

in

Mechanical Engineering

Jacky Prucz, Ph.D., Chair

Karl E Barth, Ph.D., Co-chair

Thomas Damiani, Ph.D.,

Department of Mechanical and Aerospace Engineering

\section{Morgantown, West Virginia \\ 2005}

Keywords: Finite element modeling, bridges, 3d modeling, influence surface, ABAQUS 


\section{ABSTRACT \\ Graphical User Interface for Three-Dimensional FE Modeling of Composite Steel Bridges}

\section{Aditya Vuchi}

The goal of bridge engineers has always been to design economical structures that are safe, serviceable and durable. In order to assess the performance and safety of these bridges, one of the analytical methods employed is finite-element (FE) modeling. This method involves breaking down the bridge structure into an assembly of finite-sized elements. The behavior of the elements and the overall structure can be obtained by formulating a series of constitutive relationships and algebraic equations that can be readily solved with computer processors.

Extensive research is being carried out to develop efficient finite element programs for bridge design. As a part of continuing research at West Virginia University to conduct parametric studies on in-service and model bridges, this work aims to develop a convenient and reliable analysis platform.

This is accomplished by creating a Graphical User Interface (GUI) for modeling 3D bridges that uses ABAQUS as the analysis tool. With the use of influence surfaces generated by the post-processor also developed in this research, variable loading conditions can be simulated to calculate the maximum force effects in the bridge superstructure.

The GUI uses Visual Basic.Net to generate the 3D FE model of steel-concrete composite bridges. The software provides a graphical environment to view 3D models of a bridge using OpenGL. The post-processor application, developed in Microsoft Access, generates influence surfaces for analysis of response parameters for different loading conditions.

A verification study has been conducted on two bridges; a simple-span testing bridge at University of Nebraska, Lincoln, NE and a continuous-span bridge constructed at the Turner Fairbanks Highway Research Center, Virginia. The FE analysis results obtained using the GUI shows a good correlation with previously published test results. Also, when compared with the commercial FE pre-processor, FEMAP Version 8.3, the GUI developed in this research achieves a significant reduction in modeling time for 3D tangent simply supported and continuous-span composite steel bridges. 


\section{Acknowledgements}

I would like to thank my advisor; Dr. Karl Barth for giving me the opportunity to work in a very interesting area, and for his continued support and guidance along with my committee members Dr.Jacky Prucz and Dr. Thomas Damiani

Valuable input from my colleagues, Lili Yang, Dr. Jennifer Righman, Laura Wolfe and Andrew Hayes in conducting the preliminary studies of the finite element modeling is much appreciated.

The contributions of Dr. Eric Williamson, whose research work and studies helped determine the software tools used in this study, are gratefully acknowledged.

Many thanks are due to my friends; Neelima for helping me get through the programming concepts learning curve, Raju for a great roommate and friend and Aneesh for putting up with me during numerous odd hours to help formalize my documentation. I would like to thank my family for their encouragement and support and for providing me the opportunity to study at West Virginia University. 


\section{TABLE OF CONTENTS}

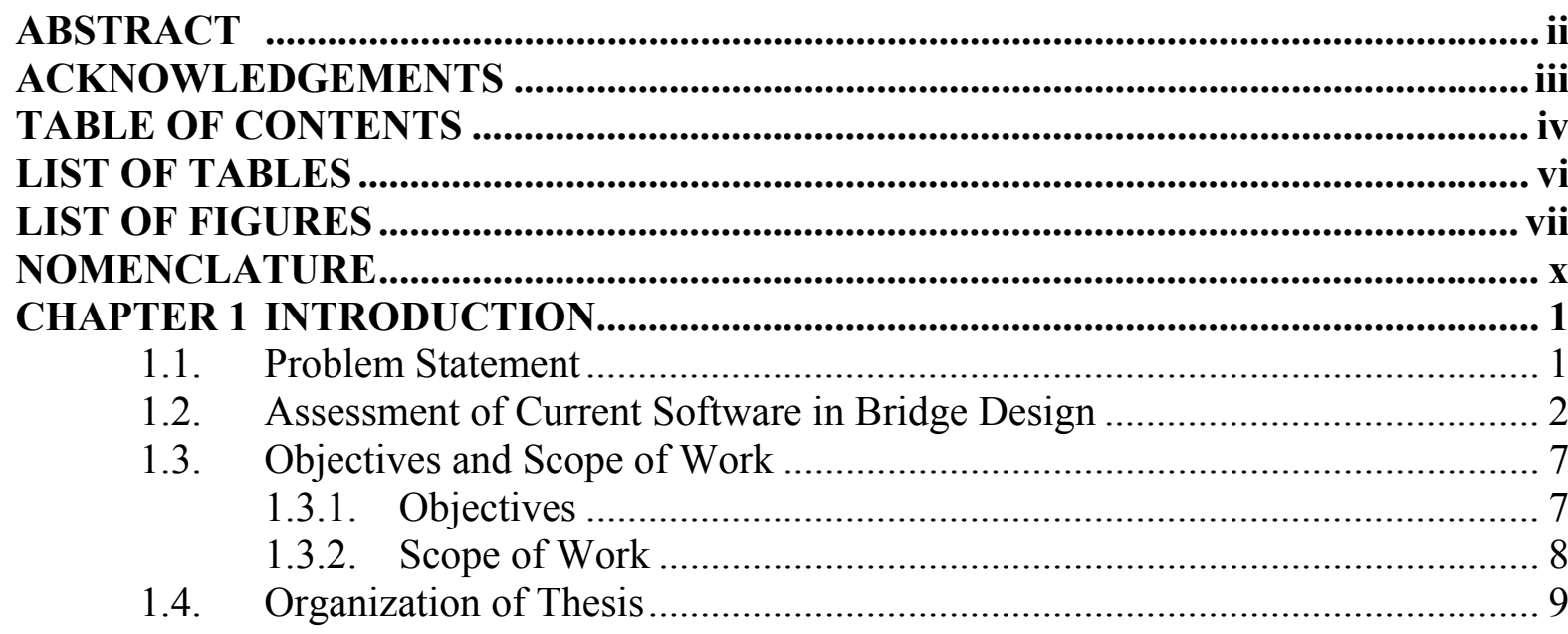

CHAPTER 2 FINITE ELEMENT MODELING OF COMPOSITE STEEL

GIRDER BRIDGES....................................................................... 12

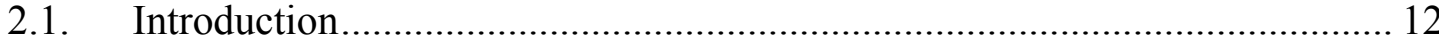

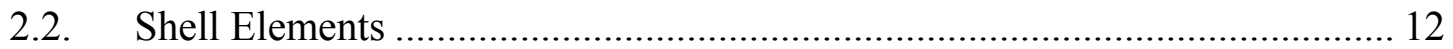

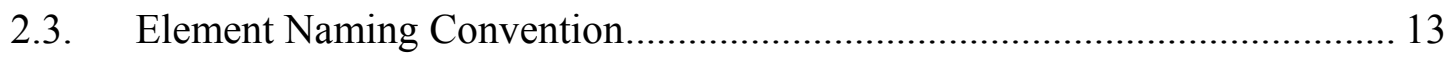

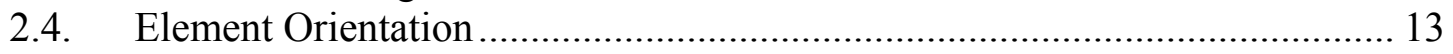

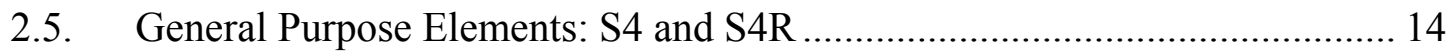

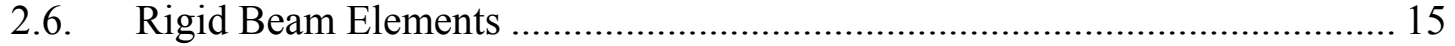

2.7. Timoshenko Beam Elements .................................................................... 16

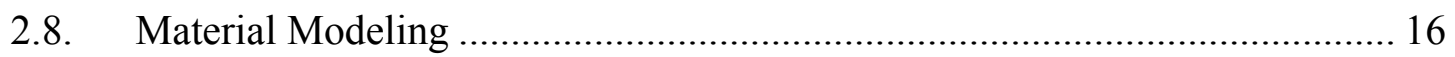

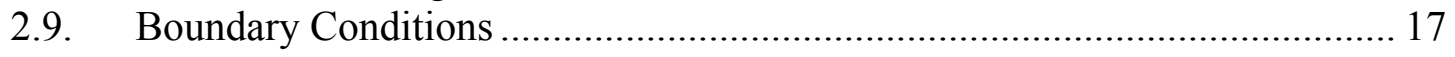

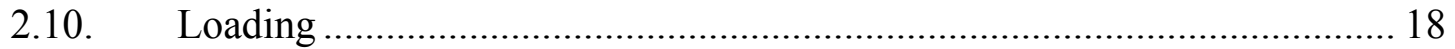

CHAPTER 3 GRAPHICAL USER INTERFACE FOR COMPOSITE STEEL GIRDER BRIDGES............................................................................... 23

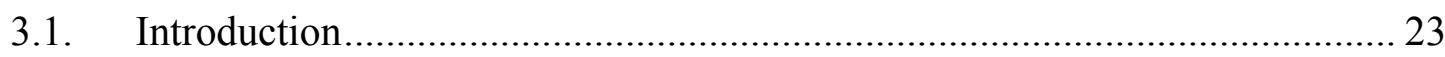

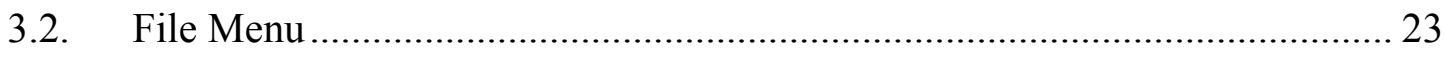

3.2.1. New Project............................................................................... 24

3.2.2. Export File ....................................................................... 24

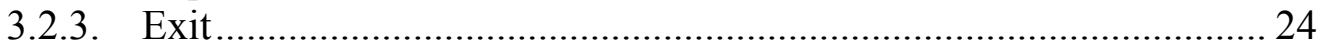

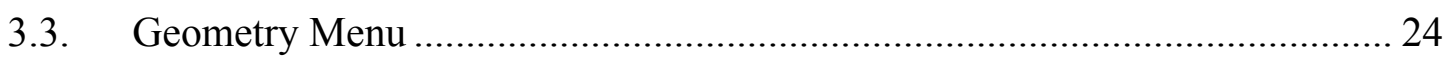

3.3.1. Span Dimensions ................................................................... 24

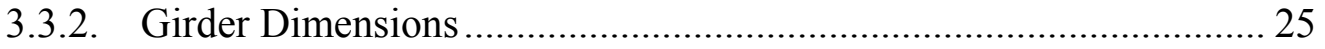

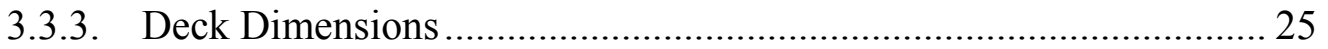

3.3.4. Cross Frame Dimensions ......................................................... 25

3.4. Material Menu..................................................................................... 25

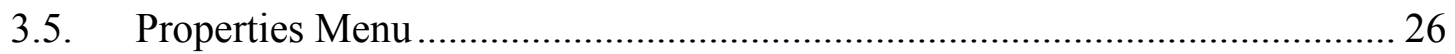

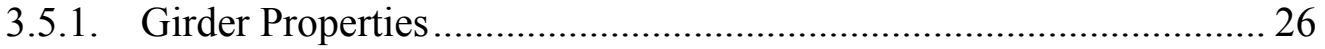

3.5.2. Deck Properties ....................................................................... 27

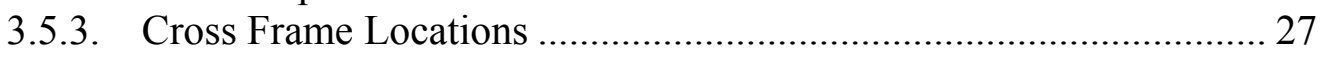

3.5.4. Stiffener Properties .................................................................... 28 


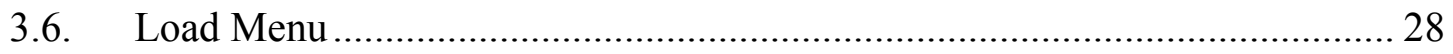

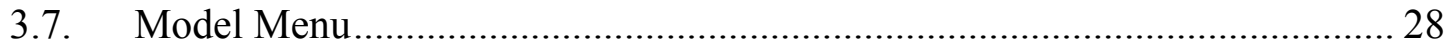

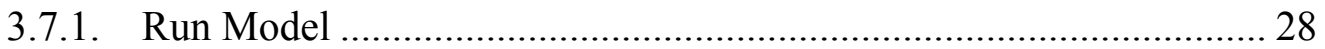

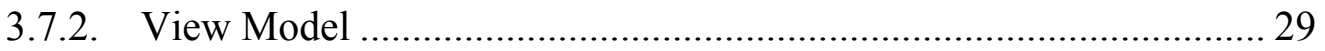

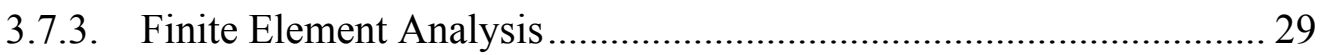

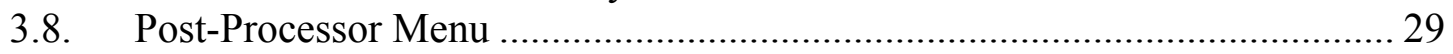

3.9. Node, Element and Constraint Generation from GUI Input Parameters ......... 30

3.9.1. Node Generation for I-section Girder .............................................. 31

3.9.2. Element Generation for I-section Girder ..................................... 33

3.9.3. Node Generation for Bridge Deck .................................................... 35

3.9.4. Element Generation for Bridge Deck ………….............................. 36

3.9.5. Node Generation for Cross Frames................................................... 37

3.9.6. Element Generation for Cross Frames............................................ 38

3.9.7. Node Generation for Transverse Stiffeners ..................................... 38

3.9.8. Element Generation for Transverse Stiffeners.................................. 39

3.9.9. MPC Beam Element Generation between Deck and Top Flange...... 39

3.9.10. Specification of Constraints ............................................................ 40

3.9.11. Generation of Node and Element Sets for Efficient Output Data.... 41

3.9.12. Input File Generation ................................................................... 41

3.10. Post-Processor/ Database Program …………………............................... 42

3.10.1. Influence Surface Approach ........................................................ 42

3.10.2. Girder Moments ........................................................................ 43

3.10.3. Deflection................................................................................. 47

3.10.4. Shear Force ………………………………............................ 47

CHAPTER 4 VERIFICATION STUDIES ....................................................................... 78

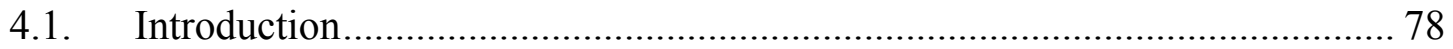

4.2. Two-span Continuous Bridge-Federal Highway Administration................... 79

4.2.1. Description of the Bridge............................................................... 79

4.2.2. Experimental Testing Overview ………………............................ 80

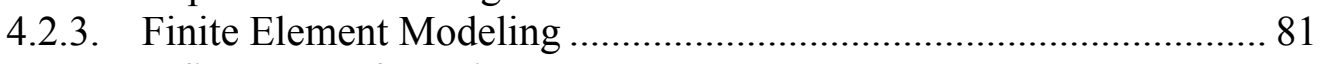

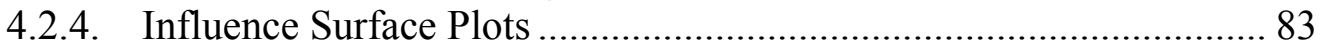

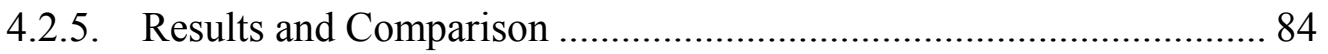

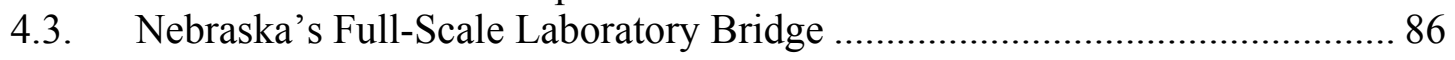

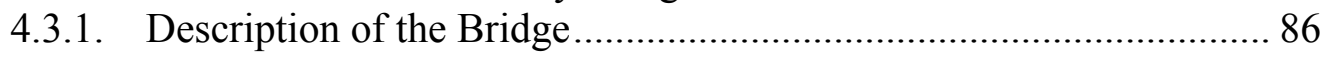

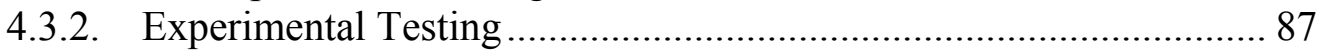

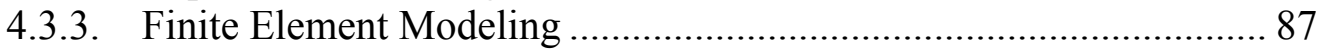

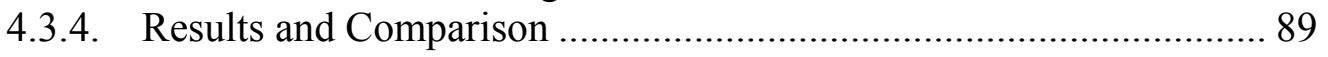

CHAPTER 5 CONCLUSIONS ..................................................................................... 107

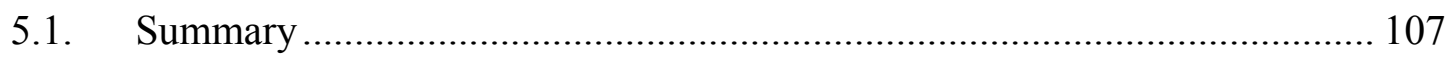

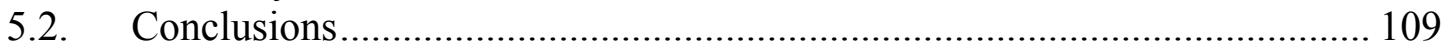

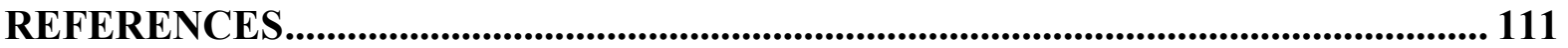

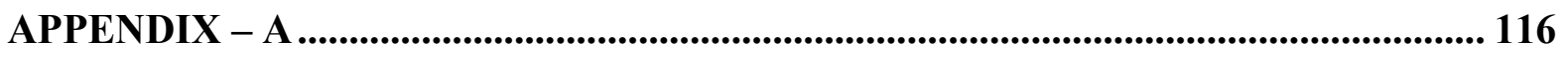

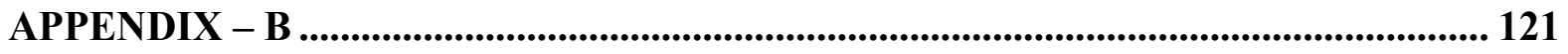




\section{LIST OF TABLES}

Table 3.1 Girder Properties without Stiffeners ............................................................ 49

Table 3.2 Girder Properties with Stiffeners .................................................................. 50

Table 4.1Input Parameters for Federal Highway Bridge ................................................. 91

Table 4.2 Input Parameters for Nebraska Bridge............................................................... 93

Table 4.3 Data for Influence Surface for Bottom Flange Stresses ..................................... 95

Table 4.4 Stress values at wheel load locations ............................................................... 96

Table 4.5 Comparison of Results between FEA and Experimental Testing........................ 97

Table 4.6 Comparison of Results-Mid-span Deflection for Nebraska Bridge...................... 98 


\section{LIST OF FIGURES}

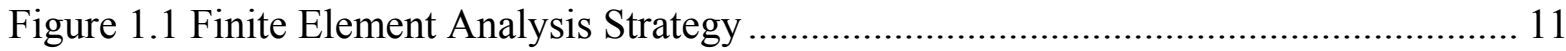

Figure 2.1 Orientation of a four-node shell element (ABAQUS/Explicit 2002) .................. 19

Figure 2.2 Rigid link between shell elements ............................................................. 20

Figure 2.3 Typical Tri-linear constitutive law for steel .................................................... 21

Figure 2.4 Load distribution of a four-node shell element (Adapted from Eom et al 2001). 22

Figure 3.1 Overall Program Flowchart ........................................................................... 51

Figure 3.2 Graphical User Interface for FE modeling of Composite Bridges ..................... 52

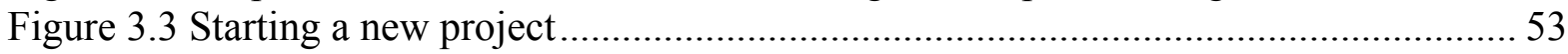

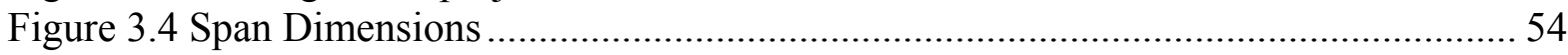

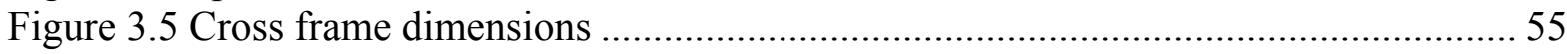

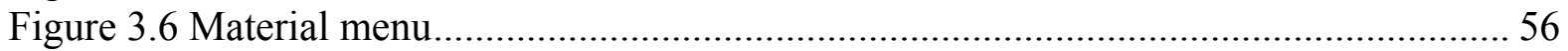

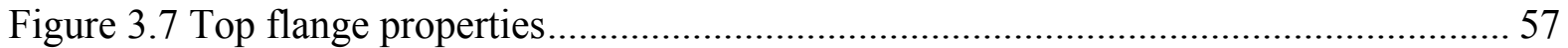

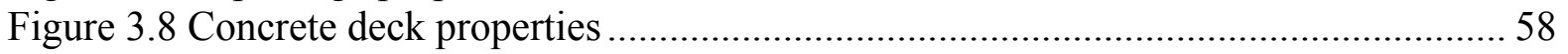

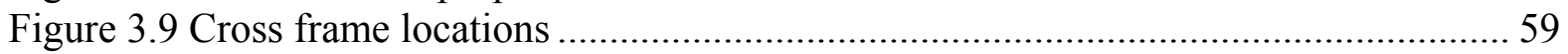

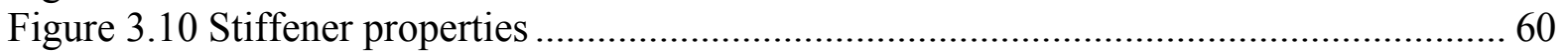

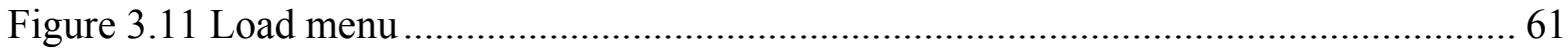

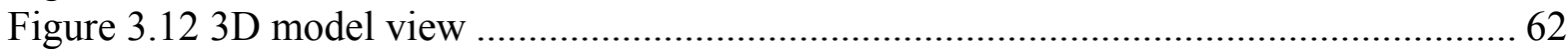

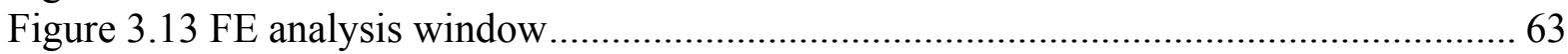

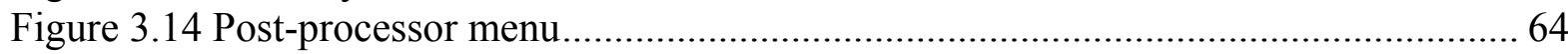

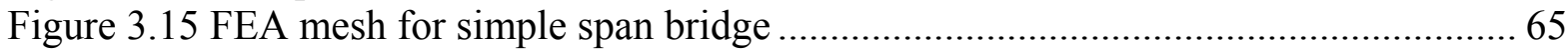

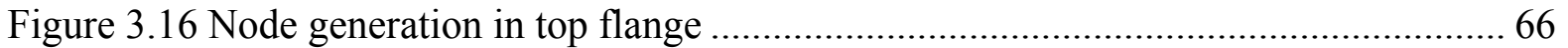

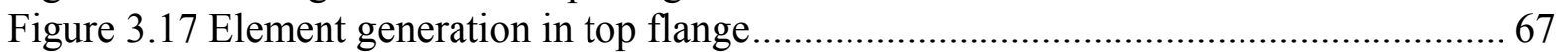

Figure 3.18 Node and element generation in concrete deck .............................................. 68

Figure 3.19 Element Generation in Concrete Deck ........................................................ 69

Figure 3.20 Cross frame in FE model......................................................................... 70

Figure 3.21 Bridge model showing transverse stiffeners............................................ 71

Figure 3.22 Bridge model showing rigid link between top flange and deck ....................... 72

Figure 3.23 Stress profile of a steel concrete composite section without a haunch............... 73

Figure 3.24 Cross-section of an I-section girder composite bridge ................................... 74

Figure 3.25 Locations of stress computation for girder moment calculation ....................... 75

Figure 3.26 Bridge Cross-section showing different moment components for calculation

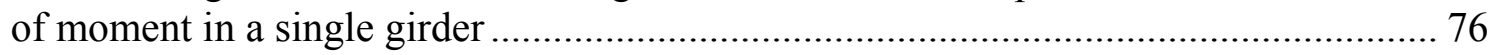

Figure 3.27 Web element showing the stress directions ............................................ 77

Figure 4.1 Cross Section elevation of FHWA Bridge ................................................... 99

Figure 4.2 Girder elevation of the left-span showing girder transitions and cross frame

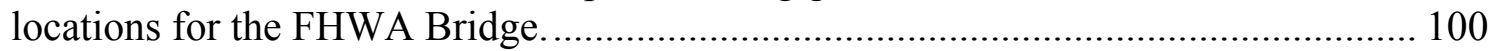

Figure 4.3 FHWA test bridge cross-sections. ............................................................. 101

Figure 4.4 Plan view showing the location of transverse loading positions from (a) Load

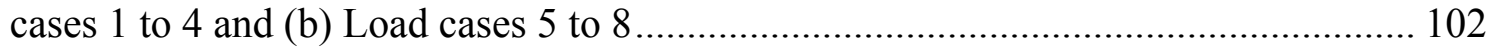

Figure 4.5 Cross section elevation of Nebraska Bridge ................................................ 103

Figure 4.6 Longitudinal Elevation of Nebraska Bridge.................................................. 104

Figure 4.7 Nebraska Bridge: Loading Case ................................................................... 105

Figure 4.8 Federal Highway Bridge: Bottom Flange Stress Influence Surface.................. 106 
Figure B.1 Influence Surface for Moment at Section 0.2 L G1 122

Figure B.2 Influence Surface for Moment at Section 0.3 L G1 123

Figure B.3 Influence Surface for Moment at Section 0.4 L G1 124

Figure B.4 Influence Surface for Moment at Section 0.5 L G1 125

Figure B.5 Influence Surface for Moment at Section 0.6 L G1 126

Figure B.6 Influence Surface for Moment at Section 0.2 L G2 ................................ 127

Figure B.7 Influence Surface for Moment at Section 0.3 L G2 .................................. 128

Figure B.8 Influence Surface for Moment at Section 0.4 L G2 .................................. 129

Figure B.9 Influence Surface for Moment at Section 0.5 L G2 ................................. 130

Figure B.10 Influence Surface for Moment at Section 0.6 L G2 ............................... 131

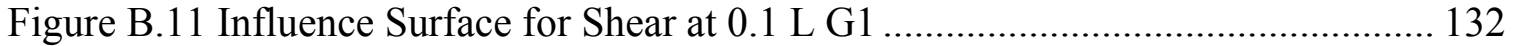

Figure B.12 Influence Surface for Shear at 0.2 L G1 ........................................... 133

Figure B.13 Influence Surface for Shear at 0.3 L G1 .............................................. 134

Figure B.14 Influence Surface for Shear at 0.4 L G1 ............................................. 135

Figure B.15 Influence Surface for Shear at 0.5 L G1 ............................................... 136

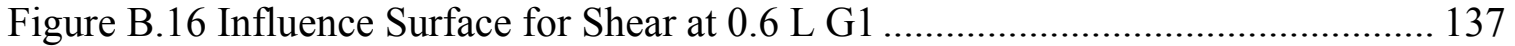

Figure B.17 Influence Surface for Shear at 0.1 L G2 .............................................. 138

Figure B.18 Influence Surface for Shear at 0.2 L G2 .............................................. 139

Figure B.19 Influence Surface for Shear at 0.3 L G2 ............................................... 140

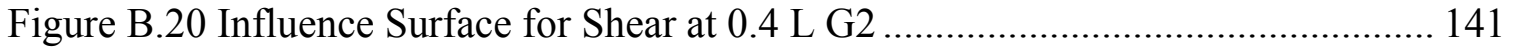

Figure B.21 Influence Surface for Shear at 0.5 L G2 ................................................ 142

Figure B.22 Influence Surface for Shear at 0.6 L G2 ............................................... 143

Figure B.23 Influence Surface for Deflection at Section 0.1 L G1 ............................. 144

Figure B.24 Influence Surface for Deflection at Section 0.2 L G1 ............................. 145

Figure B.25 Influence Surface for Deflection at Section 0.3 L G1 ............................. 146

Figure B.26 Influence Surface for Deflection at Section 0.4 L G1 ............................. 147

Figure B.27 Influence Surface for Deflection at Section 0.5 L G1 ............................ 148

Figure B.28 Influence Surface for Deflection at Section 0.6 L G1 ............................. 149

Figure B.29 Influence Surface for Deflection at Section 0.1 L G2 ............................ 150

Figure B.30 Influence Surface for Deflection at Section 0.2 L G2 ............................ 151

Figure B.31 Influence Surface for Deflection at Section 0.3 L G2 ............................ 152

Figure B.32 Influence Surface for Deflection at Section 0.4 L G2 ............................ 153

Figure B.33 Influence Surface for Deflection at Section 0.5 L G2 ............................. 154

Figure B.34 Influence Surface for Deflection at Section 0.6 L G2 ............................ 155

Figure B.35 Influence Surface for Moment at Section 0.2 L G1 ............................... 156

Figure B.36 Influence Surface for Moment at Section 0.3 L G1 ................................ 157

Figure B.37 Influence Surface for Moment at Section 0.4 L G1 ................................ 158

Figure B.38 Influence Surface for Moment at Section 0.5 L G1 ............................... 159

Figure B.39 Influence Surface for Moment at Section 0.6 L G1 ................................ 160

Figure B.40 Influence Surface for Moment at Section 0.2 L G2 ............................... 161

Figure B.41 Influence Surface for Moment at Section 0.3 L G2 ............................... 162

Figure B.42 Influence Surface for Moment at Section 0.4 L G2 ............................... 163

Figure B.43 Influence Surface for Moment at Section 0.5 L G2 ................................ 164

Figure B.44 Influence Surface for Shear at Section 0.1 L G1 .................................. 165

Figure B.45 Influence Surface for Shear at Section 0.2 L G1 .................................. 166 
Figure B.46 Influence Surface for Shear at Section 0.3 L G1 ...................................... 167

Figure B.47 Influence Surface for Shear at Section 0.4 L G1 ...................................... 168

Figure B.48 Influence Surface for Shear at Section 0.5 L G1 .................................... 169

Figure B.49 Influence Surface for Shear at Section 0.6 L G1 .................................... 170

Figure B.50 Influence Surface for Shear at Section 0.1 L G2 ..................................... 171

Figure B.51 Influence Surface for Shear at Section 0.2 L G2 .................................... 172

Figure B-52 Influence Surface for Shear at Section 0.3 L G2 ..................................... 173

Figure B.53 Influence Surface for Shear at Section 0.4 L G2 .................................... 174

Figure B.54 Influence Surface for Shear at Section 0.5 L G2 …….......................... 175

Figure B.55 Influence Surface for Shear at Section 0.6 L G2 ...................................... 176

Figure B.56 Influence Surface for Deflection at Section 0.1 L G1 .............................. 177

Figure B.57 Influence Surface for Deflection at Section 0.2 L G1 .............................. 178

Figure B.58 Influence Surface for Deflection at Section 0.3 L G1 .............................. 179

Figure B.59 Influence Surface for Deflection at Section 0.4 L G1 .............................. 180

Figure B.60 Influence Surface for Deflection at Section 0.5 L G1 .............................. 181

Figure B.61 Influence Surface for Deflection at Section 0.6 L G1 ............................. 182

Figure B.62 Influence Surface for Deflection at Section 0.1 L G2 ……...................... 183

Figure B.63 Influence Surface for Deflection at Section 0.2 L G2 ............................. 184

Figure B.64 Influence Surface for Deflection at Section 0.3 L G2 .............................. 185

Figure B.65 Influence Surface for Deflection at Section 0.4 L G2 ….......................... 186

Figure B.66 Influence Surface for Deflection at Section 0.5 L G2 ….......................... 187

Figure B.67 Influence Surface for Deflection at Section 0.6 L G2 ….......................... 188 


\section{NOMENCLATURE}

The following symbols are used in this thesis

$$
\begin{aligned}
& \sigma_{o}=\text { Stress at the bottom of bottom flange (ksi) } \\
& \sigma_{C G}=\text { Stress at the centroid of the Steel Girder (ksi) } \\
& C G=\text { Centroid of the Steel Girder (in.) } \\
& \left.S_{S T L}=\text { Section Modulus of the Steel using measured dimensions (in }{ }^{3}\right) \\
& \left.A_{S T L}=\text { Area of steel girder (in }{ }^{2}\right) \\
& d_{S T L}=\text { Depth of steel girder (in.) } \\
& h a u n c h=\text { Depth of haunch (in.) } \\
& \left.I_{S T L}=\text { Moment of Inertia of Steel girder (in }{ }^{4}\right) \\
& w_{c}=\text { Density of normal concrete (pcf) } \\
& d_{S L A B}^{\prime}=\text { Depth of concrete slab (in.) } \\
& E_{S L A B}=\text { Modulus of Elasticity of Concrete Slab (ksi) } \\
& \left.I_{S L A B}=\text { Moment of Inertia of Concrete Slab (in }{ }^{4}\right) \\
& E_{S T L}=\text { Modulus of Elasticity of Steel (ksi) }
\end{aligned}
$$


$\left(\sigma_{A V G}\right)_{w e b}=$ Average shear stress of the web (ksi)

$t_{\text {web }}=$ Thickness of the web (in.) 


\section{CHAPTER 1}

\section{INTRODUCTION}

\subsection{Problem Statement}

Traditionally, highway bridges have been designed using a two-dimensional linegirder type analysis. In this procedure, the response of the three-dimensional bridge superstructure is de-coupled and each of the girders is analyzed as a two-dimensional member. AASHTO specifications provide approximate equations to determine the effective width of the composite section and the load distribution to the member. While these methods of analysis work conservatively for most simple bridge structures, they do not adequately capture the behavior of more complex three-dimensional bridges. While a number of bridge software packages are available for conducting two-dimensional analyses and some for three-dimensional grillage analyses, few software packages are capable of fully conducting three-dimensional analyses of bridges. Recent efforts by researchers at WVU $(\mathrm{Wu}, 2003)$ have been successful in developing tools based on commercial finite element (FE) software for the refined modeling of bridges. However, model development and meshing can be quite time consuming.

The generic nature of commercial FE software packages creates inherent difficulty for the modeling of three-dimensional composite bridges. Initial model generation requires considerable time to define and mesh complicated girder geometries, stiffener and cross frame locations, deck elements and edge barriers. Subsequently, minor design changes in the bridge model require duplication of modeling steps. This redundancy in modeling becomes particularly tedious while conducting parametric 
studies. This fixed non-specific format of the pre-processor input file combined with the inability to rapidly modify basic bridge geometry without complete model regeneration leads to considerable time consumption.

The generation of an efficient input file is a critical parameter for an FE preprocessor. Commercial FE modeling tools generate input files to compute the response parameters for every node and element of the bridge model during FE analysis, leading to a large amount of redundant output data. Analysis of this large data during postprocessing leads to considerable increase in time costs. The listing of such unnecessary output data can be avoided with the development of an effective pre-processor that identifies nodes and elements of critical bridge sections and lists them during input file generation. This identification enables the recording of response parameters at critical sections and saves time during study of output data in post-processing.

Therefore, the goal of this study is to develop a graphical user interface (GUI) for the rapid generation of 3D bridge models. The GUI is built around the use of the commercial Finite Element (FE) analysis program ABAQUS as the analysis engine. ABAQUS is a robust FE analysis tool that has the capability to accurately model $3 \mathrm{D}$ geometric and material non-linearity and is used to compute the response parameters of the FE model based on the GUI input data. Further, post-processing tools developed in this research generate influence surfaces to calculate the maximum force effects for various loading conditions.

\subsection{Assessment of Current Software in Bridge Design}

Many software products currently used for composite bridge design provide ease of usage, faster analysis and advanced tools during post-processing for assessment of 
existing bridges as well as design of new ones. This section presents an overview of some key products in the market for bridge modeling and analysis. The software being reviewed is divided in to three categories; General Purpose FE Analysis softwareSTRAND7, general FE software with special bridge design modules-STAAD.PRO and SAP 2000 and exclusive bridge design software-QConBridge, StlBridge LRFD and SAM.

\section{STRAND7}

Strand7 is a general purpose, finite element analysis system developed by G+D Computing of Sydney, Australia (STRAND7, 2005). The system is used for a broad range of engineering applications including civil, structural, mechanical, naval and aeronautical engineering. Strand7, an MS Windows-based system, can be used as a stand-alone FE ANALYSIS application since it contains pre-processing modules (including import and automatic meshing of CAD models), solvers (linear and non-linear static, dynamic and heat transfer, including high-performance sparse solvers) and postprocessing functions. This program also has an interface to use Strand7 models and analysis results with other external programs.

This software, because of its generic nature, does not offer specific tools to generate 3D bridge models. Even basic bridge design becomes a complicated and timeconsuming process.

\section{SAP2000}

SAP2000 is a structural design and analysis software program developed by Computers and Structures Inc., USA (SAP, 2005). This is a general purpose FE modeling and analysis software that offers special tools for design of 3D bridge models. 
Bridge designers can utilize SAP2000 bridge templates for generating automated liveload analysis and design, bridge construction sequence analysis, large deformation cable supported bridge analysis and pushover analysis. The software can design both straight and curved girders and offers additional features to generate live-loads, moving loads with multi-step analysis and loads with standard and user-defined vehicles. Influence surfaces can also be plotted for displacements, reactions, forces and stresses. These influence surfaces are further used for moving-load envelope calculations and tabular data can be exported to other external applications. Once the model is generated, code checking is performed using the AASHTO, LFD and LRFD design codes.

\section{STAAD.Pro 2004}

This is a general-purpose FE analysis software developed by Research Engineers International, USA (STAAD, 2005). This software is used for static, dynamic, P-delta, non-linear, buckling or cable analysis. The program provides object-oriented 2D/3D graphical model generation and script style programming language. The user interface has customizable templates for application-specific model creation and Visual Basic support for implementation of additional modules.

STAAD.beava, the Bridge Engineering Automated Vehicle Application is the bridge loader module inside the STAAD.Pro environment. STAAD.beava will automatically generate influence surfaces for effects such as bending moments, support reactions, element stresses and nodal deflections. STAAD.beava follows the pre-selected design code (AASHTO, LFD or LRFD) and calculates the number of traffic lanes, influence lines at the center of the lanes, loaded length along the lanes, and the maximum and associated effect values. Graphical results display the critical position of the vehicle 
along the traffic lanes. This software has the provision to define and save a user-defined vehicle in the library for future reference. A significant limitation of STAAD for this research is its inability to interface with ABAQUS for analysis.

\section{QConBridge Version 1.2}

QConBridge is an analysis program produced by the Washington State Department of Transportation for computing the live and dead-load effects associated with the implementation of AASHTO-LRFD Bridge Design Specifications (QConBridge, 2005). This program generates dead loads, live-loads and load combinations for LRFD design requirements. QConBridge models simple and continuous bridge structures of different cross sections and can analyze for dead load, HL93 live-load, fatigue truck and pedestrian live-load cases with load combinations being performed for Strength I, Service I, Service II, Service III and Fatigue limit states.

This program has a Windows-Based user interface with the code being developed using $\mathrm{C}++$. Additional features of the software include user override capability of liveload distribution factors and user-defined point loads and uniform loads. This software provides enhanced reports showing calculation details and graphs of moments, shear and displacements.

Significant limitations of this software include the use of non-FE ANALYSIS based methodology for composite bridge design. It can only analyze straight, prismatic continuous bridges that have symmetrical spans with a maximum of 10 spans. It can only build 2D bridge frame models which do not account for additional members of a 3D bridge model such as stiffeners and cross frames. Some known problems of the software that have not yet been resolved include incorrect modeling of slab on beam cross sections 
resulting in an erroneous value of equivalent density. This leads to a non-conservative estimate of dead load. (QConBridge, 2005) In spite of these limitations, this program works well for engineers adopting AASHTO-LRFD design specifications for rapid building of bridge models.

\section{STLBridge LRFD Version 3.1}

STLBridge is a continuous steel girder bridge analysis and design software program developed by Bridgesoft Inc, Omaha, NE (STLBRIDGE, 2000). This package is used for the design of steel girder and wide flange bridges conforming to the AASHTO LRFD specifications. This program provides an interactive graphical design with the ability to model continuous bridges up to 9 spans. It can model composite hybrid sections and can accommodate variable girder spacing. The software performs live-load analysis in accordance with AASHTO LRFD and also gives the option to load using a user-defined loading case, including a combination of truck and lane loading. Special features of the software include graphical design screens for stress checks and shear stiffener design, observations of changes in performance ratio with changes in flange sizes, web plate sizes etc. This program, upon analysis, has the capability to perform AASHTO LRFD based design specification checks. Post-processing tools give a graphical output for moments, shear and other parameters.

The 2D modeling methodology of the software requires de-coupling the threedimensional bridge structure and analyzing it as a two-dimensional member. This limits the study of response parameter variation in the transverse direction. 


\section{SAM Version 4.71c}

SAM is a bridge design software developed by Bestech Systems, NewYork USA (SAM, 2005). This software is capable of integrating code checking procedures using AASHTO LRFD specifications with results of FE analysis. It uses graphical tools to define all the structural elements such as beams and sections. SAM performs distribution factor based analyses as well as grillage analysis, frame analysis and FE ANALYSIS. The advanced graphic tools of structural analysis solver of the software provide a threedimensional representation of the bridge deck and substructure and also enable visual staged construction analysis. SAM also offers refined tools for 3D live-load optimization using influence surfaces for load effects, automatic creation of loading conditions that produce the maximum force effects, in accordance with AASHTO LRFD requirements. The results from these envelopes may be directly used for code checking. This program calculates the strength and service limit states and provides interaction diagrams for shear, moment and deflection. By providing easy-to-read solutions, SAM provides a method to cross-check hand calculations with the software.

\subsection{Objectives and Scope of Work}

\subsubsection{Objectives}

This project is focused on developing a GUI for building 3D bridge models for use with commercial FE ANALYSIS software. The specific objectives of the work are:

1. To develop a user-friendly GUI for building tangent simply supported and continuous span composite bridge models,

2. to create input files, for analysis using ABAQUS, 
3. to perform data reduction by creating node and element sets of critical bridge sections for rapid data-efficient analysis,

4. to generate influence surfaces of key response parameters, and

5. to compare and benchmark the results of 3D FE bridge models developed in this research with experimental test results from other studies.

\subsubsection{Scope of Work}

Based on the review of available software in bridge design, the need to develop an economical, customized, convenient modeling tool for building three-dimensional composite bridge is established. The GUI is developed using Visual Basic. NET (Francesco, 2003). Visual Basic.NET has the ability to interface with other program modules and is ideal for FE ANALYSIS where each step of analysis (Pre-processing, Analysis and Post-Processing) is performed by different software. A graphical environment has also been incorporated in the GUI using OpenGL, an advanced graphics tool, to view 3D bridge models. Figure 1.1 outlines the procedure used to generate 3D bridge models using the GUI program developed in this effort.

The GUI provides a simple interface to input the necessary bridge parameters using drop-down menus and data cells, thus eliminating the need to understand numbering of nodes, elements, properties, materials and other model parameters. This easy data entry significantly reduces the time associated with developing 3D FE bridge models and any bridge engineer with basic computer knowledge can use this software. Once the FE model is generated, nodes and elements of critical bridge sections are grouped into data sets for rapid analysis. 
On building the FE model, the pre-processor generates an efficient input file and interfaces with the analysis tool. Once the model has been run, the data obtained from ABAQUS is input into a database program. This program, an additional module of the GUI, is developed using MS-Access. It is used to perform data reduction and create influence surfaces of key response parameters such as moments, shear force, stresses and displacements at key locations or specified points of interest. Using the influence surface, critical load points on the bridge can be easily identified and the influence coordinates at these points can be quickly used to determine the maximum forces, e.g., moment in any desired girder or other superstructure component for any desired location or truck loading.

Lastly, results from the developed FE tools have been verified against the experimental results of two full-scale composite steel bridges. Comparison of stresses and live-load deflections have been presented for a continuous span bridge tested at the Turner Fairbanks Research Center, VA (FHWA Bridge) and for a simple span bridge tested at the University of Nebraska, NE (Nebraska Bridge).

\subsection{Organization of Thesis}

There are five chapters in this thesis. Chapter 1 includes the problem statement, objectives and scope of work, overview of existing bridge analysis software and the organization of the thesis.

Chapter 2 introduces the finite element modeling techniques employed in this work. An outline of the different types of elements used for generation of an FE mesh in the study and their advantages are also presented. 
Chapter 3 presents a thorough explanation of the GUI. The programming logic for the creation of nodes and elements in girders, deck and other members are also included. This section also discusses the methods employed to create node and element sets which will be further used for data reduction during post-processing. This chapter also outlines the steps employed to find the girder moments, shear force and load deformation response from influence surfaces.

Chapter 4 presents a verification study using the FE ANALYSIS method discussed in Chapter 3. Three-dimensional FE bridge models are generated using the GUI for two full-scale experimental bridges. FE analysis is conducted using ABAQUS and the loading conditions used in the experimental tests are replicated using influence surfaces generated in the post-processor module of the GUI. A detailed comparison between experimental test results and FE ANALYSIS results is included.

Chapter 5 provides an overview of the advantages of using the GUI over other commercially available software and the significant time savings of this new FE tool. This chapter also provides a summary of results and the conclusions drawn from this study.

Appendix A provides a list of variables that are used in the program and Appendix B includes illustrations of influence surface for various response parameters generated during verification studies. 
PRE-PROCESSOR
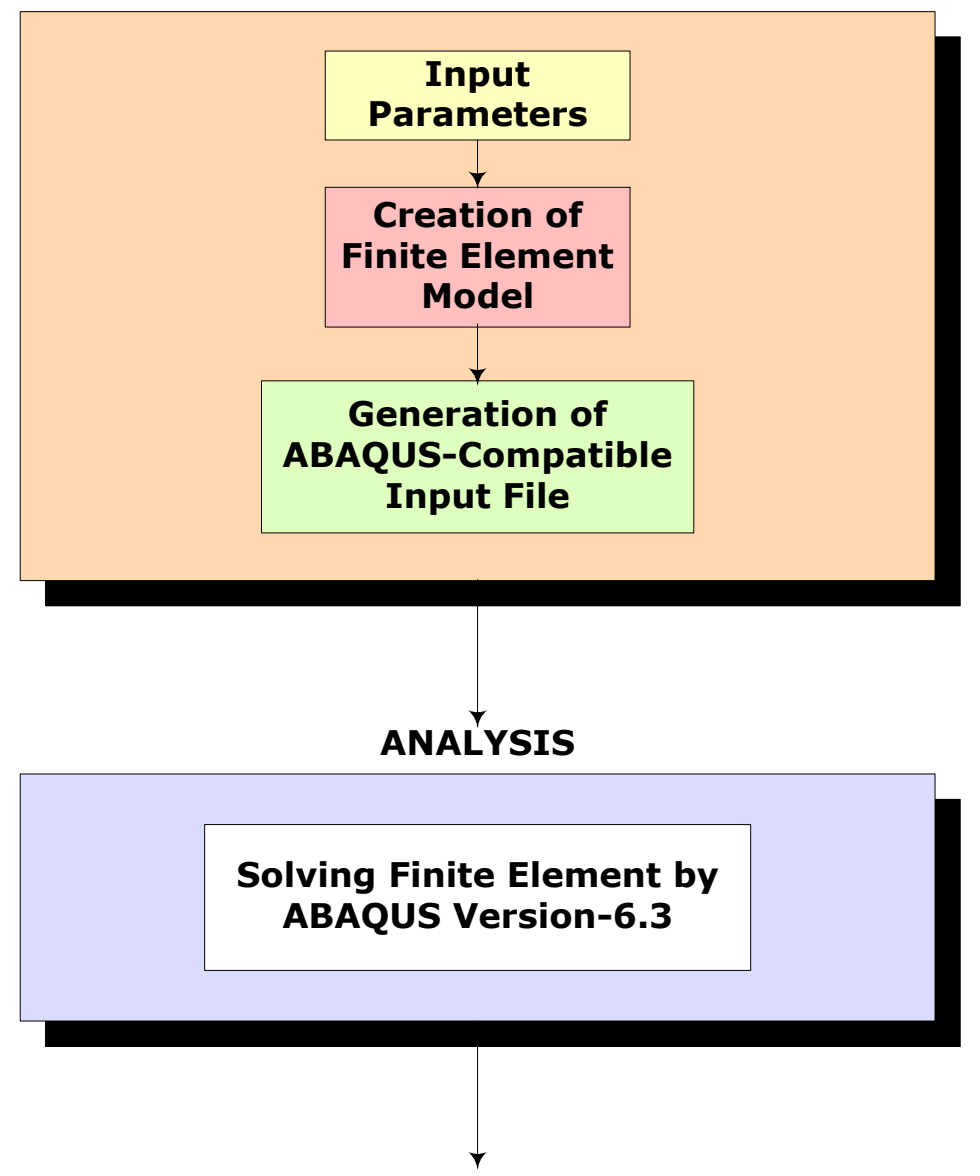

POST PROCESSOR

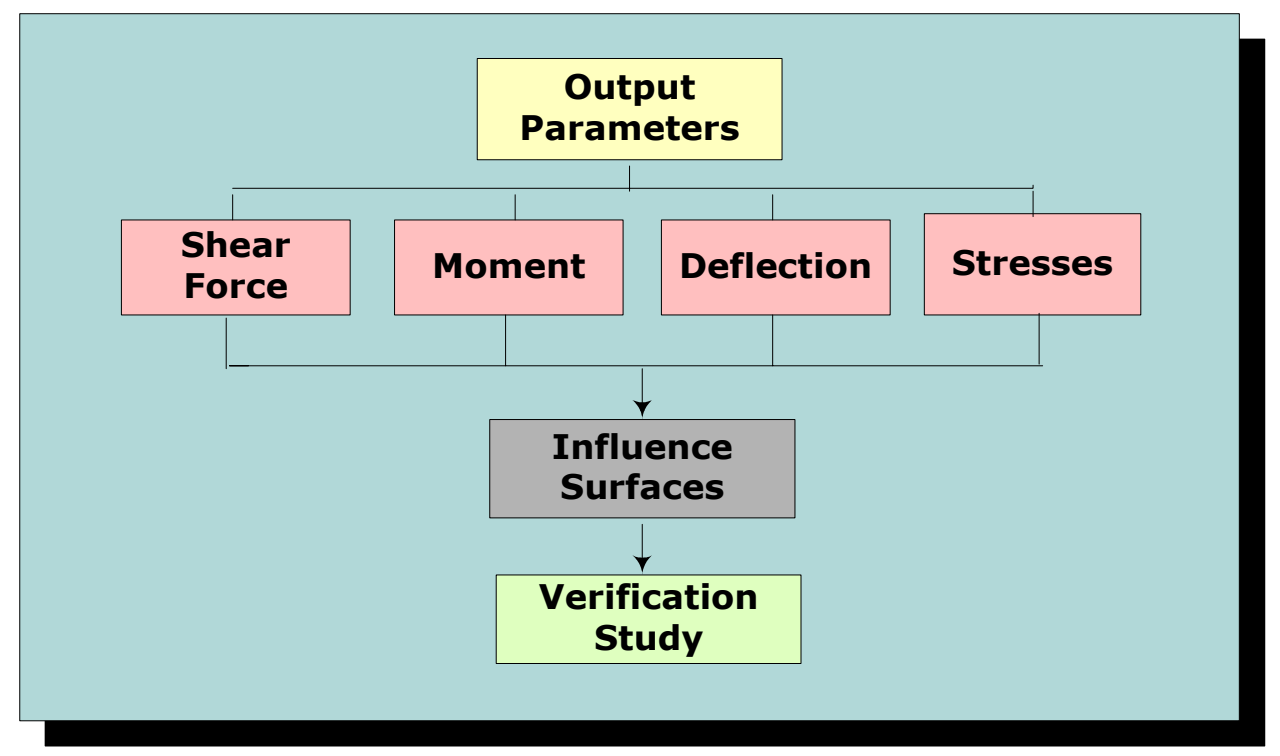

Figure 1.1 Finite Element Analysis Strategy 


\section{CHAPTER 2}

\section{FINITE ELEMENT MODELING OF COMPOSITE STEEL GIRDER BRIDGES}

\subsection{Introduction}

This chapter discusses the methods and procedures employed for the finite element analysis of composite steel I-girder bridges. In summary, FE ANALYSIS was performed using a commercially available FE ANALYSIS tool ABAQUS Version 6.3-1 (ABAQUS, 2002). The finite element model for this analysis is generated using a GUI program developed in this research. The GUI creates an ABAQUS-compatible input file and includes the complete node and element attributes, material properties and load analysis information. Thorough details of the bridge model are discussed in subsequent sections of this chapter. Throughout this chapter reference is made to specific commands which are given by the notation "* command" in ABAQUS (2002).

\subsection{Shell Elements}

ABAQUS provides complete geometric modeling capability, providing the user with a large number of available element types. Therefore, it is necessary to investigate the suitability of a given element type for the problem studied. As shown by several researchers (White et al., 1993 and Barth, 1996), FE ANALYSIS using shell elements is both sufficient and necessary for modeling the physical behavior of I-shaped steel girders. Research efforts by Hays (1986) suggest that four-node shell elements 
adequately capture the behavior of reinforced concrete bridge decks. This section will describe the characteristics of two types of shell elements, S4 and S4R, considered for developing 3 $\mathrm{D}$ bridge models.

\subsection{Element Naming Convention}

The element naming convention used in ABAQUS conveys several important attributes of the element (ABAQUS/Standard 2002). The first letter of the element name refers to the general element type (e.g. S4R5), with "S" representing a shell element. This is followed by a number indicating the number of nodes in the element. This number may be followed by the letter "R", which indicates that reduced integration is used in the

element formulation. Lastly, a "5" at the end of an element name indicates that the element only contains five degrees of freedom (three displacement components and two in-surface rotation components; otherwise all six degrees of freedom are considered).

\subsection{Element Orientation}

For isotropic materials in structural surface elements such as shells and membranes, the default coordinate system is the local surface directions defined by the standard ABAQUS convention. To define stress and strain components in a shell, the convention used in ABAQUS for such directions is as follows.

The default local 1-direction is the projection of the global $\mathrm{x}$-axis onto the surface. If the global $\mathrm{x}$-axis is within $0.1^{\circ}$ of being normal to the surface, the local 1-direction is the projection of the global x-axis onto the surface. The local 2-direction is then at right angles to the local 1-direction, so that the local 1-direction, local 2-direction, and the positive normal to the surface form a right-handed set (see Figure 2.1). The positive 
normal direction is defined in an element by the right-hand rule. The local surface directions can be redefined by using the *ORIENTATION option (ABAQUS/Explicit 2002). Stress and strain components in shells are given with respect to these surface coordinate directions.

\subsection{General Purpose Elements: S4 and S4R}

Elements S4 and S4R are 4-node general-purpose shell elements. These elements are intended to provide robust, accurate solutions for both thin and thick shells, using classical (Kirchhoff) shell theory for relatively thin shells and thick (Mindlin) shell theory as the shell thickness increases. These elements allow for finite membrane strains and rotations of the shell. Therefore, they are suitable for large strain analysis involving inelastic deformation of materials with nonzero effective Poisson's ratio. These elements allow for change in shell thickness as a function of the membrane strain. Transverse shear deformation is also included. These elements are not prone to the problems associated with hourglass effects or transverse shear locking.

The only difference between the S4 and S4R elements is the number of integration points used in the analysis; "full" integration is used for S4 elements, while "reduced" integration is used for S4R elements. In full integration, sufficient number of integration points are selected such that integration of the element stiffness matrices is exact, i. e., for second order elements, such as S4, each element has four integration points. However, reduced integration elements use one order less than that required for exact integration of the element stiffness matrix. Thus, S4R is a first order element and only one integration point is used to form the element stiffness matrix. The mass matrix and force matrix are still integrated exactly. 
S4R elements offer many advantages over the fully integrated S4 elements. For example, in reduced integration of isoparametric elements, strains and stresses are computed at the locations known to provide optimal accuracy, thus reduced integration usually produces accurate results provided the elements are not disturbed or loaded in inplane bending (Yang, 2004). Furthermore, reduced integration typically softens the response of the elements, which also leads to increased accuracy by countering the overly stiff response generally encountered in FE ANALYSIS. The use of fewer integration points benefits the user by resulting in reduced CPU time and storage requirements.

The primary disadvantage of using reduced integration is that deformation modes that cause no strain at the integration points may develop. This may lead to inaccurate results if these zero-energy modes propagate through the structures in a phenomenon commonly known as hourglassing. However, ABAQUS prevents hourglassing for S4R elements by introducing a small artificial stiffness associated with zero-energy deformation modes (ABAQUS/Standard, 2002).

Verification studies conducted by Yang (2004) also determine that the S4R is the most robust element for composite bridge modeling. Therefore, S4R will be used for subsequent modeling of steel girders and concrete deck in this study.

\subsection{Rigid Beam Elements}

Full composite action between the reinforced concrete deck and the steel girder is modeled using a multi-point constraint element. Figure 2.2 shows the cross-section of an I-section steel girder with the deck and girder layer connected by a rigid link. This element provides a rigid beam between two nodes; the center node of the top flange and the node directly above it on the deck. This rigid beam constrains the displacement and 
rotation at the first node to the displacement and rotation at the second node, assuring nodal compatibility between the deck and girder layer. The element mesh of the slab is generated to assure that nodes will exist that are directly above the nodes on the middle of top flanges in order to create these rigid beam elements.

\subsection{Timoshenko Beam Elements}

A 3D two-node Timoshenko beam element (B31) is used to model the cross frames of a composite bridge model. Since the B31 elements can be subjected to large axial strains and allow for shear deformation (Wu , 2003), they are used to simulate the behavior of cross frames. Their function is to provide lateral stability to the top and bottom flanges of the girder, reduce any flange lateral bending effects.

\subsection{Material Modeling}

For structural steel, the analyses performed in this study incorporate full nonlinear material behavior including a tri-linear stress-strain response. The tri-linear behavior assumed for structural steel is given in Figure 2.3, where the parameters $E, F_{y}, \varepsilon_{y}$ etc. are specific for a given grade of steel. Classical metal plasticity models are used for the nonlinear effects of the steel. Of many material modeling options available in ABAQUS, an elastic-plastic constitutive model with standard von Mises yield surface, associated plastic flow rule and isotropic work hardening, has been found to be suitable to represent rate independent behavior of metal materials subjected to a relatively monotonic loading, where creep effects are not important (Yang 2004). Inelastic material properties must be input into ABAQUS in the form of true (Cauchy) stress $\left(\sigma_{\text {true }}\right)$ and true (logarithmic) 
strain $\left(\varepsilon_{\text {true }}\right)$, which can be calculated from the engineering stress $\left(\sigma_{\text {eng }}\right)$ and the engineering strain $\left(\varepsilon_{\text {eng }}\right)$ shown in Figure 2.3 using

$$
\begin{aligned}
& \sigma_{\text {true }}=\sigma_{\text {eng }}\left(1+\varepsilon_{\text {eng }}\right) \\
& \varepsilon_{\text {true }}=\ln \left(1+\varepsilon_{\text {eng }}\right)
\end{aligned}
$$

The Comitè Europèen du Bèton (CEB) concrete model was chosen to represent the compressive concrete properties used in the analyses in this work. Previous research, conducted by Wittry (1993) and Mans (2001), has shown that the CEB model (see Eq. 2.3) successfully captures the compressive behavior of the type of decks studied in this work. The concrete material properties are included in the ABAQUS input file using the *CONCRETE option, which allows the user to input stress and strain values that represent the non-linear material properties of the concrete.

$$
f_{c}=\frac{0.85 f^{\prime}{ }_{c}\left(a-206000 \varepsilon_{c}\right) \varepsilon_{c}}{1+b \varepsilon_{c}}
$$

\subsection{Boundary Conditions}

The boundary conditions for the simple span bridges include a pin-type constraint with the three translation displacements constrained for all nodes along one end of the bottom flanges and roller-type constraints preventing vertical displacement for all nodes along the other end of the bottom flange. Similar boundary conditions are imposed for the continuous span bridges analyzed by adding additional roller constraints along the bottom flanges at the pier location(s). 


\subsection{Loading}

In this research, a live-load generator is developed by placing a unit load on the deck at points defined by a rectangular grid. The grid is created by dividing each span of the bridge deck into ten divisions in both the transverse and longitudinal directions. When the coordinates of any point on the grid do not match the nodes of the bridge deck, the load is linearly distributed to the adjacent nodes based on simple extrapolation (see Figure 2.4). This live-load generator is used to generate influence surfaces of key response parameters such as shear force, stresses, deflections and girder moments and is capable of finding the maximum force effects due to various vehicular loading conditions. 


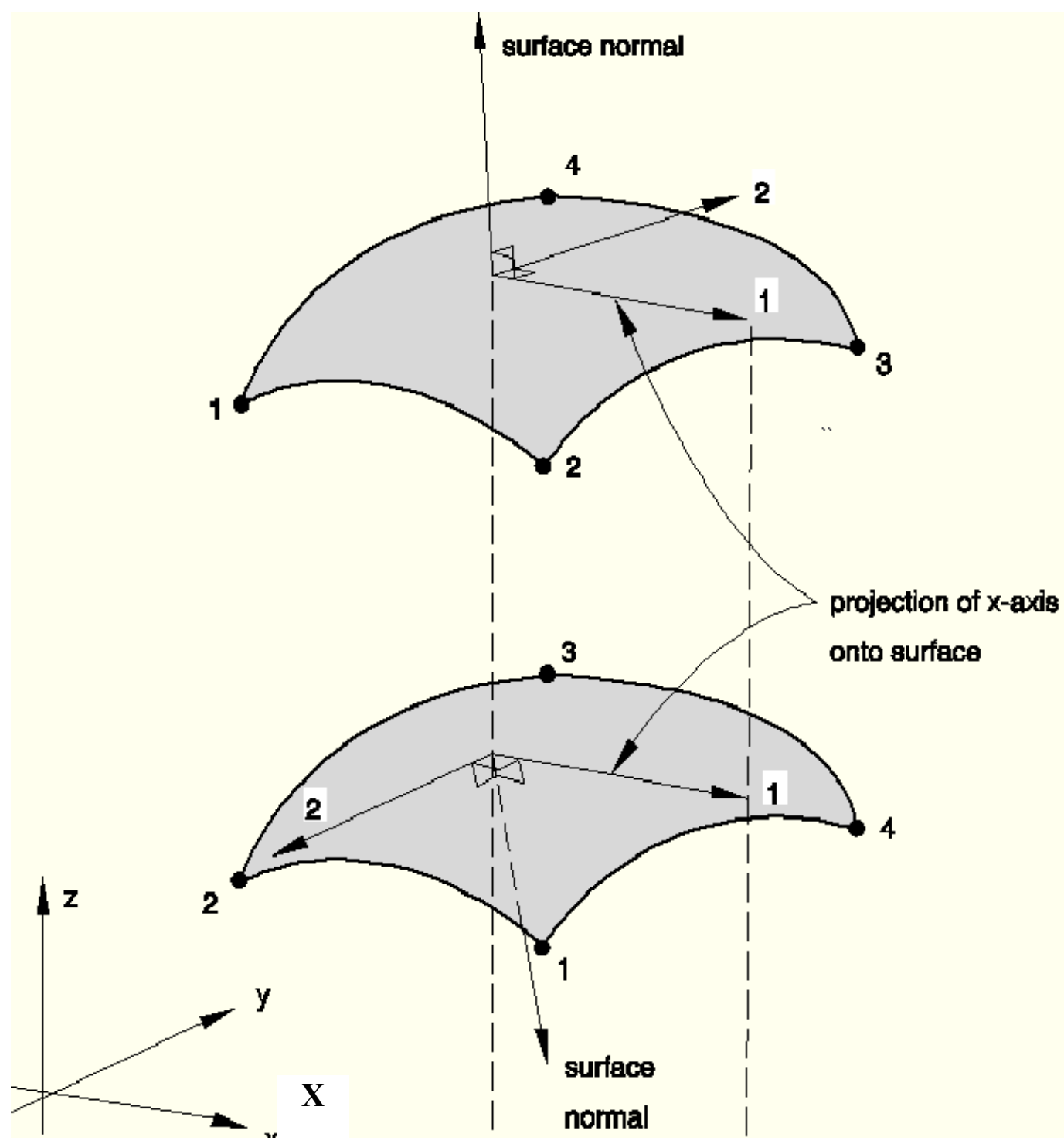

Figure 2.1 Orientation of a four-node shell element (ABAQUS/Explicit 2002) 


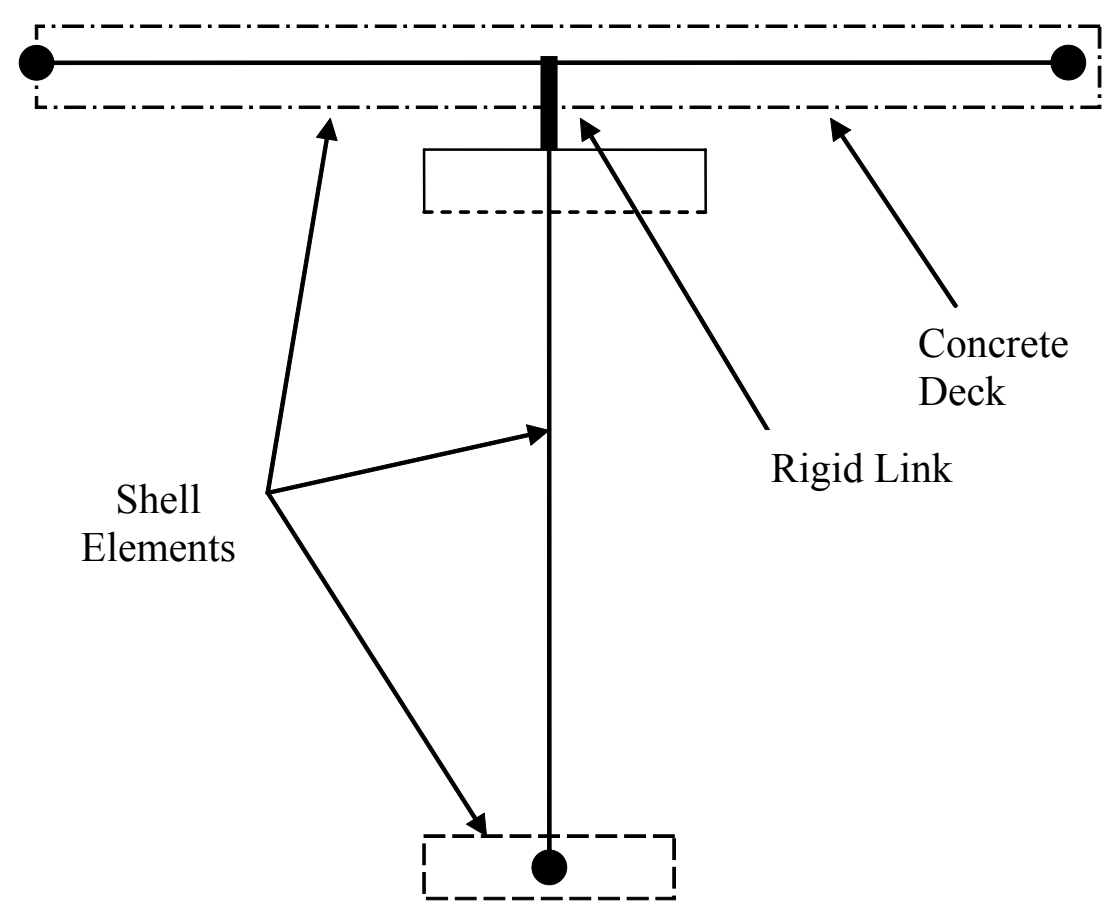

Figure 2.2 Rigid link between shell elements 


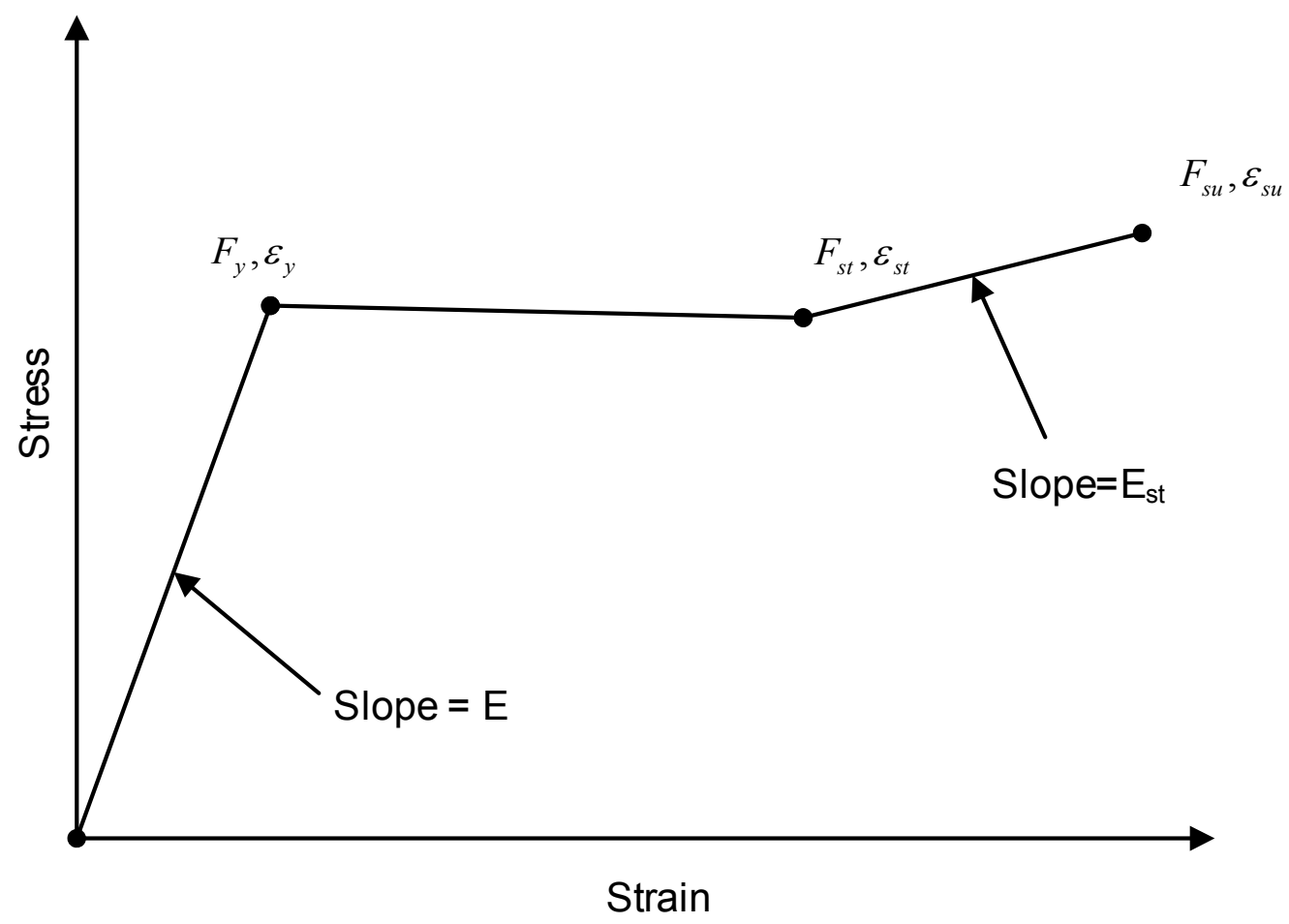

Figure 2.3 Typical Tri-linear constitutive law for steel 

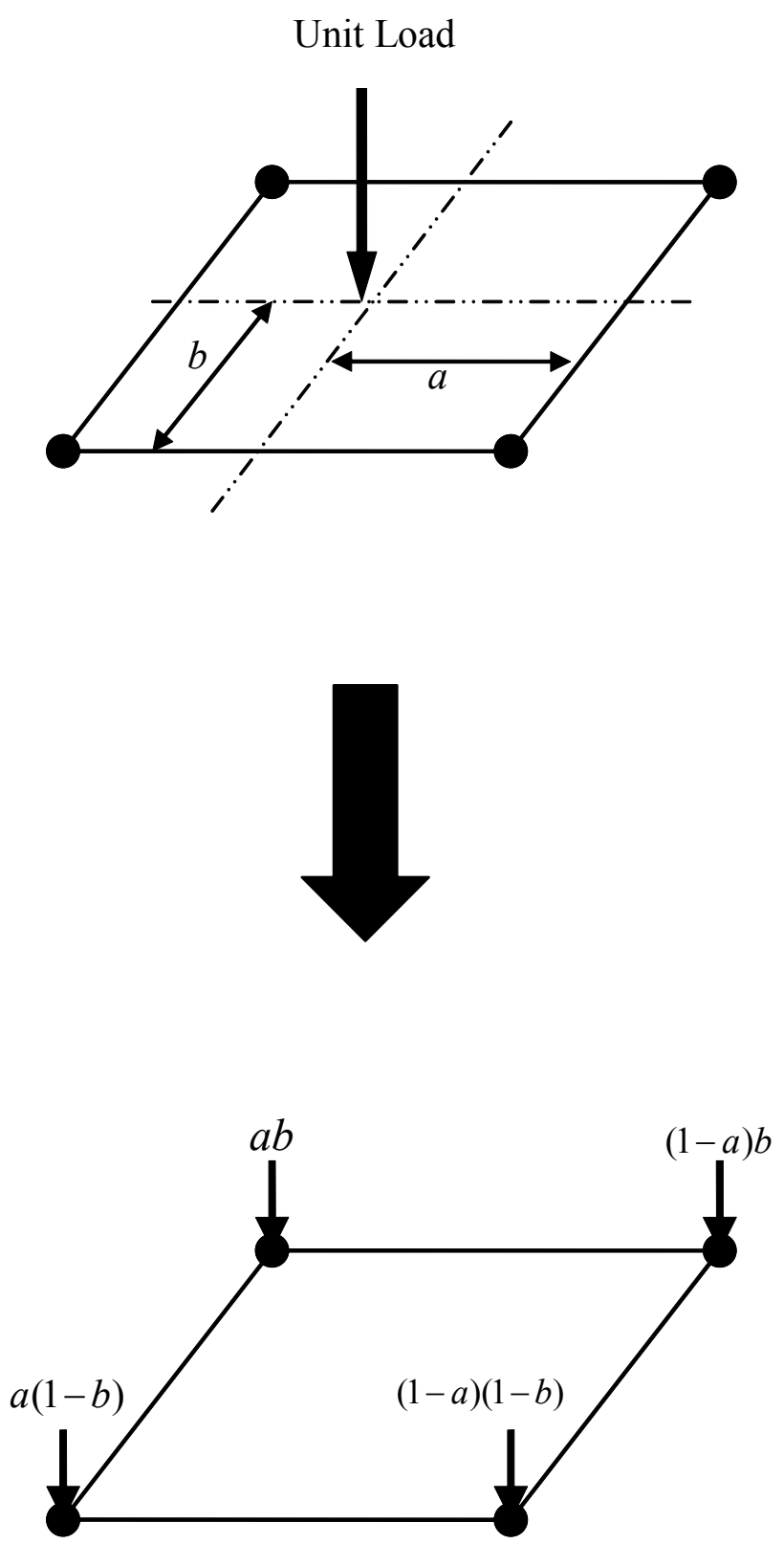

Figure 2.4 Load distribution of a four-node shell element (Adapted from Eom et al., 2001) 


\section{CHAPTER 3}

\section{GRAPHICAL USER INTERFACE FOR COMPOSITE STEEL GIRDER BRIDGES}

\subsection{Introduction}

This chapter presents a comprehensive outline of the GUI developed in this study. The menu structure and the input parameters for each of the forms in the program are explained. Once the necessary input parameters are specified by the user, the GUI generates an ABAQUS-compatible input file. The steps employed for the generation of nodes and elements for different members of the 3D bridge model are also provided. The program uses ABAQUS version 6.3-1 as the analysis engine. The post-processor is used for the generation of influence surfaces for various response parameters. Figure 3.1 shows the overall program flowchart with the required input parameters and the steps employed from the development of the FE model to the generation of influence surfaces

The graphical user interface of this program has a total of 5 menus (see Figure 3.2). The information, assumptions and conditions necessary for FE modeling of steel concrete composite bridges using the GUI developed in this research are presented in this chapter.

\subsection{File Menu}

File handling functionalities such as starting a new project, exporting the FE input file to ABAQUS and exiting the application can be accessed using the File menu. All the other menus are disabled at this point. 


\subsubsection{New Project}

The user can enter the title of the project using a file dialog box (see Figure 3.3). Once the title has been defined, other menus are enabled. All the input values that are provided by the user and necessary for 3D FE bridge model generation are stored in the project file.

\subsubsection{Export File}

Once the complete model has been generated by entering the necessary input for generation of the 3D bridge model, the user can create an input file which is exported to ABAQUS (Version 6.3-1) for FE analysis.

\subsubsection{Exit}

This sub-menu is used to exit the application and all the previous input parameters are stored in the project file specified at the beginning of the project for review. In order to generate a new bridge model, the project has to be restarted.

\subsection{Geometry Menu}

This sub-menu invokes a tab-controlled form to specify the span, girder, deck and cross frame dimensions of the bridge model.

\subsubsection{Span Dimensions}

This tab control is used to enter the basic dimensions of the bridge such as the total length of the bridge, number of spans, respective span lengths and the girder web depth. Figure 3.4 shows the form used to enter the span dimensions. The other key dimensions; width of the top and bottom flanges are input later in the Properties menu to allow for variable flange widths within different segments of the bridge. 


\subsubsection{Girder Dimensions}

This tab control is used to enter the number of girders and the center-to-center distance between the girders.

\subsubsection{Deck Dimensions}

Basic deck dimensions such as overhang width, deck thickness and the haunch are entered using this tab control. The haunch is defined as the distance between the bottom of the deck and the bottom of the top flange.

\subsubsection{Cross Frame Dimensions}

In this sub-menu, the user gives the cross-section dimensions of the cross frames. It should be noted that the program currently only employs angle-type cross frames. The user also specifies the material properties of the cross frame (Young's Modulus, Poisson's Ratio etc.) for calculating the torsional constant, shear modulus, shear center and moments of inertia of the cross frame. Figure 3.5 shows the tab-control to enter the cross frame dimensions.

\subsection{Material Menu}

The GUI has a set of materials in its library available to the user via a drop-down menu. More materials can be subsequently added to the material library in the back-end of the program. The form gets refreshed each time the Save button is clicked with an auto-generated Material ID. The form has a text box to enter the compressive strength of concrete $\left(f_{c}^{\prime}\right)$. Figure 3.6 shows the material menu to specify various materials for the FE model generation. 


\subsection{Properties Menu}

This menu invokes a tab-controlled form to allow the user to enter the section properties of various members of the composite bridge.

In order to create complex bridge models with variable flange widths, thicknesses and materials, the GUI first generates the bridge cross-section. This cross-section is then used as a basis to extrude the entire bridge model in sections, with each section demarcated by a single or multiple changes in girder properties (thickness, flange width or material). Using this menu item, the user enters the length, mesh density, flange width, flange thickness and flange material for each section.

\subsubsection{Girder Properties}

The girder properties are divided into three tab controls; Top Flange, Web and Bottom Flange. Figure 3.7 shows a form displaying the top flange properties menu. Based on user input for the number of properties, a data table is generated to enter the section properties of each member of the girder (top flange, web and bottom flange). This table allows the user to enter the thickness, width of the flange/depth of the web, material ID and the location (along the length of the bridge) of the section property transition. The last row in each data table corresponds to the total length of the bridge. Each tab control has a text box to enter the mesh density across the width of the flanges and through the depth of the web. The mesh size across the width of the top and bottom flanges should be an even number so that a node is present at the centerline of the girder. This ensures necessary connectivity between the elements in the girder and deck. 


\subsubsection{Deck Properties}

This tab control has a data table to enter the mesh density across the width of the deck (see Figure 3.8). Since the mesh density along the length of the bridge is the equal for both the girders and the deck during this modeling, the longitudinal element divisions for all members (girder, deck etc.) are entered in a common form that populated immediately after the submission of the deck properties form.

\subsubsection{Cross Frame Locations}

This tab control enables the user to specify the locations of the cross frames (see Figure 3.9). Currently, the program incorporates only standard X-type cross frames. To ensure a connection between the cross frame and the bridge model, cross frames can only be modeled at nodal locations. To achieve this, the user should specify a section transition in the top flange with two identical properties as outlined below.

For example, if a cross frame is required to be modeled at $30 \mathrm{ft}$ from the left end of the bridge; the user needs to specify two identical properties in the girder properties (top flange tab control) such that nodes are generated in two intermediate steps, thus ensuring the presence of nodes at the cross-section of $30 \mathrm{ft}$.

Table 3.1 shows the specifications of the variable girder properties without a cross frame. However, in cases where a cross frame needs to be specified at a location (30 ft from left support), the girder properties' input would be specified according to Table 3.2. Although there is no change in the top flange property in the two sections, (section 1 and 2 of Table 3.2) this atypical property specification ensures the presence of nodes at the section transition at $30 \mathrm{ft}$. and a cross frame can be specified at that location. 


\subsubsection{Stiffener Properties}

Based on the user's input for the number of stiffeners, a data grid is generated that allows for specification of stiffener properties. Figure 3.10 shows the form of the data grid where the user can enter the properties of the stiffener; single or double sided stiffener and if it is single, whether it is left or right-sided, thickness of the stiffener, mesh size along the depth, mesh size across the width and the location of the stiffener along the length of the bridge.

It is important to ensure that there are nodes across the bridge section at every stiffener location. This can be achieved by specifying a change in the property at that location using the girder properties menu, similar to the process discussed for cross frames.

\subsection{Load Menu}

As shown in Figure 3.11, this sub-menu displays a form that requires the user to enter the magnitude of the live-load.

Once all the input parameters have been specified, the program is ready to be executed for the modeling of the composite bridge.

\subsection{Model Menu}

\subsubsection{Run Model}

Invoking the Run menu executes a series of functions that are listed below.

- Create nodes and elements for I-section girders

- Create nodes and elements for the deck

- Create nodes and elements for stiffeners 
- Create MPC beams/rigid links between the deck and the top flange

- Create nodes and elements for cross frames

- Create trapezoidal (quadrilateral) elements at flange sections of variable width

- Generate nodal constraints for the bridge model

- Specify Node and element sets for deflection, moment and shear stress computation.

Once the FE model has been generated, all of the information of nodes and elements are stored in arrays for further reference.

\subsubsection{View Model}

This sub-menu is used to view the $3 \mathrm{D}$ model of a bridge. Figure 3.12 shows the 3D model of a continuous-span three-girder steel concrete composite bridge. The 3D bridge model can be rotated, zoomed and translated using the menu features available in this graphical window.

\subsubsection{Finite Element Analysis}

Selecting this menu item starts an ABAQUS analysis using the input file generated above. Results of the analysis are then subsequently stored in an MS-Access database file. Figure 3.13 shows the command window to execute the FE analysis.

\subsection{Post-Processor Menu}

In this menu, the user needs to specify the folder to store the generated output file using a file dialog box. The output parameters from the ABAQUS data file are used to generate influence surfaces for various response parameters which are exported in MS 
Excel spreadsheet format. Figure 3.14 shows the post-processor menu which allows the user to generate influence surfaces for stresses, displacements and moments.

The influence surface files that are created are given as:

1. Displacement Influence Surface: data_disp.xls

2. Moment Influence Surface: data_moment.xls

3. Shear Force Influence Surface: data_shear.xls

4. Bottom Flange Stresses Influence Surface: data_stresses.xls

\subsection{Node, Element and Constraint Generation from GUI Input Parameters}

The code developed in this study is an efficient tool for modeling specific 3D FE bridge models (tangent, continuous span models) using ABAQUS as the analysis tool. Although further upgrades and extensions to this software will significantly enhance the program's range for application in bridge model generation and increase the utility in modeling more complex bridge structures, the present version of the GUI provides tools to model fairly complex composite bridges with variable flange widths and thicknesses and also to specify and model an unlimited number of spans.

Subsequent sections of this chapter provide a detailed explanation of the generation of specific FE model parameters (node, elements etc.) for different members of a steel concrete composite bridge using the GUI. In this program, the orientation of the model is such that the length of the bridge is along the z-axis, cross section of the bridge along the $\mathrm{x}$-axis and the depth of the bridge along the y-axis. The top flange, bottom flange and deck elements lie in the $\mathrm{x}-\mathrm{z}$ plane (y-coordinate is constant), the web elements lies in the $\mathrm{y}-\mathrm{z}$ plane (x-coordinate is constant) and other additional members 
(stiffeners, cross frames, rigid links etc.) of the model are oriented accordingly. Figure 3.15 shows the FE ANALYSIS mesh of a simple span bridge elevation.

\subsubsection{Node Generation for I-section Girder}

Based on the user's input of bridge parameters in Section 3.2, the generation of nodes is performed as a series of operations. Node generation is described individually for each FE bridge member (girder, deck etc.)

To create the nodes in the girder's top flange, the following parameters are required; the transverse mesh density, longitudinal mesh density, width of flange and the length of the bridge. All the above required parameters are input in the top flange tab control of the girder properties sub-menu except the length of the bridge, which is input in the dimensions menu. The generation of nodes of the top flange for the first girder is presented here.

The GUI follows a different approach than some other bridge design software during node generation of the top flange (presented here) and the other bridge members (discussed later in the chapter). Instead of creating a single slab of the top flange and dividing into grid divisions based on a single mesh density value, node generation is performed in a number of intermediate steps with each step generating a section of the top flange. A section is defined by the area of the top flange specified by a property (flange thickness, width and material). A change in property at a cross-section of the girder specifies the start of a new section. The length of each section corresponds to the cross-section location along the length of the bridge where there is change in property as specified in the girder properties. The width of each section is equal to the width of the flange. Using an iterative process, the $\mathrm{x}, \mathrm{y}$ and $\mathrm{z}$ coordinates of each node are generated 
and stored in a multi-dimensional array. Since the top flange is a shell element in the $\mathrm{x}-\mathrm{Z}$ plane, the $\mathrm{y}$ coordinate is zero $(\mathrm{y}=0)$. Figure 3.16 shows the top flange of an I-section girder outlining the node numbering scheme followed by the program.

With a constant $\mathrm{z}$-coordinate $(\mathrm{z}=0)$, nodes are generated along the $\mathrm{x}$-direction with the incremental $\mathrm{x}$-distance $\Delta x_{t}=$ width of the section / number of elements across the width of the flange. Once a line of nodes are generated in the $\mathrm{x}$-direction, the $\mathrm{z}$ coordinate is incremented using a value $\Delta z_{t}=$ length of the section / number of longitudinal elements in that section. This z-coordinate value generates another line of nodes along the $\mathrm{x}$-direction. The above process continues such that all that nodes are generated for that section. Subsequent sections are modeled along the length of the bridge in a similar manner. Each of the generated nodes is assigned a node number. For a multiple-girder system, this node generation process is implemented considering the offset between girder centerlines in the x-direction.

Node creation for the web follows a similar approach as that of the top flange. Input parameters of this member are taken from the web properties tab control of the properties menu. The nodes are generated in sections such that length of each section is the same as the top flange and the depth of each section is equal to the depth of the web. Since the web lies in the $y-z$ plane, the $x$-coordinate for the web of each girder is constant. In this generation, nodes are created along the depth of the web (y-direction) for a constant z-coordinate. Once a line of nodes is generated, the z-coordinate is then changed by an incremental value $\Delta z_{w}=$ length of the section/number of elements in that section. This sequence of node generation is performed for each section. Nodes are subsequently created for every section along the length of the bridge. 
The creation of nodes in the bottom flange is similar to that of the top flange with the only difference being a different y-coordinate. For the bottom flange, the ycoordinate is constant $(\mathrm{y}=\mathrm{depth}$ of the web). The necessary input parameters; transverse mesh density, longitudinal mesh density, flange widths and the length of the bridge are retrieved from the bottom flange properties sub-menu and the dimensions menu. The node generation in the bottom flange is also performed in sections. The dimensions of each section are specified by the locations of the property transitions and the width of the bottom flange. During the generation of nodes for each section, the $\mathrm{x}, \mathrm{y}$ and $\mathrm{z}-$ coordinates of each node are stored in a multi-dimensional array for further reference.

Once all the nodes of the girder have been generated, the program executes the element generation of the girder by retrieving the node numbers and the coordinates of the top flange, bottom flange and web.

\subsubsection{Element Generation for I-section Girder}

Once the nodes of the girder have been generated, the next step is to generate the girder shell elements. Since the program analyzes straight girder bridges, each of the elements is rectangular in shape. The key to generate an element is to identify the four nodes that constitute the smallest rectangular area between them and group them together by associating an element number.

Figure 3.17 illustrates the element generation sequence in the top flange. An outline of the generation of an element, $K_{1}$ in the top flange is presented below. Using the first node $N_{1-1}\left(x_{1}, y_{1}, z_{1}\right)$ of the top flange as a reference, the second node $N_{2-1}\left(x_{2}, y_{2}, z_{2}\right)$ is identified such that $y_{1}=y_{2}, z_{1}=z_{2}$ and $x_{2}-x_{1}=\Delta x_{t}$, the incremental distance in the x-direction (width of the section/ number of elements). The third node 
$N_{3-1}\left(x_{3}, y_{3}, z_{3}\right)$ is identified such that $x_{2}=x_{3}, y_{2}=y_{3}$ and $z_{3}-z_{2}=\Delta z_{t}$, the incremental distance in the z-direction (length of the section/ number of elements). The fourth node $N_{4-1}\left(x_{4}, y_{4}, z_{4}\right)$ is identified such that $x_{1}=x_{4}, y_{1}=y_{4}$ and $z_{4}-z_{1}=\Delta z_{t}$, the incremental distance in the z-direction (length of the section/ number of elements).

This set of four nodes are identified by an element number and stored in a multidimensional array along with their nodal coordinates. The process of identifying the nodes and storing their corresponding node numbers in an array for further reference constitutes the generation of an element.

To generate the next element $K_{2}$, the x-coordinate of the first node $N_{1-1}$ of the previous element $K_{1}$ is incremented in the x-direction to find the coordinates of $N_{1-2}\left(x_{1}, y_{1}, z_{1}\right)$. Figure 3.17 shows that $x_{1-2}=x_{2}, y_{1-2}=y_{2}$ and $z_{1-2}=z_{2}$. This implies that the sequence of element generation follows the pattern of generation of nodes (traverse first in the $\mathrm{x}$-direction for a line of nodes and then in the $\mathrm{z}$-direction). Other corresponding nodes are identified using a similar procedure to that described above. This generation of elements is performed for each section and the process is then repeated for subsequent sections. Generation of the top flange elements for additional girders is done in a similar manner.

The elements for the web and bottom flange are also generated by defining the element and its four dependent nodes. The nodes of each element are represented by a local naming convention. $N_{1}$ is always the reference node; $N_{2}, N_{3}$ and $N_{4}$ are the dependent nodes such that the four nodes define a rectangular area in the anti-clockwise direction. 


\subsubsection{Node Generation for Bridge Deck}

For the creation of nodes in the deck, the following parameters; overhang distances, longitudinal mesh density and transverse mesh density are input in the deck properties tab control of the properties menu.

The node generation for the deck is also carried out in sections. A section corresponds to the smaller areas of the deck that are segmented based on the number of girders, overhang distance and the longitudinal mesh density. In order to ensure connectivity between the deck and girder layers, the longitudinal mesh density for the top flange, web, bottom flange and deck is the same. Figure 3.18 shows the dimensions and the node generation conventions for the deck of a three-girder bridge superstructure. The width of the first section, $\mathrm{w}_{1}$ extends from the left overhang to the centerline of the first girder. Subsequent sections extend between the centerlines of each girder. The last section $\left(\right.$ width $\left.=\mathrm{w}_{4}\right)$ extends from the centerline of the last girder to the right overhang. So the total number of sections in the deck are equal to $n_{1}\left(n_{2}+1\right)$, where $n_{1}=$ number of transitions in the longitudinal direction (specified by the number of property changes in the girder) and $n_{2}=$ number of girders.

The deck is also modeled using four-node shell elements. Using incrementing loops, the $\mathrm{x}, \mathrm{y}$ and $\mathrm{z}$ coordinates of each node are generated and stored in a multidimensional array. Since the deck is modeled in the $\mathrm{x}-\mathrm{z}$ plane, the $\mathrm{y}$-coordinate is constant $(y=$ haunch $+1 / 2$ (deck thickness-top flange thickness).

With a constant $\mathrm{z}$-coordinate $(\mathrm{z}=0)$, the first line of nodes are generated for the deck along the $\mathrm{x}$-direction with the incremental $\mathrm{x}$-distance $\Delta x_{d}=$ width of the section $\left(\mathrm{w}_{1}\right)$ /number of elements. Once a line of nodes are generated in the $\mathrm{x}$-direction at the left 
end of the bridge, the z-coordinate is incremented using a value $\Delta z_{d}=$ length of the section/number of elements in that section of the deck. This z-coordinate value generates another line of nodes along the x-direction. The above process continues until all the nodes are generated for that section. Subsequent sections are modeled along the length and width of the bridge in a similar manner. Each of the generated nodes is assigned a node number which is used for further reference.

\subsubsection{Element Generation for Bridge Deck}

Element generation for the deck is similar to that of the generation of elements in girders. Four-node shell elements, S4R, are used to model the bridge deck. Each element will be formed by four nodes that form the smallest rectangular area. Once the nodes are identified, they are stored in an array and assigned an element number which is used for further reference. Figure 3.19 shows the node numbering conventions adopted for the creation of elements in the deck.

The first element, $K_{i}$, is generated as follows. With the first node $N_{1}\left(x_{1}, y_{1}, z_{1}\right)$ as a reference, the second node $N_{2}\left(x_{2}, y_{2}, z_{2}\right)$ is identified according to the condition that the incremental $\mathrm{x}$-distance $\Delta x_{d}=$ width of the section/number of elements, $y_{1}=y_{2}$ and $z_{1}=z_{2}$. Similarly, the third node $N_{3}\left(x_{3}, y_{3}, z_{3}\right)$ is identified such that $x_{2}=x_{3}$, $y_{2}=y_{3}$ and $z_{3}-z_{2}=\Delta z_{d}$, the incremental distance in the z-direction (length of the section/ number of elements). The fourth node $N_{4}\left(x_{4}, y_{4}, z_{4}\right)$ is identified such that $x_{1}=x_{4}, y_{1}=y_{4}$ and $z_{4}-z_{1}=\Delta z_{d}$, the incremental distance in the z-direction (length of the section/ number of elements). These four nodes are stored in an array and constitute 
the generation of an element. Once the dependent nodes are defined, other material and sectional properties associated with this element are also stored in the array.

For the generation of the next element $K_{1-2}, N_{1-2}\left(x_{1}, y_{1}, z_{1}\right)$, the node immediately next to node $N_{1-1}$ in the x-direction is considered the reference node. Other nodes, $N_{2-2}$, $N_{3-2}$ and $N_{4-2}$ are identified such that they form the smallest rectangular area with this

new node, $N_{1-2}$. These nodes stored in an array along with a new element number. Subsequent elements of the deck are generated using the same procedure described above.

\subsubsection{Node Generation for Cross Frames}

Cross frames are modeled using beam elements (B31) and are placed at user defined locations along the length of the bridge. The beam elements connect the center of the top flange of one girder with the center of the bottom flange of the adjacent girder (see Figure 3.20). An outline of the node generation for these members is presented herein.

The geometric dimensions and mesh density for the cross frame members are obtained from the cross frame tab control of the geometry menu. The locations for the cross frames are specified in the properties menu. Since each cross frame is an individual member occurring at a section of the bridge (modeled in the $x-y$ plane), the $z-$ coordinate is constant. At a given cross frame location, the member length is determined based on the depth of the web and the girder spacing. Each cross frame member is then discretized into X-X elements as defined by the user. 


\subsubsection{Element Generation for Cross Frames}

The cross frames of the bridge are modeled using timoshenko beam elements (B31). As these elements are 2-node elements, the generation of a cross frame element constitutes defining the element number and identifying the two nodes that are associated with it. The distance between the two nodes $N_{1}$ and $N_{2}$ is specified by the mesh density value provided by the user. The dependent nodes $N_{1}$ and $N_{2}$, the material and section properties associated with the element and the element number are stored in a multidimensional array.

\subsubsection{Node Generation for Transverse Stiffeners}

Transverse stiffeners are placed at user-defined locations and may be modeled as single or double sided. For single sided stiffeners, the user may define the desired side of the web for stiffener placement. Figure 3.21 shows a typical transverse stiffener at one end of a multi-girder bridge model. For ease of modeling, the width of each stiffener is equal to the lesser value of the top or bottom flange width and the depth of each stiffener is equal to the depth of the web. Appropriate connections are made between the stiffener and the flanges with the use of rigid links. Since the stiffener is modeled using shell elements in the $\mathrm{x}-\mathrm{y}$ plane, the $\mathrm{z}$-coordinate is constant $(\mathrm{z}=$ location of stiffener along the length of the bridge). The input parameters for the stiffener node creation include mesh density across the width, mesh density along the depth and location of each stiffener. These values are obtained from the stiffener tab control of the properties menu.

Since the $\mathrm{z}$-coordinate is constant for each stiffener, the $\mathrm{x}$ and $\mathrm{y}$ coordinates for each node are calculated based on the mesh density specified by the user and these values 
are stored in an array along with the corresponding node number. This node array is further utilized to generate the elements of the stiffener.

\subsubsection{Element Generation for Transverse Stiffeners}

Once the nodes of the stiffener have been defined, the element generation is similar to that used for the other members. Since the stiffeners are also modeled using shell elements, the four nodes that define the element are identified and an element number is assigned to it. The incremental distances in the $\mathrm{x}$-direction $\Delta x_{s}$ and $\mathrm{y}$-direction $\Delta y_{s}$ are calculated using the mesh density and the geometrical dimensions of the stiffener. ( $\Delta x_{s}=$ width of the stiffener/mesh density across the width and $\Delta y_{s}=$ depth of the web/mesh density along the depth).

\subsubsection{MPC Beam Element Generation between Deck and Top Flange}

An MPC beam element generates a rigid link between two nodes by allowing constraints to be imposed between different degrees of freedom of the model. This element is necessary to create the connection between the elements of the deck and the top flange. The deck and girder layers are offset by a distance $G_{L}=$ haunch $+1 / 2($ deck thickness - top flange thickness) of the bridge superstructure. The rigid links are modeled between the nodes at the centerline of the top flange and the deck nodes directly above them. During the FE modeling of the bridge model, the longitudinal mesh densities of the girder and the deck are equal. Furthermore, the deck has been modeled in smaller sections such that the width of each section extends up to the centerline of each girder. Figure 3.22 shows a rigid link between the girder and deck layer in a composite bridge 
model. This ensures that there is a node on the deck above every node on the centerline of the top flange.

For each rigid link, the first node or the reference node $N_{1}\left(x_{1}, y_{1}, z_{1}\right)$, is on the centerline of the top flange. The second node or the dependent node $N_{2}\left(x_{2}, y_{2}, z_{2}\right)$ is the node directly above it and is identified such that $x_{1}=x_{2}, z_{1}=z_{2}$ and $y_{2}-y_{1}=$ haunch $+1 / 2$ (deck thickness +top flange thickness). In this manner, all the nodes on the centerline of the top flange are identified and the corresponding nodes on the deck established. The two nodes for each rigid link are stored as a set in an array and used for further reference.

\subsubsection{Specification of Constraints}

In order to adequately constrain a $3 \mathrm{D}$ continuous-span bridge model, the bottom flange nodes at one end of the bridge; where $z=0$ and $y=$ depth of the web, are identified. The node numbers associated with these nodes are stored in an array and three attributes ' 1 ', '2' and ' 3 ' are associated to it indicating that the above nodes have been constrained in the $\mathrm{x}, \mathrm{y}$ and $\mathrm{z}$-directions (equivalent to a pin-type constraint). Similarly, the nodes on the bottom flange at the other end of the bridge ( $\mathrm{z}=$ length of the bridge) are identified and stored in an array. An attribute ' 2 ' indicating a y-direction constraint (equivalent to a roller-type constraint) is attached to these nodes. Additional pier locations are constrained in the y-direction by identifying the bottom flange nodes at that pier cross-section, storing them in an array and associating the attribute ' 2 ' to it. The node numbers and the attributes attached to them are then written into the input file. 


\subsubsection{Generation of Node and Element Sets for Efficient Output Data}

Once the FE model has been created, the nodes and elements at which the response parameters have to be recorded needs to be specified. This ensures that the output parameters such as deflection and stresses are recorded at the key sections of the bridge saving considerable computation time during FE analysis.

For deflection, the nodes at the centerline of the top flange for specific cross sections are identified and stored in a deflection data set. For calculation of girder crosssectional moments, the elements at three specific locations on the web and bottom flange are identified. The procedure employed to identify these elements is discussed subsequently in section 3.10.2. For calculation of cross-section shear, the web elements at specific cross sections are identified and stored in an array.

\subsubsection{Input File Generation}

Once all the members of the FE model have been generated and the associated properties stored in corresponding arrays, an input file is generated that is used by ABAQUS for analysis.

Once the input file has been generated, the ABAQUS analysis engine may be invoked. Based on the commands specified in the input file, ABAQUS generates the necessary output values in a data file. This output file is used by the post processor database program to get the final response parameters for different loading conditions using influence surfaces. Section 3.10 discusses the generation of influence surfaces 


\subsection{Post-Processor/ Database Program}

This module of the GUI uses the results from the data file obtained by FE ANALYSIS using ABAQUS to compute the final results that can be used for correlation with experimental data. Since the moments and shears at desired locations of the bridge model are not directly obtainable from the ABAQUS data file, the post-processor module invokes Microsoft-Access and Microsoft-Excel (Microsoft, 2005) to make necessary computations that provide the moments and shear values and report specified girder displacements. Additionally, the module generates influence surfaces whose ordinates give the responses at critical load points on the bridge. The final data and plots are available in Excel spreadsheet format.

\subsubsection{Influence Surface Approach}

Influence surfaces provide a method to capture the force effects of concrete steel composite girders and bridge superstructures by computing the various response parameters in the model due to different loading conditions and help to determine the worst possible load-case scenarios. An influence surface is a 3D surface graph that is generated by plotting a specific response parameter as the ordinate, on the surface of the bridge deck. In this study, the concrete deck is divided into a $10 \mathrm{X} 10$ grid for every span. A unit load is placed at every point on the grid and the responses (e.g. moment, shear and vertical deflection) are computed. An envelope of these responses for a point of interest constitutes the influence surface of the response parameter and interpolation of the influence surface data provides the results for different loading conditions. 


\subsubsection{Girder Moments}

In order to calculate the girder moments, linear regression is applied to the stress values computed at specific points on the web and the bottom flange to generate a linear stress profile of the bridge section. Figure 3.23 shows an example stress distribution at a given cross-section in the bridge. The slope and intercept from the profile, in conjunction with the geometrical properties of the bridge model (center of gravity of I-section girder, $C G$, moment of inertia of concrete slab, $I_{S L A B}$ and moment of inertia of steel

girder, $I_{S T L}$ ) are utilized to calculate the stress at the bottom flange and the stress at the centroid of the steel girder. The equations to calculate these values will be presented later in this section. The moment of inertia of the concrete slab $I_{S L A B}$ is calculated by finding the effective slab width based on AASHTO (1998) specifications as follows. Figure 3.24 shows the cross-section of an I-section girder showing the effective width of the slab.

For interior beams, the effective slab width is taken as the least of:

1. One-quarter of the effective span length

2. 12.0 times the average thickness of the slab, plus the greater of web thickness or one-half the width of the top flange of the girder; or

3. The average spacing of adjacent beams

For exterior beams, the effective flange width may be taken as one-half the effective width of the adjacent interior beam, plus the least of:

1. One-eighth of the effective span length

2. 6.0 times the average thickness of the slab, plus the greater of half the web thickness or one-quarter of the width of the top flange of the basic girder; or

3. The width of the overhang. 
For adequate representation of the stress profile of a steel concrete composite bridge section, three stress values; stresses at the center of the bottom flange, quarterpoint of the web and mid-point of the web (see Figure 3.25) are obtained from the ABAQUS data file. Figure 3.25 shows a cross-section of the girder and the locations at which the stress values are recorded. In the absence of a node at any of those locations, interpolation is done between stress values at adjacent nodes to compute the stress value. The method to retrieve these data points from the large ABAQUS output file which contains data from all load steps is described further.

In this project, the influence surface graphs are generated by plotting the unit load responses for 100 points (10X10 grid) for each span on the bridge deck. ABAQUS analysis is performed for each of the 100 load steps and the girder stress values for userdefined bridge cross-sections are computed. The location of the applied load for each load step is outlined in section 3.10.1.

Once the multiple load-step analysis is complete, data from the ABAQUS output file is then imported into the post-processor database program for correlation of resultant stress values with the bridge geometry and element numbers. This correlation generates a comprehensive database table that lists the element number, its associated node numbers and nodal coordinates for each stress response value. Using this data, girder cross-section moments are calculated using the linear stress distribution profile as follows.

Based on three stress values described above, linear regression is performed to develop a best fit line that represents the cross section stress profile.

$$
\left[\begin{array}{cc}
\sum \sigma_{i}^{2} & \sum \sigma_{i} \\
\sum \sigma_{i} & 3
\end{array}\right] *\left\{\begin{array}{c}
\text { Slope } \\
\text { Intercept }
\end{array}\right\}=\left\{\begin{array}{c}
\sum\left(\sigma_{i}^{*} d_{i}\right) \\
\sum d_{i}
\end{array}\right\}
$$


Using Equation 3.1, the slope and intercept of the profile analysis are calculated with $\sigma_{i}$ indicating the stress value at a distance $d_{i}$ from the bottom flange. $\sigma_{i}$ and $d_{i}$ are obtained from the data table outlined above.

The above stress profile is used to compute the girder moment at a cross-section by breaking the load carrying mechanism into three components (Bakht 1988). The first component is the steel girder bending about it's own neutral axis, $M_{l}$. The second component is the concrete area bending about its own neutral axis, $M_{u}$. The third component arises out of a couple between the deck and the steel girder and is a function of the composite action between the concrete area and the steel section, $M_{a}$. Figure 3.26 shows the different moment components for a composite bridge cross-section.

The first moment component which is due to the steel girder bending about its own neutral axis is given by,

$$
M_{l}=\left(\sigma_{o}-\sigma_{C G}\right) S_{S T L}
$$

The stresses at the centroid of the steel girder, $\sigma_{C G}$ and stress at the bottom of the bottom flange, $\sigma_{0}$ are calculated using the following equation:

$$
\begin{aligned}
& \sigma_{0}=-\frac{\text { Intercept }}{\text { Slope }} \\
& \sigma_{C G}=\frac{\text { CG-Intercept }}{\text { Slope }}
\end{aligned}
$$

where,

$$
C G=\frac{\sum \text { Area }^{*} y}{\sum \text { Area }}
$$


The geometrical properties, $C G, I_{S T L}$ and $I_{S L A B}$ are calculated for required cross sections by using the basic dimensions of the bridge model that are input into a table in the database.

The second moment component, due to the bending of the deck about its neutral axis, is given by,

$$
M_{u}=\left[\frac{E_{S L A B} I_{S L A B}}{E_{S T L} I_{S T L}}\right] M_{l}
$$

The third component, the moment due to a couple between the deck and the steel girder is,

$$
M_{a}=\sigma_{C G} A_{S T L}\left[\left(d_{S T L}-C G\right)+\text { haunch }+\frac{d_{S L A B}}{2}\right]
$$

where $\sigma_{C G} A_{S T L}=N$, is the axial force due to the composite action and $\left[\left(d_{S T L}-C G\right)+\right.$ haunch $\left.+\frac{d_{S L A B}}{2}\right]=a$ is the distance between the neutral axes of the concrete deck and the steel girder.

The total girder moment for each girder cross section is given by:

$$
M_{\text {total }}=M_{l}+M_{u}+M_{a}
$$

The total moment values are calculated for every $10^{\text {th }}$ point along the length of the bridge for all girder using the database program. As discussed before, these moment values form the ordinates of the influence surface graphs which are auto-generated in Microsoft-Excel. 


\subsubsection{Deflection}

The nodes at the centerline of the top flange are identified and grouped into a node set. FE analysis computes the load deformation response at these nodes and lists them in a data file. These deflections are then input into the database program to correlate the deflection with the nodal coordinates to generate influence surfaces.

\subsubsection{Shear Force}

For the calculation of cross-section shear force, the ABAQUS analysis first computes the shear stress for each web element along specified cross sections. In this GUI, the web elements are oriented in the $y-z$ plane (x-coordinate specifies the thickness of the web) and the shear stress for each element is defined by $\sigma_{12}$

Figure 3.27 shows the orientation of a web element and sign convention of the stresses adopted for the calculation of the shear stress. The average shear stress at each cross-section $\left(\sigma_{A V G}\right)_{\text {web }}$ is given by

$$
\left(\sigma_{A V G}\right)_{\text {web }}=\left(\frac{\sum_{i=1}^{n}\left(\sigma_{12}\right)_{i}}{n}\right)
$$

where $\mathrm{n}$ is number of elements along the depth of the web. In the absence of nodes at that cross-section, interpolation is done to calculate the exact value of shear stress at that location.

The average shear stress along all the web elements at the section is used for the calculation of the shear force of the web.

$$
S F=\left(\sigma_{A V G}\right)_{w e b} \times t_{w e b} \times d_{S T L}
$$

Eq.3.10 
Using the database program, these shear force values are computed for desired cross sections and form the basis for generation of influence surfaces for shear in the post-processor module. 
Table 3.1 Girder Properties without Stiffeners

\begin{tabular}{|c|c|c|c|}
\hline Length (in.) & Width (in.) & Thickness (in.) & Material \\
\hline 120 & 5.625 & 0.25 & 1 \\
\hline 600 & 6.125 & 0.40 & 1 \\
\hline
\end{tabular}


Table 3.2 Girder Properties with Stiffeners

\begin{tabular}{|c|c|c|c|}
\hline Length (in.) & Width (in.) & Thickness (in.) & Material \\
\hline 120 & 5.625 & 0.25 & 1 \\
\hline 360 & 5.625 & 0.25 & 1 \\
\hline 600 & 6.125 & 0.40 & 1 \\
\hline
\end{tabular}




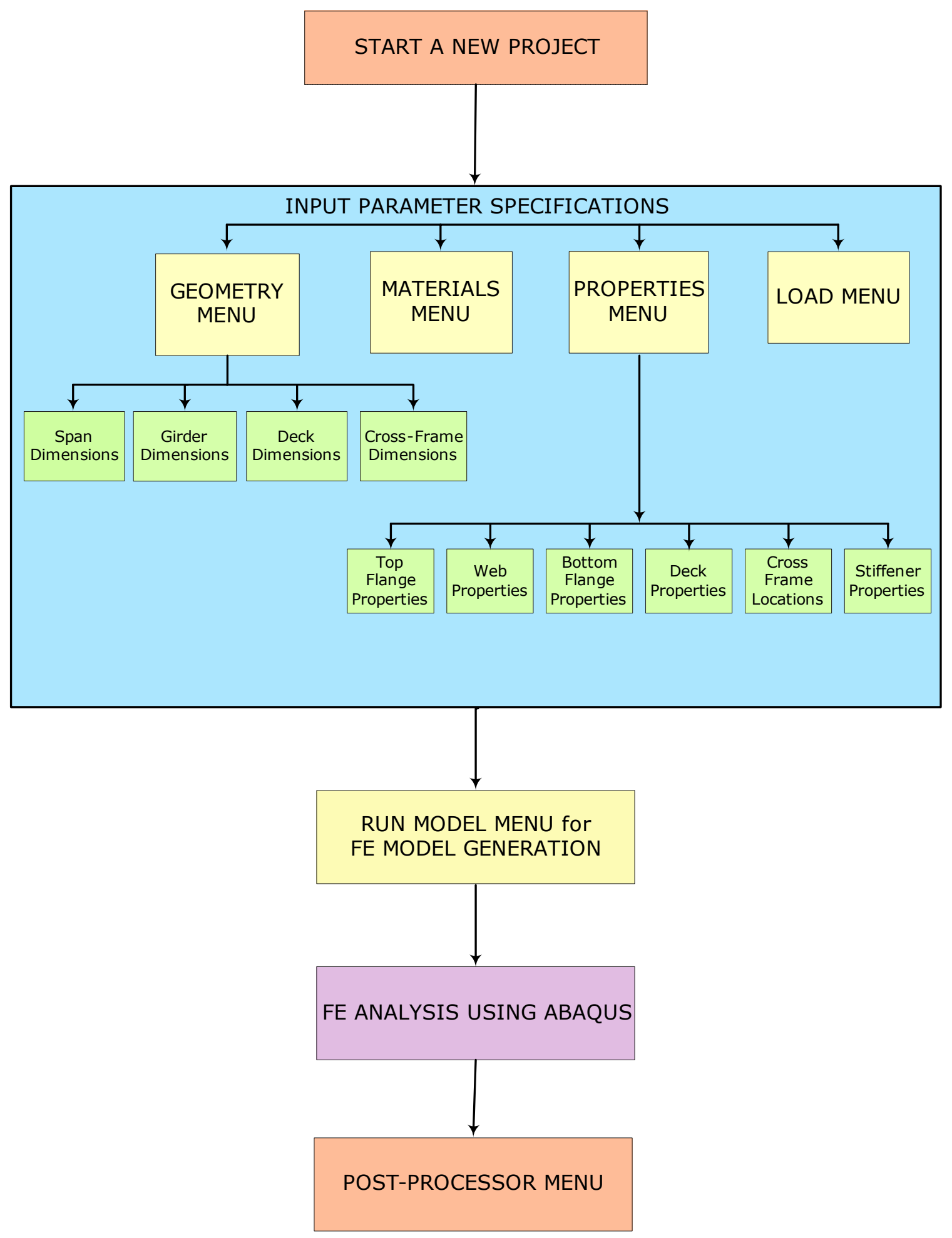

Figure 3.1 Overall Program Flowchart 


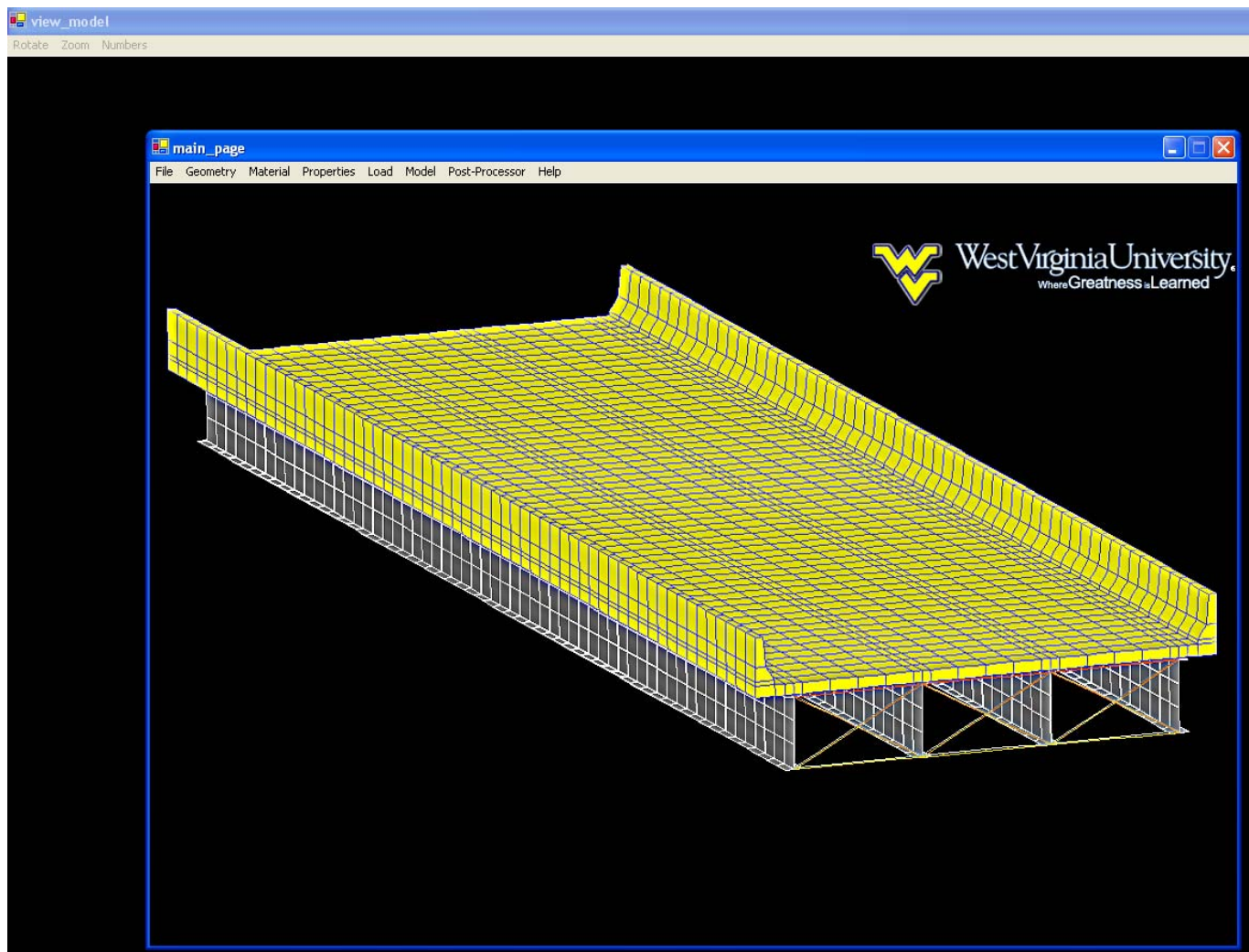

Material Properties Load Model Post Processor Her 


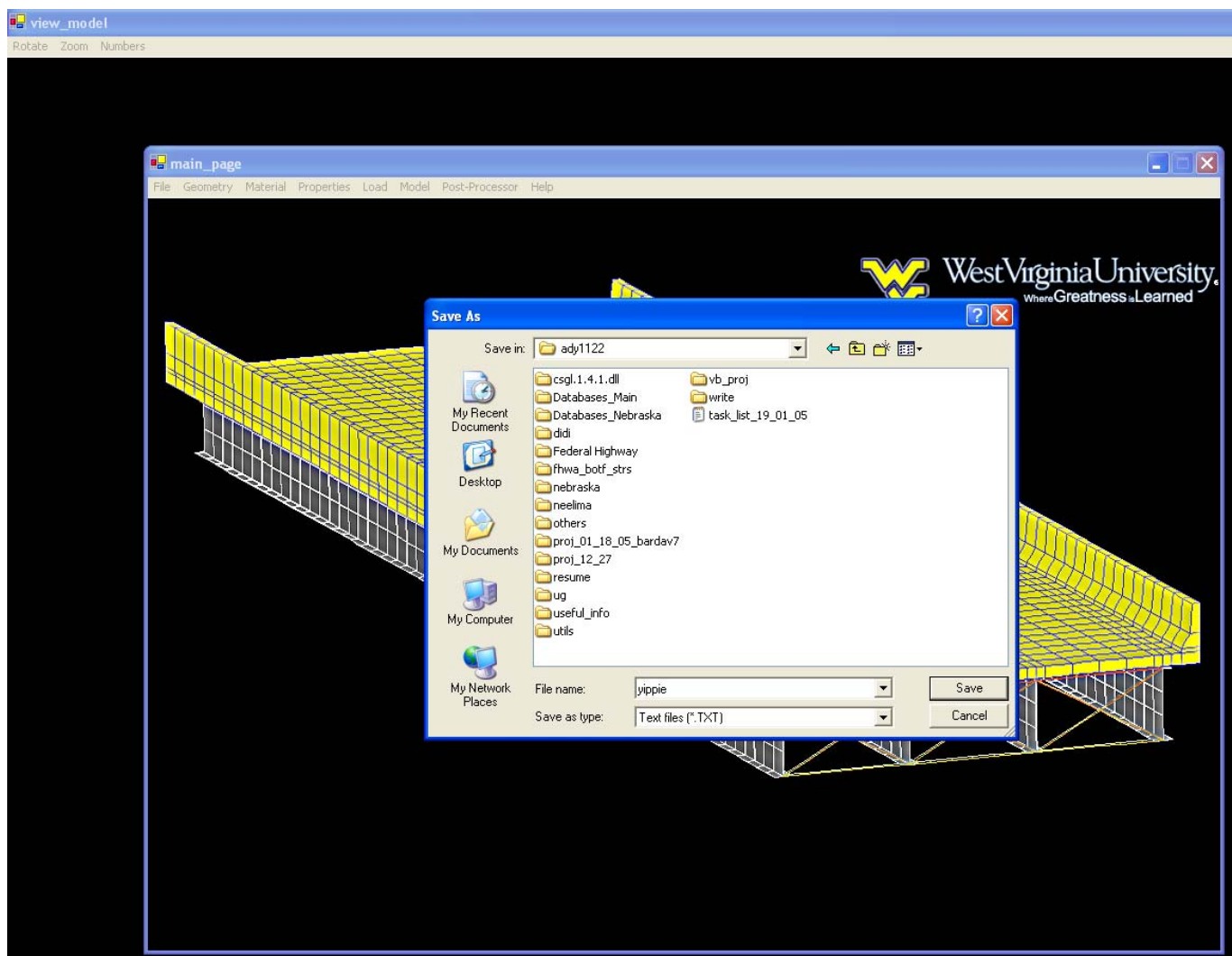

Figure 3.3 Starting a new project 


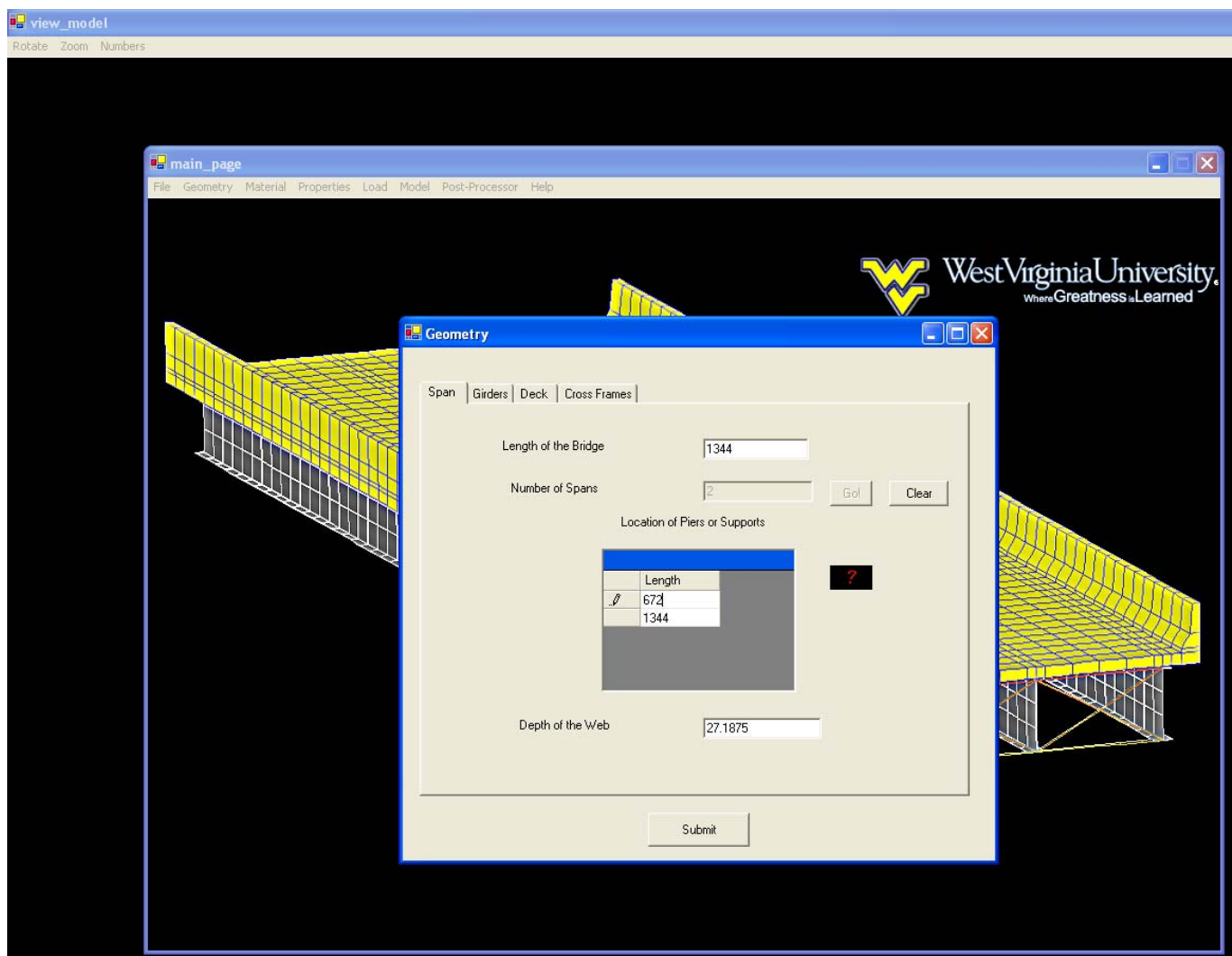

Figure 3.4 Span Dimensions 


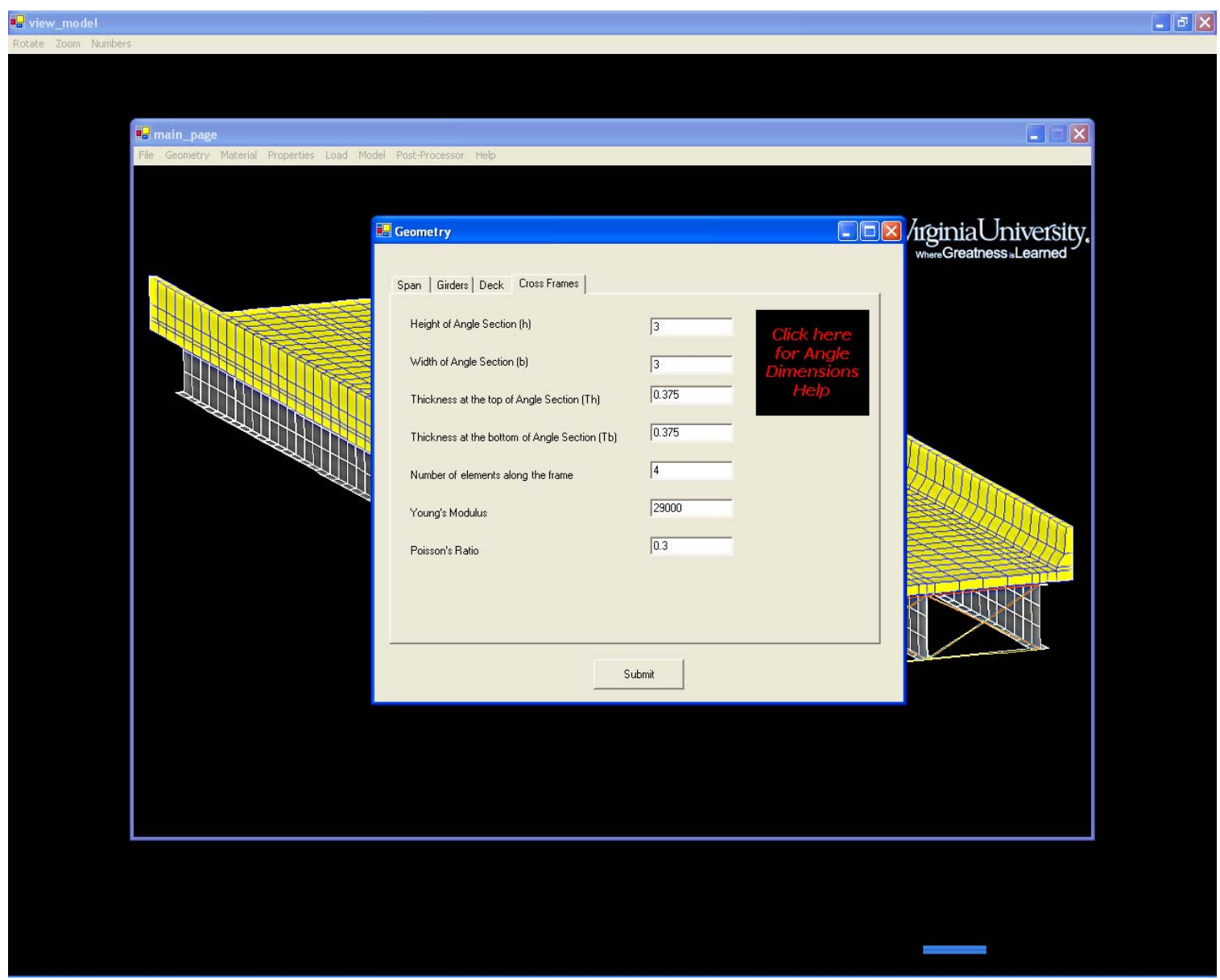

Figure 3.5 Cross frame dimensions 


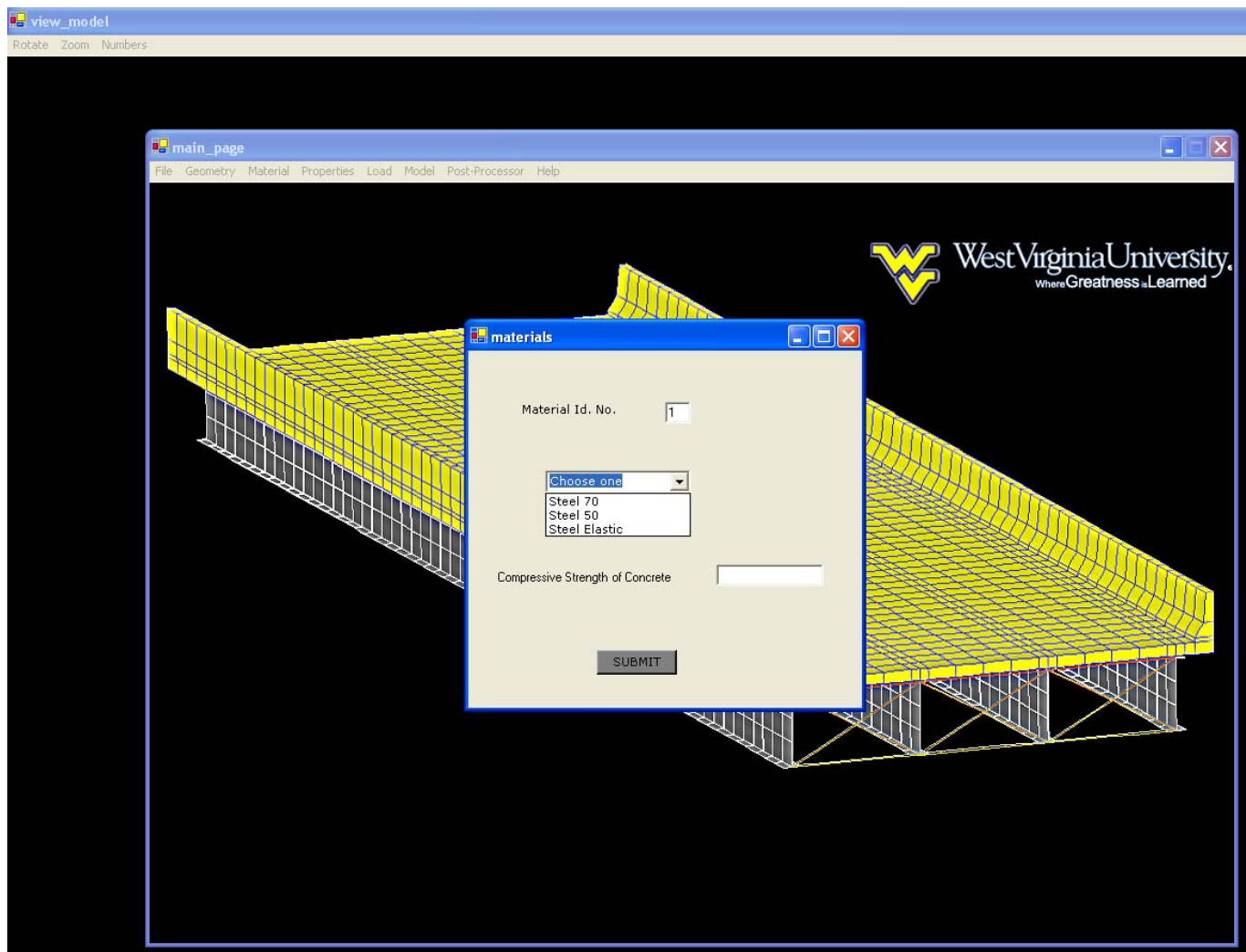

Figure 3.6 Material menu 


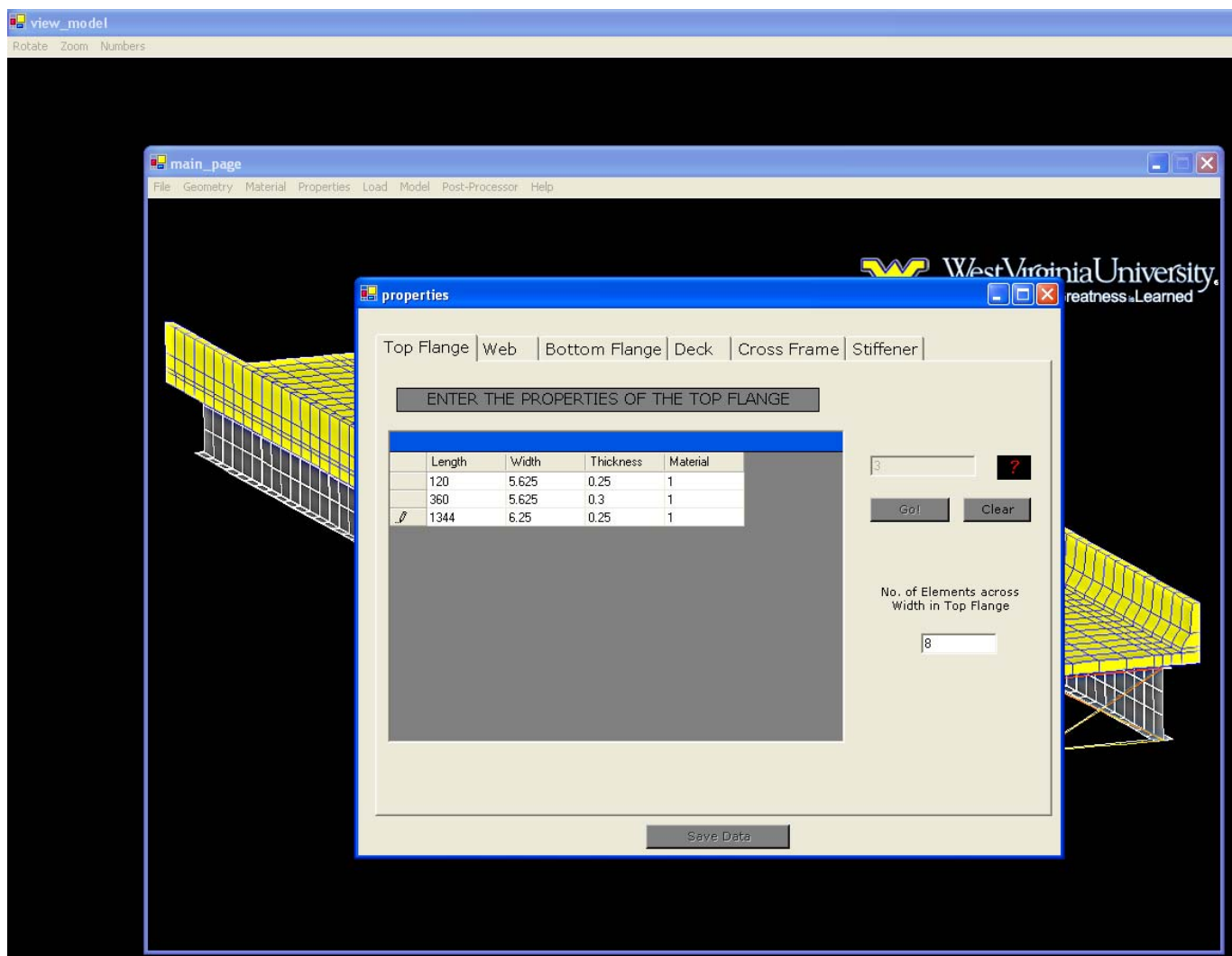

Figure 3.7 Top flange properties 


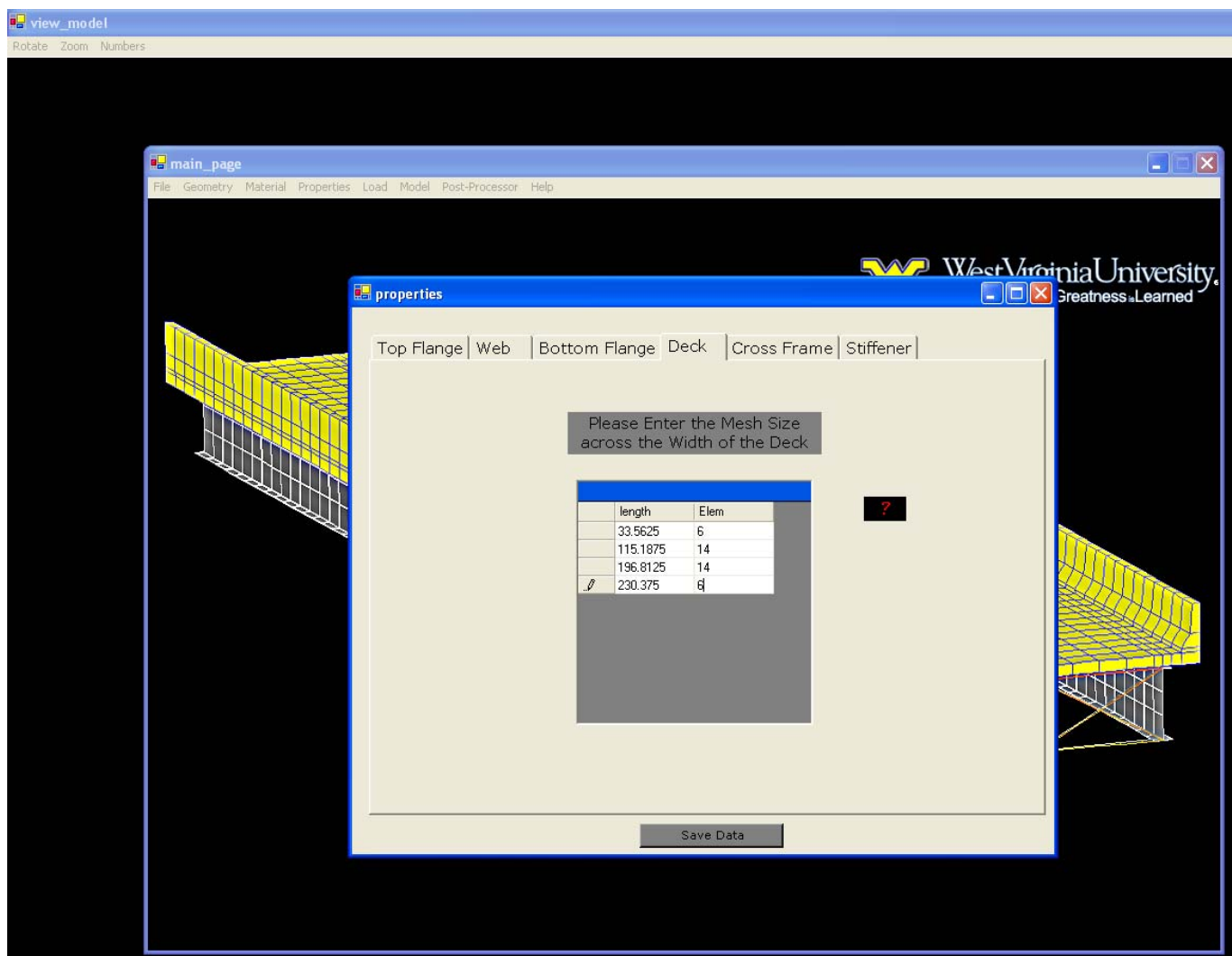

Figure 3.8 Concrete deck properties 


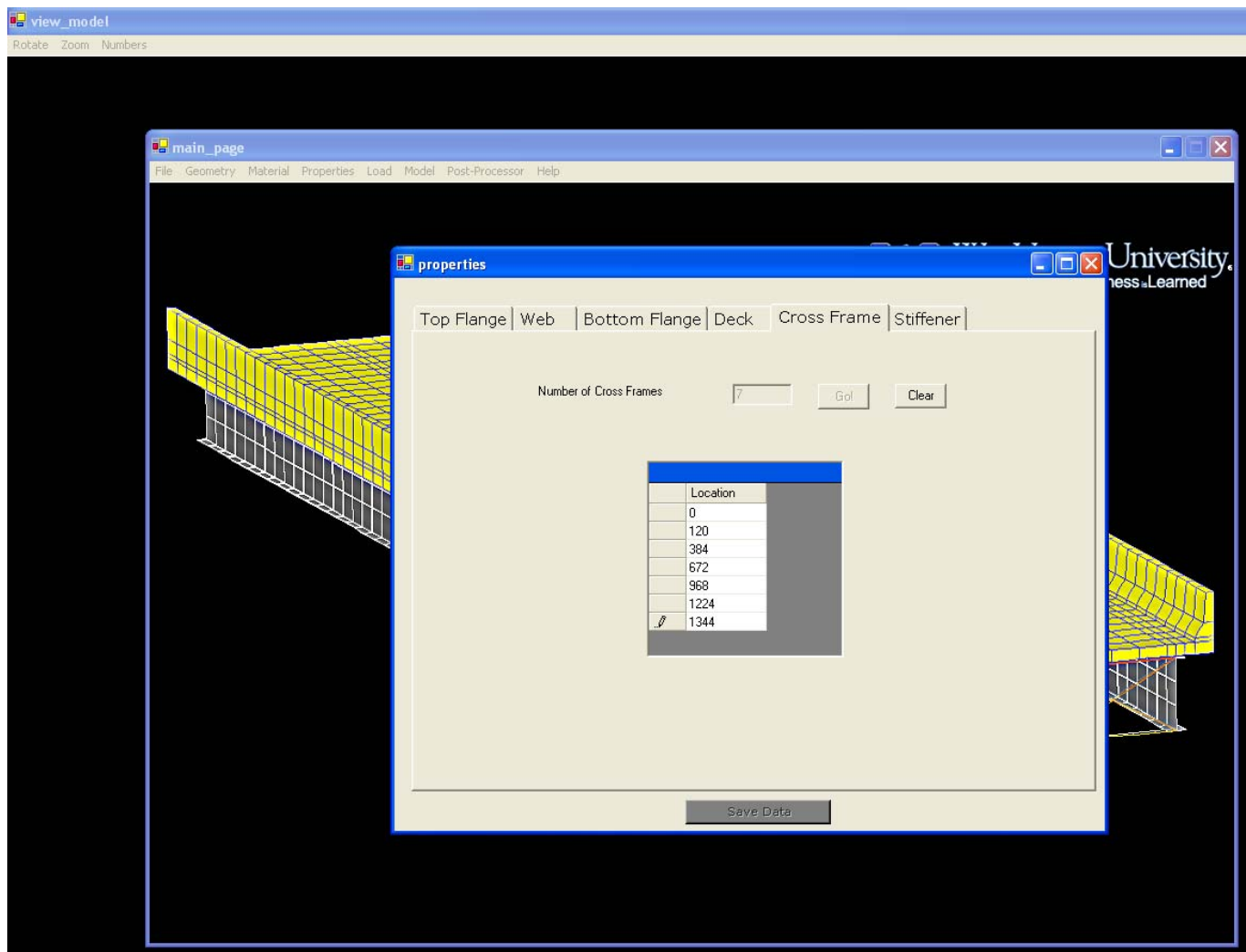

Figure 3.9 Cross frame locations 


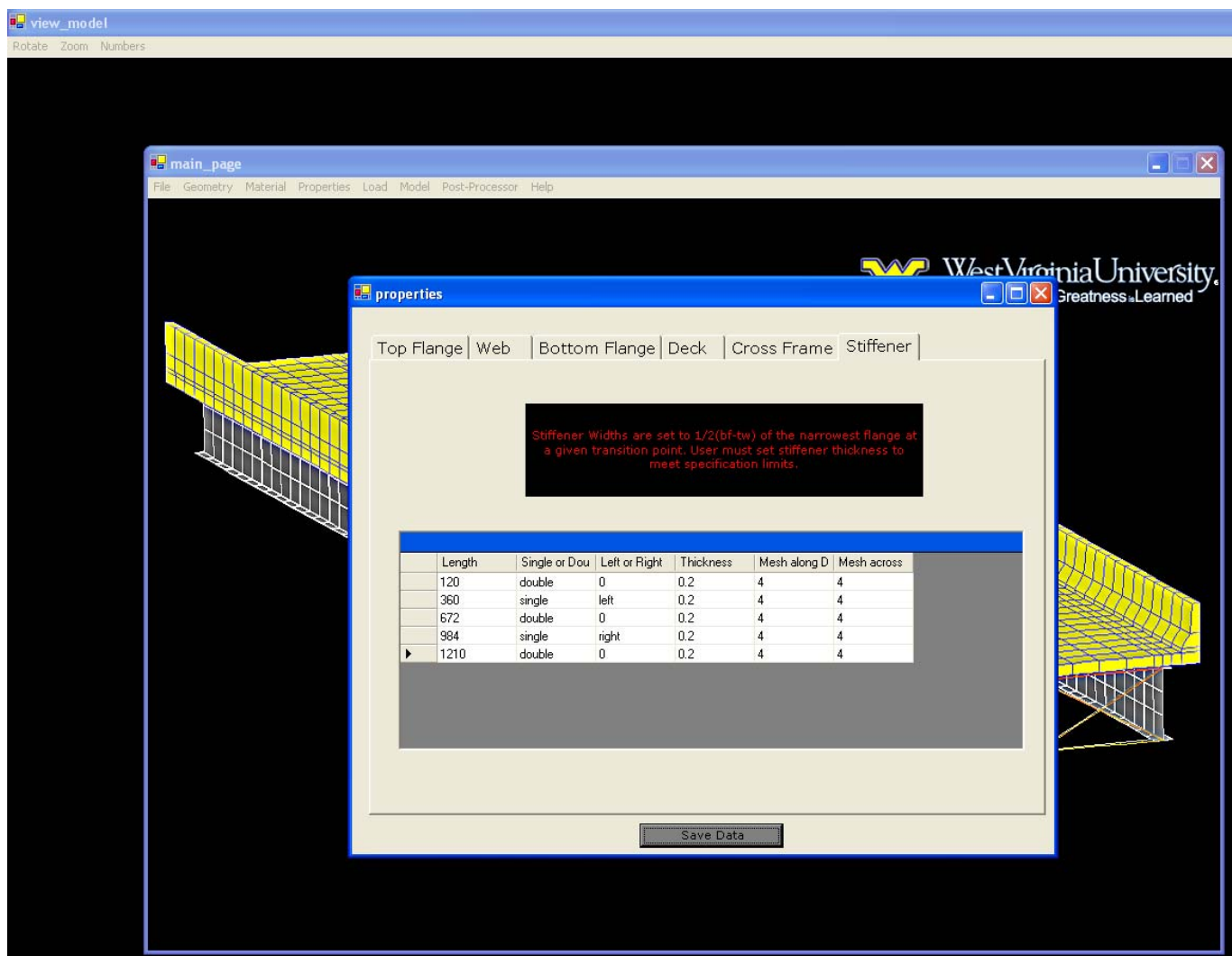

Figure 3.10 Stiffener properties 


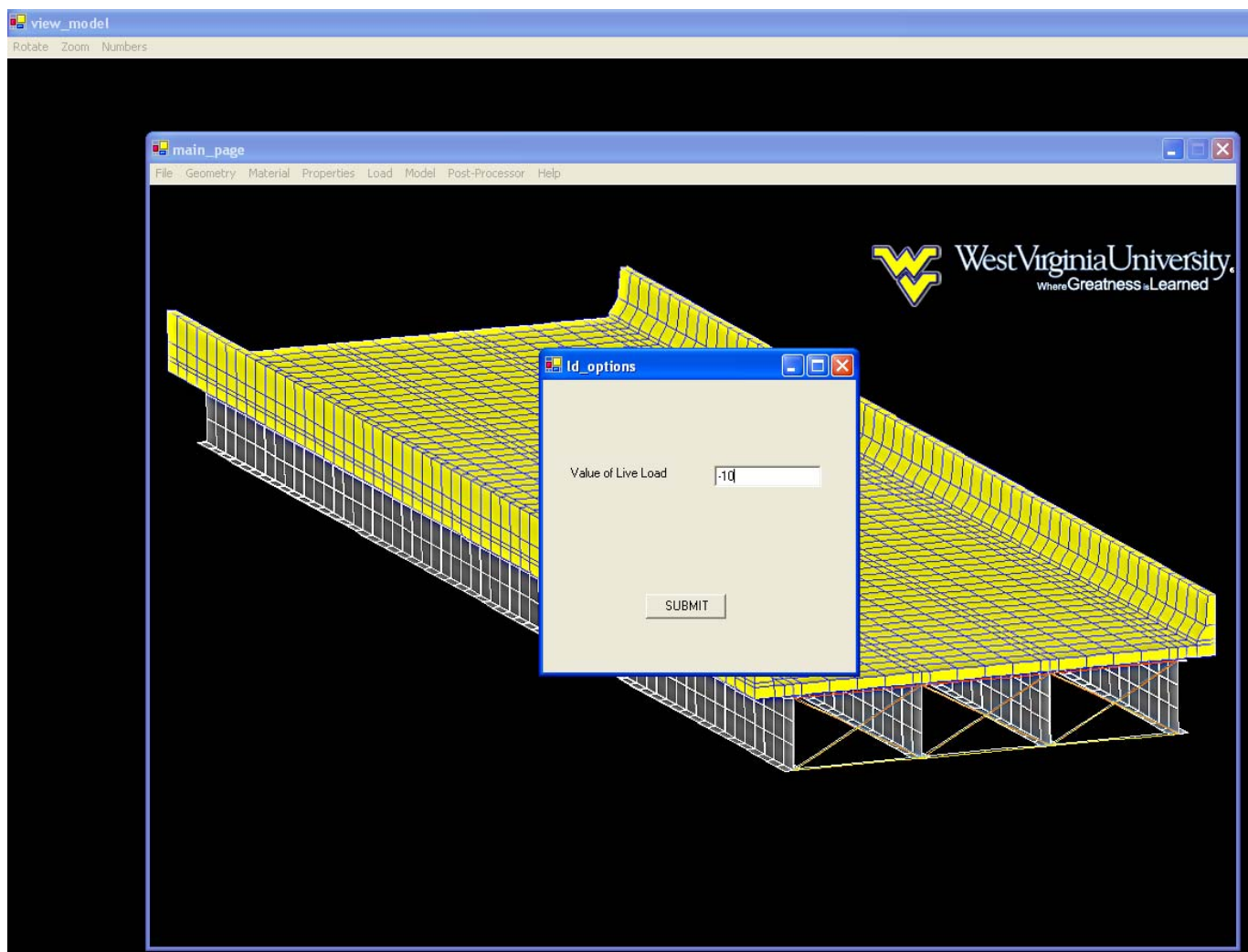

Figure 3.11 Load menu 


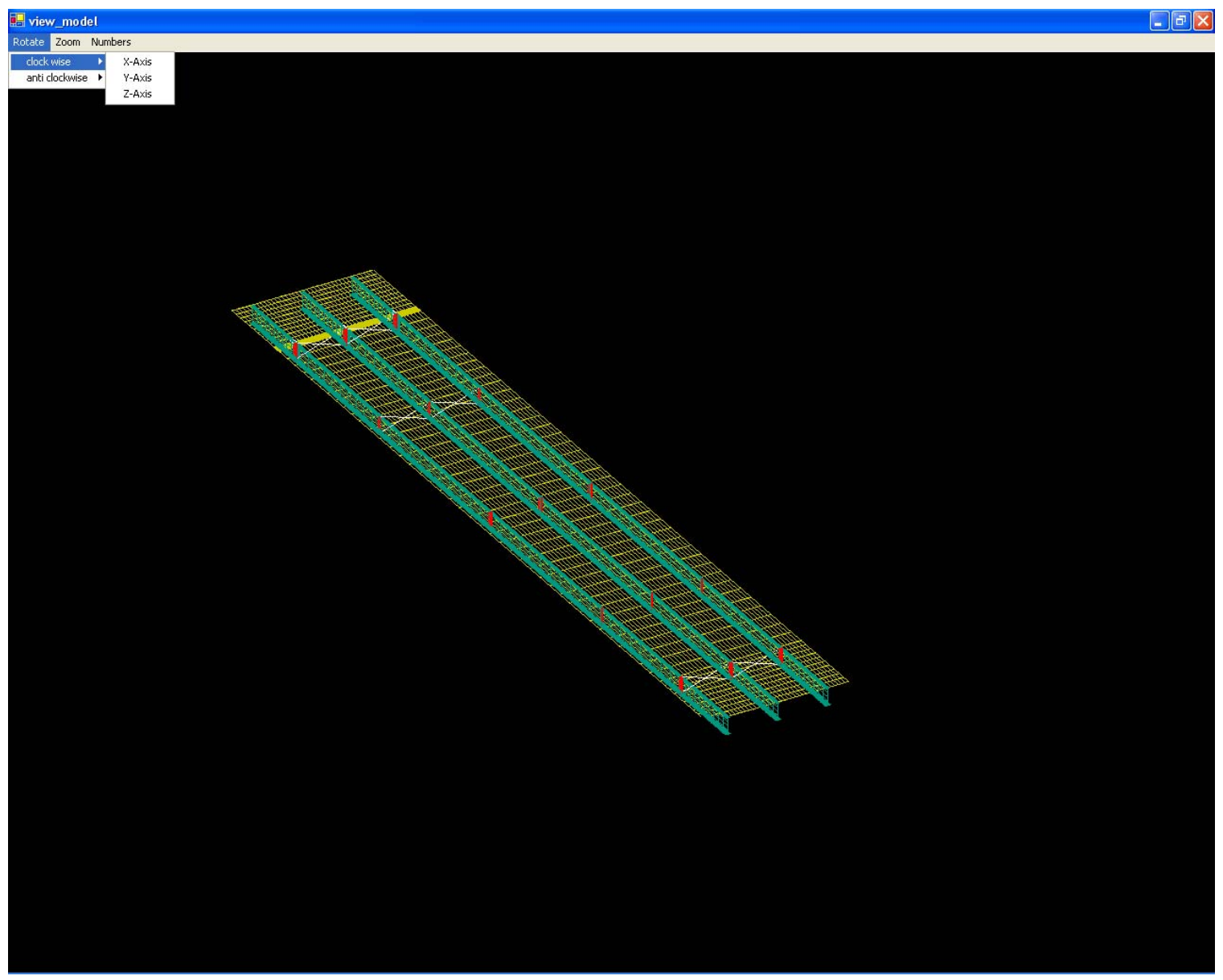

Figure 3.12 3D model view 


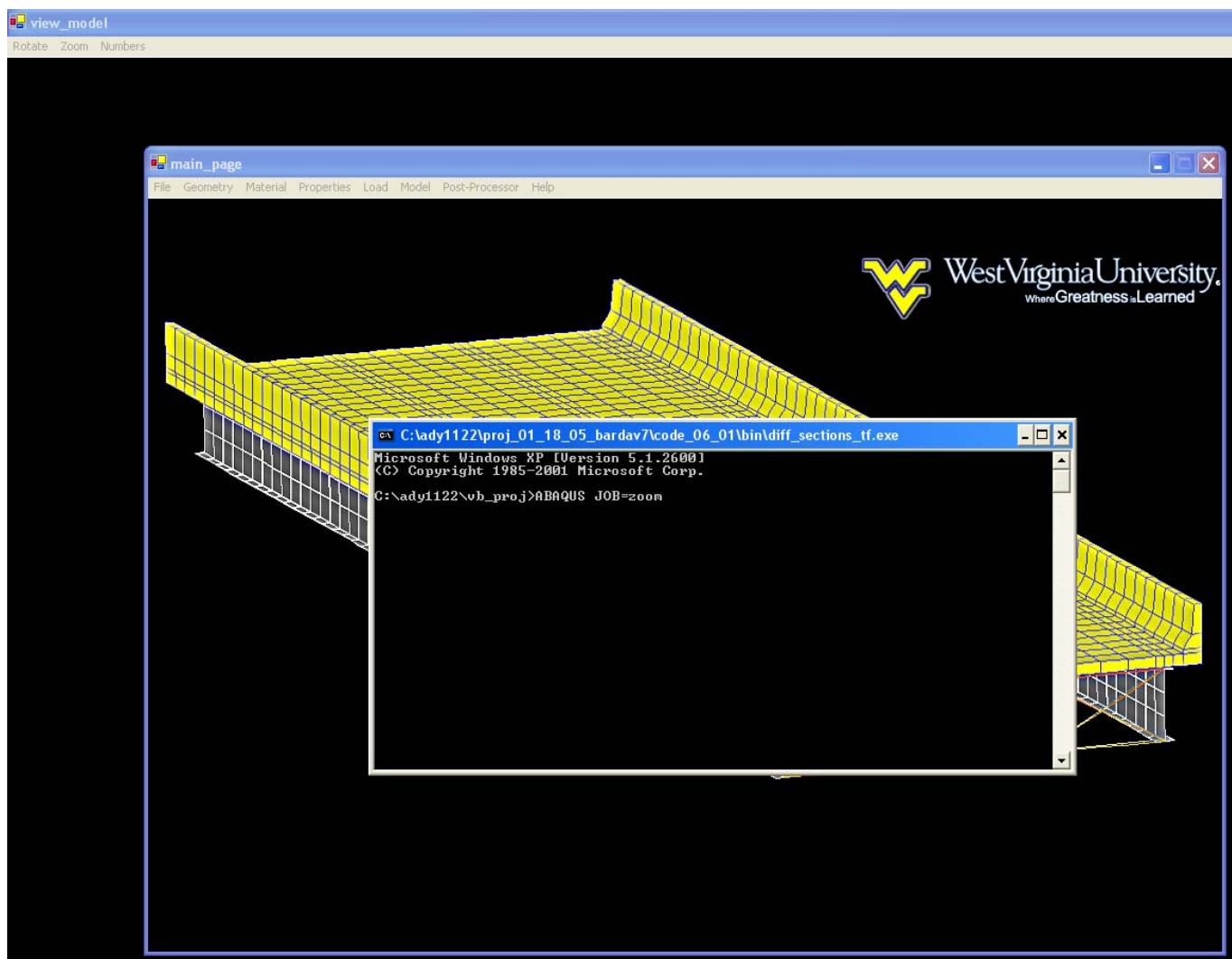

Figure 3.13 FE analysis window 


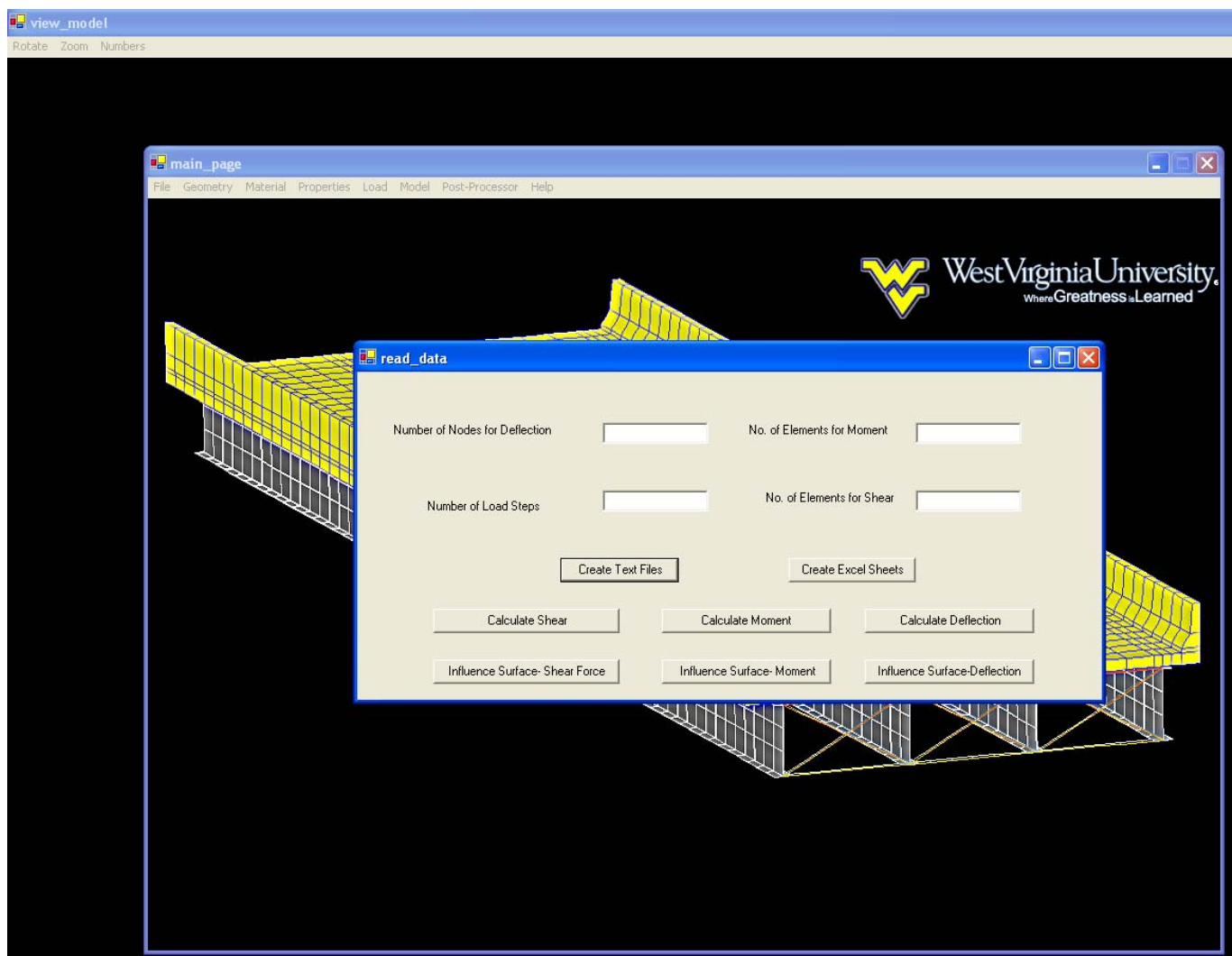

暗 main natge

Figure 3.14 Post-processor menu 


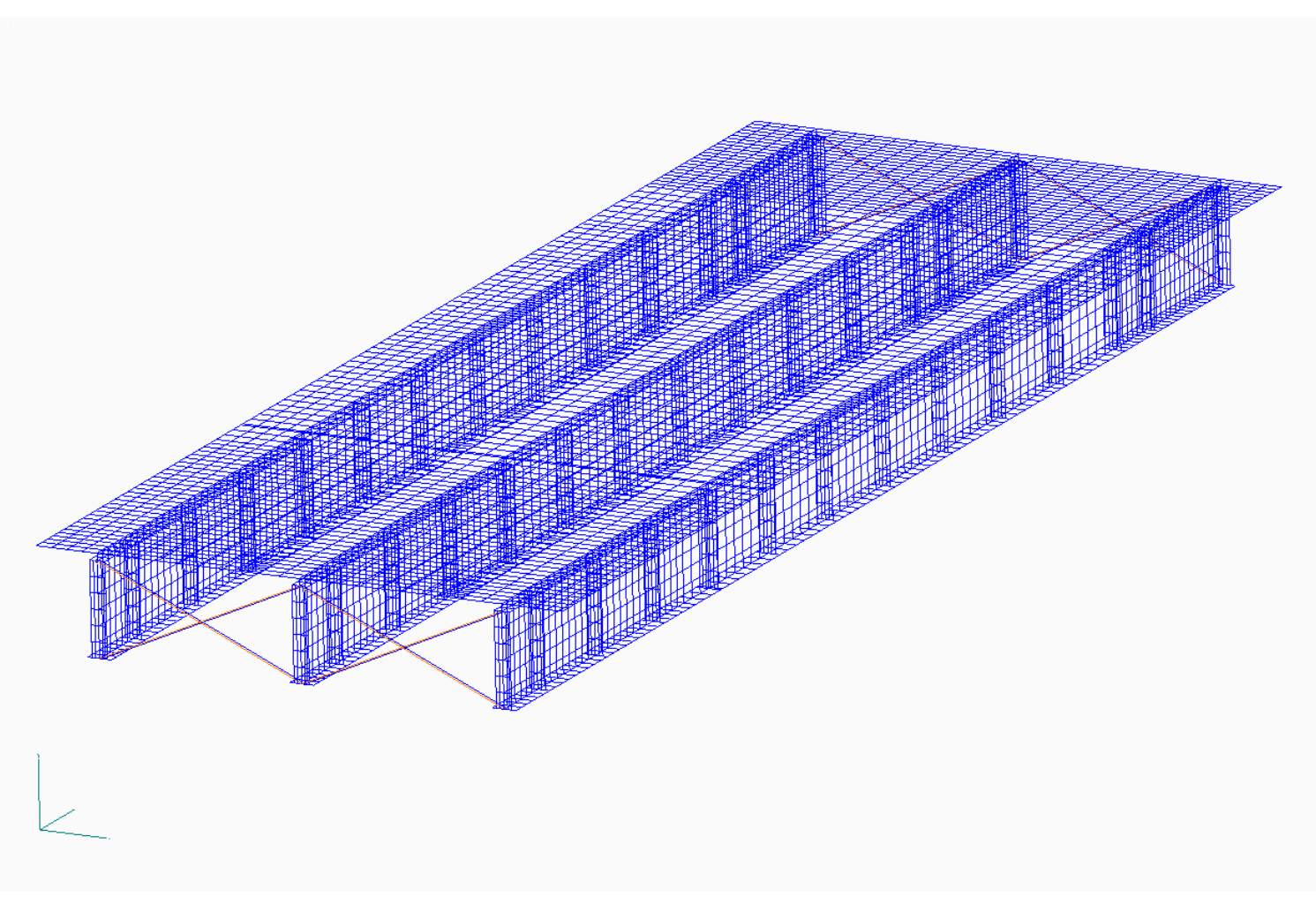

Figure 3.15 FE ANALYSIS mesh for simple span bridge 


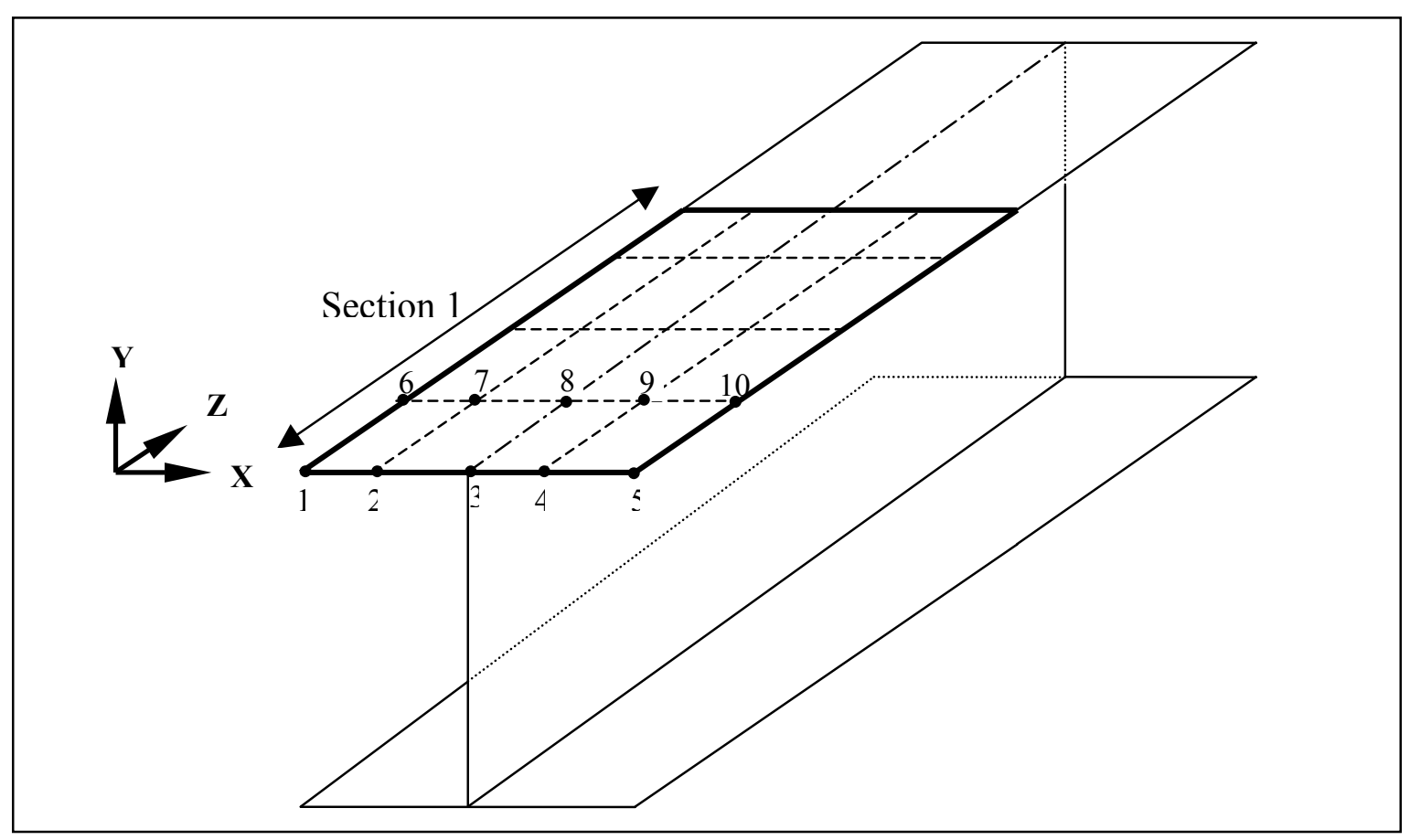

Figure 3.16 Node generation in top flange 


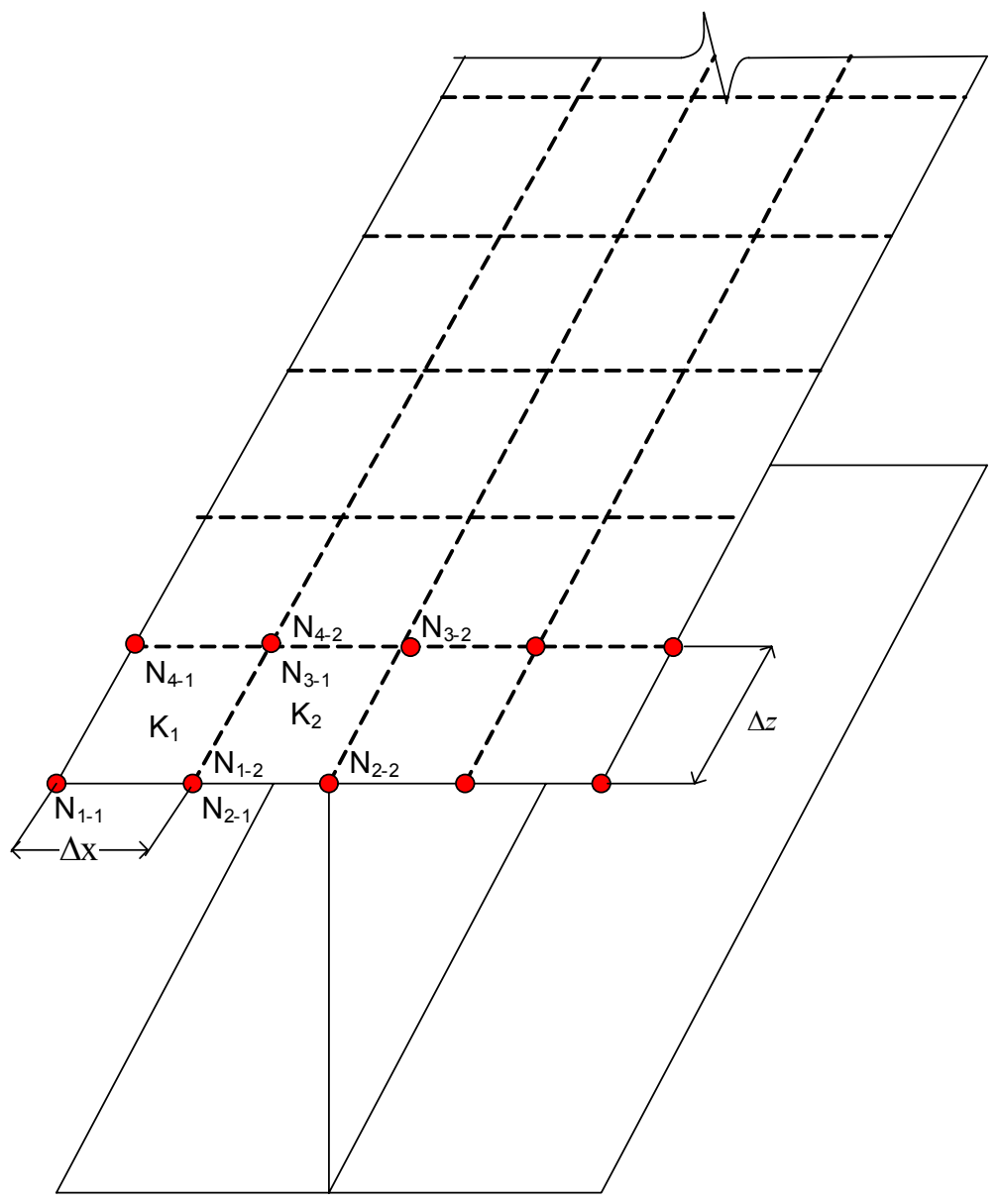

Figure 3.17 Element generation in top flange 


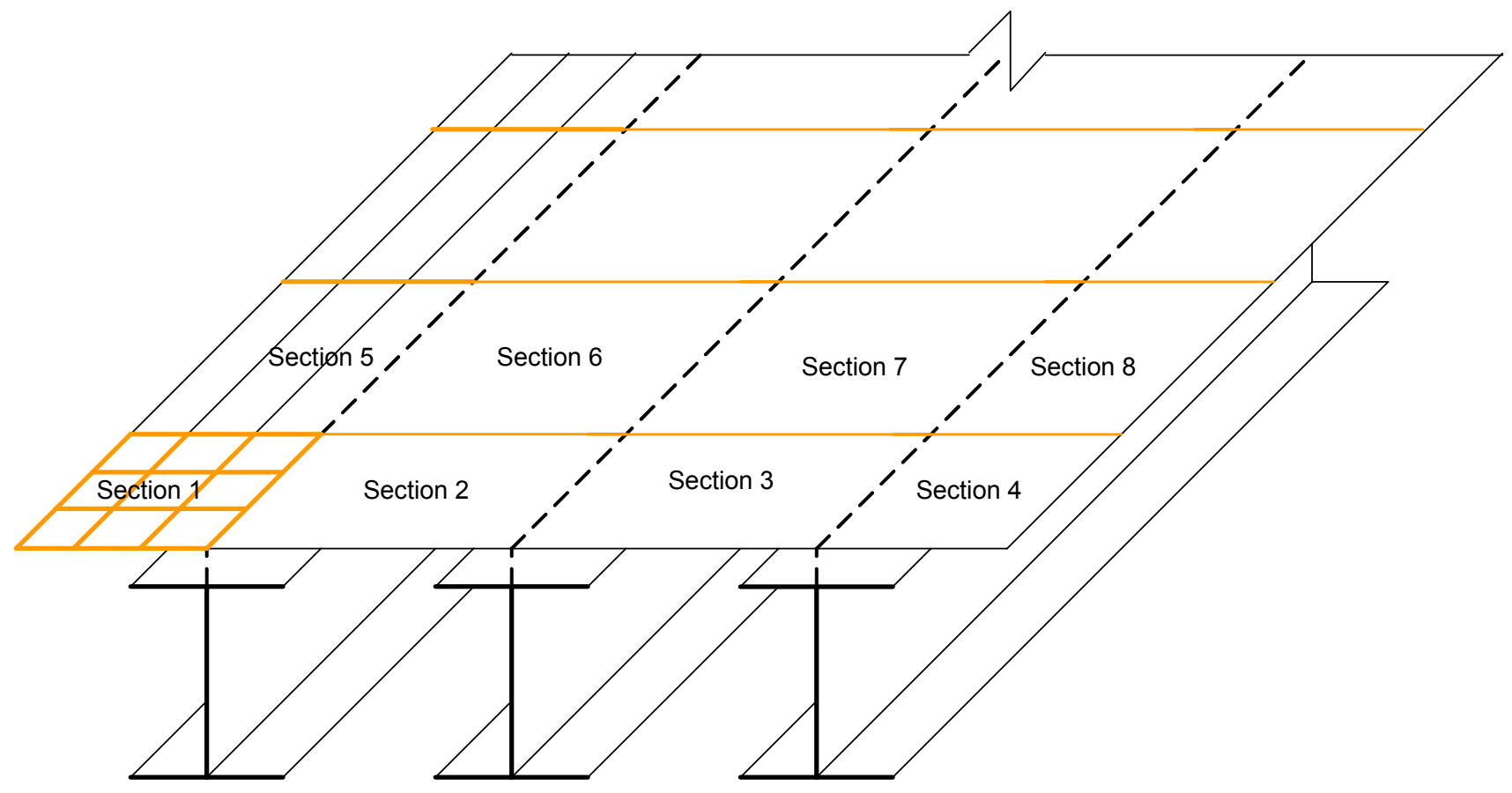

Figure 3.18 Node and element generation in concrete deck 


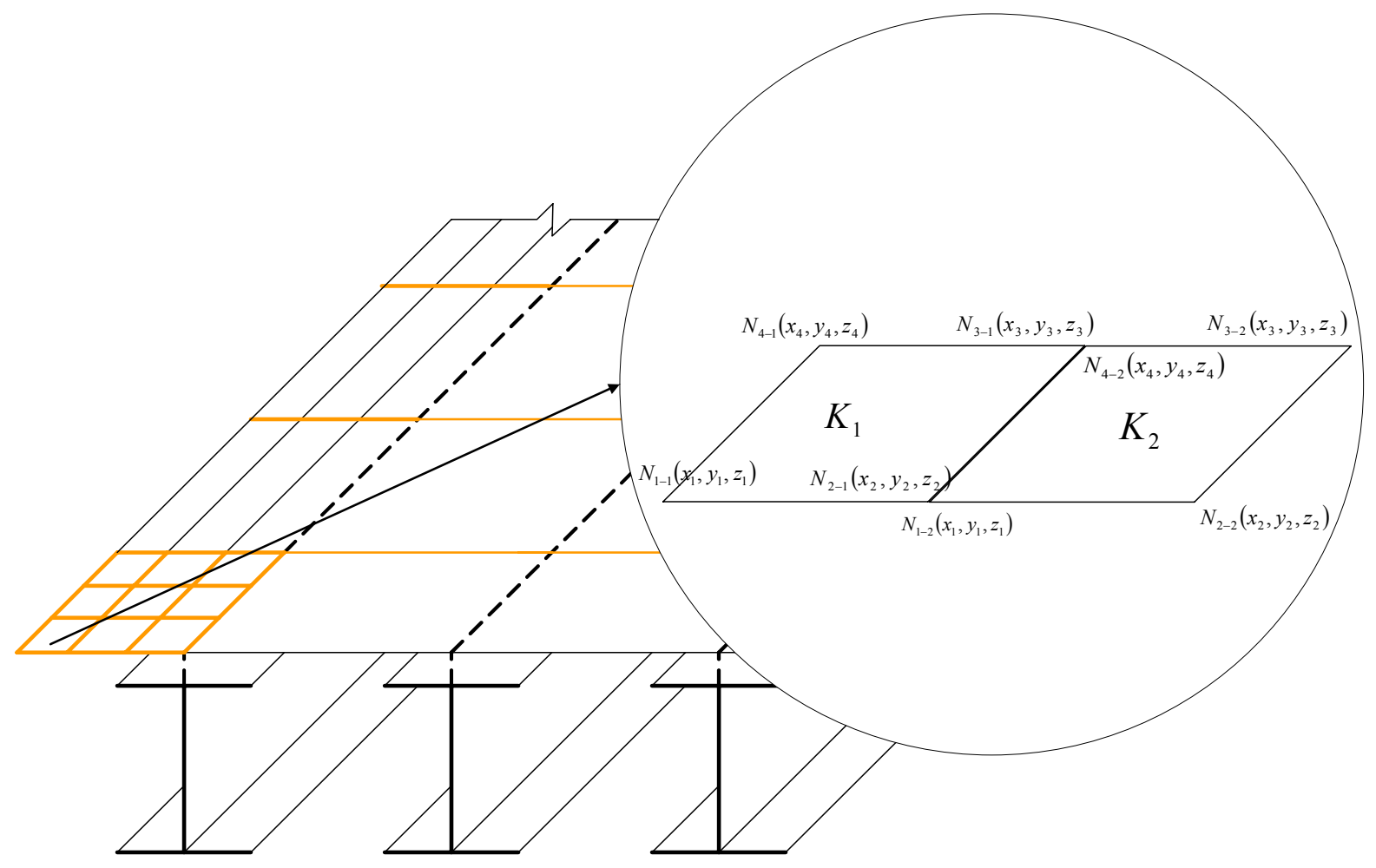

Figure 3.19 Element Generation in Concrete Deck 


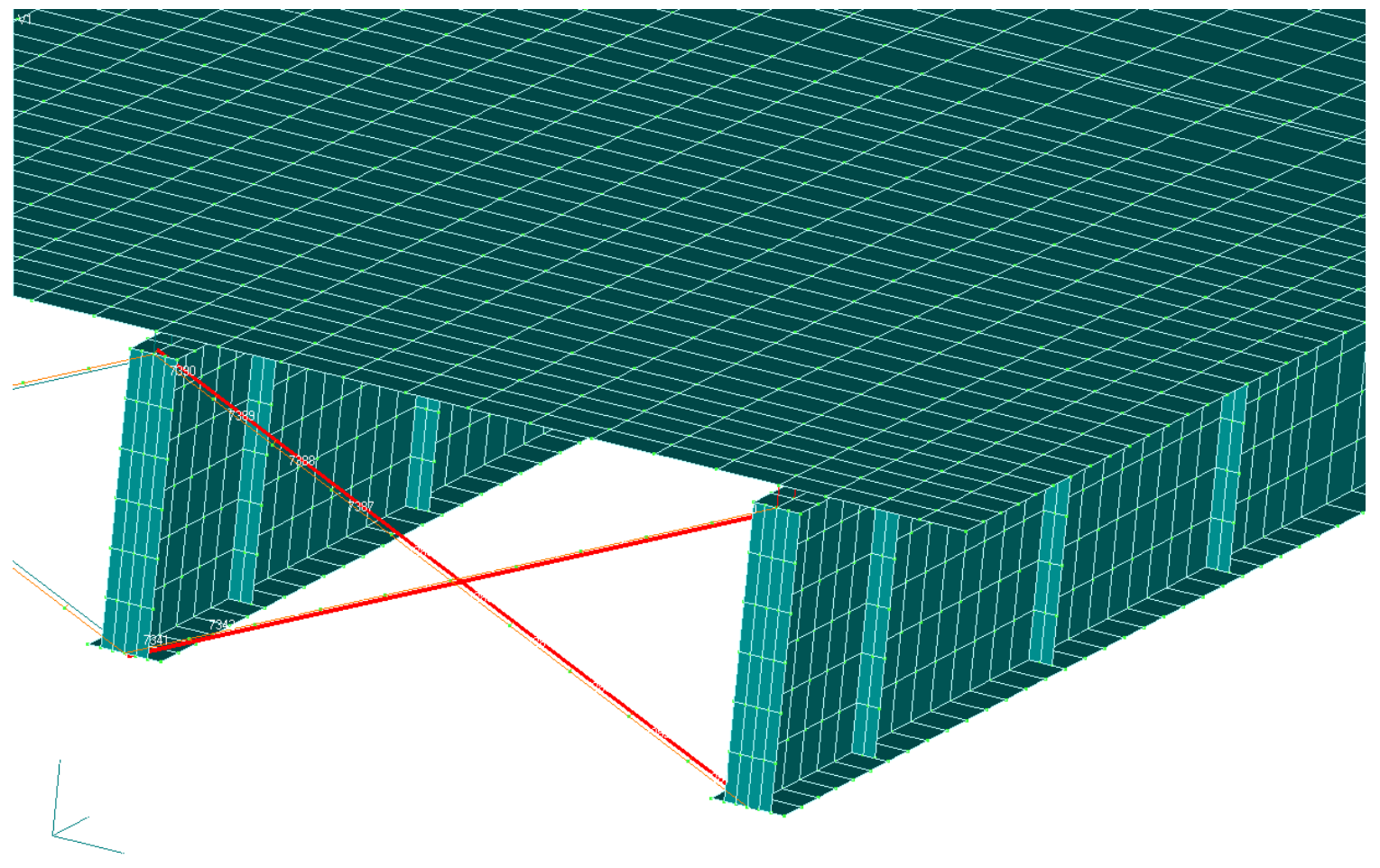

Figure 3.20 Cross frame in FE model 


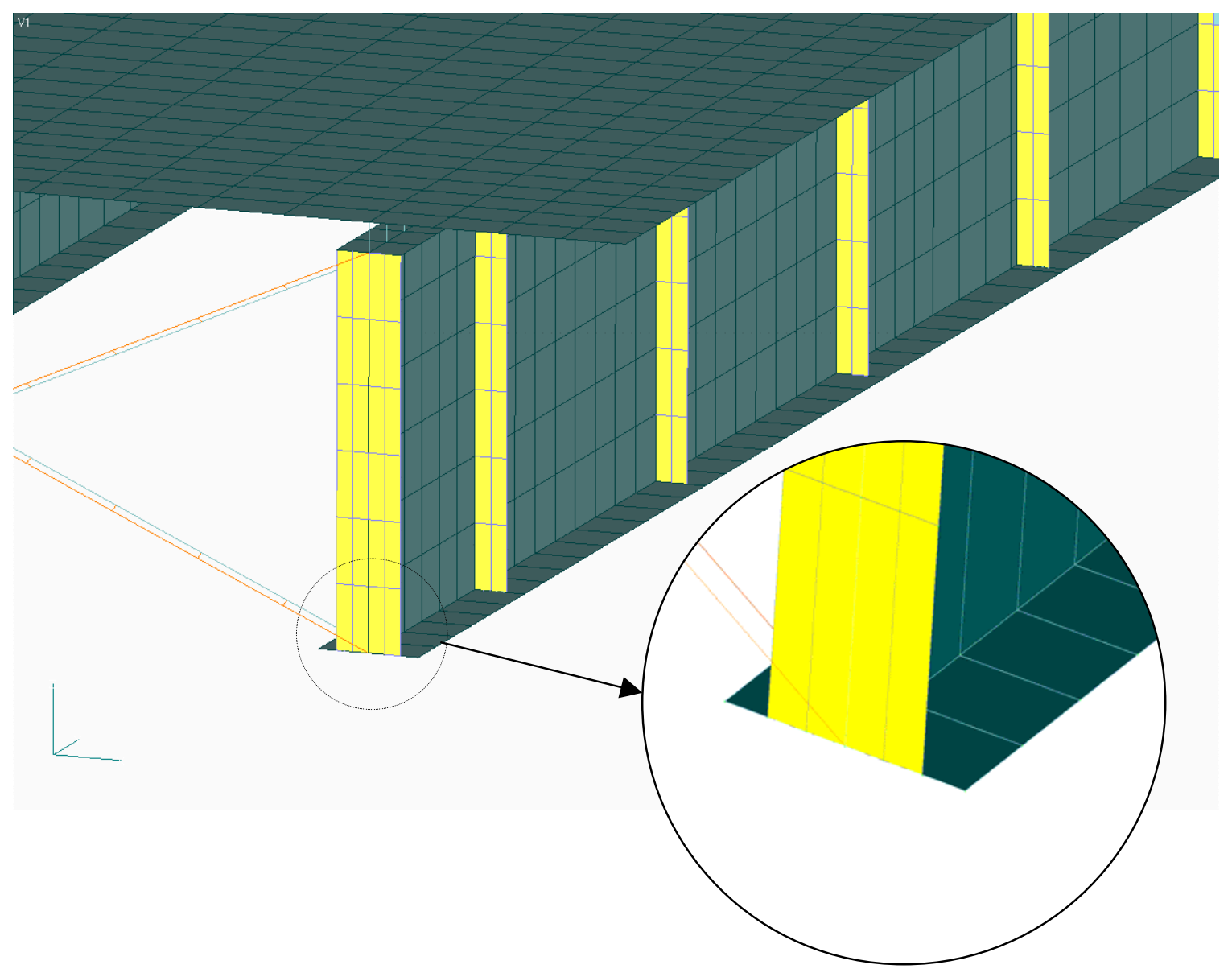

Figure 3.21 Bridge model showing transverse stiffeners 


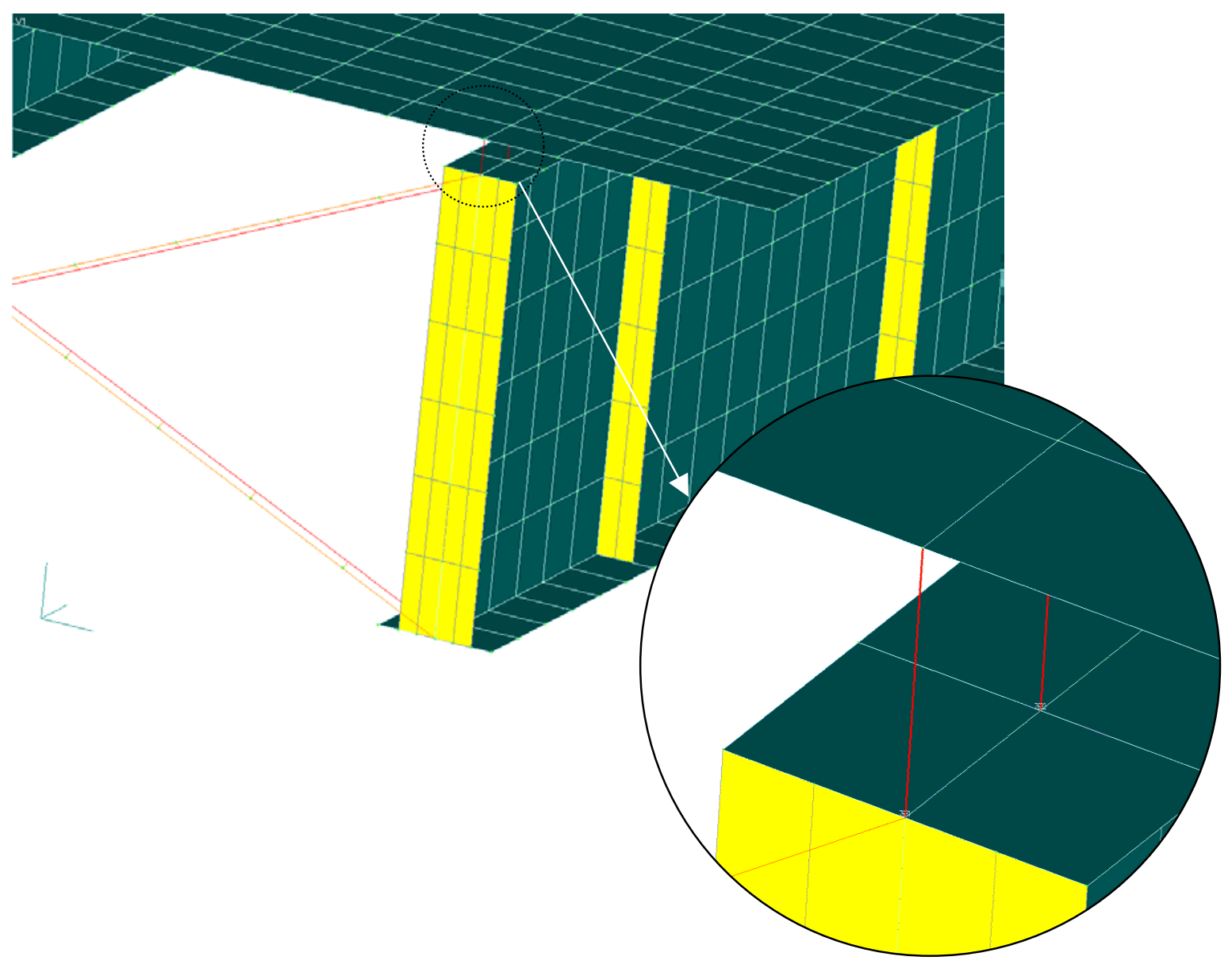

Figure 3.22 Bridge model showing rigid link between top flange and deck 

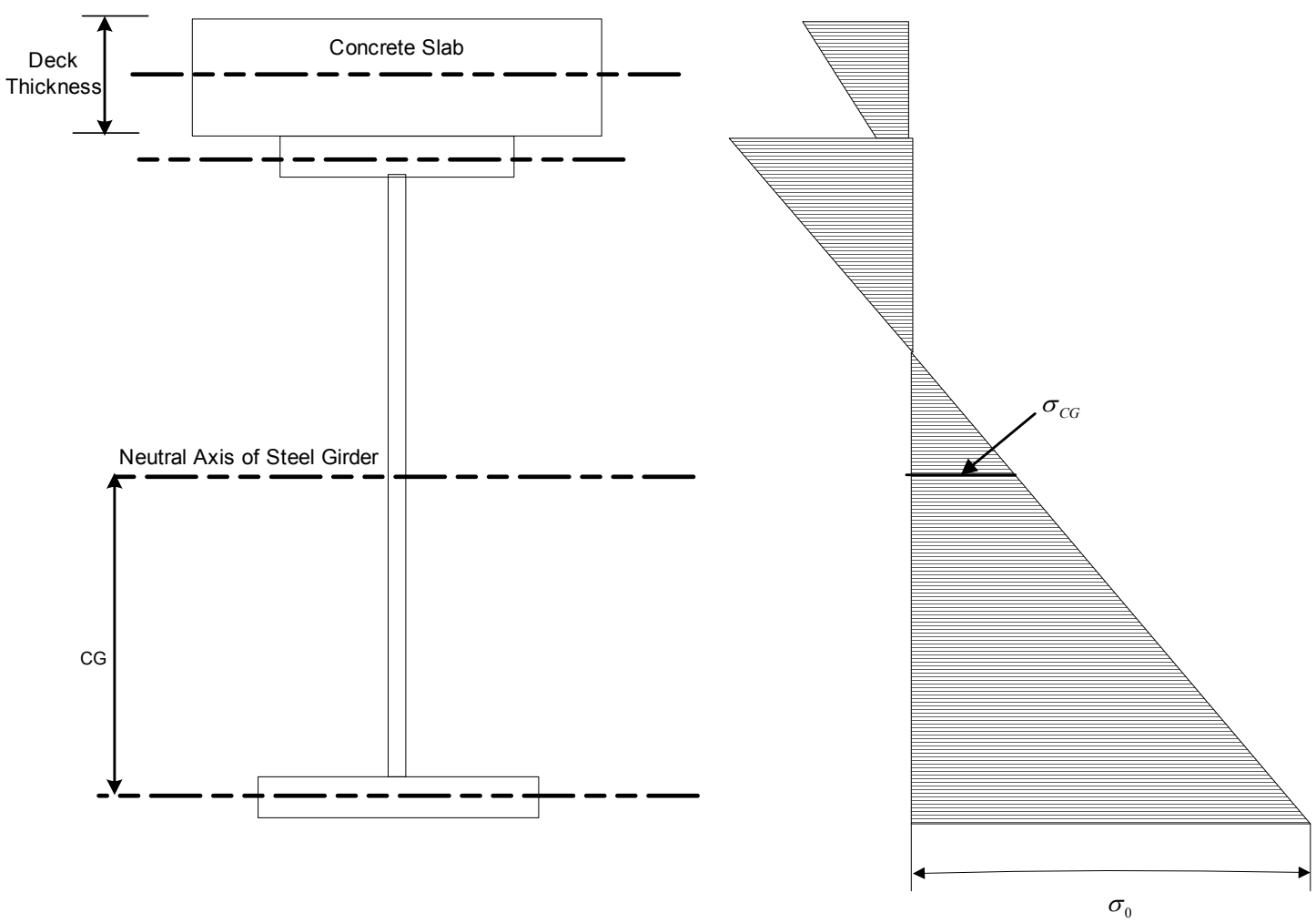

Figure 3.23 Stress profile of a steel concrete composite section without a haunch 


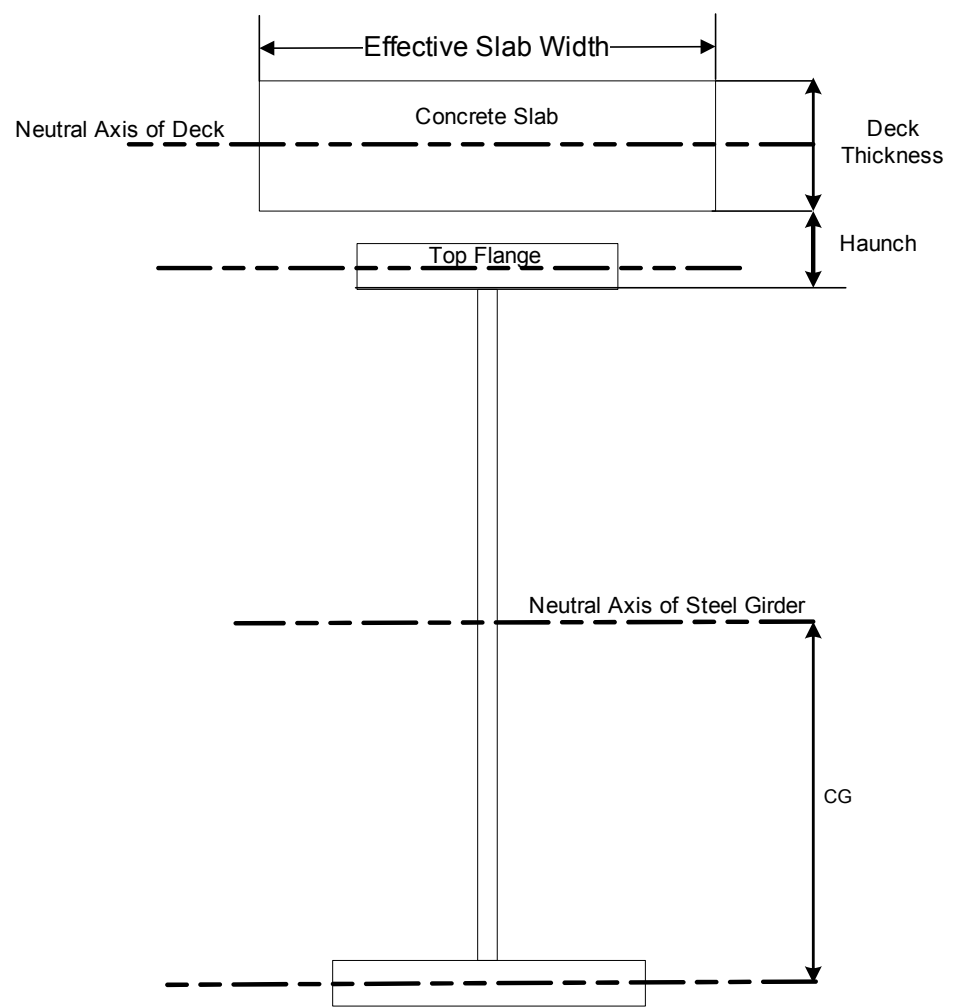

Figure 3.24 Cross-section of an I-section girder composite bridge 


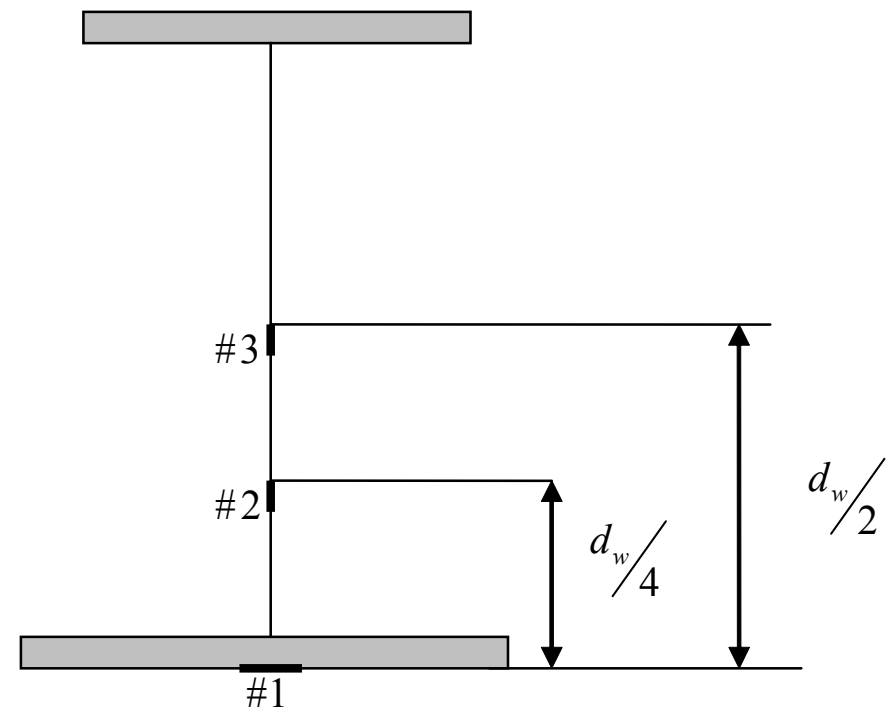

Figure 3.25 Locations of stress computation for girder moment calculation 


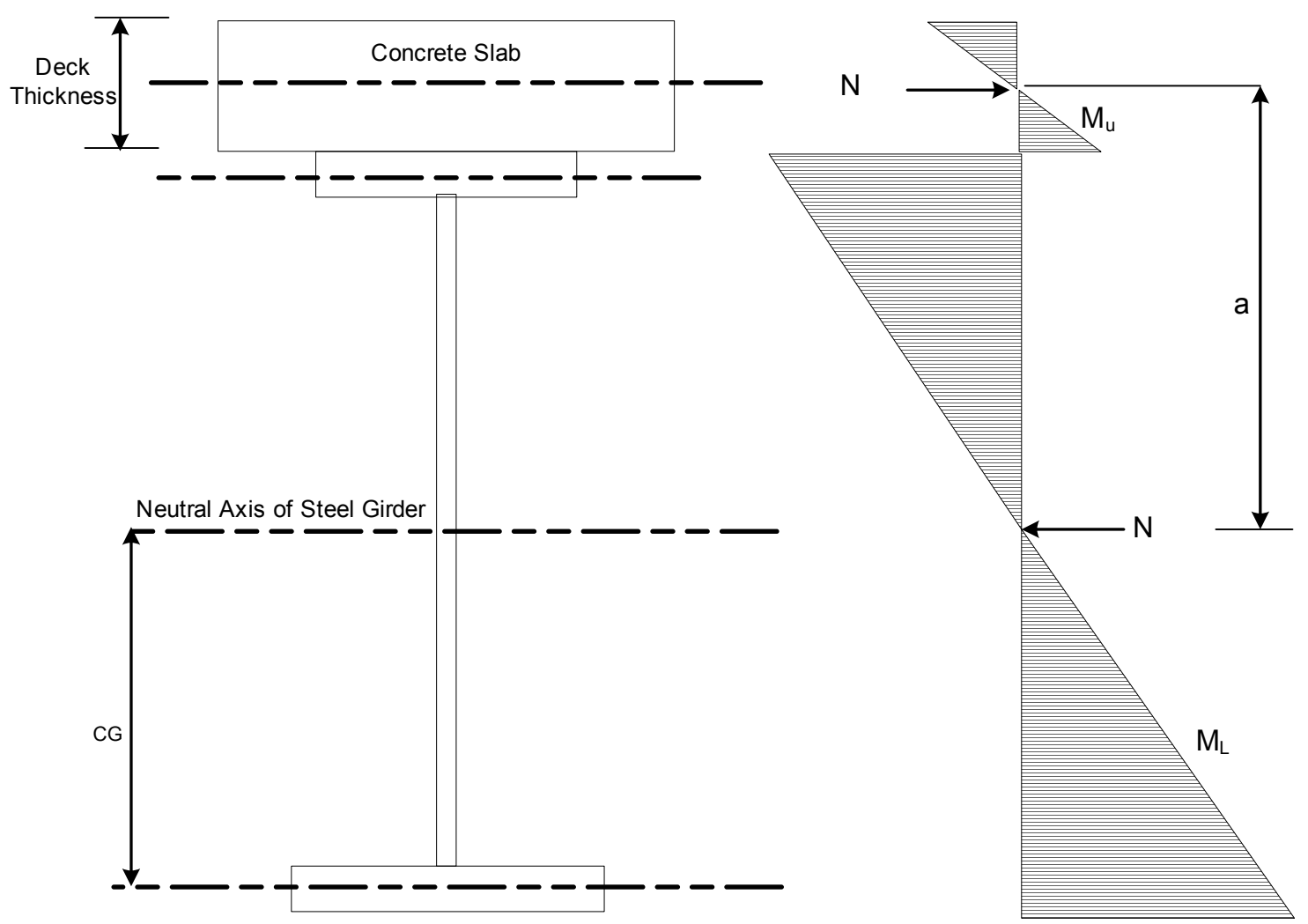

Figure 3.26 Bridge Cross-section showing different moment components for calculation of moment in a single girder 


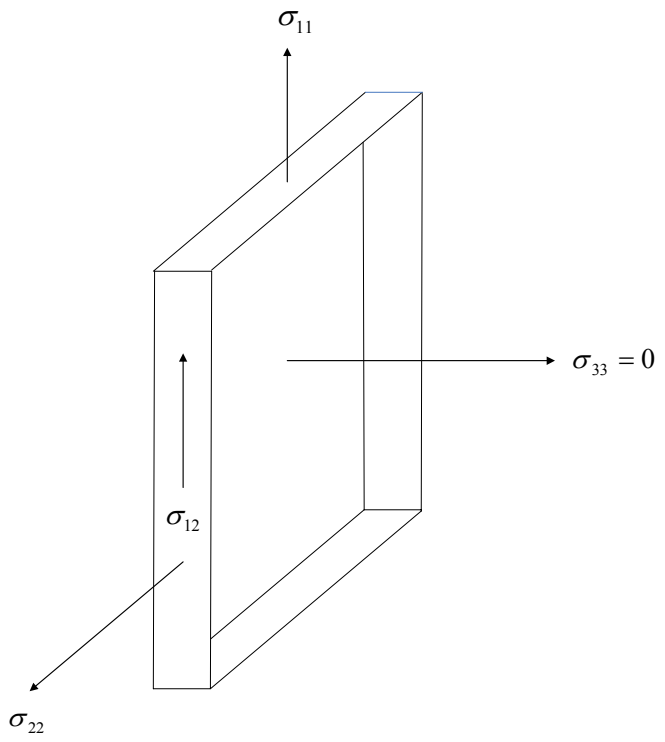

Figure 3.27 Web element showing the stress directions 


\section{CHAPTER 4}

\section{VERIFICATION STUDIES}

\subsection{Introduction}

The GUI developed in this research provides a simple and effective way to rapidly generate $3 \mathrm{D}$ FE models of continuous-span steel concrete composite bridges. The input parameters of the bridge are entered using an easy-to-use menu structure with text boxes and data grids. Using these input values, FE analysis is performed on the bridge model to compute the response parameters such as moments, stresses, deflections and shear. Further, the post-processing tool generates influence surfaces for these responses to calculate the force effects due to different loading conditions. This FE modeling approach and subsequent post-analysis using influence surfaces needs to be verified and correlated with experimental and other analytical studies. A verification study was conducted on two large-scale laboratory bridges and the results due to various load cases were compared with results obtained from the GUI.

The following two bridges were chosen for the validation study:

1. Two-span continuous bridge constructed at the Turner Fairbanks Highway Research Center's structures laboratory for the Federal Highway Administration, and the American Iron and Steel Institute (Tiedeman et al, 1993).

2. Full-scale simple-span bridge constructed at the Structural Laboratory, University of Nebraska-Lincoln, Lincoln, Nebraska as part of a sponsored project for the Nebraska Department of Roads (Kathol et al, 1995). 
These two bridges, one of them a simple-span bridge and the other, a continuous span bridge had variable section properties with changes in flange thickness along the length. They also had other members such as stiffeners and cross frames. Verification of these two bridges demonstrated the full capabilities and features of the GUI. Also, extensive experimental data available for these bridges helped to test the developed postprocessor by comparing the experimental results with the predictions from the influence surfaces generated by the new software tool for different response parameters.

\subsection{Two-span Continuous Bridge-Federal Highway Administration}

Experimental tests were conducted on a two-span continuous bridge (FHWA Bridge) constructed at the Turner Fairbanks Research center and the results from the tests are used a basis for validating the GUI developed in this study.

\subsubsection{Description of the Bridge}

The FHWA test bridge was a 0.4 scale model of a prototype bridge. The fullscale prototype consisted of a two-span continuous structure with equal spans of $140 \mathrm{ft}$. The out-to-out of deck width was $48 \mathrm{ft}$. and the clear roadway width of $44 \mathrm{ft}$. 6 in. allowed for three design lanes. The deck consisted of uniform 10in. thick pre-cast concrete panels $8 \mathrm{ft}$ wide by $49 \mathrm{ft}$. long. The bridge consisted of three parallel flange (68 in. web depth) steel girders equally spaced at $17 \mathrm{ft}$. with a deck overhang of $7 \mathrm{ft}$.

Figure 4.1 shows a cross-section of the 0.4 scale-model bridge constructed in the FHWA laboratory. The bridge was a two-span continuous structure with equal 56 foot spans and a 4 in. concrete deck. The $19 \mathrm{ft}$ 2-3/8 in. wide deck was supported by three

girders equally spaced at $6 \mathrm{ft}$. 9-5/8 in. with $2 \mathrm{ft}$. 9-9/16 in. overhangs. The girders 
consisted of a $55 / 8 \times 1 / 4$ in. top flange and a 27-3/16 x 1/4 in. web. The bottom flange of each girder was $8 \times 5 / 8$ in. throughout, except $11 \mathrm{ft} .-2$ in. from the abutments where the flange thickness was reduced to $3 / 8$ in. Figure 4.2 shows the girder elevation of the bridge along with the locations for bottom flange thickness transition. Cross frame connection plates were located at $10 \mathrm{ft}$ intervals, measured from the abutments. Each cross frame comprised of four members; a diagonal member, a vertical post and a top and bottom horizontal member each; all WT 2 x 6-1/2 rolled sections. Intermediate cross frames were placed on either side of the interior pier at a distance of $6 \mathrm{ft}$. The cross frame locations are shown in Figure 4.2. Cross frame connection plates, 5/16 in. thick, were located at each of the cross frame locations on both sides of the web for the interior girder and on the inside face of the web for the exterior girder. Transverse stiffeners, 27$3 / 16 \times 55 / 8$ in. were located on both sides of the web of each girder over the supports.

\subsubsection{Experimental Testing Overview}

As discussed in Tiedeman et al. (1993), loading equivalent to a single axle load of an AASHTO truck (HS20-44) was simulated using a pair of concentrated loads that were applied by pulling pairs of rods through the deck using a hydraulic jacking system. Two 7 kip loads equivalent to the axle of a HS20-44 truck were applied transversely to one span only. The spacing between the loads was also reduced to conform to the scaleddown spacing between the wheels of the truck. Placing the single-axle loads at $0.22 \mathrm{~L}$ and $0.325 \mathrm{~L}$ induced the maximum positive moment at $0.2 \mathrm{~L}$ and the maximum negative moment at the interior support $(0.5 \mathrm{~L})$ respectively. These locations were therefore used for the experimental load cases. 
Eight general loading cases were applied for this study. Figure 4.4(a) and (b) illustrate the loading conditions and location of the wheel loads for single and multi-lane loading. Loading in each lane comprised of two 7 kip loads. The cases may be summarized as follows:

1. Single-lane loading at $0.22 \mathrm{~L}$ (wheel loads, $\mathrm{W}_{5}$ and $\mathrm{W}_{6}$ of Fig. 4.4 (a)) that maximizes the positive moment at section $0.2 \mathrm{~L}$ in girder $\mathrm{G}_{1}$.

2. Three-lane loading at $0.22 \mathrm{~L}$ (wheel loads, $\mathrm{W}_{1}$ to $\mathrm{W}_{6}$ of Fig. 4.4 (a)).

3. Single lane loading at $0.325 \mathrm{~L}$ (wheel loads, $\mathrm{W}_{5}$ and $\mathrm{W}_{6}$ of Fig. 4.4 (a)) on girder $\mathrm{G}_{1}$ which maximizes the negative moment at section $0.5 \mathrm{~L}$ (pier location) in girder $\mathrm{G}_{1}$.

4. Three-lane loading at $0.325 \mathrm{~L}$ (wheel loads, $\mathrm{W}_{1}$ to $\mathrm{W}_{6}$ of Fig. 4.4 (a)).

5. Single-lane loading at $0.22 \mathrm{~L}$ (wheel loads, $\mathrm{W}_{5}$ and $\mathrm{W}_{6}$ of Fig. 4.4 (b)) which maximizes the positive moment at section $0.2 \mathrm{~L}$ in girder $\mathrm{G}_{2}$.

6. Three-lane loading at $0.22 \mathrm{~L}$ (wheel loads, $\mathrm{W}_{1}$ to $\mathrm{W}_{6}$ of Fig. 4.4 (b)).

7. Single-lane loading at $0.325 \mathrm{~L}$ (wheel loads, $\mathrm{W}_{5}$ and $\mathrm{W}_{6}$ of Fig. 4.4 (b)) which maximizes the negative moment at section $0.5 \mathrm{~L}$ (pier location) in girder $\mathrm{G}_{2}$.

8. Three-lane loading at $0.325 \mathrm{~L}$ (wheel loads, $\mathrm{W}_{1}$ to $\mathrm{W}_{6}$ of Fig. 4.4 (b)).

The summary of these experimental results along with their comparison with the predicted FE ANALYSIS results is presented later in this chapter.

\subsubsection{Finite Element Modeling}

Using the GUI developed in this study, a 3D model of the bridge superstructure is created. The top flange, bottom flange and web of each of the three plate girders, modeled using four-node shell elements (S4R), are divided into 60 grid divisions per span 
lengthwise along the model. In the transverse direction, the top and bottom flanges were divided into 4 elements each. The web was divided into 8 elements along its depth. The deck panels, also modeled using four-node shell elements, were set at an offset from the top flange surface to accommodate for shear stud connection between the girder and deck. The deck panel had a total of 52 grid divisions across each section; 12 elements each for the overhangs and 14 elements each between the girders. In the longitudinal direction, the mesh density of the deck was made equal to the girders and also consisted of 60 divisions per span. With this equal longitudinal element lengths, connection between the deck and girder layers was established using multi-point constraint (MPC) elements at all nodes of the centerline of girders, $G_{1}, G_{2}$ and $G_{3}$. Cross frames were modeled as standard X-frames using two-node timoshenko beam elements (B31). Each cross frame member was divided into 4 elements. Transverse stiffeners were modeled using shell elements (S4R) on both sides of the web at the interior support and abutments. This presents a deviation from the experimental bridge parameters where the transverse stiffeners were modeled only on the inside of the exterior girders. A Poisson's ratio of 0.15 and a modulus of elasticity of $4700 \mathrm{ksi}$ were assumed for the deck elements. For the steel girder, a modulus of elasticity of $27600 \mathrm{ksi}$ and a Poisson's ratio of 0.3 were used. Appropriate boundary conditions were input at each girder support. Table 4.1 shows the all input values, including flange width transitions and material properties, used for the generation of the FE model of this bridge.

\section{Analysis}

In order to generate influence surfaces in the post-processor, the bridge responses are computed for multiple load steps. A concentrated load of 10 kips was placed at every 
point on a $20 \times 10$ grid on the bridge deck. The locations of load placement are outlined in section 3.10.1. FE analysis was then performed using ABAQUS version 6.3-1 to compute the moments, shear, deflection and stresses due to the effect of each 10 kip load. The results for all the load steps were stored in a data file. Interpolation between responses due to different load cases provides the ability to simulate various loading conditions.

\subsubsection{Influence Surface Plots}

In order to generate influence surface plots for different response parameters of the bridge model, the results from the ABAQUS output file were input into a database tool developed in this study. The database tool correlated the magnitude and location of each response (shear, stress or deflection) and generated an envelope of responses (influence surface). Parameters, such as moments and shear at a section, which were not readily available in the ABAQUS output file, were computed in the database. Since influence surfaces provide a method to easily calculate the response of a bridge for a variety of loading conditions, a comparison with the experimental test results is always readily available.

For the FHWA bridge, Tiedmann et al. (1993) reported the bottom flange stresses of the bridge model at the locations of largest positive moment $(0.2 \mathrm{~L})$ and negative moment $(0.5 \mathrm{~L})$. These maximum moment values were obtained by placing loads in single and multi-lanes at $0.22 \mathrm{~L}$ (to induce maximum positive moment at $0.2 \mathrm{~L}$ ) and at $0.325 \mathrm{~L}$ (to induce maximum negative moment at $0.5 \mathrm{~L}$ ). A comparison of the results from the GUI with the experimental results is presented herein. 


\subsubsection{Results and Comparison}

As outlined in section 4.2.2 eight loading cases were considered in order to compare the results obtained from the FE study with the experimental results.

From previous experimental studies, maximum positive moment is to occur at $0.2 \mathrm{~L}$ and maximum negative moment at $0.5 \mathrm{~L}$. So stresses in the bottom flange are observed at these locations for single and multi-lane loading. The steps employed to compute the bottom flange stresses for load cases 1 and 2 using the GUI are presented below.

For these two cases, the wheel loads, $\mathrm{W}_{1}$ to $\mathrm{W}_{6}$ were applied at $0.22 \mathrm{~L}(24.64 \mathrm{ft}$.) of the bridge and the bottom flange stresses are observed at 0.2L. From the GUI, an influence surface plot for $0.2 \mathrm{~L}$ provides the bottom flange stresses for different load locations at the point of interest, $0.2 \mathrm{~L}$. The data corresponding to this influence surface graph is presented in Table 4.3 and used as a basis for further calculation. Based on the highlighted stress values in the table, the stress values for load cases 1 and 2 are calculated by interpolation. For example, the bottom flange stress due to the first wheel load, $\mathrm{W}_{1}$, located at $5.69 \mathrm{ft}$ from the left overhang and at $0.22 \mathrm{~L}$ along the bridge is calculated from the table as follows.

Interpolation between the stress values at $0.2 \mathrm{~L}(22.4 \mathrm{ft})$ and $0.25 \mathrm{~L}(28 \mathrm{ft}$.) provides bottom flange stresses at the cross-section, 0.22L. The obtained stress values across the width of the deck at $0.22 \mathrm{~L}$ are further used to interpolate between $3.84 \mathrm{ft}$ and $5.76 \mathrm{ft}$ to find the bottom flange stress corresponding due to the wheel load, $\mathrm{W}_{1}$, located at $5.69 \mathrm{ft}$. In this case, the stress value is $0.339 \mathrm{ksi}$. Similarly, stresses due to the other wheel loads, $\mathrm{W}_{2}$ to $\mathrm{W}_{6}$, are computed. Summation of the individual stress values due to single wheel loads, $\mathrm{W}_{5}$ and $\mathrm{W}_{6}$ provides the total bottom flange stress value for load case 1 . In a 
similar manner, the stress value for load case 2 is calculated by adding the individual stress values due to wheel loads, $\mathrm{W}_{1}$ to $\mathrm{W}_{6}$. Table 4.4 shows the resultant stress values for loading case 1 and 2. Since a reference load of 10 kips was used in the FE study and each wheel load in the experimental tests was 7 kips, the results obtained from the influence plots are factored by 0.7 .

Although, the analytical model from the GUI does not specifically calculate the responses at the exact locations presented in the experimental tests, influence surface plots provide a generic approach for any loading condition and also the ability to calculate for load cases presented in these experimental studies.

In comparison, stress values from the GUI and experimental results for load cases 1 and 2 achieve a good correlation within acceptable error limits. For the above load case 1 of a single lane of loads at $0.22 \mathrm{~L}$, the bottom flange stress of the exterior girder at $0.2 \mathrm{~L}$ from the experimental data was -7.2 ksi against the predicted result from the GUI's finite element analysis as $-6.96 \mathrm{ksi}$, a deviation of $3.3 \%$. For load case 2 of three-lane (all) loading, the experimental observation was -12.5 ksi against the GUI result of $-12.18 \mathrm{ksi}$., a $2.6 \%$ deviation.

Load cases 3 and 4 were analyzed and stresses computed for the interior girder at $0.2 \mathrm{~L}$, which correspond to the location of maximum positive bending moment. Additional tests for load cases 5 to 8 which simulate the maximum negative bending moment were run for both the interior and exterior girders.

Table 4.5 lists the results of all 8 load cases, both from the experimental testing and those obtained from the influence surfaces. Also reported in the table is the percent 
error between these two data sets, where the percent error is calculated as the difference between the two values divided by the experimental value.

\subsection{Nebraska's Full-Scale Laboratory Bridge}

The results from the experimental tests and FE modeling results for a second large-scale bridge, conducted at the University of Nebraska, Lincoln as part of a project for Nebraska Department of Roads (NDOR), were used to validate the results from the GUI developed in this research. (Kathol et al., 1995)

\subsubsection{Description of the Bridge}

This bridge was a simple span three-girder composite structure spanning $70 \mathrm{ft}$. and was $26 \mathrm{ft}$. wide. It consisted of welded plate girders with a $7.5 \mathrm{in}$. reinforced concrete deck. The bridge had a girder spacing of $10 \mathrm{ft}$. and an overhang of $3 \mathrm{ft}$. The center girder was elevated by $2.375 \mathrm{in}$. over the end girder producing a crown of $0.02 \mathrm{ft} / \mathrm{ft}$. Figure 4.5 shows the cross-section elevation of the bridge. The plates making up the girders consisted of a top flange of 9 in. with a thickness of 0.375 in. throughout. The web was $54 \mathrm{in.} \mathrm{in} \mathrm{depth} \mathrm{with} \mathrm{a} \mathrm{thickness} \mathrm{of} 0.375 \mathrm{in}$. The bottom flange had a width of $14 \mathrm{in}$. and a thickness of $0.75 \mathrm{in}$. at the end bottom flange and a thickness of 1.25 in. for the center bottom flange. Figure 4.6 shows the girder elevation of the bridge along with locations of section transitions.

As outlined in Figure 4.6, intermediate stiffeners with the dimensions, 0.3125 in. $\mathrm{x} 4 \mathrm{in}$. were placed at the following locations: 2 at $39.5 \mathrm{in.} 10$ at $67.2 \mathrm{in.}$ and 2 at $39.5 \mathrm{in}$. Shear studs 0.875 in. in diameter and 5 in. length were placed symmetrically across the girder from left to right at locations, 18 at 7 in., 14 at 9 in. and 10 at 10.1875 in. WT4 x 9 
members were used for the top and bottom chords. L $3 \times 0.375 \times 0.375$ members were used for the end-diagonal cross frames. During the ultimate load testing, only end cross frames were used (intermediate cross frames were removed).

\subsubsection{Experimental Testing}

Preliminary load tests, which were conducted to determine the elastic limit of the structure, concluded that an elastic load for this test be defined 2.5 times that of HS20-44 standard truck loading. AASHTO (1996) specifications for HS20-44 standard truck loading are, 4 kip load for each front wheel, 16 kip load for each center wheel and 16 kip load for each rear wheel. The spacing between the front and center wheel is $14 \mathrm{ft}$. and 14 to $30 \mathrm{ft}$. between center and rear wheels. The design truck (2.5 times HS20-44) used in this study consists of 40kip load center and rear wheel loads and 10 kip front wheel loads, for a total truck weight of 180,000lbs (Kathol 1995). The load case illustrated in Figure 4.7 where two trucks are present in each lane was used as the comparison test in this study.

\subsubsection{Finite Element Modeling}

A three-dimensional FE model of the bridge structure was generated using the GUI developed in this study. The following assumptions were made during the modeling of the bridge against the specifications of the experimental test bridge.

1. The elevation of the interior girder against the exterior girders (crown of $0.2 \mathrm{ft} / \mathrm{ft}$ ) was neglected.

2. Intermediate cross frames were removed. Only the end cross frames were considered.

3. Open concrete rails were not modeled in this study. 
Four-node shell elements with reduced integration (S4R) were used to model the girder and the deck. Both the girder and deck were divided into 125 grid division along the length of the bridge with an approximate element length of $6.72 \mathrm{in.}$ The top and bottom flanges were divided into 4 elements with lengths equal to 2.25 and $3.5 \mathrm{in}$. respectively. The web elements were divided into 9 divisions with an element length of 6 in. The composite action between the deck and girder was simulated with the use of multi-point constraint (MPC) beam elements, which are modeled at every node along the centerline of the girders. Cross frames, 55 in. X 0.25 in., were modeled at the supports (ends) using timoshenko beam elements (B31). Transverse stiffeners, 54 in. X 9 in., were modeled at locations specified in the experimental bridge using four-node shell elements (S4R).

The elastic modulus of steel was assumed to be 29,000 ksi. The average 28 -day compressive strength of the concrete, was $5.576 \mathrm{ksi}$ and the elastic modulus of slab concrete, was assumed as $4527 \mathrm{ksi}$, which is based on American Concrete Institute (ACI) empirical equation of elastic modulus in pounds for normal concrete.

$$
E_{c}=33 w_{c}^{3 / 2} \sqrt{f_{c}^{\prime}}
$$

Boundary conditions were input by preventing displacements in all three directions at one end of the bridge to simulate hinge-type constraint and preventing vertical displacement at the other end of the bridge to simulate roller-type constraint.

\section{Analysis}

Using the 3D model generated using the GUI, FE analysis was performed for multiple load steps. In a similar approach to the FHWA Bridge, the responses of the 
Nebraska Bridge were computed using influence surfaces plots, which were further used to compare against previously available experimental and analytical results.

\subsubsection{Results and Comparison}

The experimental tests conducted on the Nebraska bridge consisted of open bridge concrete rails which were shown to have a significant impact on the results $(\mathrm{Wu}$, 2002). Previous studies conducted using FEMAP (Version 8.1) by Wu (2002) reported the results of the mid-span deflection of the interior and exterior girder with HS20-44 trucks in each lane of the bridge model with and without the concrete rails. Figure 4.7 shows the locations of wheel loads for this loading case. This previous study concluded that open bridge concrete rails had a considerable effect on the mid-span deflections, about $30 \%$ for the exterior girders and $11.6 \%$ for the interior girder $(\mathrm{Wu}, 2002)$.

Due to the unavailability of experimental results of the bridge without the concrete rails, a true comparison could not be achieved between the GUI and the test data. However, previously published results by Haiyong $\mathrm{Wu}$ provide analytical data to compare the results of different modeling software; the GUI and FEMAP (Version 8.1). Also, the results obtained from the two analytical/FE approaches verify the postprocessor methodology employed in this research. Haiyong Wu's results are obtained by directly placing loads at appropriate locations. This process is time-consuming and manually intensive. In contrast, the GUI uses a more generic approach, generating influence surface plots and computing the load deformation responses due to different loading conditions. This broad approach proves to be beneficial while conducting multiple load test cases. 
In this study, the mid-span deflections were obtained from the GUI by studying the influence surface plot at $0.5 \mathrm{~L}$ for girder, $\mathrm{G}_{2}$. To simulate the loading case illustrated in Figure 4.7 which shows two HS20-44 trucks, one in each lane of the bridge, the deflection at the mid-span of all three girders due to each individual wheel load was calculated. Since a standard load of 10 kip was used to generate the influence surfaces, individual deflections were factored by 0.4 to generate a 4 kip load for the front axle and by 1.6 to generate a $16 \mathrm{kip}$ load for the rear axle. The summation of all these deflections provided the load deformation response due to two HS20-44 trucks. The final deflection values were then compared with Wu's results.

As shown in Table 4.6, the results obtained in this study and those by Wu (2002) were in close agreement with each other, with a deviation of $1.4 \%$ for the interior and $0.5 \%$ for the exterior girders (average deviation between the two exterior girders). 
Table 4.1Input Parameters for Federal Highway Bridge

\begin{tabular}{|l|l|l|}
\hline Input Parameter & Value & Units \\
\hline Basic Dimensions & & \\
\hline Total Length of the Bridge & 112 & Ft. \\
\hline Number of Spans & 2 & \\
\hline Location of Piers or Supports & 56,112 & Ft. \\
\hline Depth of the Web & 27.1875 & in. \\
\hline & & \\
\hline Girder Dimensions & & \\
\hline Number of Girders & 3 & \\
\hline Distance between Girders & 81.625 & in. \\
\hline & & \\
\hline Deck Dimensions & & \\
\hline Left Overhang & 33.625 & in. \\
\hline Right Overhang & 33.625 & in. \\
\hline Haunch & 0.25 & in. \\
\hline Depth of the Slab & 4.0 & in. \\
\hline & & \\
\hline Cross Frame Dimensions & & \\
\hline Height of Angle Section (h) & 3 & in. \\
\hline Width of the Angle Section (b) & 3 & in. \\
\hline Thickness at the top of angle (Th) & 0.375 & in. \\
\hline Thickness at bottom (Tb) & 0.375 & in. \\
\hline Number of Elements along the frame & 4 & Ksi. \\
\hline Youngs' Modulus & 29000 & \\
\hline Poisson's Ratio & 0.3 & in. \\
\hline & & in. \\
\hline Material & & in. \\
\hline Material ID \# & 1 & \\
\hline Material & Steel 50 & \\
\hline Girder Properties & & \\
\hline Top Flange Properties & 12 & \\
\hline Number of Sections & $120,240,360,480,600,672,744,864,984,1104,1$ \\
\hline Length & 224,1344 & \\
\hline Width & 5.625 & \\
\hline Thickness & 0.25 & \\
\hline Material ID \# & 1344 & \\
\hline & & \\
\hline Web Properties & & \\
\hline Number of Sections & & \\
\hline Length & & \\
\hline
\end{tabular}


Table 4.1 Input Parameters for Federal Highway Bridge (Continued)

\begin{tabular}{|l|l|l|}
\hline Input Parameter & Value & Units \\
\hline Thickness & 0.25 & in. \\
\hline Material ID \# & 1 & \\
\hline & & \\
\hline Bottom Flange Properties & 3 & \\
\hline Number of Sections & $134,1210,1344$ & in. \\
\hline Length & 8 & in. \\
\hline Width & $0.3125,0.5625,0.3125$ & in. \\
\hline Thickness & 1 & \\
\hline Material ID \# & & \\
\hline & & in. \\
\hline Mesh Size along the Length & $120,134,240,360,480,600,672,744,864,984$, & \\
\hline Length & $1104,1210,1224,1344$ & \\
\hline Number of Elements & $10,2,10,10,10,10,8,8,10,10,10,10,2,10$ & \\
\hline & & \\
\hline & & \\
\hline & & in. \\
\hline Deck Properties & & \\
\hline Mesh Size along the width of deck & & \\
\hline Length & $0,33.5625,115.1875,196.8125,230.375$ & \\
\hline Number of Elements & $6,14,14,6$ & \\
\hline & & \\
\hline Stiffener Properties & & \\
\hline Number of Stiffeners & 13 & \\
\hline Length & $0,120,240,360,480,600,672,744,864,984,1104$ & in. \\
\hline Single or Double-Sided & 1224,1344 & \\
\hline Left or Right (If single?) & Double & \\
\hline Thickness & & \\
\hline Mesh along Depth & 0.2 & \\
\hline Mesh across Width & 4 & \\
\hline & & \\
\hline Mesh Size in Girders & 8 & \\
\hline Number of Elements across the width in \\
the top flange & Number of Elements along depth in the \\
web & 4 & \\
\hline $\begin{array}{l}\text { Number of Elements across the width in } \\
\text { the bottom flange }\end{array}$ & 8 & \\
\hline & & \\
\hline
\end{tabular}


Table 4.2 Input Parameters for Nebraska Bridge

\begin{tabular}{|l|l|l|}
\hline Input Parameter & Value & Units \\
\hline Basic Dimensions & & \\
\hline Total Length of the Bridge & 840 & in. \\
\hline Number of Spans & 1 & \\
\hline Location of Piers or Supports & 840 & in. \\
\hline Depth of the Web & 54 & in. \\
\hline Girder Dimensions & & \\
\hline Number of Girders & 3 & \\
\hline Distance between Girders & 120 & in. \\
\hline & & \\
\hline Deck Dimensions & & \\
\hline Left Overhang & 36 & in. \\
\hline Right Overhang & 36 & in. \\
\hline Haunch & 0.75 & in. \\
\hline Depth of the Slab & 7.5 & in. \\
\hline & & \\
\hline Cross Frame Dimensions & & \\
\hline Height of Angle Section (h) & 3 & in. \\
\hline Width of the Angle Section (b) & 3 & in. \\
\hline Thickness at the top of angle (Th) & 0.375 & in. \\
\hline Thickness at bottom (Tb) & 0.375 & in. \\
\hline Number of Elements along the frame & 4 & ksi. \\
\hline Youngs' Modulus & 29000 & \\
\hline Poisson's Ratio & 0.3 & in. \\
\hline Material & & in. \\
\hline Material ID \# & 1 & in. \\
\hline Material & Steel & \\
\hline Girder Properties & & \\
\hline Top Flange Properties & & \\
\hline Number of Sections & 14 & \\
\hline Length & $39.5,106.7,173.9,238.82,241.1,308.3$, \\
\hline & $375.5,442.7,509.9,562.92,577.1$, & \\
\hline Width & $642.3,711.5,751,790.5,840$ & \\
\hline Thickness & 9 & \\
\hline Material ID \# & 0.75 & \\
\hline Web Properties & 1 & \\
\hline Number of Sections & 1 & \\
\hline Length & 840 & \\
\hline Depth & & \\
\hline Thickness & Material ID \# & \\
\hline
\end{tabular}


Table 4.2 Input Parameters for Nebraska Bridge (Continued)

\begin{tabular}{|c|c|c|}
\hline Input Parameter & Value & Units \\
\hline \multicolumn{3}{|l|}{ Bottom Flange Properties } \\
\hline Number of Sections & 3 & \\
\hline Length & $210,630,840$ & in. \\
\hline Width & 14 & in. \\
\hline Thickness & $0.75,1.25,0.75$ & in. \\
\hline Material ID \# & 1 & \\
\hline \multicolumn{3}{|l|}{ Mesh Size along the Length } \\
\hline$\overline{\text { Length }}$ & $\begin{array}{l}39.5,106.7,173.9,210,238.92,241.1,308.3, \\
375.5,442.7,509.9,562.92,577.1,630, \\
642.3,711.5,751,790.5,840\end{array}$ & in. \\
\hline Number of Elements & 6 , & \\
\hline \multicolumn{3}{|l|}{ Deck Properties } \\
\hline \multicolumn{3}{|l|}{ Mesh Size along the width of deck } \\
\hline Length & $36,156,276,308$ & in. \\
\hline Number of Elements & $4,10,10,4$ & \\
\hline \multicolumn{3}{|l|}{ Stiffener Properties } \\
\hline Number of Stiffeners & 14 & \\
\hline Length & $\begin{array}{l}39.5,106.7,173.9,241.1,308.3,375.5,442.7 \\
509.9,577.1,642.3,711.5,751,790.5,840\end{array}$ & in. \\
\hline Single or Double-Sided & Double & \\
\hline \multicolumn{3}{|l|}{ Left or Right (If single?) } \\
\hline Thickness & 0.3125 & in. \\
\hline Mesh along Depth & 6 & \\
\hline Mesh across Width & 2 & \\
\hline \multicolumn{3}{|l|}{ Mesh Size in Girders } \\
\hline $\begin{array}{l}\text { Number of Elements across the width in } \\
\text { top flange }\end{array}$ & 2 & \\
\hline $\begin{array}{l}\text { Number of Elements along depth in the } \\
\text { web }\end{array}$ & 6 & \\
\hline $\begin{array}{l}\text { Number of Elements across the width in } \\
\text { bottom flange }\end{array}$ & 2 & \\
\hline
\end{tabular}


Table 4.3 Data for Influence Surface for Bottom Flange Stresses

\begin{tabular}{|c|c|c|c|c|c|c|c|c|c|c|c|c|}
\hline & \multicolumn{12}{|c|}{ Width of the Deck (ft) } \\
\hline \multirow{22}{*}{ 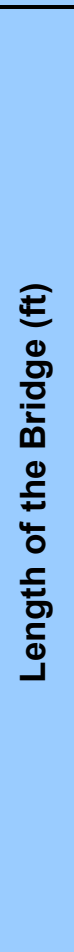 } & & 0.000 & 1.920 & 3.840 & 5.759 & 7.679 & 9.599 & 11.519 & 13.439 & 15.358 & 17.278 & 19.198 \\
\hline & 0.0 & -0.194 & -0.051 & 0.027 & 0.045 & 0.032 & 0.008 & -0.012 & -0.029 & -0.025 & 0.027 & 0.130 \\
\hline & 5.6 & -0.501 & -0.251 & -0.016 & 0.221 & 0.433 & 0.624 & 0.792 & 0.952 & 1.120 & 1.308 & 1.512 \\
\hline & 11.2 & -0.904 & -0.481 & -0.059 & 0.384 & 0.815 & 1.223 & 1.592 & 1.942 & 2.299 & 2.685 & 3.084 \\
\hline & 16.8 & -1.286 & -0.705 & -0.112 & 0.495 & 1.115 & 1.744 & 2.361 & 2.964 & 3.571 & 4.226 & 4.917 \\
\hline & 22.4 & -1.431 & -0.794 & -0.148 & 0.510 & 1.200 & 1.968 & 2.856 & 3.836 & 4.899 & 5.831 & 6.620 \\
\hline & 28.0 & -1.313 & -0.720 & -0.117 & 0.500 & 1.139 & 1.803 & 2.483 & 3.165 & 3.847 & 4.571 & 5.323 \\
\hline & 33.6 & -1.062 & -0.567 & -0.065 & 0.456 & 0.953 & 1.446 & 1.910 & 2.361 & 2.819 & 3.299 & 3.793 \\
\hline & 39.2 & -0.737 & -0.380 & -0.024 & 0.348 & 0.686 & 1.021 & 1.333 & 1.630 & 1.930 & 2.249 & 2.570 \\
\hline & 44.8 & -0.443 & -0.221 & 0.021 & 0.226 & 0.425 & 0.624 & 0.809 & 0.986 & 1.164 & 1.348 & 1.537 \\
\hline & 50.4 & -0.197 & -0.093 & \begin{tabular}{|c|}
0.018 \\
\end{tabular} & 0.107 & 0.192 & 0.278 & 0.359 & \begin{tabular}{l|}
0.438 \\
\end{tabular} & 0.517 & 0.600 & 0.684 \\
\hline & 56.0 & -0.018 & -0.006 & 0.003 & 0.005 & 0.003 & 0.001 & 0.001 & 0.000 & 0.000 & 0.001 & 0.004 \\
\hline & 61.6 & 0.095 & 0.044 & $\begin{array}{l}-0.019 \\
\end{array}$ & -0.074 & -0.133 & -0.195 & -0.255 & $\begin{array}{l}-0.315 \\
\end{array}$ & $\begin{array}{l}-0.373 \\
\end{array}$ & $\mid-0.431$ & -0.488 \\
\hline & 67.2 & 0.160 & 0.068 & $\begin{array}{ll}-0.038 \\
\end{array}$ & -0.130 & -0.226 & -0.327 & -0.427 & -0.526 & $\begin{array}{ll}-0.624 \\
\end{array}$ & -0.720 & -0.816 \\
\hline & 72.8 & 0.192 & 0.077 & $\mid-0.054$ & -0.166 & -0.282 & -0.405 & $\begin{array}{l}-0.526 \\
\end{array}$ & \begin{tabular}{|c|}
-0.648 \\
\end{tabular} & \begin{tabular}{|c|}
-0.768 \\
\end{tabular} & $\mid-0.887$ & -1.005 \\
\hline & 78.4 & 0.199 & 0.076 & \begin{tabular}{|c|}
-0.064 \\
\end{tabular} & -0.183 & -0.306 & -0.435 & -0.565 & -0.694 & -0.822 & -0.948 & -1.075 \\
\hline & 84.0 & 0.189 & 0.069 & $\mid-0.067$ & -0.182 & -0.301 & -0.426 & -0.551 & -0.676 & -0.800 & -0.923 & -1.045 \\
\hline & 89.6 & 0.165 & 0.058 & -0.063 & -0.166 & -0.271 & -0.383 & -0.494 & -0.605 & -0.715 & -0.825 & -0.934 \\
\hline & 95.2 & 0.133 & 0.045 & -0.054 & -0.137 & -0.223 & -0.313 & -0.403 & $\mid-0.493$ & -0.582 & -0.671 & -0.761 \\
\hline & 100.8 & 0.094 & 0.031 & -0.039 & -0.098 & -0.159 & -0.222 & -0.286 & -0.349 & -0.413 & -0.476 & -0.540 \\
\hline & 106.4 & 0.055 & 0.018 & -0.022 & -0.053 & -0.085 & -0.116 & -0.148 & -0.180 & -0.214 & -0.251 & -0.288 \\
\hline & 112.0 & 0.029 & 0.007 & 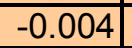 & -0.006 & -0.004 & -0.001 & $\begin{array}{l}0.002 \\
\end{array}$ & 0.003 & 0.001 & -0.009 & -0.030 \\
\hline
\end{tabular}


Table 4.4 Stress values at wheel load locations

\begin{tabular}{|l|c|}
\hline \multicolumn{1}{|c|}{ Wheel Loads } & $\begin{array}{c}\text { Stress Value } \\
\text { (ksi) }\end{array}$ \\
\hline Load 1 & 3.847 \\
\hline Load 2 & 3.144 \\
\hline Load 3 & 2.327 \\
\hline Load 4 & 1.595 \\
\hline Load 5 & 0.932 \\
\hline Load 6 & 0.339 \\
\hline Total Stress & $\mathbf{1 2 . 1 8 4}$ \\
\hline
\end{tabular}


Table 4.5 Comparison of Results between FE ANALYSIS and Experimental Testing

\begin{tabular}{|c|c|c|c|c|c|c|}
\hline \multirow{2}{*}{ Case No. } & \multirow{2}{*}{ Loading Case } & \multirow{2}{*}{ Section } & \multirow{2}{*}{$\begin{array}{c}\text { Number of } \\
\text { Lanes Loaded }\end{array}$} & \multicolumn{2}{|c|}{ Bottom Flange Stresses (Ksi) } & \multirow{2}{*}{$\%$ Erro } \\
\hline & & & & Experimental Data & FEA using GUI & \\
\hline 1 & $0.22 \mathrm{~L} / \mathrm{G} 1$ & $0.2 \mathrm{~L} / \mathrm{G} 1$ & 1 & 7.2 & 6.96 & 3.3 \\
\hline 2 & $0.22 \mathrm{~L} / \mathrm{G} 1$ & $0.2 \mathrm{~L} / \mathrm{G} 1$ & 3 & 12.5 & 12.18 & 2.6 \\
\hline 3 & $0.325 \mathrm{~L} / \mathrm{G} 1$ & $0.5 \mathrm{~L} / \mathrm{G} 1$ & 1 & -3.8 & -3.5 & 8.1 \\
\hline 4 & $0.325 \mathrm{~L} / \mathrm{G} 1$ & $0.5 \mathrm{~L} / \mathrm{G} 1$ & 3 & -6.2 & -6.24 & 0.6 \\
\hline 5 & $0.22 \mathrm{~L} / \mathrm{G} 2$ & $0.2 \mathrm{~L} / \mathrm{G} 2$ & 1 & 2.5 & 2.65 & 6.1 \\
\hline 6 & $0.22 \mathrm{~L} / \mathrm{G} 2$ & $0.2 \mathrm{~L} / \mathrm{G} 2$ & 3 & 8.8 & 8.45 & 3.9 \\
\hline 7 & $0.325 \mathrm{~L} / \mathrm{G} 2$ & $0.5 \mathrm{~L} / \mathrm{G} 2$ & 1 & -2 & -1.78 & 11.0 \\
\hline 8 & $0.325 \mathrm{~L} / \mathrm{G} 2$ & $0.5 \mathrm{~L} / \mathrm{G} 2$ & 3 & -5.4 & -5.02 & 7.0 \\
\hline
\end{tabular}


Table 4.6 Comparison of Results-Mid-span Deflection for Nebraska Bridge

\begin{tabular}{|l|r|r|}
\hline \multicolumn{2}{|c|}{ Mid-Span Deflection (in.) for 2 HS20-44 Trucks } \\
\hline & $\begin{array}{c}\text { FEA using FEMAP } \\
\text { (Wu, 2002) }\end{array}$ & $\begin{array}{c}\text { FEA Using } \\
\text { GUI }\end{array}$ \\
\hline Girder 1 & 0.303 & 0.302 \\
\hline Girder 2 & 0.35 & 0.355 \\
\hline Girder 3 & 0.303 & 0.303 \\
\hline
\end{tabular}




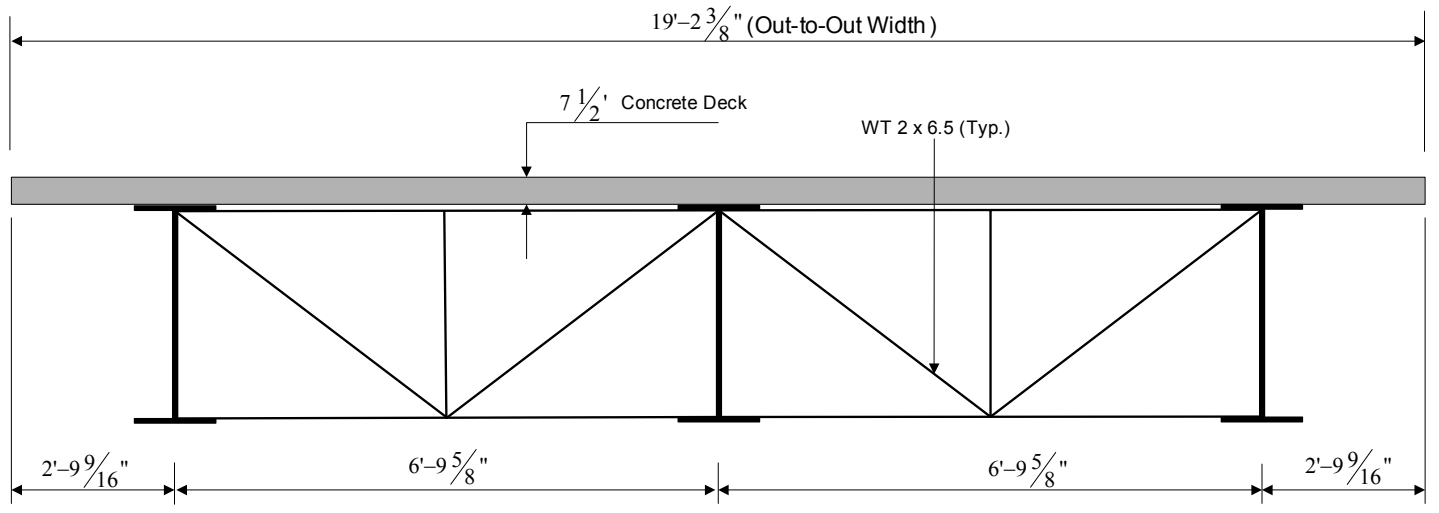

Figure 4.1 Cross Section elevation of FHWA Bridge 


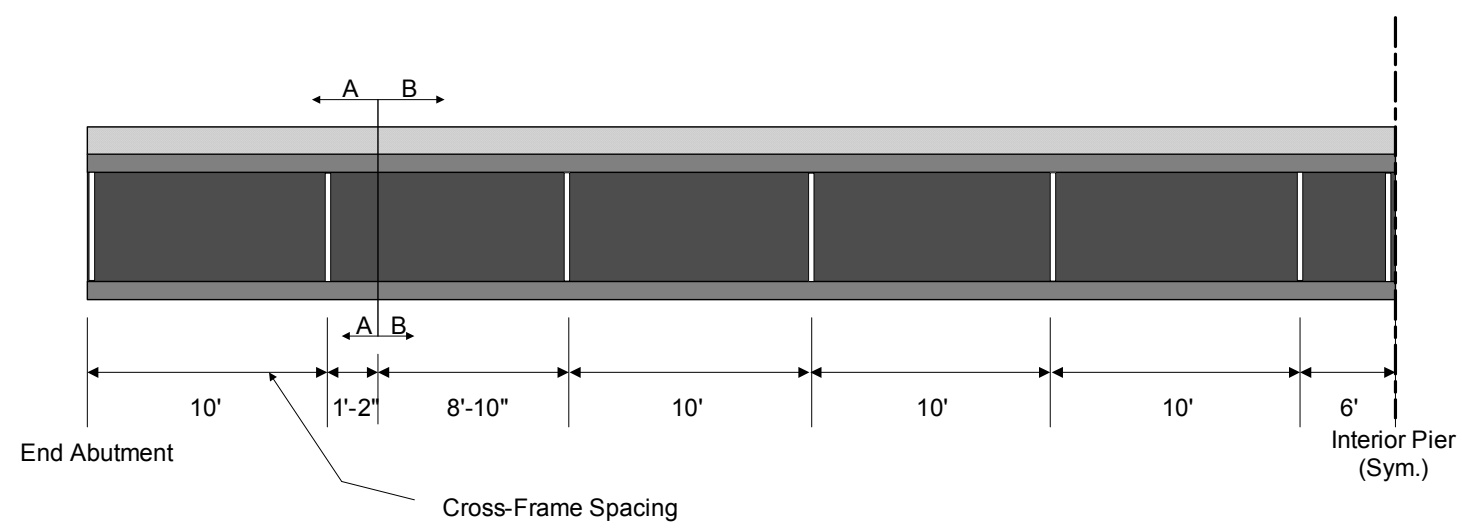

Figure 4.2 Girder elevation of the left-span showing girder transitions and cross frame locations for the FHWA Bridge. 


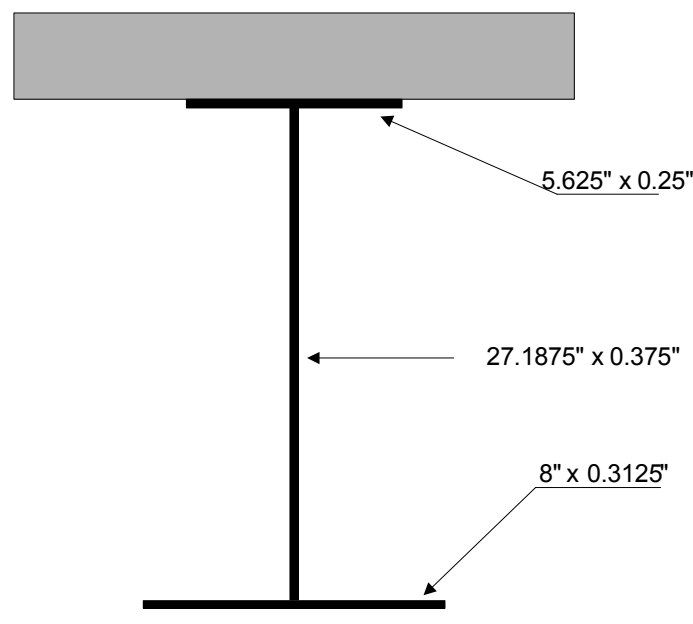

Section A-A

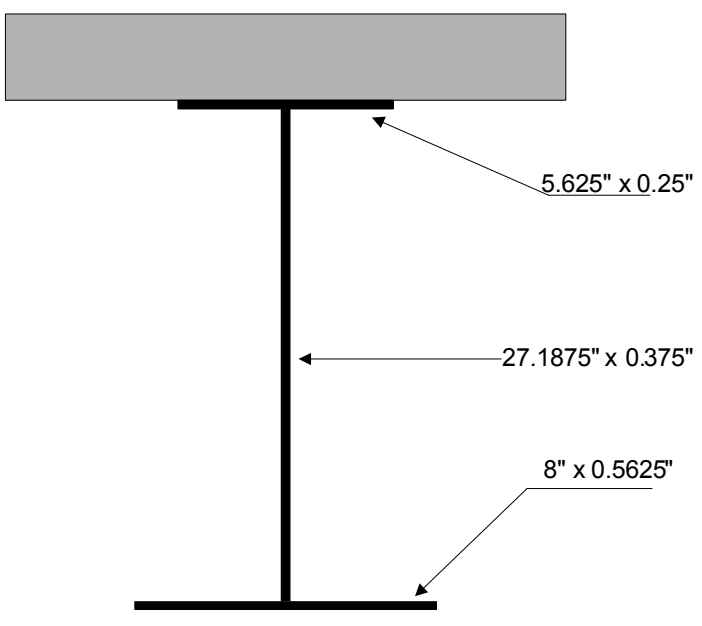

Section B-B

Figure 4.3 FHWA test bridge cross-sections 


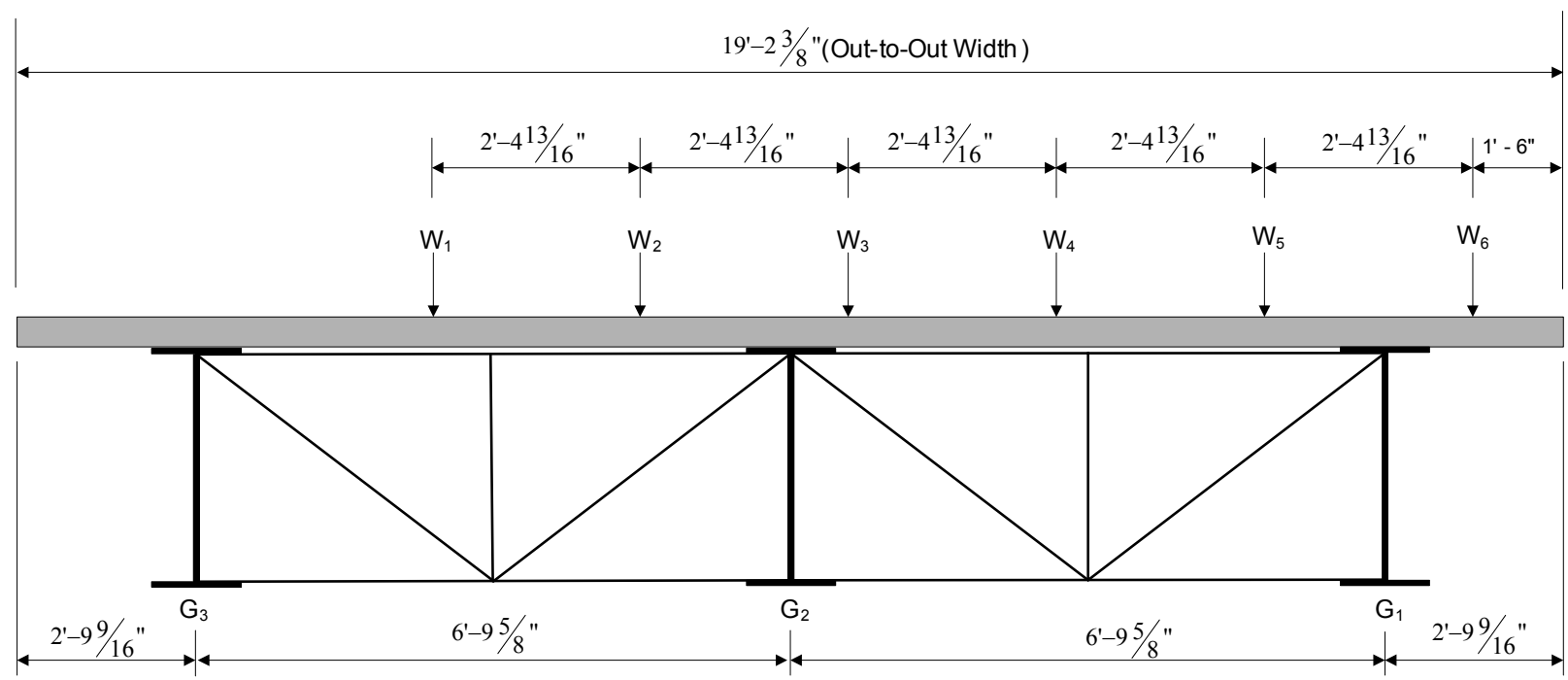

(a) Details of individual wheel loads at $0.22 \mathrm{~L}$ corresponding to load cases 1 to 4

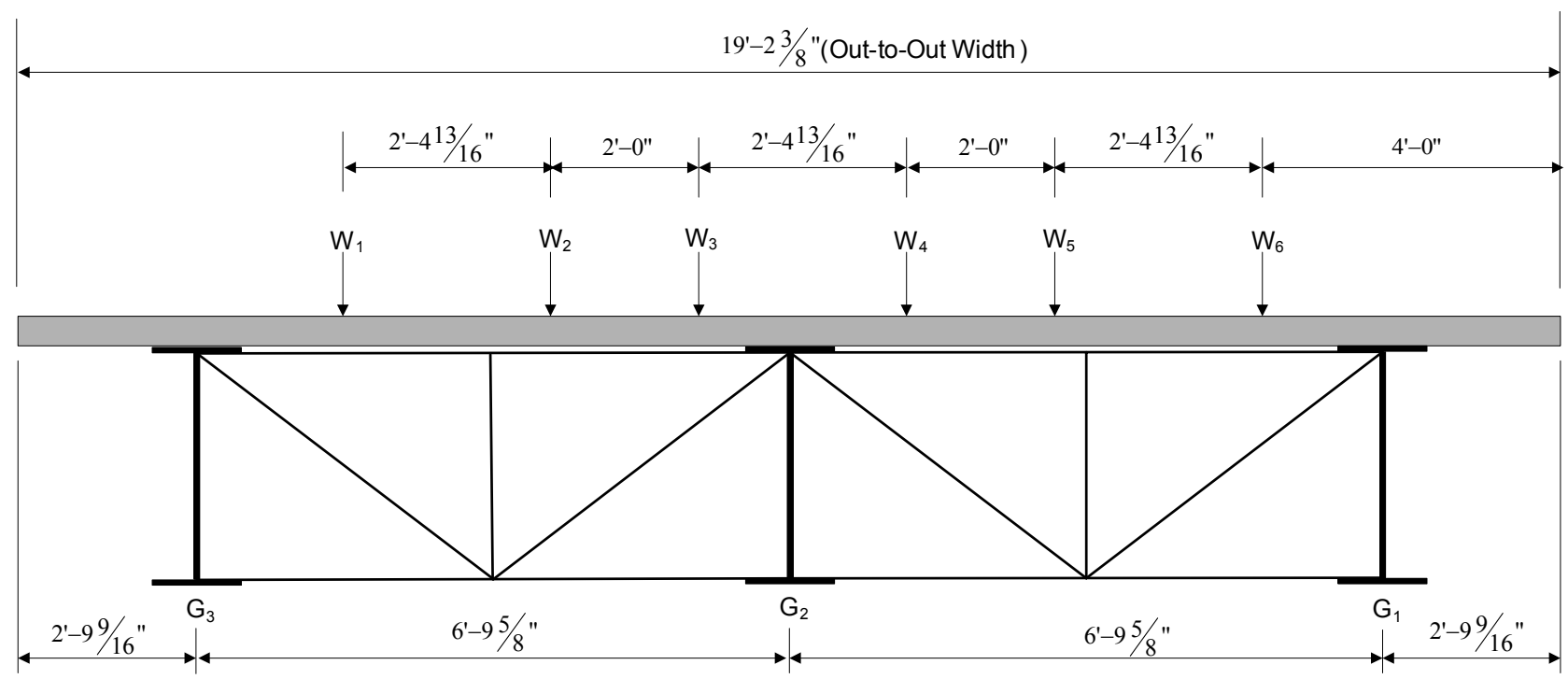

(b) Details of individual wheel loads at $0.33 \mathrm{~L}$ corresponding to load cases 5 to 8

Figure 4.4 Cross-sectional views illustrating transverse load positions from (a) Load cases 1 to 4 and (b) Load cases 5 to 8 


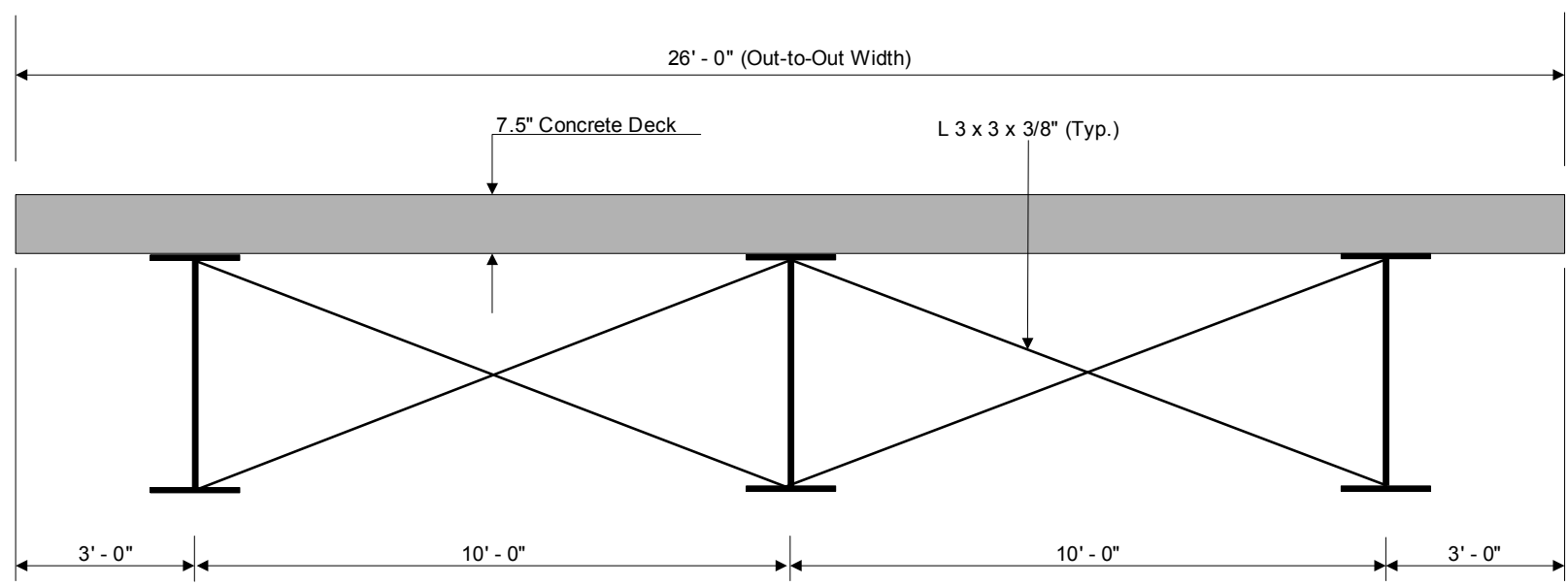

Figure 4.5 Cross section elevation of Nebraska Bridge 


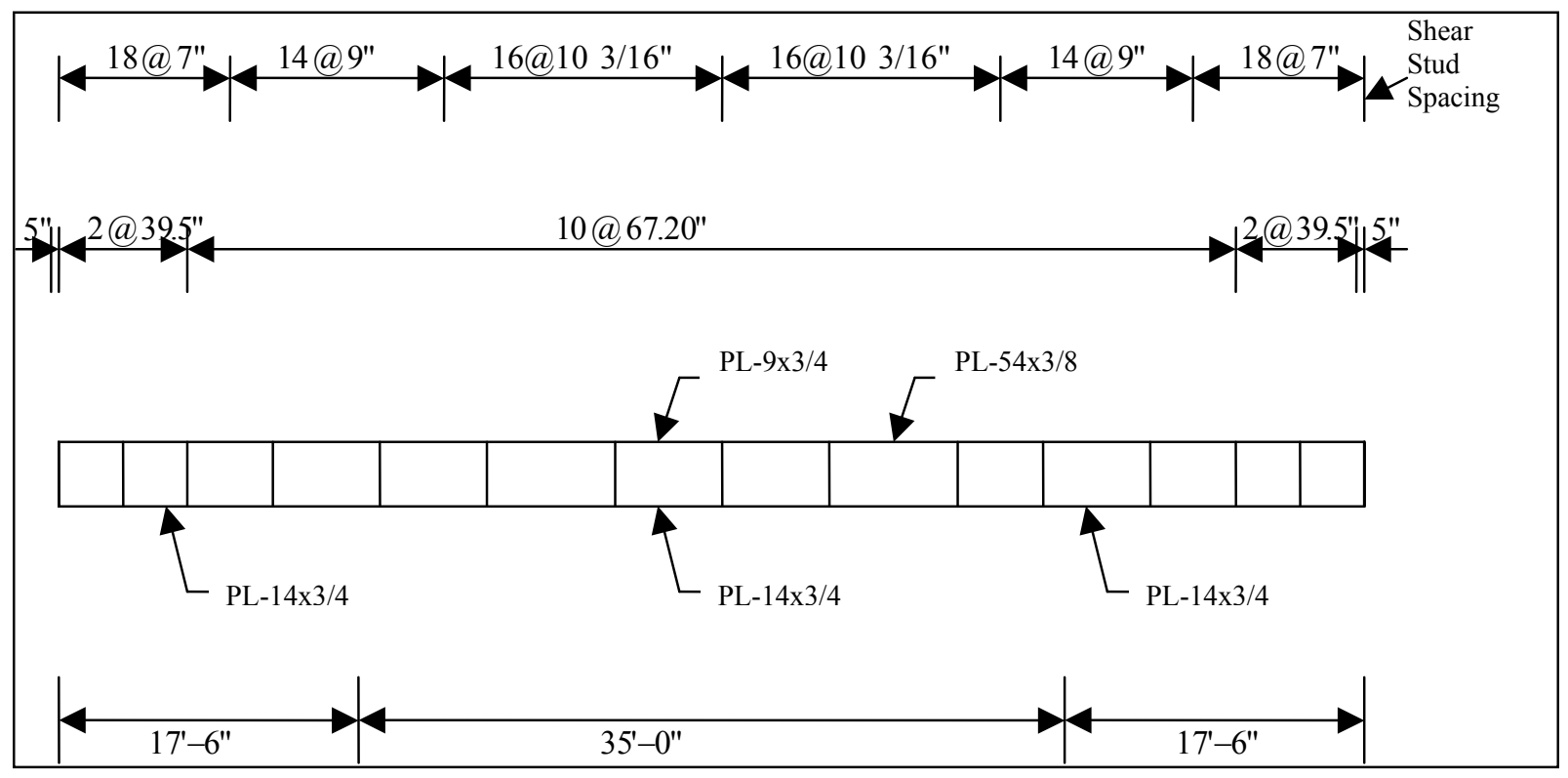

Figure 4.6 Longitudinal Elevation of Nebraska Bridge (Adapted from Kathol et al, 1995) 


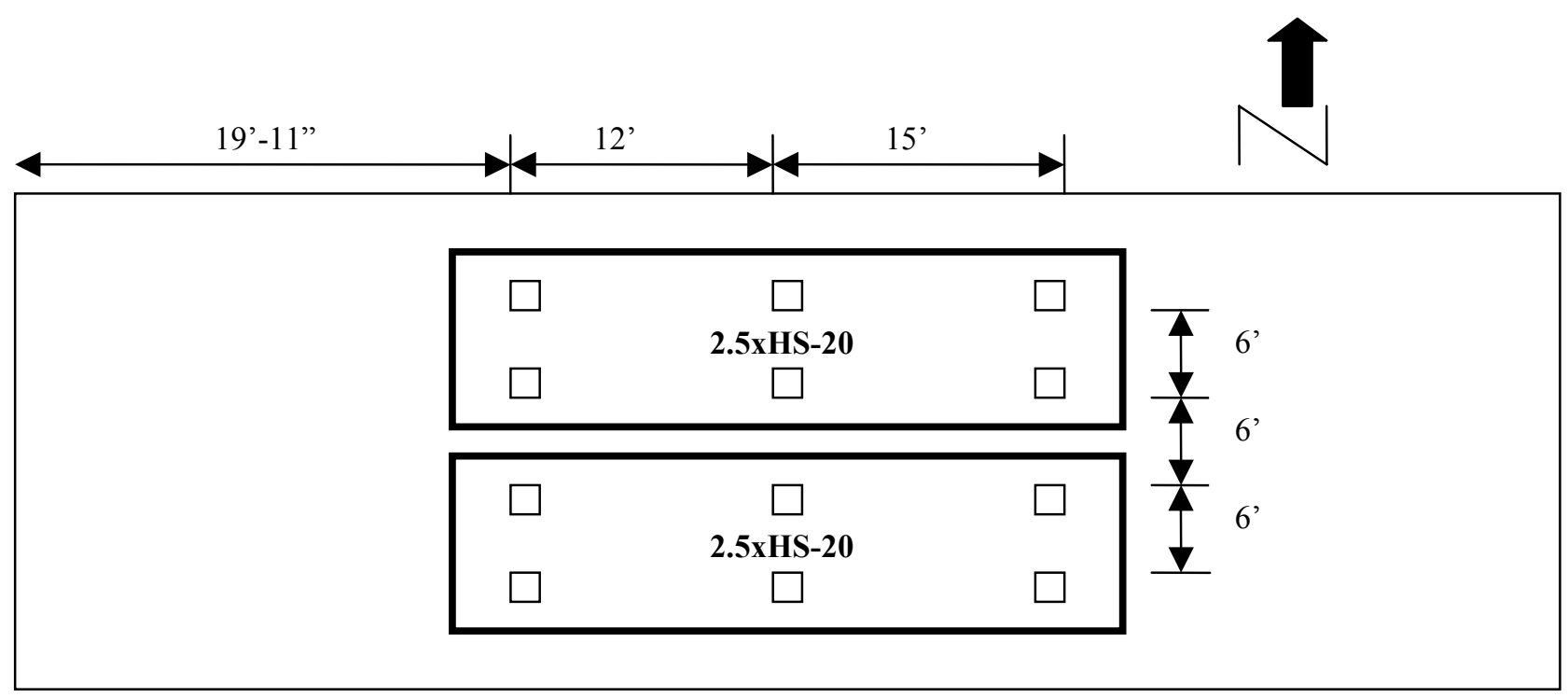

Figure 4.7 Nebraska Bridge: Loading Case (Adapted from Kathol et al, 1995) 


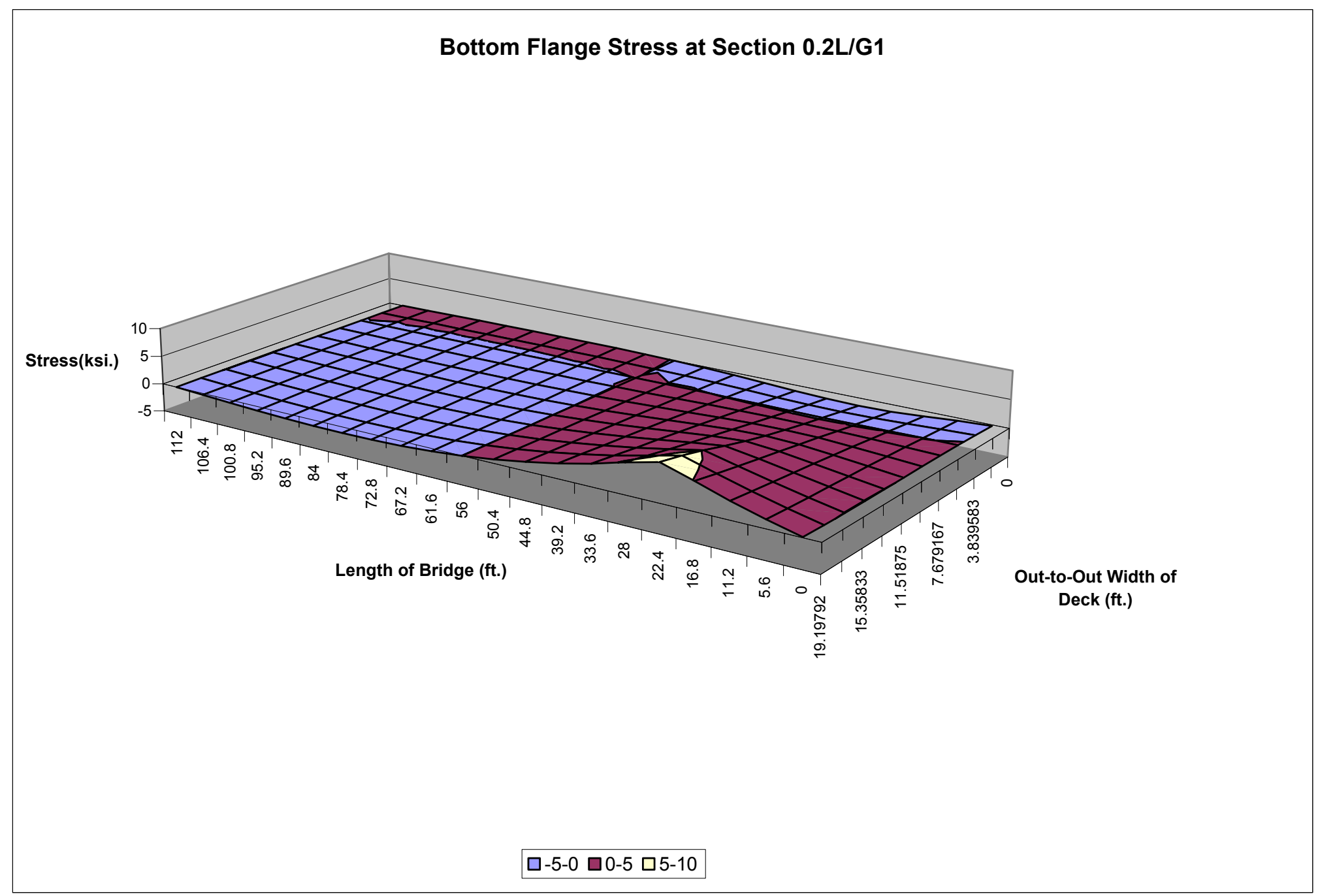

Figure 4.8 Federal Highway Bridge: Bottom Flange Stress Influence Surface 


\section{CHAPTER 5}

\section{CONCLUSIONS}

\subsection{Summary}

This study has presented the development of a graphical interface for the generation of 3D FE models of continuous-span steel-concrete composite bridges. The GUI has a number of advantages over commercially available software for the design of three-dimensional bridge models.

\section{Reduction in Time Costs}

The time savings of using the interface in every stage of the FE analysis process makes it a highly effective tool. The model generation in the GUI is completely automated, only requiring user input of basic bridge geometry and mesh properties. Using this data, complete bridge models can be generated very quickly. This presents a significant advantage during modeling of asymmetrical bridge designs over commercially available software packages such as FEMAP. Depending on the complexity of the bridge design, model generation using the GUI can reduce the time involved by anywhere from $50 \%$ to $70 \%$. For the bridge models generated during verification studies in this research, modeling using FEMAP took upwards of 4 hours for each bridge. Using the GUI, that time has been reduced to about 1.5 hours, a time reduction of $63 \%$.

Also, bridges with variable flange widths, which pose a significant challenge during manual modeling of three-dimensional bridges using software such as FEMAP, can be modeled with ease using the GUI. During modeling using FEMAP, the bridge 
model needs to be constructed in stages ensuring necessary connections at the flange transitions and consumes a lot of time. The automated process of the GUI ensures the presence of nodes at all flange transitions and reduces the time required during model creation. This feature of the GUI was a huge factor into the time savings that were realized during the verification studies in this research.

After completion of model generation using FEMAP, considerable user manipulation of the input file is required in preparation for analysis using ABAQUS. This step is done to ensure that the stresses and deflections are not computed for every node and element, which in turn, will increase the CPU cost. This input file management step is completely avoided when using the GUI, and an efficient, ABAQUS-compatible input file is created to compute the responses at only the critical bridge cross-sections. Again, based on the size of the bridge model, this could save up to 2 hours of the designer's time.

As discussed above, modeling continuous span bridges using the GUI can save a considerable amount of time and prove effortless to the designer. On an average, the total modeling time reduction is between $50 \%$ and $70 \%$. This is especially beneficial during parametric studies which require a single model parameter change. For example, in order to study the effect of girder spacing on a continuous span bridge, complete model regeneration is required for all iterations. An exercise of 5 such iterations using the GUI would mean a reduction of modeling time from about 4 days (32 hours) to 7-8 hours.

Other significant and convenient features include the use of the GUI as a single interface for the modeling, analysis and post-processing of a bridge structure. Also, advanced graphical tools allow for three-dimensional visual representation of the bridge 
model. The model can be panned, zoomed or rotated to check for irregularities before analysis.

\section{Integration with ABAQUS}

The GUI also provides seamless integration with ABAQUS, a robust analysis tool that has a large library of elements to accurately model and predict the response due to loading on a composite bridge superstructure. Non-linear material modeling can be executed using ABAQUS. Thus, the GUI developed in this research uses the advantages of this powerful analysis tool while eliminating the user-involved preparation time of the input file.

\section{Advanced Post-Processing Tools}

The access database program developed in this study provides automated methods for the calculation of response parameters that are not directly available in the ABAQUS result set. Girder moments and shear forces at girder cross sections are derived from the stress values and the database program can auto-calculate to provide ready results for

further investigation. Also, post-processing tools generate influence surfaces of the different response parameters that help to find the maximum force effects due to various loading conditions. This presents a significant upgrade from other bridge design software packages that only generate influence lines and not surfaces.

\subsection{Conclusions}

The software developed in this research has shown a significant decrease in the time to generate 3D FE models of straight continuous composite bridges when compared 
with the commercially available general modeling package, FEMAP Ver 8.3 (FEMAP, 2003). The tools developed in this software provide a user-friendly interface to generate the three-dimensional FE bridge models.

The GUI is also shown to provide ease of modeling bridge girders that have variable flange widths and thicknesses along the length of the bridge. Also, additional members such as transverse stiffeners and cross frames can be modeled quickly and accurately. The GUI has also demonstrated the ability to generate analysis-ready ABAQUS input files, which, unlike other commercial packages, does not require further user manipulation for the computation of composite bridge-related response parameters.

By performing effective data reduction by creating node and element sets of critical bridge sections, the GUI provided the optimal input file for rapid, data-efficient analysis. The GUI has shown to generate influence surfaces for key response parameters, which presents a significant upgrade from other bridge design software tools.

Verification studies conducted in this research on two experimentally-tested bridges present a comparison and are able to benchmark the results of 3D bridge models developed in this study with the experimental results, with an acceptable amount of error. Hence, the tools developed in this research can be used to reliably building tangent, simply supported and continuous span composite bridge models.

Further upgrades to this version of the software tool can find increased applications and generate a broader range of bridge models if additional features such as curved girders and skew angle can be incorporated into the modeling interface. 


\section{REFERENCES}

AASHTO (1998), LRFD Bridge Design Specifications, $2^{\text {nd }}$ Edition, American Association of State Highway and Transportation Officials, Washington D.C.

ABAQUS/Standard User's Manual, Version 6.3(2002), Hibbitt, Karlsson and Sorenson Inc.

ABAQUS/Explicit User's Manual, Version 6.3(2002), Hibbitt, Karlsson and Sorenson Inc.

Austin M. A., Creighton, S. and Albrecht, P. (1993), “X-Build: Pre-processor for Finite Element Analysis of Steel Girder Bridge Structures”, Journal of Computing in Civil Engineering, Vol. 7, No. 1, January 1993, pp 54-70

Avery, P. and Mahendran M. (1997)., “Buckling experiments on hollow flange beams with web stiffeners, ” J. Struct. Engrg., ASCE, 123(9), 1130-1134.

Bakht B.(June 1988) "Observed Behaviour of a New Medium Span Slab-on Girder Bridge”, The Research and Development Branch, Ministry of Transportation, Ontario

Balena, Francesco, (2003), "Programming Microsoft Visual Basic. NET”

Barker M., G., Cory M. Imhoff, W. Travis McDaniel and Troy L. Frederick, "Steel Girder Bridge Field Test Procedures”, University of Missouri-Columbia, Columbia, $M O$.

Barker, M., Imhoff, C.M., Daniel, T.W. and Frederick, T.L. (1999), "Field Testing and Load Rating procedures for Steel Girder Bridges" University of Missouri, Columbia 
Barth, K.E.(1996), “Moment-rotation Characteristics for Inelastic Design of Steel Bridge Beams and Girders, Ph. D Dissertation, Purdue University, West Lafayette, Indiana.

Biggs, M., Furman, B.W., Gomez, P.J., Massarelli P.P. and Wallace, M.T. Jr.(2000), "Finite Element Modeling and Analysis of Reinforced-Concrete Bridge Decks" Virginia Transportation Research Council

Brockenbrough, R.L (1986), "Distribution factors or curved I-girder bridges", J. Struct. Engrg., ASCE, 112(10).

Cedric M. (1997), "Design of Single and Multiple Angle Columns and Beams", J. Struct. Engrg., ASCE 123(7) 847-856

Eom, J. and Nowak, A.S (2001)., "Live-Load Distribution for Steel Girder Bridges", ASCE, Journal of Bridge Engineering, Vol. 6, No. 6, 2001, pp. 489-497

FEMAP (2003), Finite Element Modeling and Post-processing Version 8.3.0.1, Electronic Data Systems Corp.

Grubb, M.A., and Moore, M. (1984). "Structural modeling for autostress by loading through a precast deck system." Report of Preliminary Bridge Design, Federal Highway Administration, McLean, Va.

Moore, M. (1985). "Fabrication, erection and instrumentation of the model bridge: structural modeling for autostress by loading through a precast deck." Report, Federal Highway Administration, McLean, Va.

Hays, C. Jr., Hays, C.O. Jr., Sessions, L.M., and Berry, A.J. (1986), "Further Studies on Lateral Load Distribution Using a Finite Element Method", Transportation 
Research Record 1072, Transportation Research Board, National Research Council, Washington, D.C., pp 6-14

Jusnik, E. and Nowak, A.S. (2001), "Live-load Distribution for Steel Girder Bridges", J. Bridge Engrg., ASCE, Vol 6(6) 489-497

Kathol, S., Azizinamini A. and Luedke J. (1995), "Strength Capacity of Steel Girder Bridges", Nebraska Department of Roads Research Project Number RES1(0099) P469

Mans, P.H. (2001) "Full-Scale Testing of Composite Plate Girders Constructed Using 70-ksi High Performance Steel”. MS Thesis, University of Nebraska-Lincoln.

Microsoft (2005), Microsoft Corporation website, http://office.microsoft.com/enus/default.aspx, (Last Accessed 2005)

Moore, M., Strand, K.A., Grubb, M.A. and Lloyd R Cayes (1990), "Wheel Load Distribution Results from the AISI-FHWA Model Bridge Study", 69 $9^{\text {th }}$ Annual Transportation Board

Mounir, E. M., Tarhini K., Frederick, G.R. and Tayar, C. (1997).," Finite Element Analysis of Steel Girder Highway Bridges, ” J. Bridge Engrg., ASCE Vol2. No.3 83-87.

Newmark, N. M., (1948) “Design of I-Beam Bridges,” Proc. ASCE, March, pp. 305-331.

Padur D. S. (2004), "Development and Testing of an Enhanced Preprocessor for creating 3D Finite Element Models of Highway Bridges and a Postprocessor Roberts, N. (2004) "Evaluation of the Ductility of Composite Steel I-girders in Positive Bending”, Masters Thesis, Department of Civil Engineering, West Virginia University, Morgantown, West Virginia 
QConBridge (2005), Washington State Department of Transportation, http://www.wsdot.wa.gov/eesc/bridge/softwarel, (Last Accessed 2005)

SAP (2005), Computers and Structures Inc., http://www.csiberkeley.com (Last Accessed 2005)

SAM (2005), SAM Integrated Bridge Design Software, Bestech Systems, http://www.lrfdsoftware.com/products.html (Last Accessed 2005)

STAAD (2005), Research Engineers International, netGuru Inc., http://www.reiusa.com, (Last Accessed 2005)

Standard Specifications for Highway Bridges(1996), American Association for State Highway and Transport Officials

STLBRIDGE (2000), STLBridge LRFD User's Manual, Bridgesoft Inc.

STRAND7 (2005), Strand7 Pty Ltd., http://www.strand7.com, (Last Accessed 2005)

Tarhini K. and Frederick, G.R.(1992) "Wheel Load Distribution in I-Girder Highway Bridges" Journal of Structural Engineering, Vol. 118, No. 5, May 1992, pp. $1285-1294$

Tiedeman, J. L., Albrecht, P. and Cayes L. R., (1993), "Behavior of Two-Span Continuous Bridge under Truck Axle Loading”, Journal of Structural Engineering, Vol. 119, No. 4

Topkaya C. and Williamson, E. B. (2003), "Development of Computational Software for Analysis of Curved Girders under Construction Loads." Computers and Structures, Vol. 81, No. 21, pp. 2087-2098

Turer, A. (2000) “Condition Evaluation and Load Rating of Steel Stringer Highway Bridges using Field Calibrated 2-D Grid and 3D FE Models”, PHd 
Dissertation, Department of Civil and Environmental Engineering, University of Cincinnati, Cincinnati, Ohio

Wittry, D.M. (1993) “An Analytical Study of the Ductility of Steel-Concrete Composite Sections". MS Thesis, The University of Texas-Austin.

Wonseok, C. and Sotelin, E.D. "Three-Dimensional Finite Element Modeling of Composite Girder Bridges", Unpublished Manuscript, School of Civil Engineering, Purdue University, West Lafayette, Indiana

Wu, H, (2003), Influence of Live-Load Deflections on Superstructure Performance of Slab on Stringer Bridges, PhD dissertation, Department of Civil Engineering, West Virginia University, Morgantown, West Virginia.

Yang, L. (2003) “Evaluation of Moment Redistribution for Hybrid HPS 70W Bridge Girders", Masters Thesis, Department of Civil Engineering, West Virginia University, Morgantown, West Virginia 


\section{APPENDIX - A}

\section{Top Flange Variable Declaration}

\begin{tabular}{|l|l|l|}
\hline Variable Name & Type & Description/Explanation \\
\hline Tfnn & 3D Array & Creating and storing nodes in the top flange. \\
\hline Tfele & 4-d Array & Creating and storing elements in the top flange. \\
\hline Tfx,tfy,tfz & Double & X Y and Z coordinates of nodes in top flange. \\
\hline Ntfwidth & Double & Number of Elements across the width of top flange. \\
\hline Tfxint & Double & Initial X coordinate of each top flange. \\
\hline Tfp & Integer & Counter for the number of nodes. \\
\hline Tfm & Integer & Counter for the number of elements. \\
\hline Tfq, tfr, tfi, tfj, tfk & Integer & General Counters for running 'for' loops. \\
\hline Tfndcnt1,tdndcnt2,tfndent3 & Integer & Counter variables while creating the nodes. \\
\hline Tfincr1 & 1-d Array & X increment between successive nodes. \\
\hline Tfincr3 & 1-d Array & Z increment between successive nodes. \\
\hline Cout, coutele & String & String variables to write into the input file. \\
\hline Tfboom & 2-d Array & Count of number of nodes in each section. \\
\hline Tfboomele & 2-d Array & Count of number of elements in each section. \\
\hline Topyoung & Double & \\
\hline Topmat & Double & \\
\hline & &
\end{tabular}

\section{Bottom Flange Variable Declaration}

\begin{tabular}{|l|l|l|}
\hline Botfnn & 3D Array & Creating and storing nodes in Bottom Flange. \\
\hline Botfele & 4-d Array & Creating and storing elements in the Bottom flange. \\
\hline Botfx, botfy, botfz & Double & X Y and Z coordinates of nodes in the bottom flange. \\
\hline Nbotfwidth & Double & $\begin{array}{l}\text { Number of elements across the width of bottom } \\
\text { flange. }\end{array}$ \\
\hline Botfxint & Double & Initial X coordinate of each bottom flange. \\
\hline Botfp & Integer & Counter for the number of nodes. \\
\hline Botfm & Integer & Counter for the number of elements. \\
\hline Botfq, botfr,botfi,botfj,botfk & Integer & General Counters for running 'for' loops. \\
\hline $\begin{array}{l}\text { Botndcnt1,botfndcnt2,botfndc } \\
\text { nt3 }\end{array}$ & Integer & Counter Variables while creating the nodes. \\
\hline Botfincr1 & 1-d Array & X increment between successive nodes. \\
\hline Botfincr3 & 1-d Array & Z increment between successive nodes. \\
\hline Botfboom & 2-d Array & Count of number of nodes in each section. \\
\hline Botfboomele & 2-d Array & Count of number of elements in each section. \\
\hline \multirow{2}{|l}{} & & \\
\hline Web Variables Declaration & \multicolumn{2}{|l}{} \\
\hline Webdepth & Double & Depth of the web (Constant for the whole bridge). \\
\hline Nwebheight & Integer & Number of elements along the depth of the web. \\
\hline Webnn & 3D Array & Creating and storing nodes in the web. \\
\hline Webele & 4-d Array & Creating and storing elements in the Web. \\
\hline
\end{tabular}




\begin{tabular}{|c|c|c|}
\hline Webx,weby,webz & Double & $\mathrm{X} \mathrm{Y}$ and $\mathrm{Z}$ coordinates of nodes in the web. \\
\hline Webp & Integer & Counter for the number of nodes. \\
\hline Webm & Integer & Counter for the number of elements. \\
\hline Webq,webr,webi,webj,webk & Integer & General Counters for running the loops. \\
\hline $\begin{array}{l}\text { Webndent } 1 \text {, webndent } 2 \text {, webnd } \\
\text { cn3 }\end{array}$ & Integer & Counter Variables while creating the nodes. \\
\hline Webincr2 & 1-d Array & Y increment between successive nodes. \\
\hline Webincr3 & 1-d Array & $\mathrm{Z}$ increment between successive nodes. \\
\hline Webboom & 2-d Array & Count of number of nodes in each section. \\
\hline Webboomele & 2-d Array & Count of number of elements in each section. \\
\hline \multicolumn{3}{|c|}{ Property Array Variable Declaration } \\
\hline Prop & 2-d Array & $\begin{array}{l}\text { Property Array storing change in values of thickness } \\
\text { etc. }\end{array}$ \\
\hline Prop_all & 2-d Array & $\begin{array}{l}\text { Array after removing repeating values of change in } \\
\text { section. }\end{array}$ \\
\hline Prop_tf & 2-d Array & Property array for the top flange. \\
\hline Prop_web & 2-d Array & Property array for the web. \\
\hline Prop_botf & 2-d Array & Property array for the bottom flange. \\
\hline Prop_dck & 2-d Array & Property array for the deck. \\
\hline Tf_rent & Integer & Number of section changes (rows) in the top flange. \\
\hline Web_rcnt & Integer & Number of section changes (rows) in the web. \\
\hline Botf_rent & Integer & $\begin{array}{l}\text { Number of section changes (rows) in the bottom } \\
\text { flange. }\end{array}$ \\
\hline Totsecs & Integer & $\begin{array}{l}\text { Total number of sections (Top flange }+ \text { Bot. Flange }+ \\
\text { web). }\end{array}$ \\
\hline Pall & Integer & Total number of unique property rows. \\
\hline Tf_propno & Integer & Number of properties in top flange. \\
\hline Web_propno & Integer & Number of properties in the web. \\
\hline Botf_propno & Integer & Number of properties in the bottom flange. \\
\hline Propi, propj, propk & Integer & Counter variables to run 'for' loops in properties. \\
\hline $\mathrm{I}, \mathrm{j}, \mathrm{k}, \mathrm{l}$ & Integer & Counter variables. \\
\hline \multicolumn{3}{|c|}{ Variables to Merge Co-incident nodes from various Sections } \\
\hline Ndent1-ndent6 & Integer & Counter Variables. \\
\hline \multicolumn{3}{|c|}{ Variable Declaration for Materials } \\
\hline Matrow & Integer & Number of Materials. \\
\hline \multicolumn{3}{|c|}{ Variable Declaration for Stiffeners } \\
\hline Stff_rcnt & Integer & Number of stiffeners per girder. \\
\hline Stffi, stfj, stfk & Integer & Counter Variables. \\
\hline stfq, stfu, stfv, stfa, stfw & Integer & Counter Variables. \\
\hline Stfprop & 2-d Array & $\begin{array}{l}\text { Stiffener property array for number of elements, } \\
\text { thickness. }\end{array}$ \\
\hline
\end{tabular}




\begin{tabular}{|c|c|c|}
\hline Stfnn & 2-d Array & Creating and storing nodes of stiffener. \\
\hline Stfele & 3D Array & Creating and storing elements of stiffener. \\
\hline Stfboom,stfboom1 & 2-d Array & Number of nodes in each section. \\
\hline Stfboomele & 2- d Array & Number of elements in each section. \\
\hline Mpcstfboom & 1-d Array & Number of MPC beams between stiffener and girders. \\
\hline Stfincr1 & Integer & $\mathrm{X}$ increment during creation of nodes. \\
\hline Stfincr2 & Integer & Y increment during creation of nodes. \\
\hline Stfx, stfy, stfz & Double & $\mathrm{X} \mathrm{Y}$ and $\mathrm{Z}$ coordinates for nodes of stiffener. \\
\hline Stfr & Integer & Counter Variable \\
\hline Stfp & Integer & Counter for nodes of stiffener. \\
\hline Stfm & Integer & Counter for elements of stiffener. \\
\hline \multicolumn{3}{|c|}{ Variable Declaration for MPC Beams } \\
\hline Mpcstf & 3D Array & $\begin{array}{l}\text { Storing Elements for MPC Beam between Stiffener } \\
\text { and Flange (Top/Bottom). }\end{array}$ \\
\hline \multicolumn{3}{|c|}{ Variable Declaration for Triangular Elements } \\
\hline Triagele & 3D Array & Creating and Storing elements of Triangular Elements. \\
\hline Triagk & Integer & Number of Triangular Elements. \\
\hline Triagj & Integer & Counter to run 'for' loop. \\
\hline Triam & Integer & Number of Triangular Elements. \\
\hline \multicolumn{3}{|c|}{ Variable Declaration for Girders } \\
\hline Grddis & Double & Distance between the girders. \\
\hline Ngrdr & Integer & Number of Girders. \\
\hline Gent1-gent4 & Integer & Counter Variables. \\
\hline \multicolumn{3}{|c|}{ Variable Declaration for Deck } \\
\hline Dckwdth & Double & Width of the Deck. \\
\hline Hnch & Double & Haunch of the Deck. \\
\hline Lfthng & Double & Left Overhang of the Deck. \\
\hline Rghthng & Double & Right Overhang of the Deck. \\
\hline Slbdpth & Double & Depth of the Slab. \\
\hline Oodckwdth & Double & Out-Out Deck Width. \\
\hline $\begin{array}{l}\text { Dcki, dckj, dckk, dckp, dckq, } \\
\text { dckm, dckr,dcks, dckt, dcku, } \\
\text { dck1 }\end{array}$ & Integer & General Counters for running 'for' loops. \\
\hline Dckx,dcky, dckz & Double & $\mathrm{X} Y$ and $\mathrm{Z}$ coordinates of nodes in the deck. \\
\hline Dckincr1-dckincr3 & Double & $\mathrm{X} Y$ and $\mathrm{Z}$ Increments between successive nodes. \\
\hline Latdcksec & Integer & Number of Sections across the width of the Deck. \\
\hline Dckxint & 1-d Array & Initial X Coordinate of each node of the Deck. \\
\hline Dcknn & 2-d Array & Creating and storing nodes in the deck. \\
\hline Dckboom & 2-d Array & Count of number of nodes in each section. \\
\hline Dckboomele & 2-d Array & Count of number of elements in each section. \\
\hline Dckele & 2-d Array & Creating and storing elements in the deck. \\
\hline \multicolumn{3}{|c|}{ Variable Declaration for Deck-Top Flange MPC Beams } \\
\hline Mpcdckfl & 3D Array & $\begin{array}{l}\text { Storing Elements of MPC Beam between Deck and } \\
\text { Top Flange. }\end{array}$ \\
\hline Dckfl & Integer & $\begin{array}{l}\text { Number of MPC Beams between Deck and Top } \\
\text { Flange. }\end{array}$ \\
\hline \multicolumn{3}{|c|}{ Variable Declaration for Cross Frames } \\
\hline Ncrmsh & Integer & $\begin{array}{l}\text { Mesh Size of Cross Frame along the length of the } \\
\text { frame. }\end{array}$ \\
\hline
\end{tabular}




\begin{tabular}{|c|c|c|}
\hline Crfrp & Integer & Counter for the Number of nodes. \\
\hline Crfrp1 & Integer & Node Number for the Cross Frame. \\
\hline Cri,crj,crk & Integer & $\mathrm{X} \mathrm{Y}$ and $\mathrm{Z}$ coordinates of Cross Frames. \\
\hline Crsbment1,crsbment2 & Integer & Counters to run 'for' loops. \\
\hline Crsm & Integer & Counter for the Number of elements. \\
\hline Crsm1 & Integer & Element Number for the Cross Frame. \\
\hline Crsfrnn & 2-d Array & Creating and storing nodes for the Cross Frames. \\
\hline Crsfrele & 4-d Array & Creating and storing elements for the Cross Frames. \\
\hline Crsboom & 1-d Array & Count of number of nodes for the Cross Frames. \\
\hline Crsboomele & 1-d Array & Count of number of elements for the Cross Frames. \\
\hline Crshght & Double & Height of the Cross Frame. \\
\hline Crswdth & Double & Width of the Cross Frame. \\
\hline Crsthktop & Double & Thickness of the Cross Frame at the top. \\
\hline Crsthkbot & Double & Thickness of the Cross Frame at the bottom. \\
\hline Crincr1,crincr2 & Double & $\mathrm{X}$ and $\mathrm{Y}$ increments for the Cross Frame. \\
\hline Crsyng & Double & Young's Modulus for the Cross Frame. \\
\hline Crspsn & Double & Poisson's Ratio for the Cross Frame. \\
\hline $\begin{array}{l}\text { Xcentr1,xcentr2,ycentr1,ycentr } \\
\text { 2,crsarea1, crsarea2, } \\
\text { crsareatot, x0, y0, x1bar,y1bar, } \\
\text { x2bar, y2bar, Ixx, Iyy, Ixy, } \\
\text { q1x, q2x, f1x, f2x, ex, ey, } \\
\text { rvsdx0, rvsdy0, trsnj, Gtrsn, } \\
\text { spt }\end{array}$ & Double & Variables for calculating properties of cross frames \\
\hline \multicolumn{3}{|c|}{ Variable Declarations for Load } \\
\hline Prop_load & 2-d Array & Stores coordinates and Load values for point Load. \\
\hline Ld & 3D Array & Extrapolated load values for live-load. \\
\hline Ldval & Double & Value of Live-load. \\
\hline Nldstep & Integer & Number of Load Steps. \\
\hline \multicolumn{3}{|c|}{ Variable Declarations for Finding Element Number } \\
\hline Tfgrdi, tfgrdq, tfgrdj & Integer & Counters to run 'for' loops. \\
\hline Tfgrd & 2-d Array & Coordinates for node sets in displacement. \\
\hline Tfgrdincr1,tfgrdincr3 & Double & $\begin{array}{l}\text { Incremental values for coordinates of node set in } \\
\text { displacement. }\end{array}$ \\
\hline \multicolumn{3}{|c|}{ Variable Declaration for Constraints } \\
\hline Constr & 2-d Array & Directional Restraint at the Restrained Locations. \\
\hline Ncstr & Integer & Number of Constraints. \\
\hline Span_rent & Integer & Number of Spans. \\
\hline Spani & Integer & Counter Variable to run 'for' loop. \\
\hline Span & 1-d Array & Location of Pier supports. \\
\hline \multicolumn{3}{|c|}{ Variable Declaration for finding Deck Grid for Influence Surface } \\
\hline Dckgrdincr1, dckgrdincr3 & Double & Incremental values for specifying live-load generator. \\
\hline Dckgrdq, dckgrdi, dckgrdj & Integer & Counter Variables to run 'for' loops. \\
\hline Dckgrd & 2-d Array & Stores coordinates and Load values for Live-load. \\
\hline \multicolumn{3}{|c|}{ Variable Declaration for finding Node set for Deflections } \\
\hline Defl & 1-d Array & Node set for listing Deflection during analysis. \\
\hline Deflp & Integer & Number of nodes in the Deflection Node set. \\
\hline Deflbak & 3D Array & Element set for listing Deflection during analysis. \\
\hline Deflbakp & Integer & Number of elements in the Deflection Node set. \\
\hline
\end{tabular}




\begin{tabular}{|c|c|c|}
\hline \multicolumn{3}{|c|}{$\begin{array}{l}\text { Variable Declaration for finding elements on the web corresponding to girder moment } \\
\text { calculation }\end{array}$} \\
\hline $\begin{array}{l}\text { Webgrdi, webgrdq, webgrdj, } \\
\text { webgrdk }\end{array}$ & Integer & Counters to run 'for' loops. \\
\hline Webgrd & 2-d Array & Stores co-ordinates for Moment calculations. \\
\hline Webgrdincr1- webgrdincr3 & 1-d Array & Incremental values in web for moment calculations. \\
\hline Momwebele & 3D Array & $\begin{array}{l}\text { Element Numbers, nodes and co-ordinates for moment } \\
\text { calculation. }\end{array}$ \\
\hline \multicolumn{3}{|c|}{ Variable Declaration for Calculation of Element set for Shear } \\
\hline Botfgrd & 2-d Array & Stores co-ordinates for shear calculations. \\
\hline Elshear & 2-d Array & $\begin{array}{l}\text { Element Numbers and co-ordinates for shear } \\
\text { calculations. }\end{array}$ \\
\hline Botfgrdincr1-botfgrdincr3 & Double & Incremental values for shear calculations. \\
\hline $\begin{array}{l}\text { Botfgrdq, botfgrdi, botfgrdj, } \\
\text { botfgrdk }\end{array}$ & Integer & Counters to run 'for' loops. \\
\hline
\end{tabular}




\section{APPENDIX - B : \\ INFLUENCE SURFACE PLOTS FOR FHWA BRIDGE}




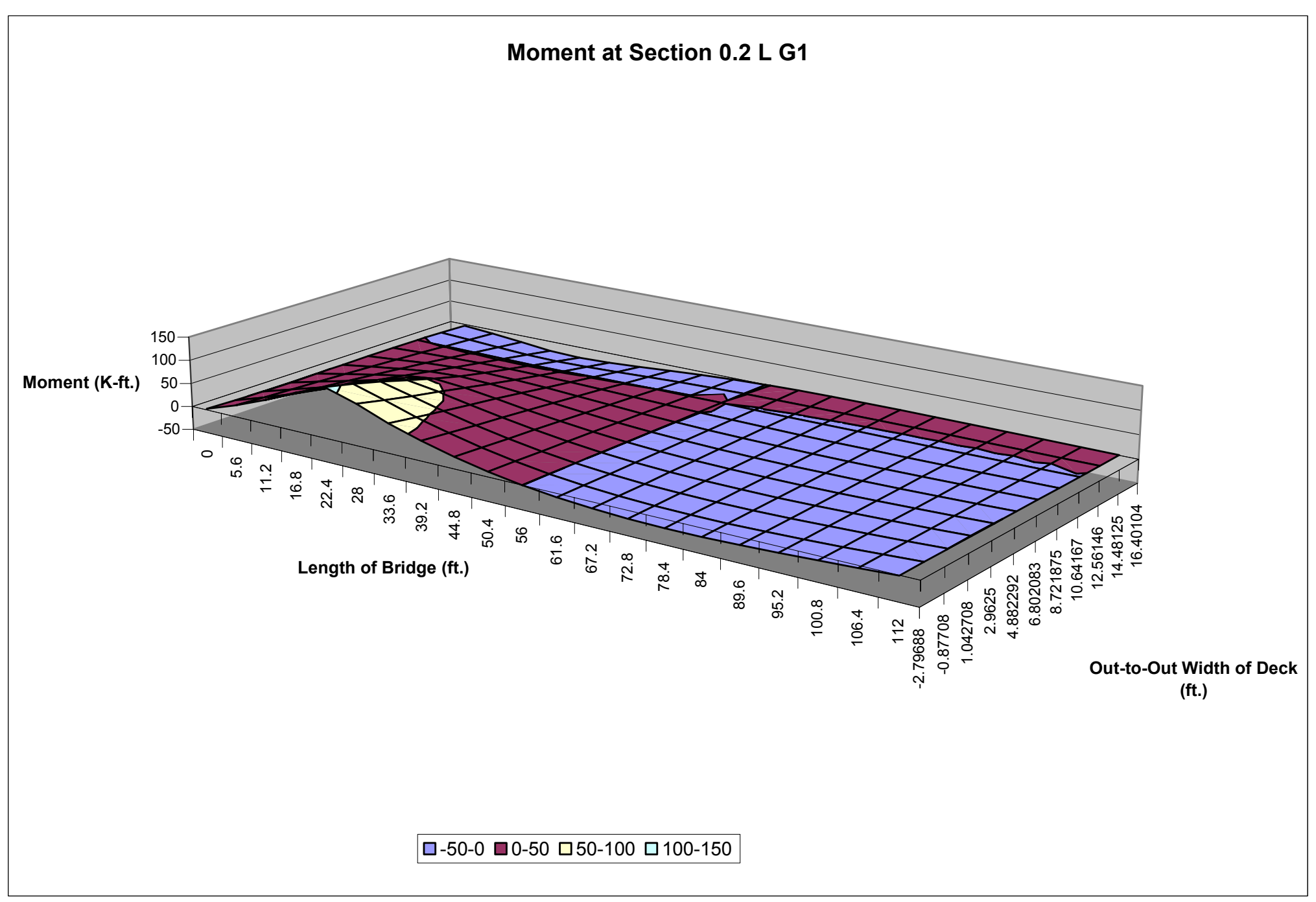

Figure B.1 Influence Surface for Moment at Section 0.2 L G1 


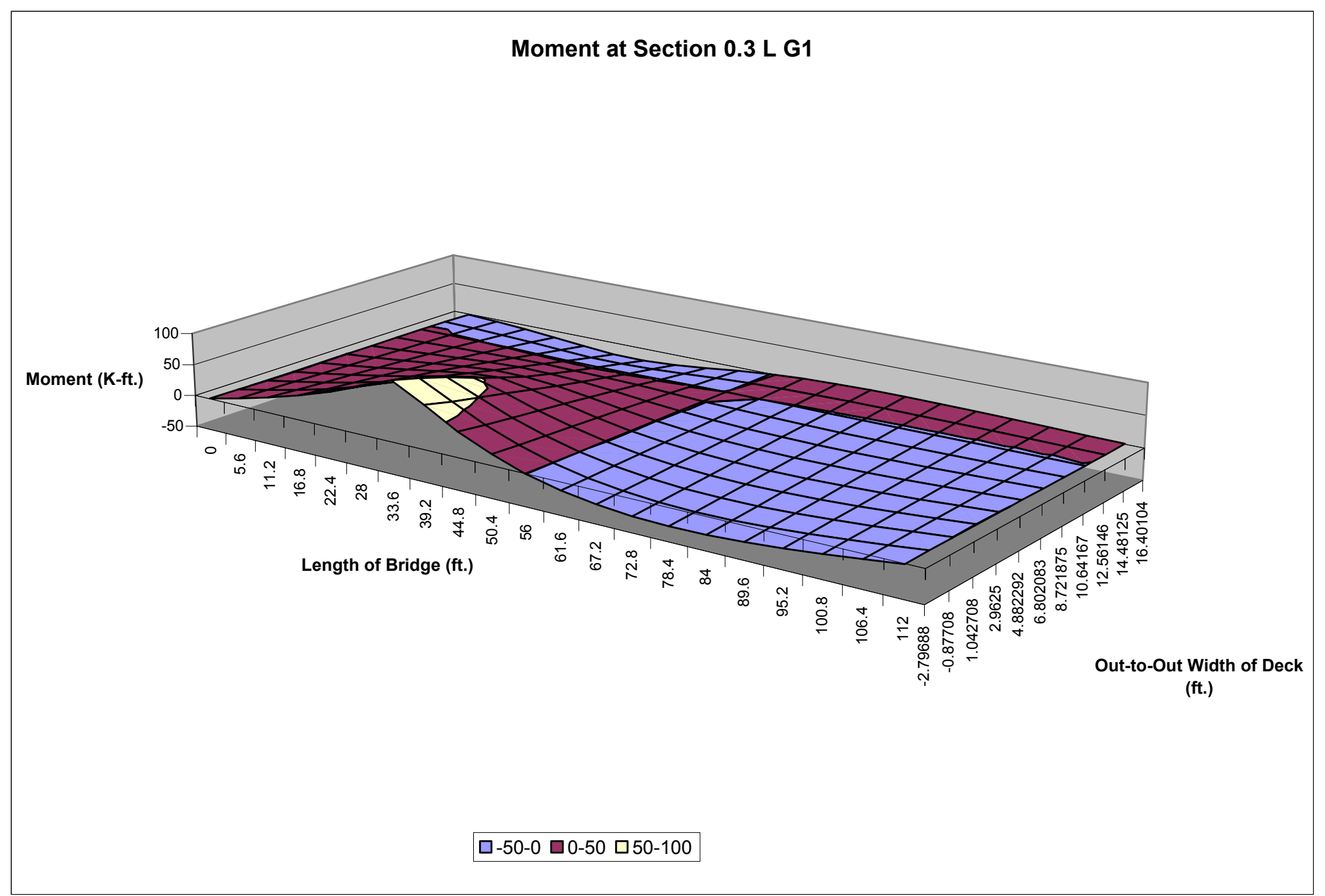

Figure B.2 Influence Surface for Moment at Section 0.3 L G1 


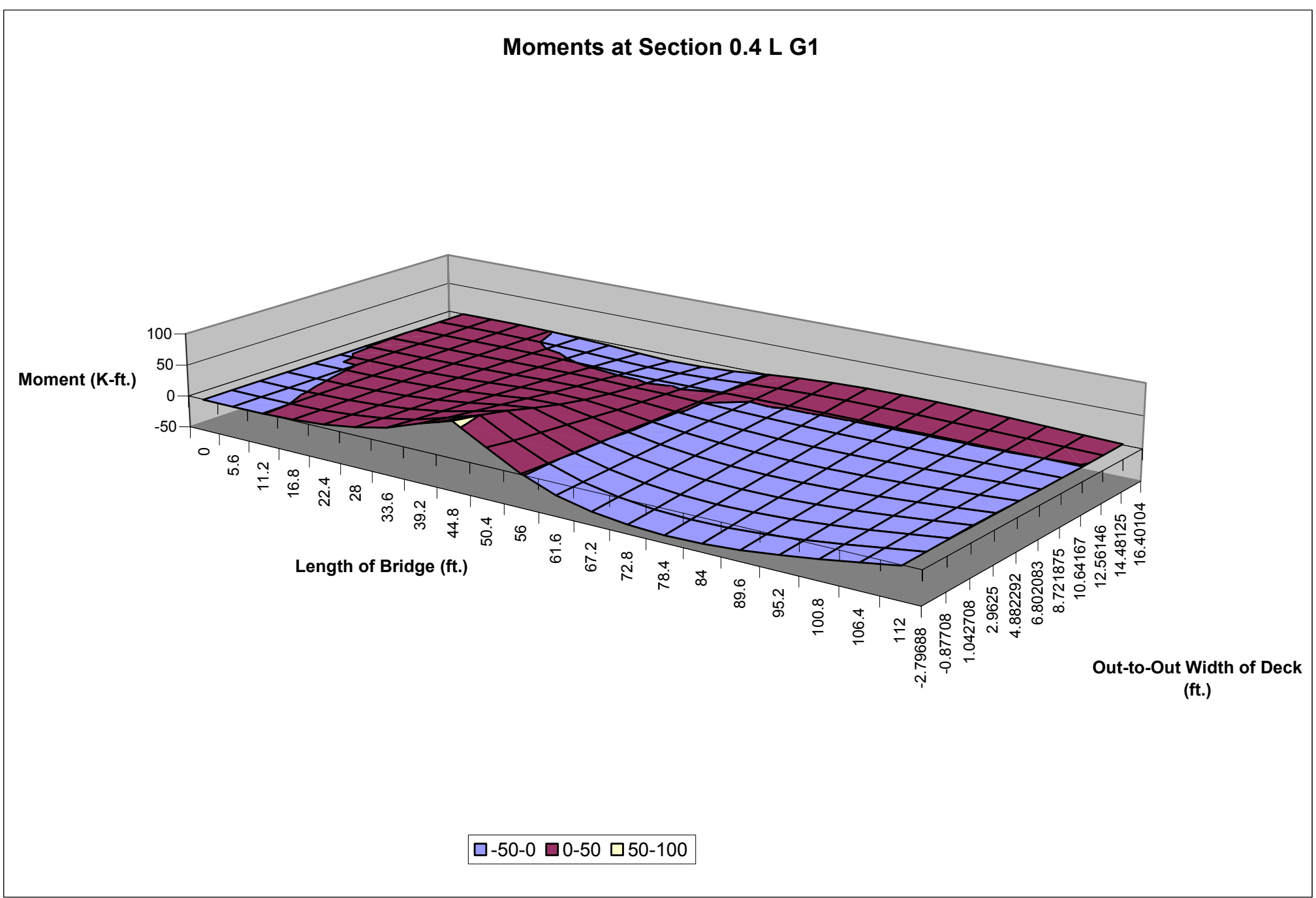

Figure B.3 Influence Surface for Moment at Section 0.4 L G1 


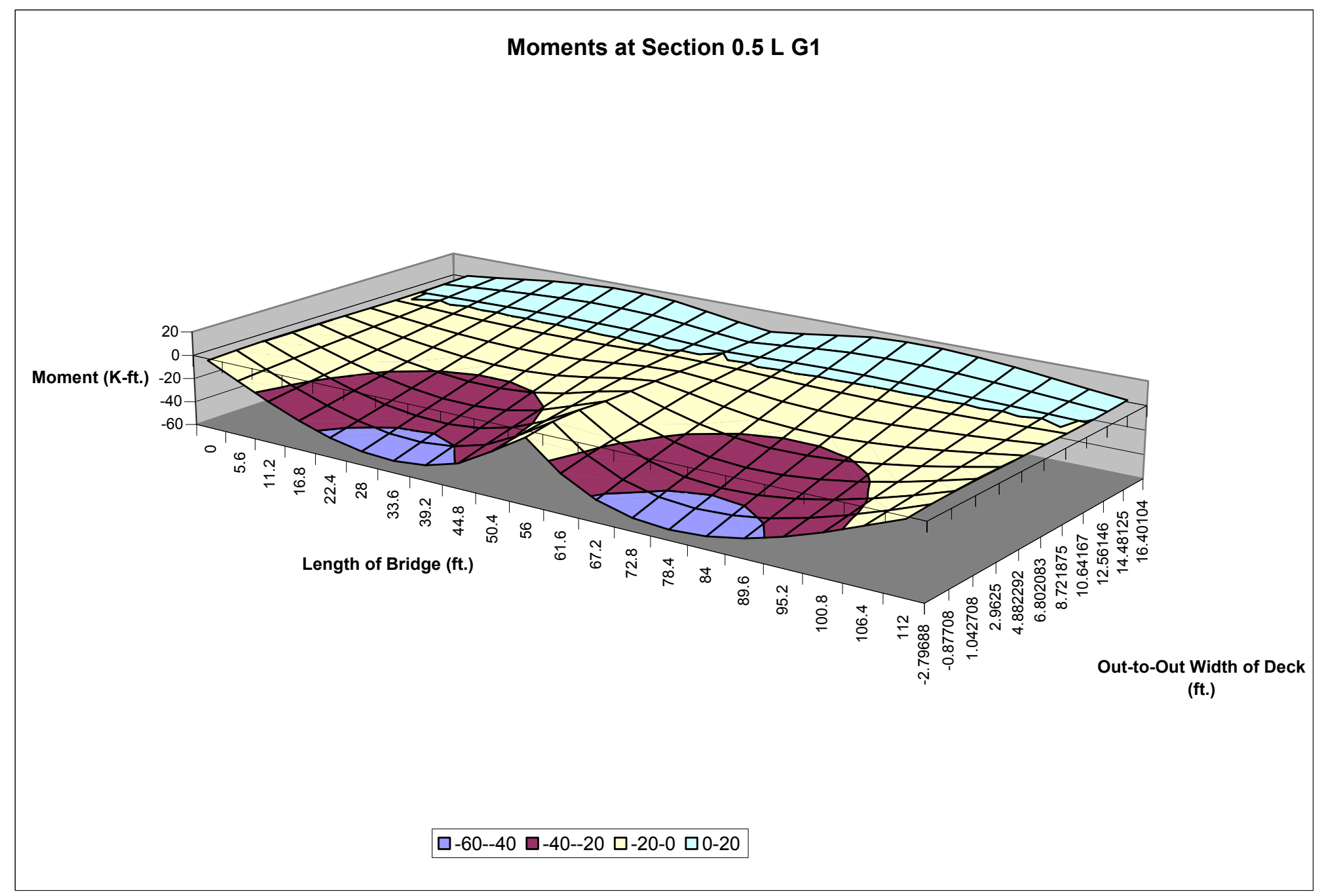

Figure B.4 Influence Surface for Moment at Section 0.5 L G1 


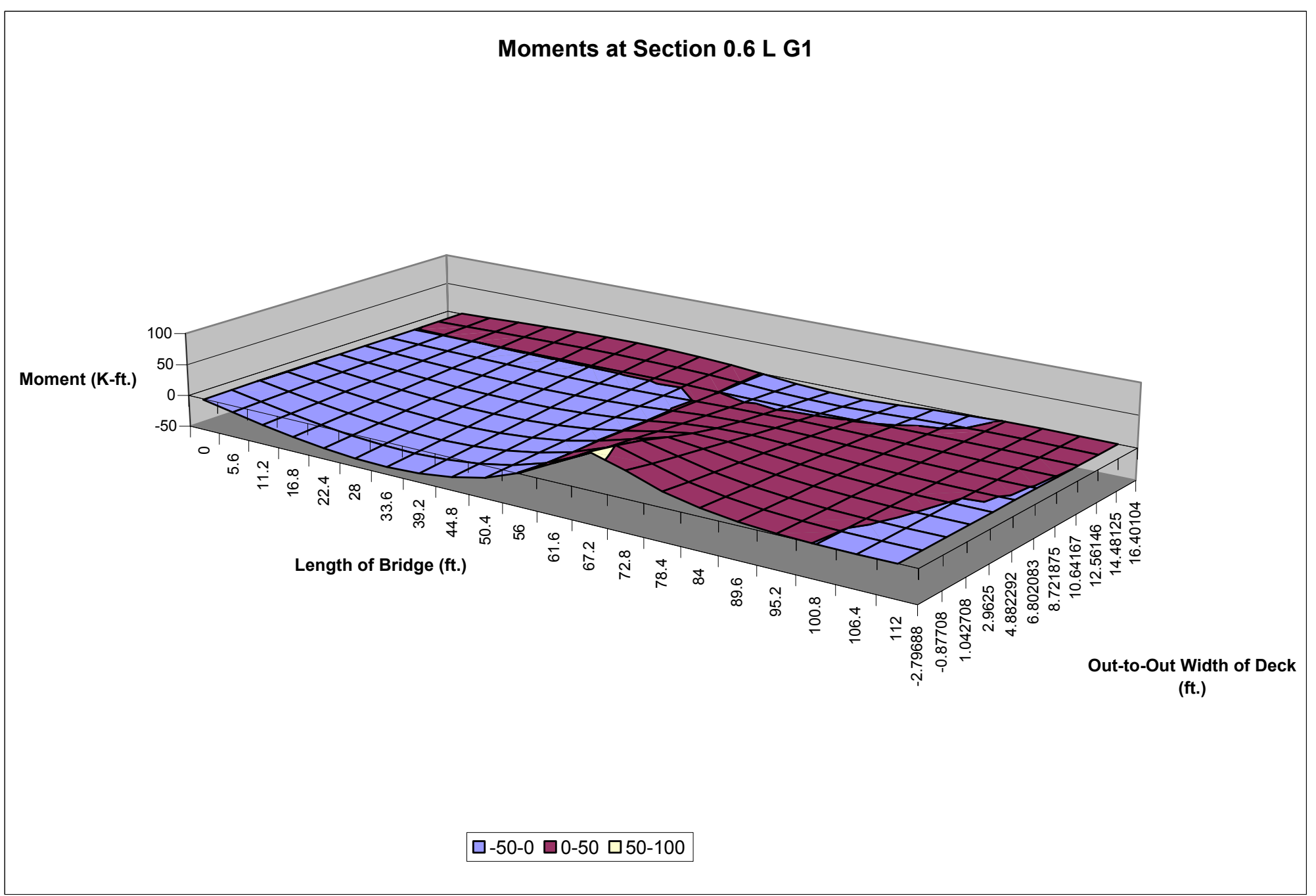

Figure B.5 Influence Surface for Moment at Section 0.6 L G1 


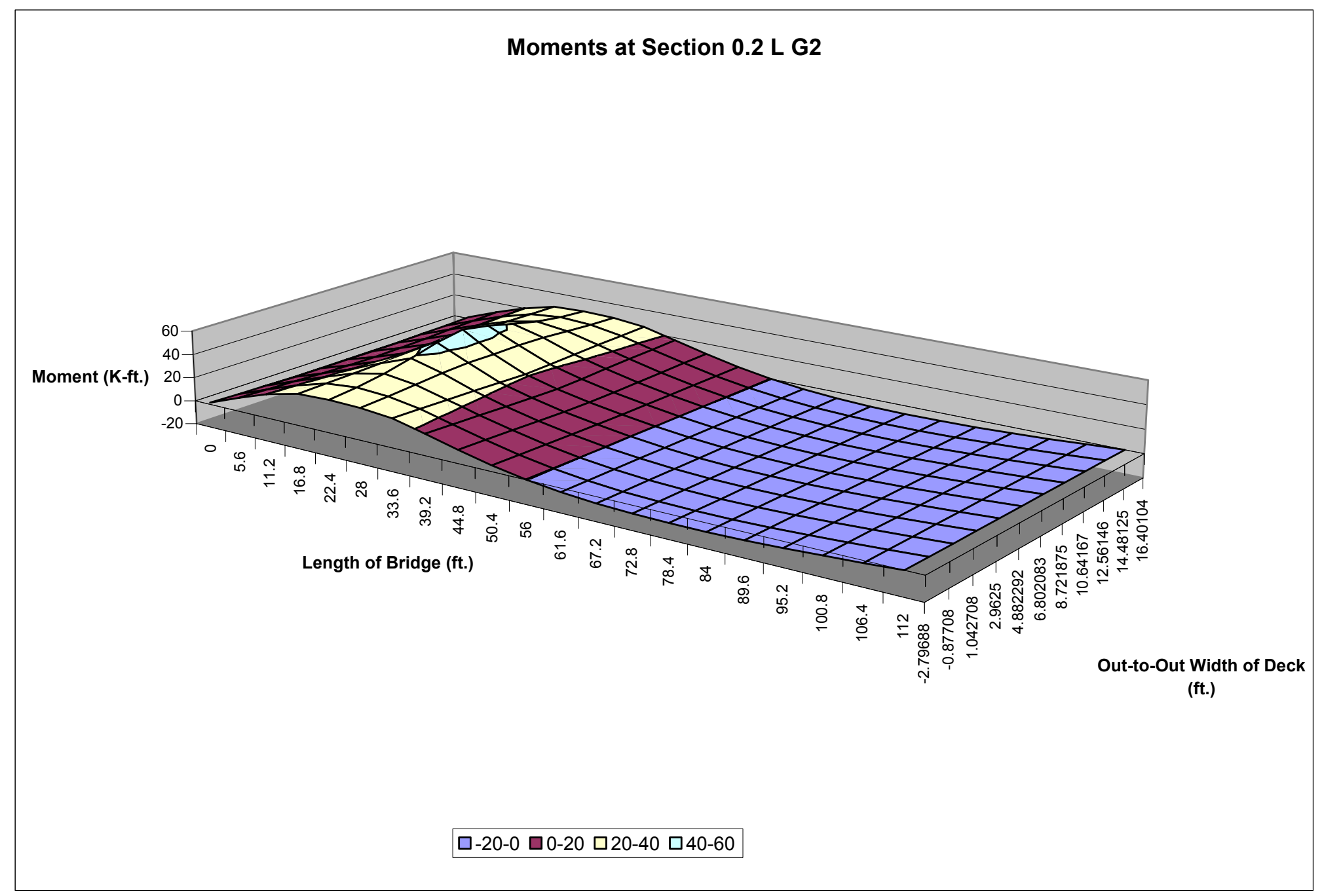

Figure B.6 Influence Surface for Moment at Section 0.2 L G2 


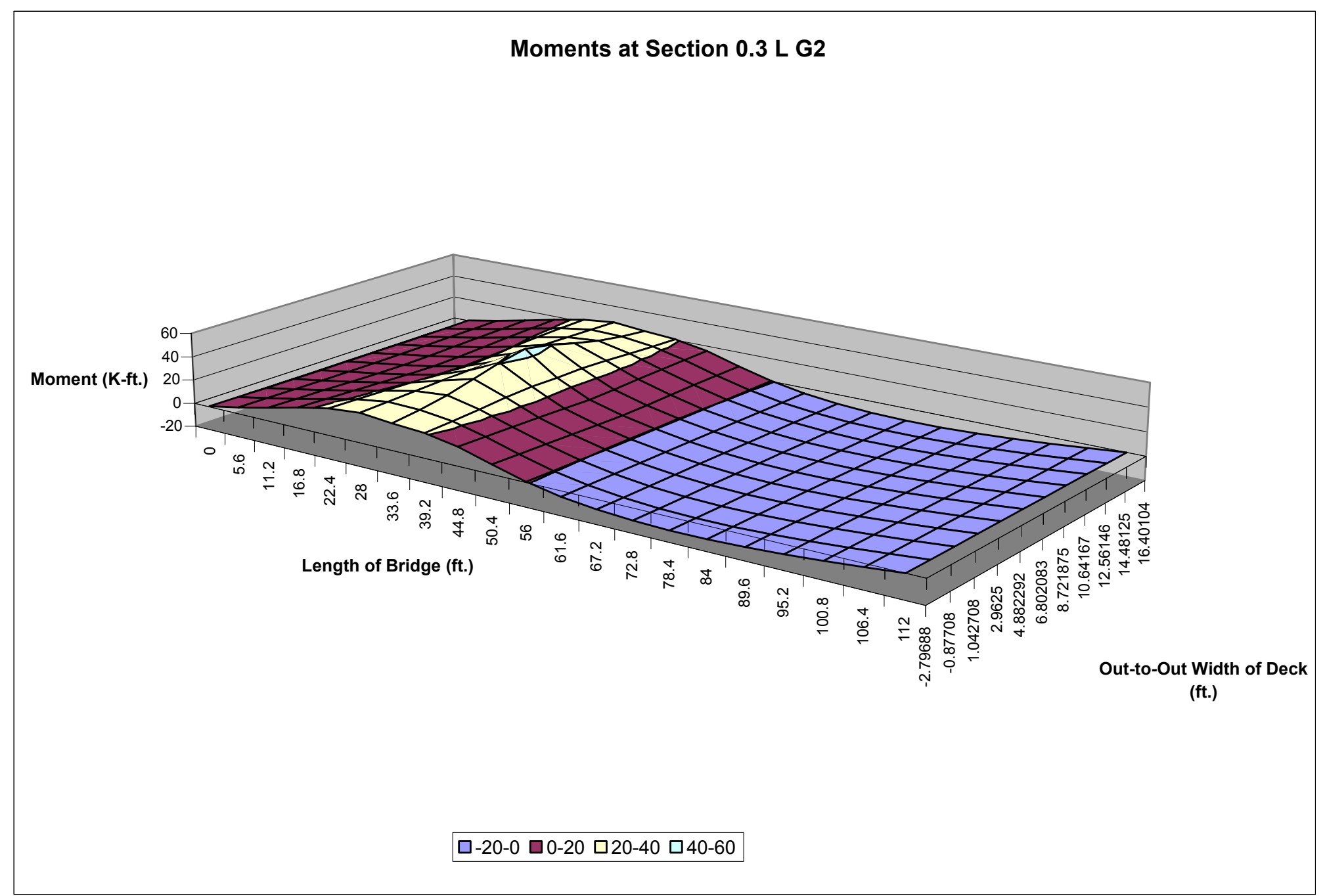

Figure B.7 Influence Surface for Moment at Section 0.3 L G2 


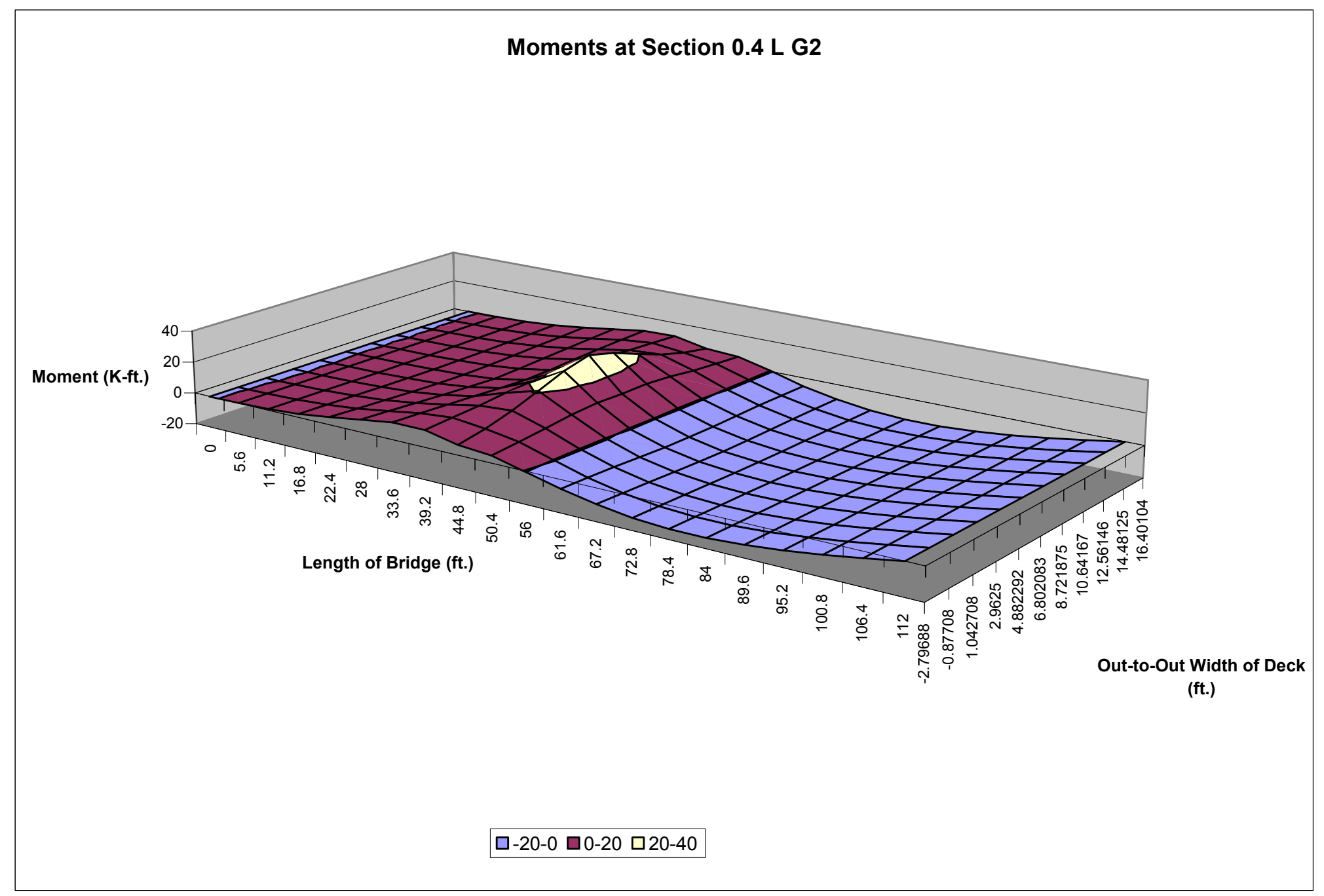

Figure B.8 Influence Surface for Moment at Section 0.4 L G2 


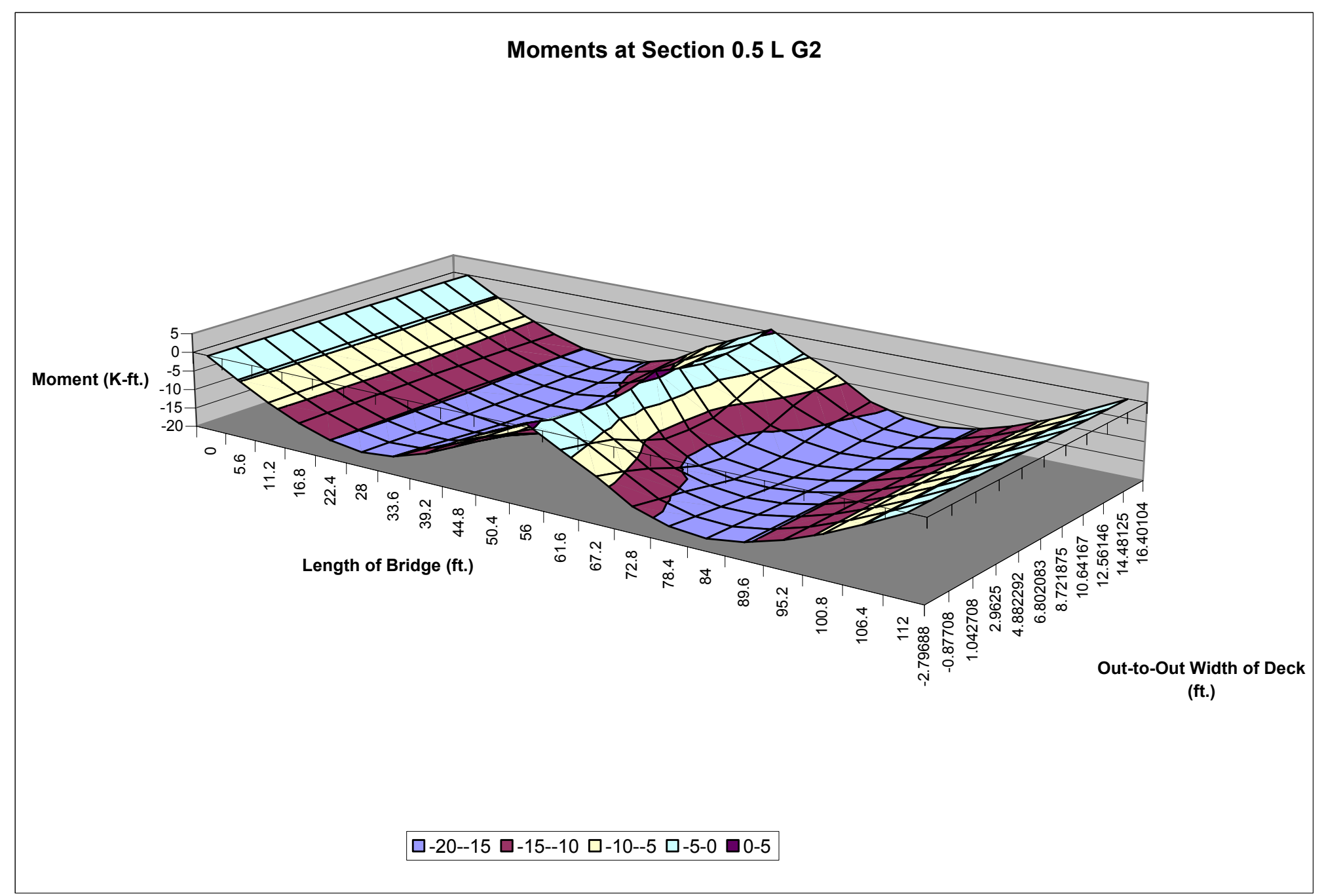

Figure B.9 Influence Surface for Moment at Section 0.5 L G2 


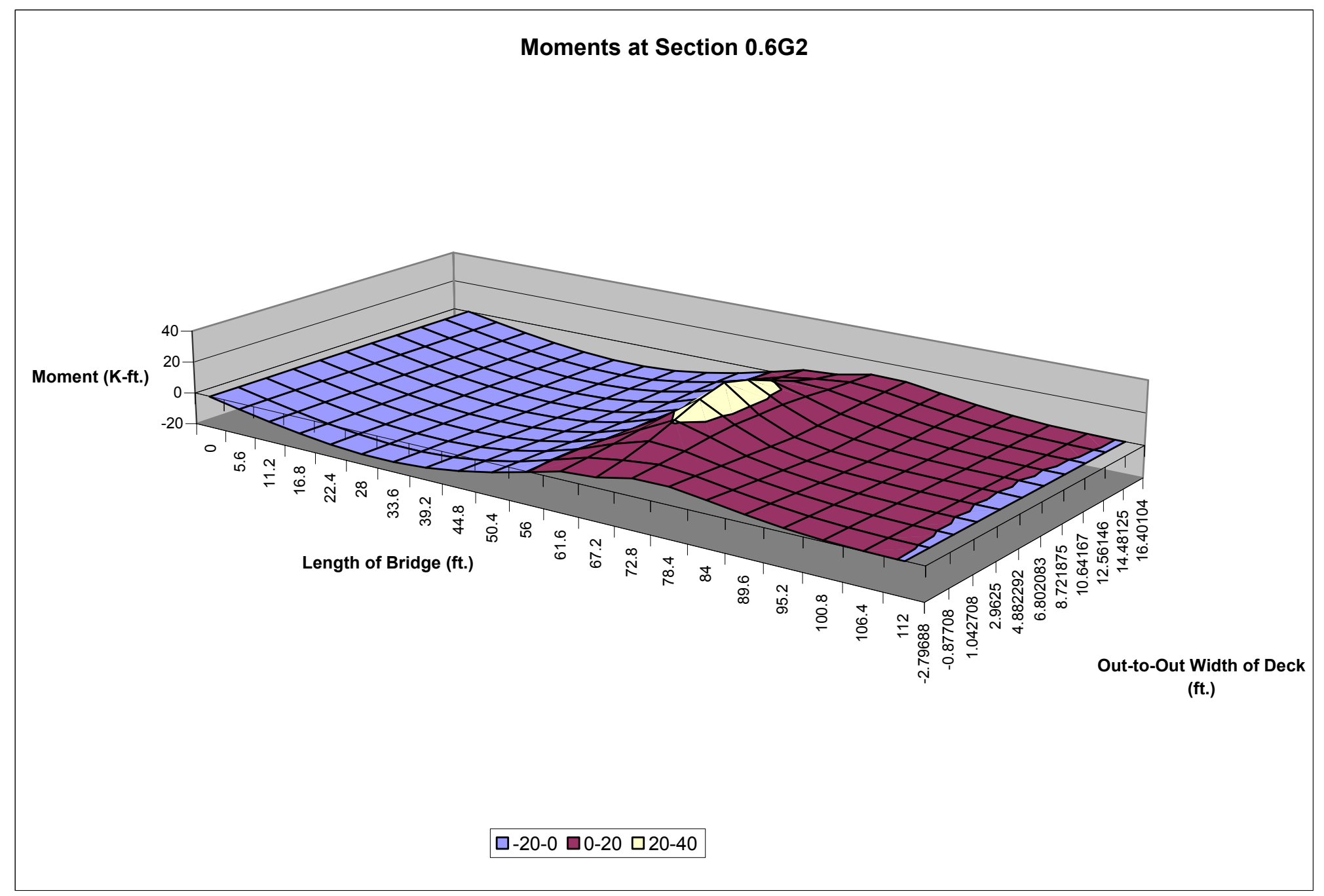

Figure B.10 Influence Surface for Moment at Section 0.6 L G2 


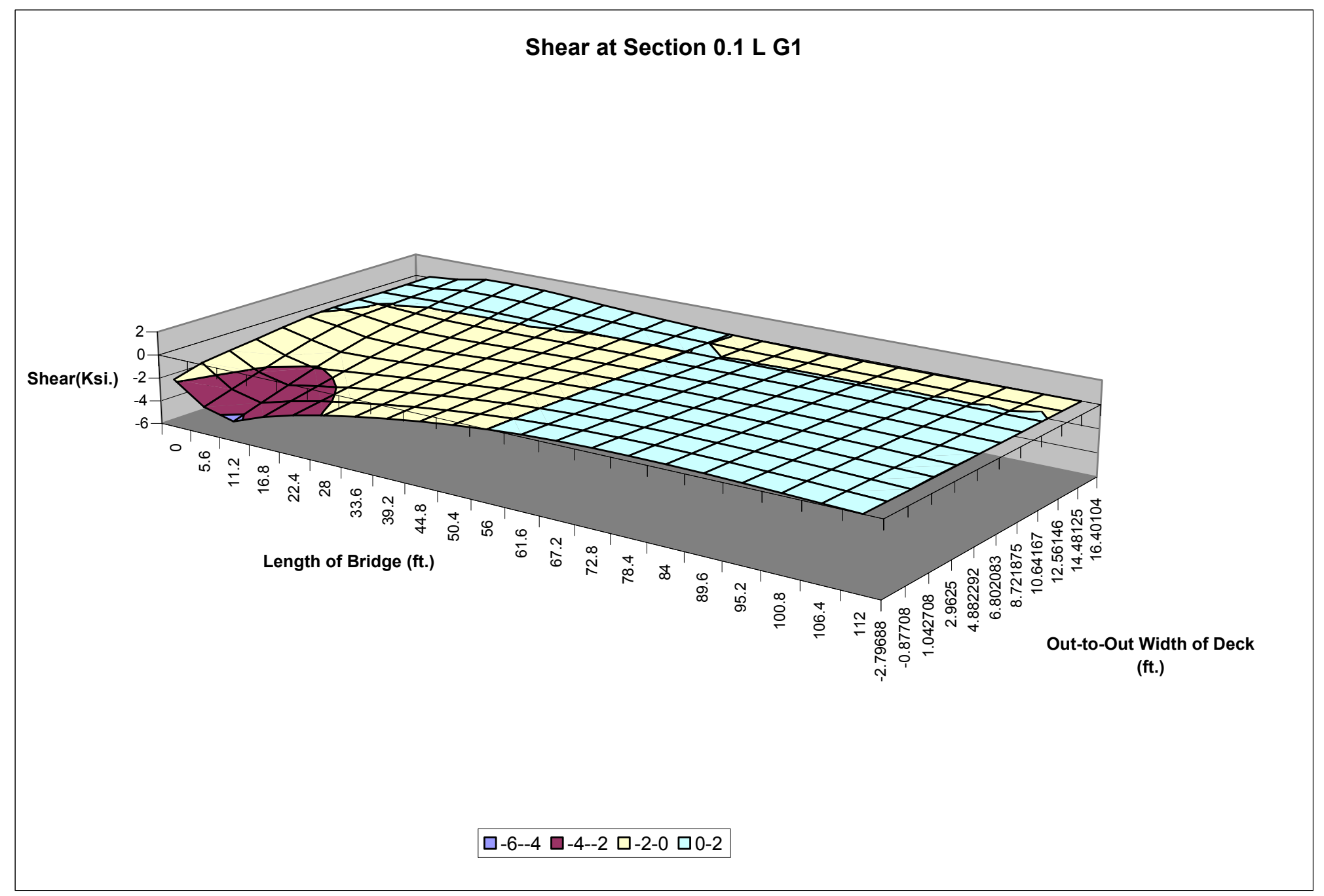

Figure B.11 Influence Surface for Shear at 0.1 L G1 


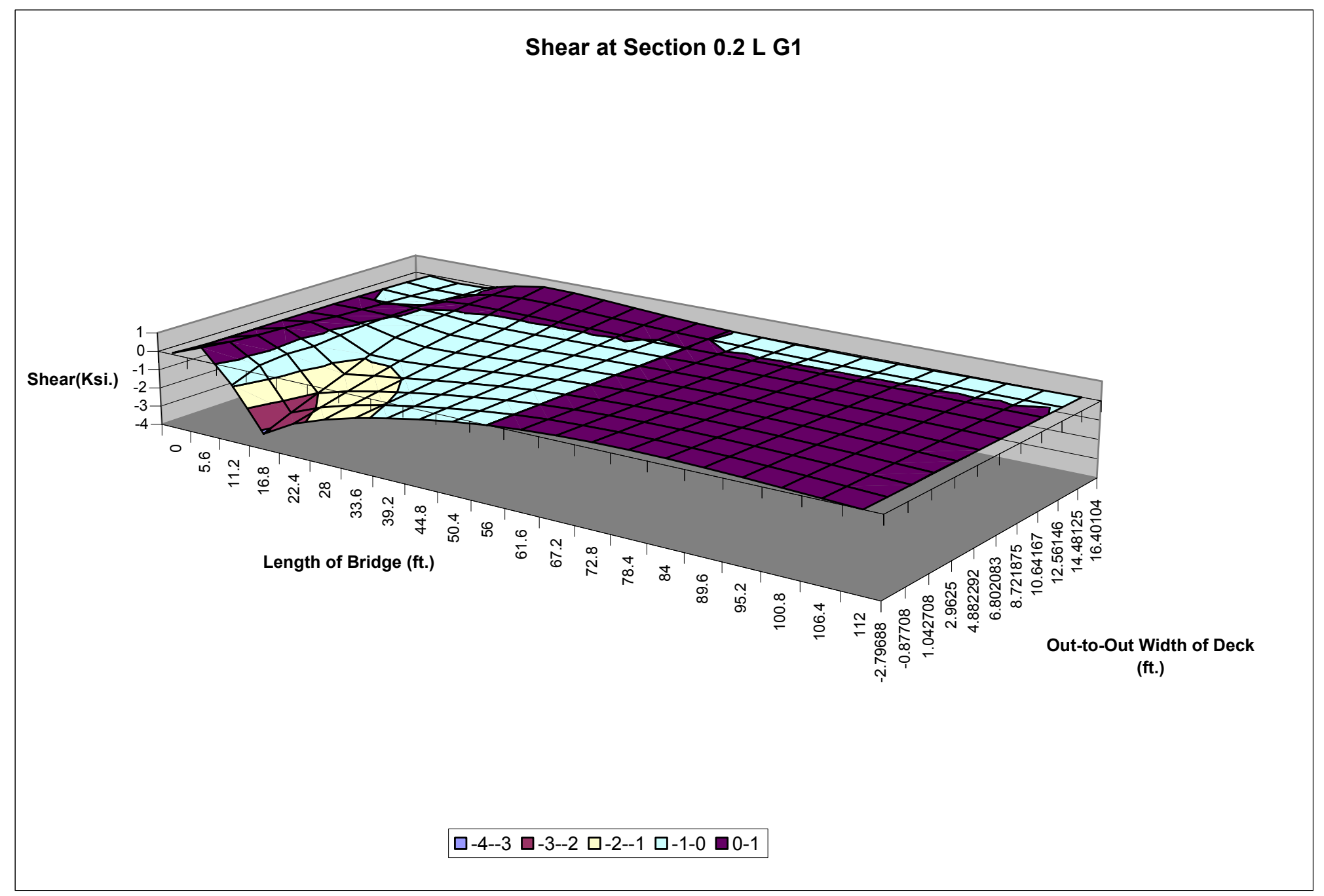

Figure B.12 Influence Surface for Shear at 0.2 L G1 


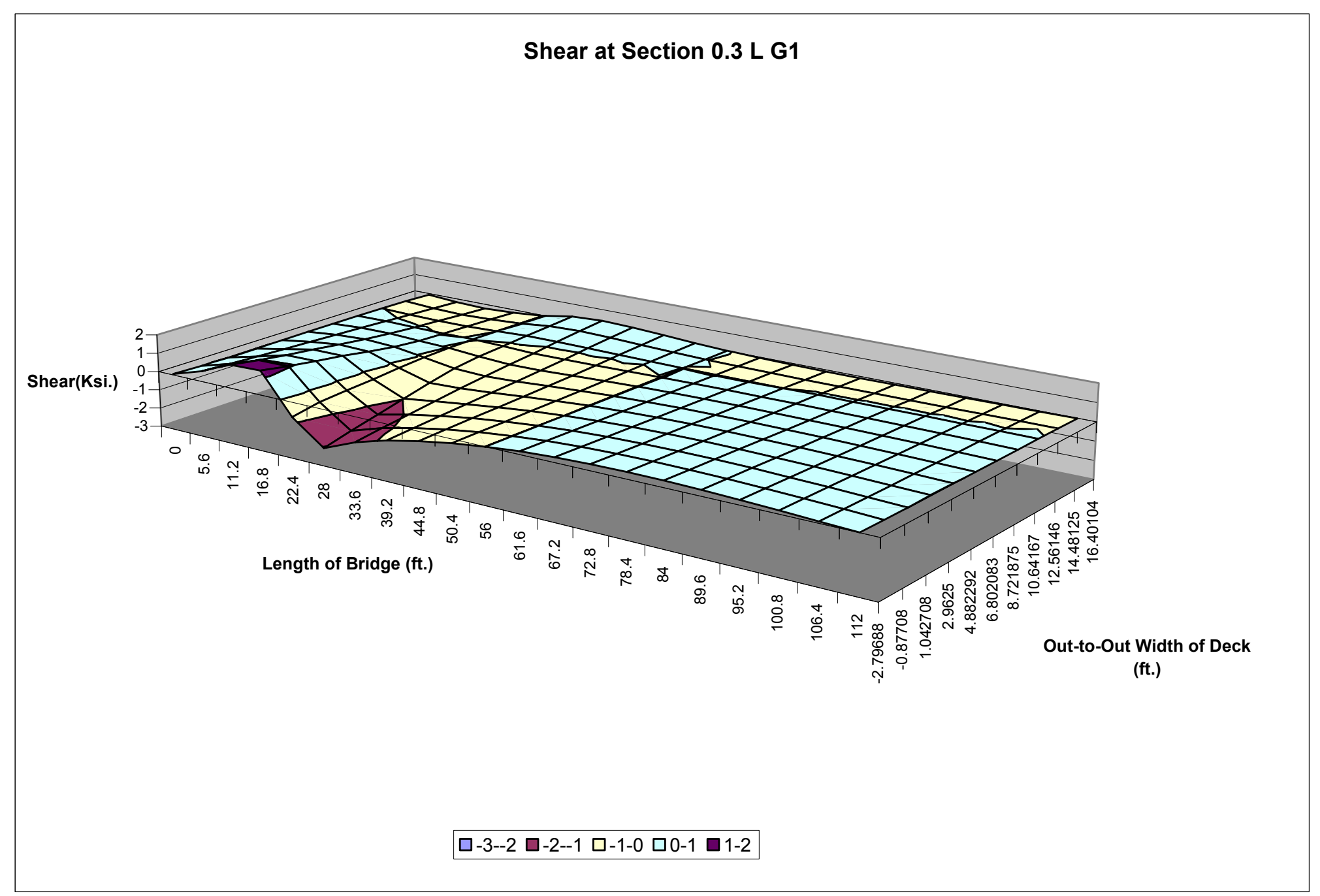

Figure B.13 Influence Surface for Shear at 0.3 L G1 


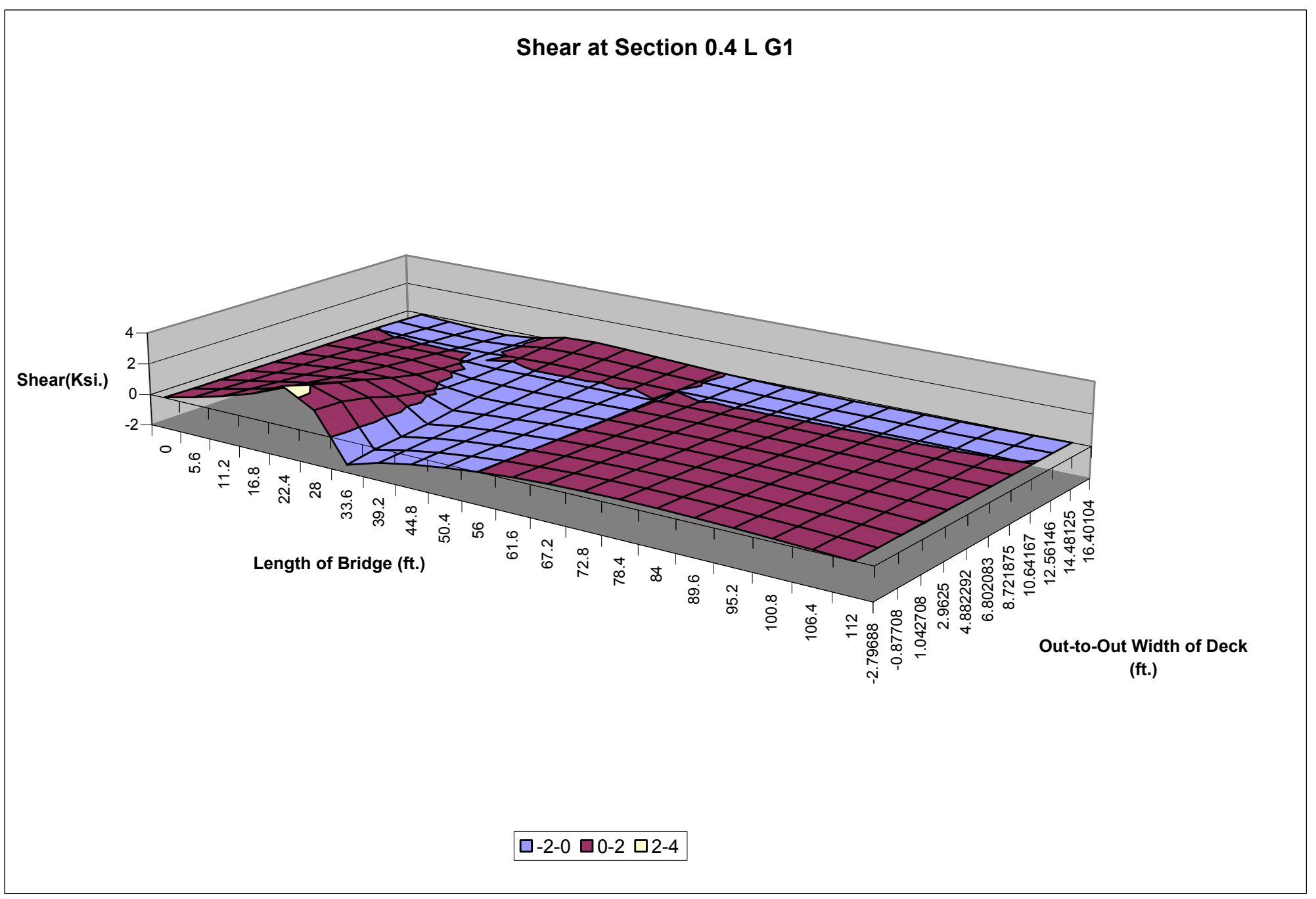

Figure B.14 Influence Surface for Shear at 0.4 L G1 


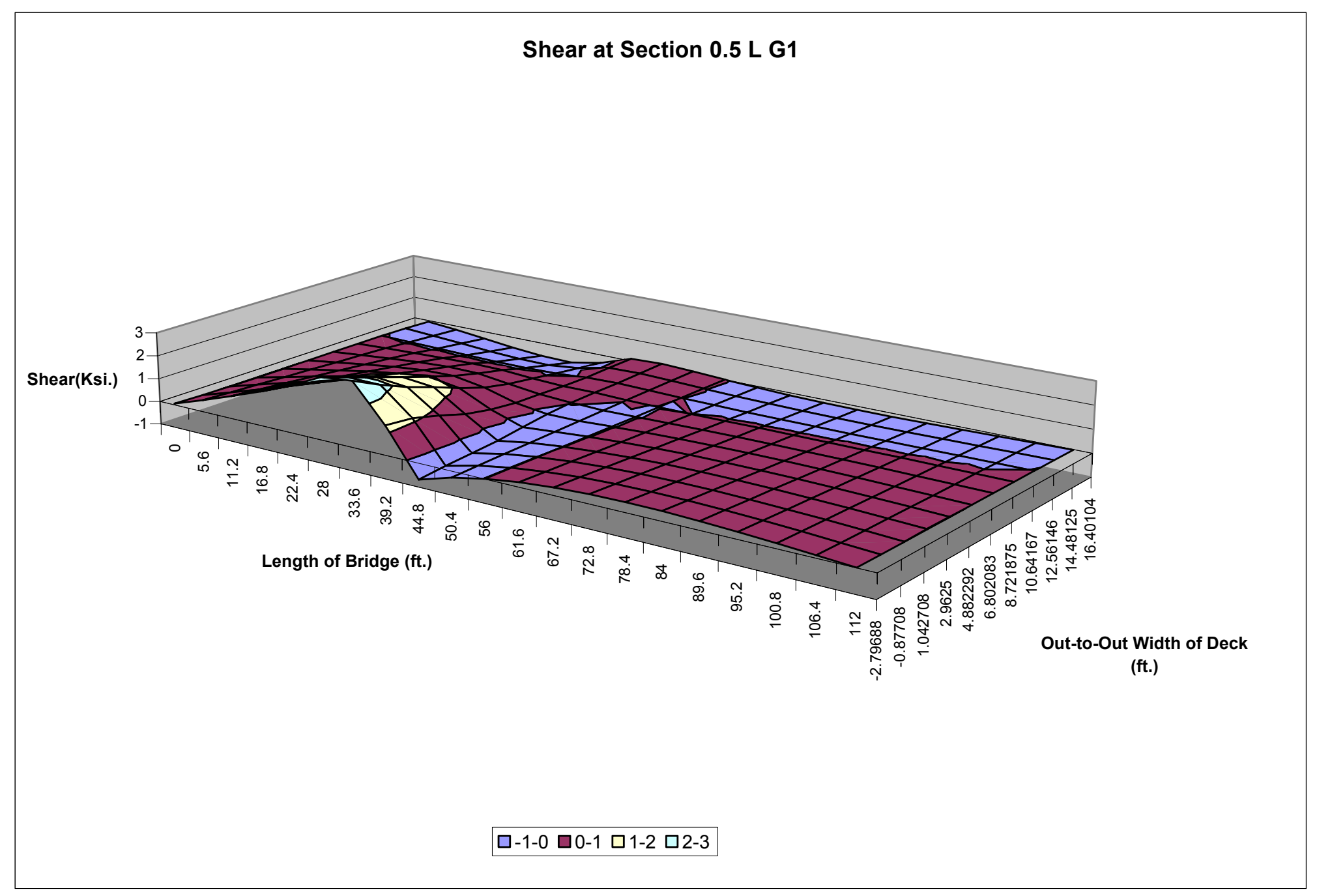

Figure B.15 Influence Surface for Shear at 0.5 L G1 


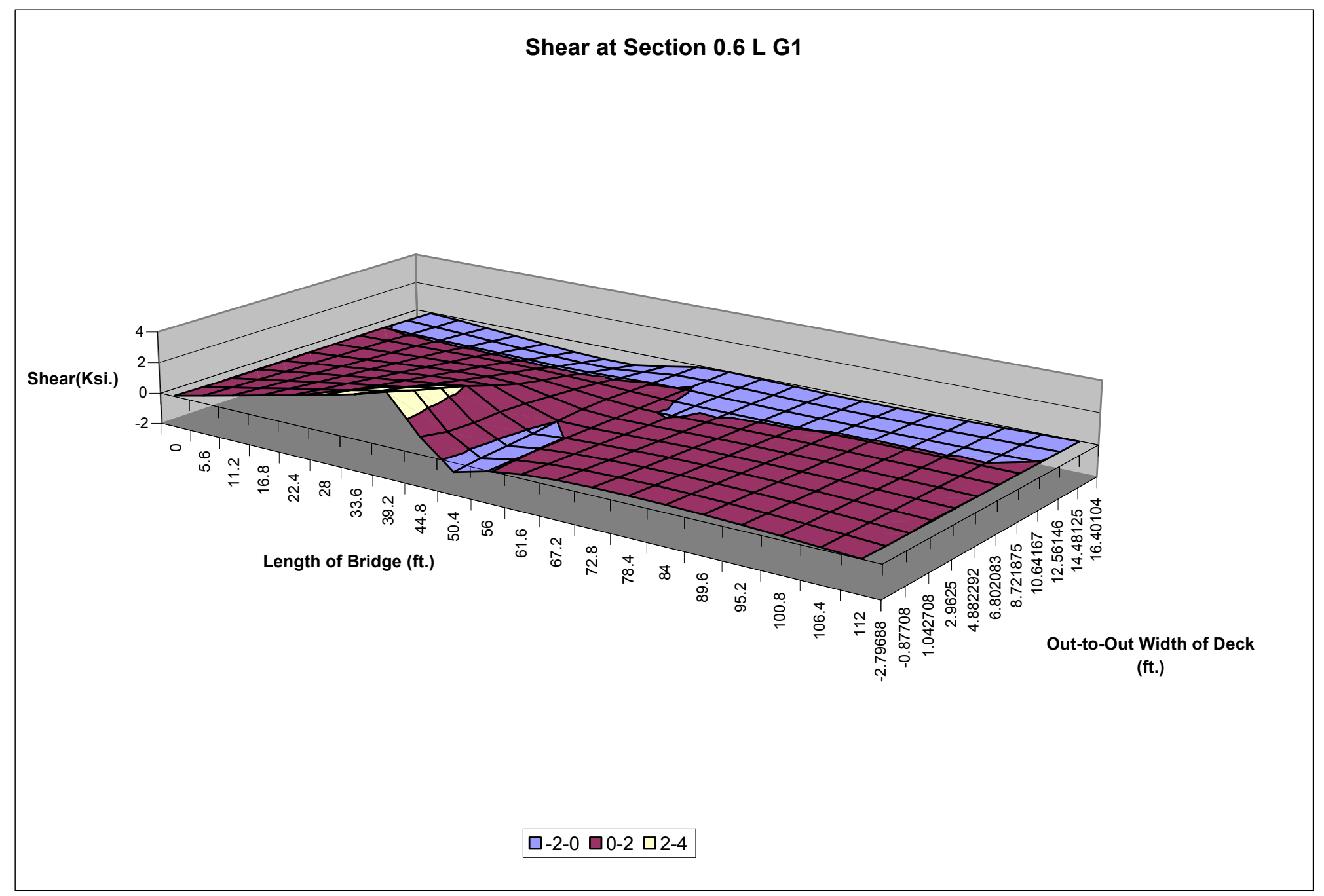

Figure B.16 Influence Surface for Shear at 0.6 L G1 


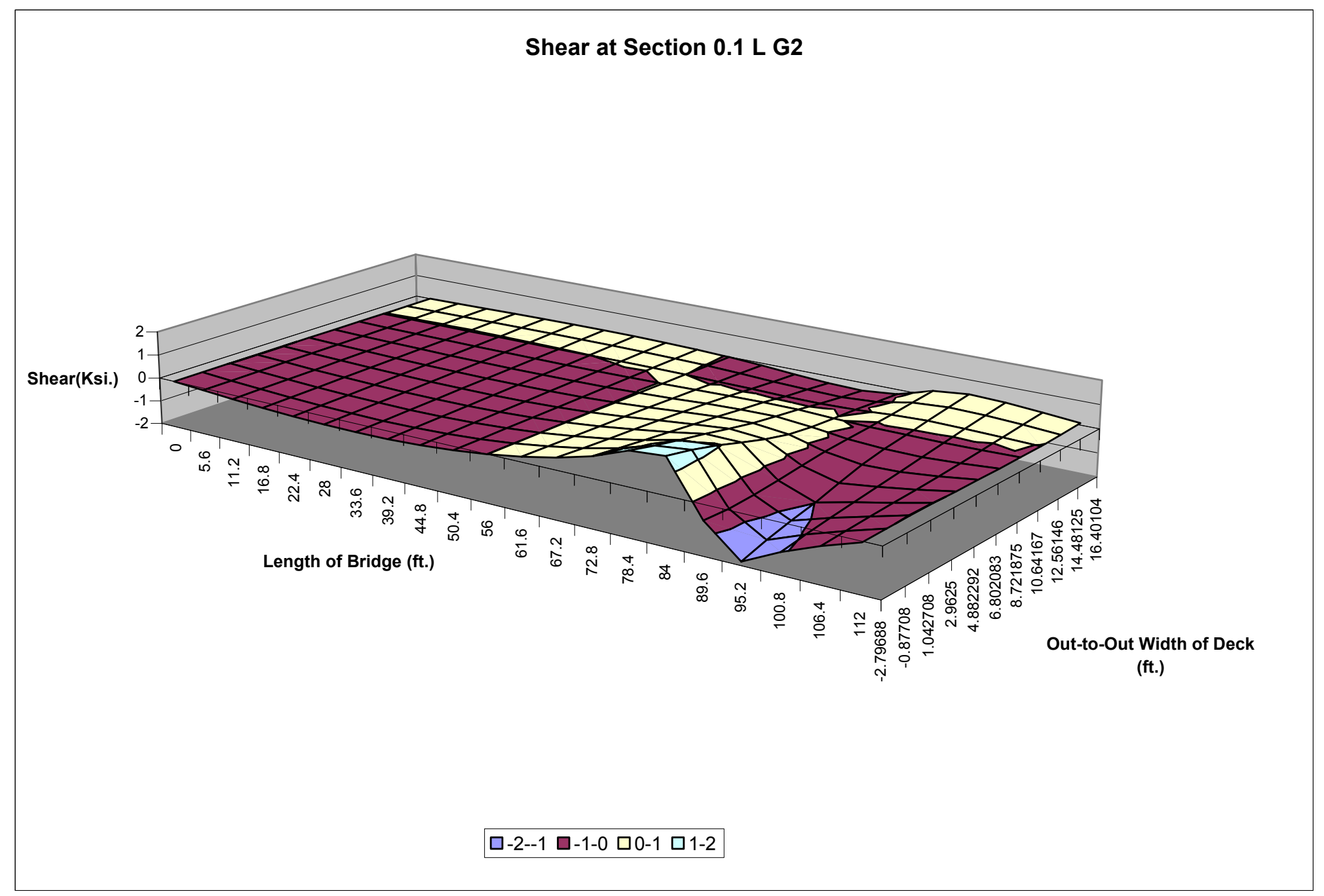

Figure B.17 Influence Surface for Shear at 0.1 L G2 


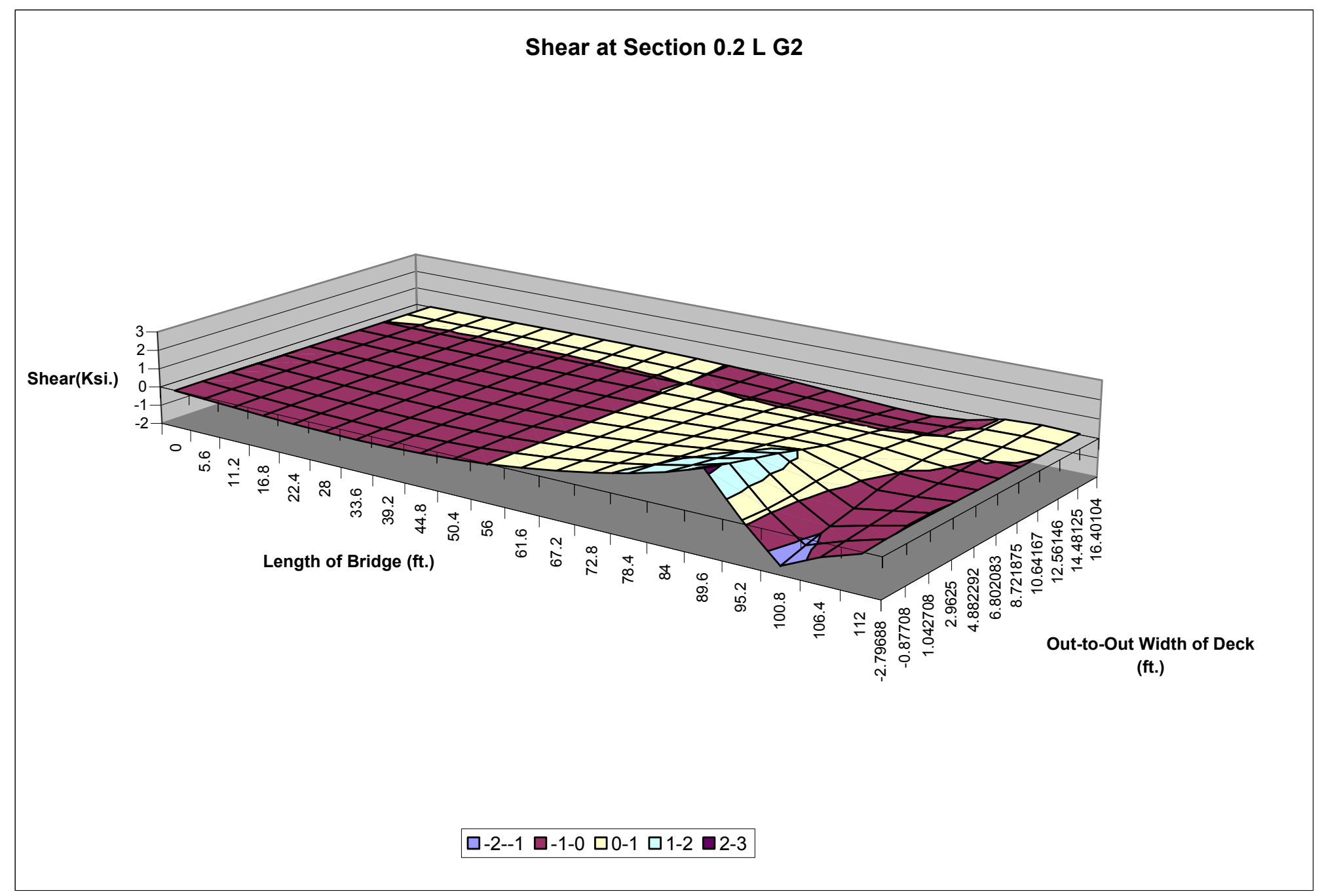

Figure B.18 Influence Surface for Shear at 0.2 L G2 


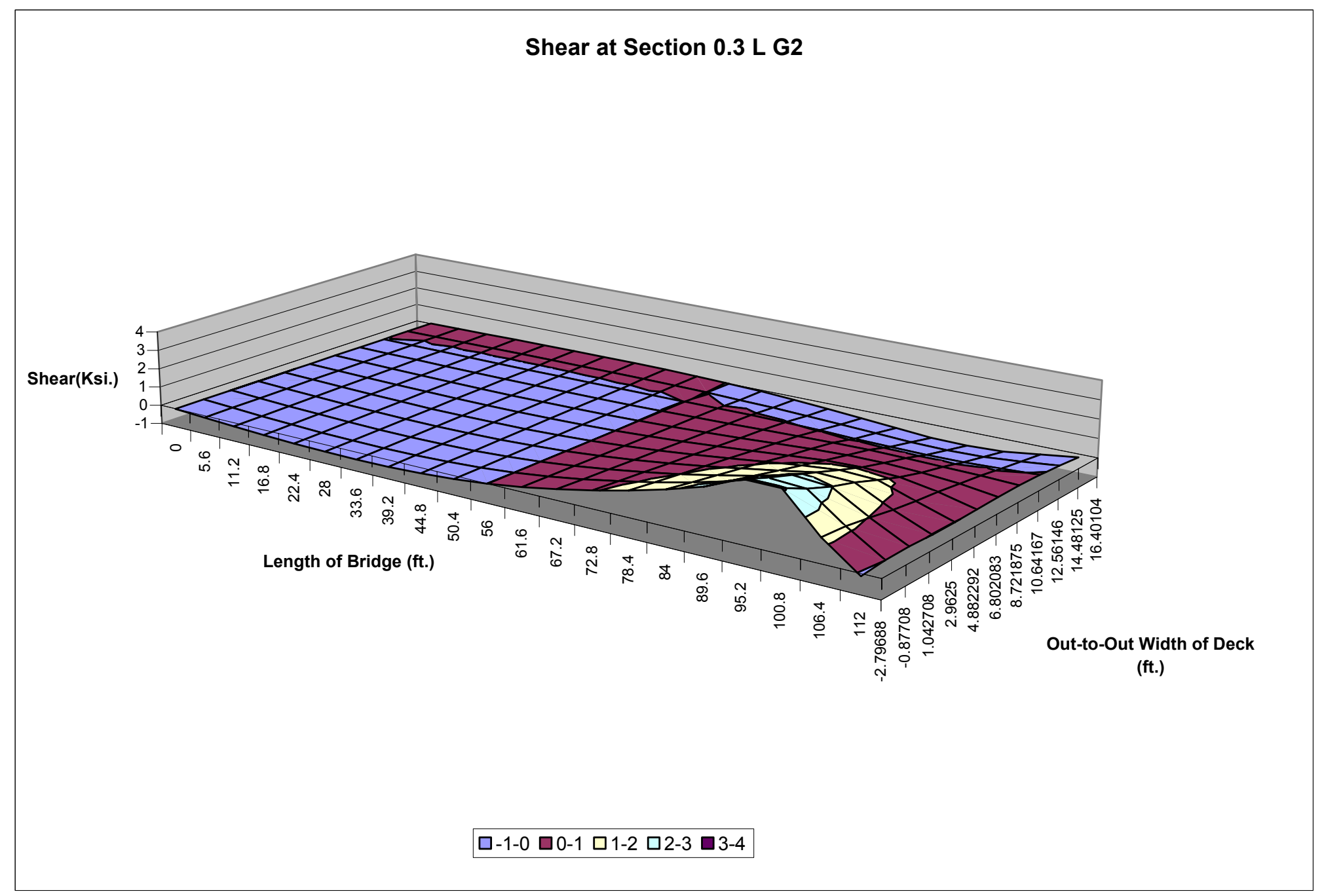

Figure B.19 Influence Surface for Shear at 0.3 L G2 


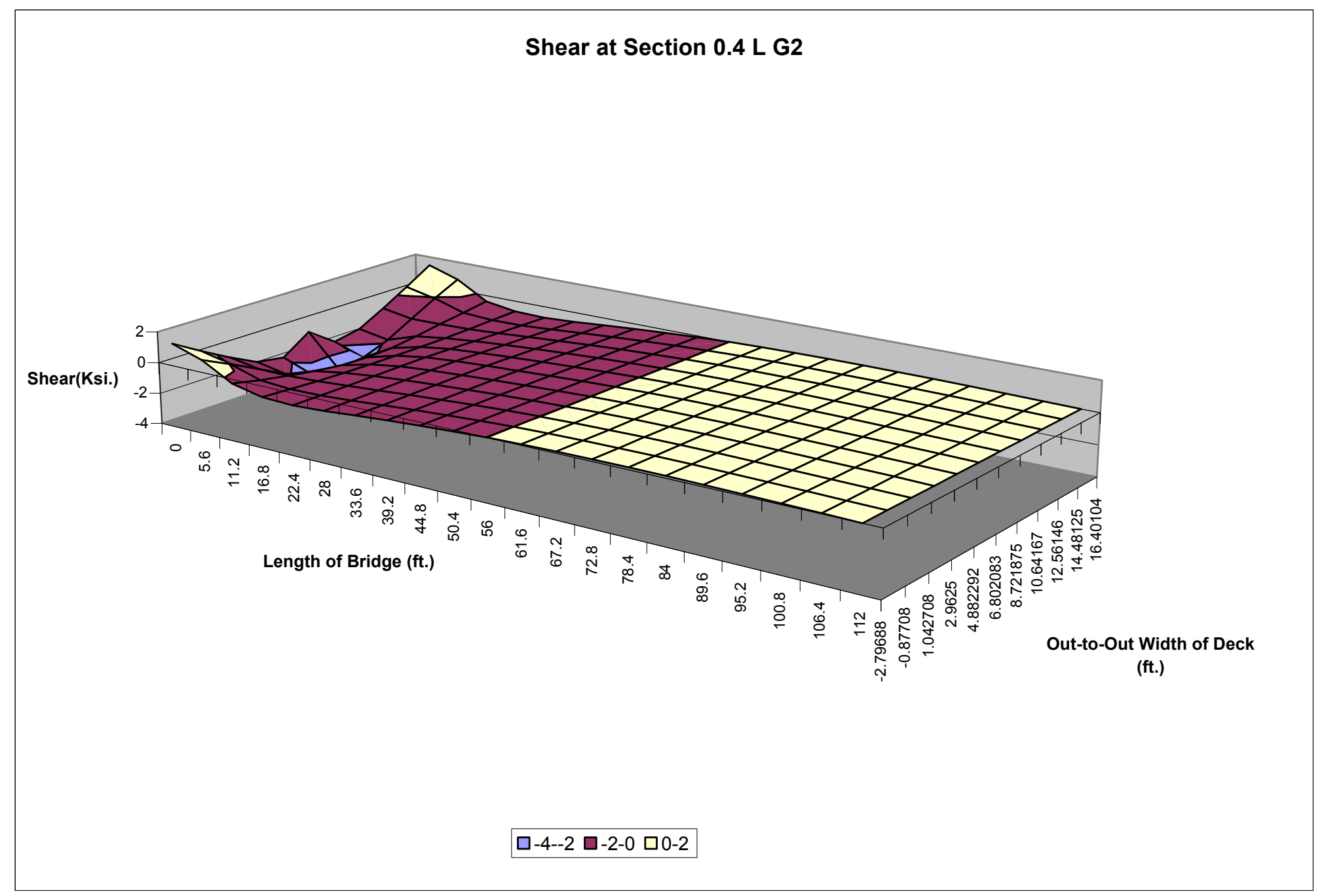

Figure B.20 Influence Surface for Shear at 0.4 L G2 


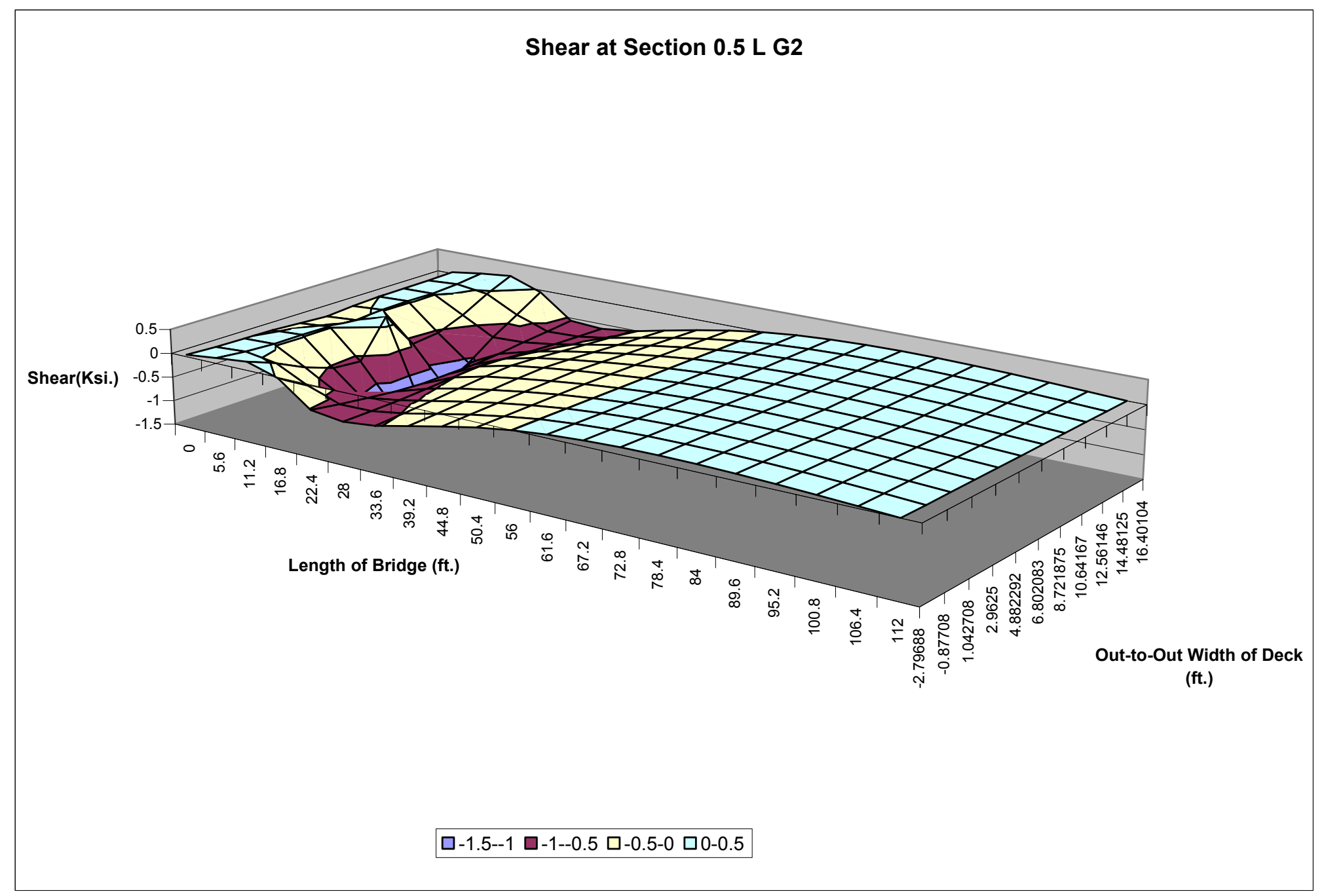

Figure B.21 Influence Surface for Shear at 0.5 L G2 


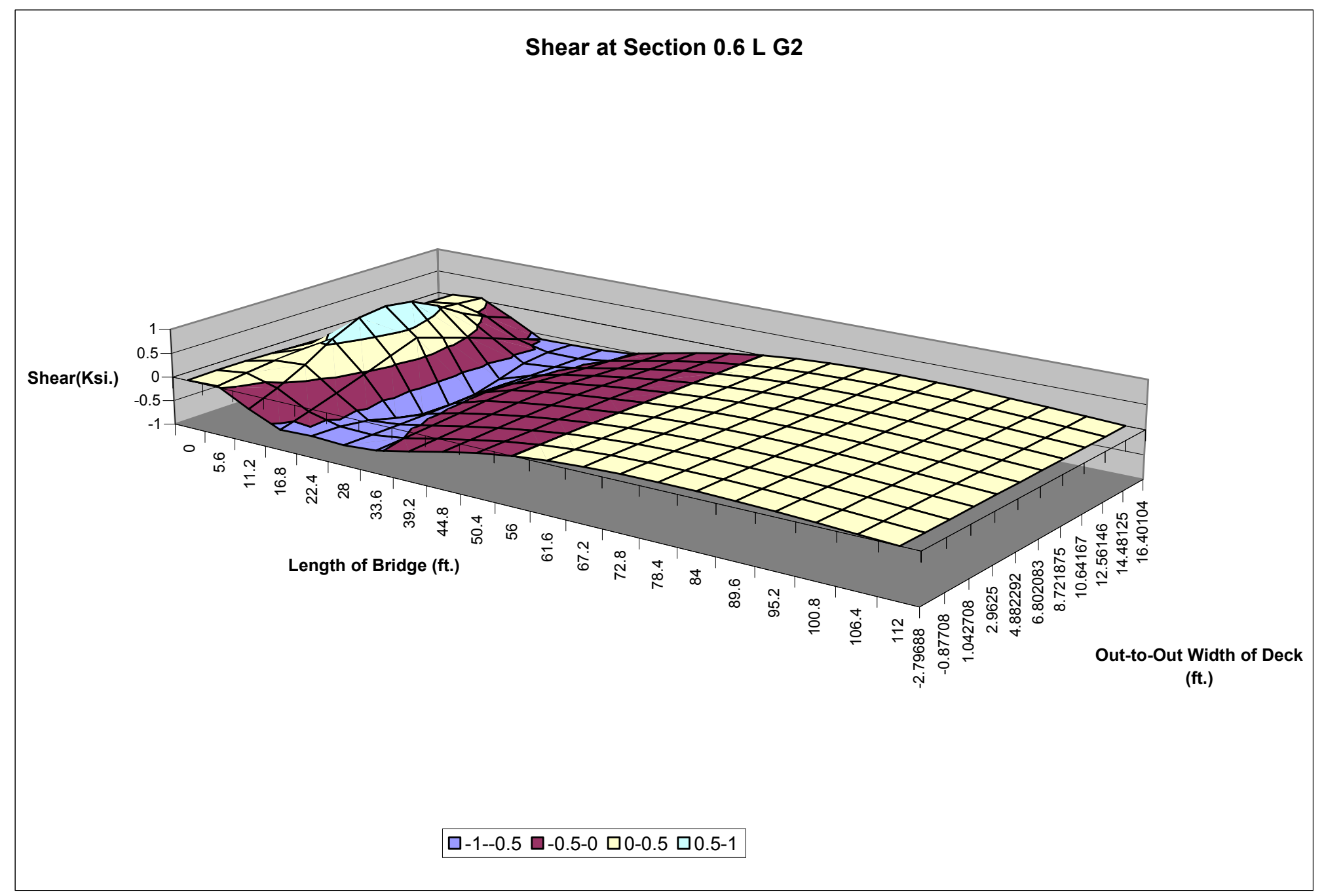

Figure B.22 Influence Surface for Shear at 0.6 L G2 


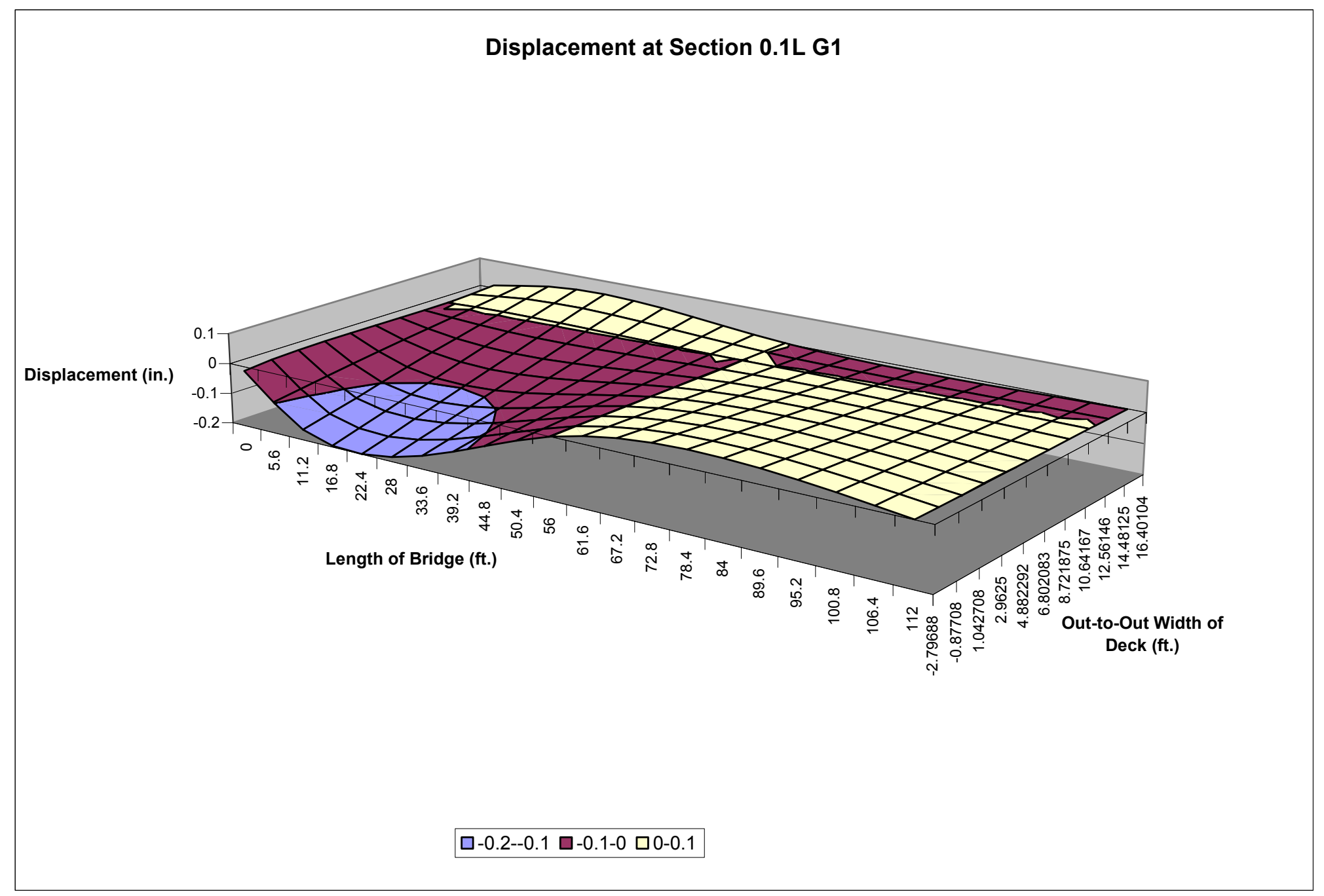

Figure B.23 Influence Surface for Deflection at Section 0.1 L G1 


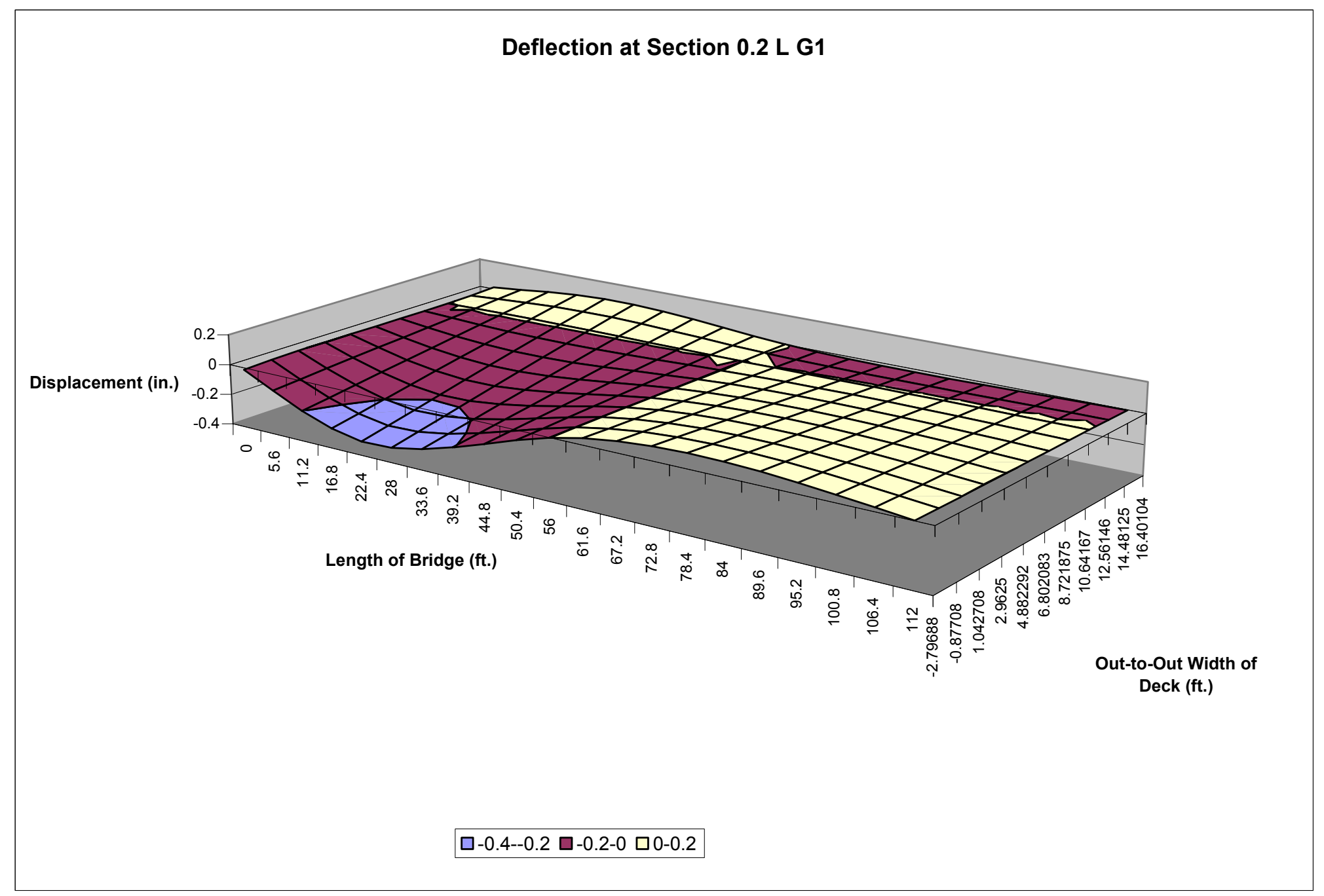

Figure B.24 Influence Surface for Deflection at Section 0.2 L G1 


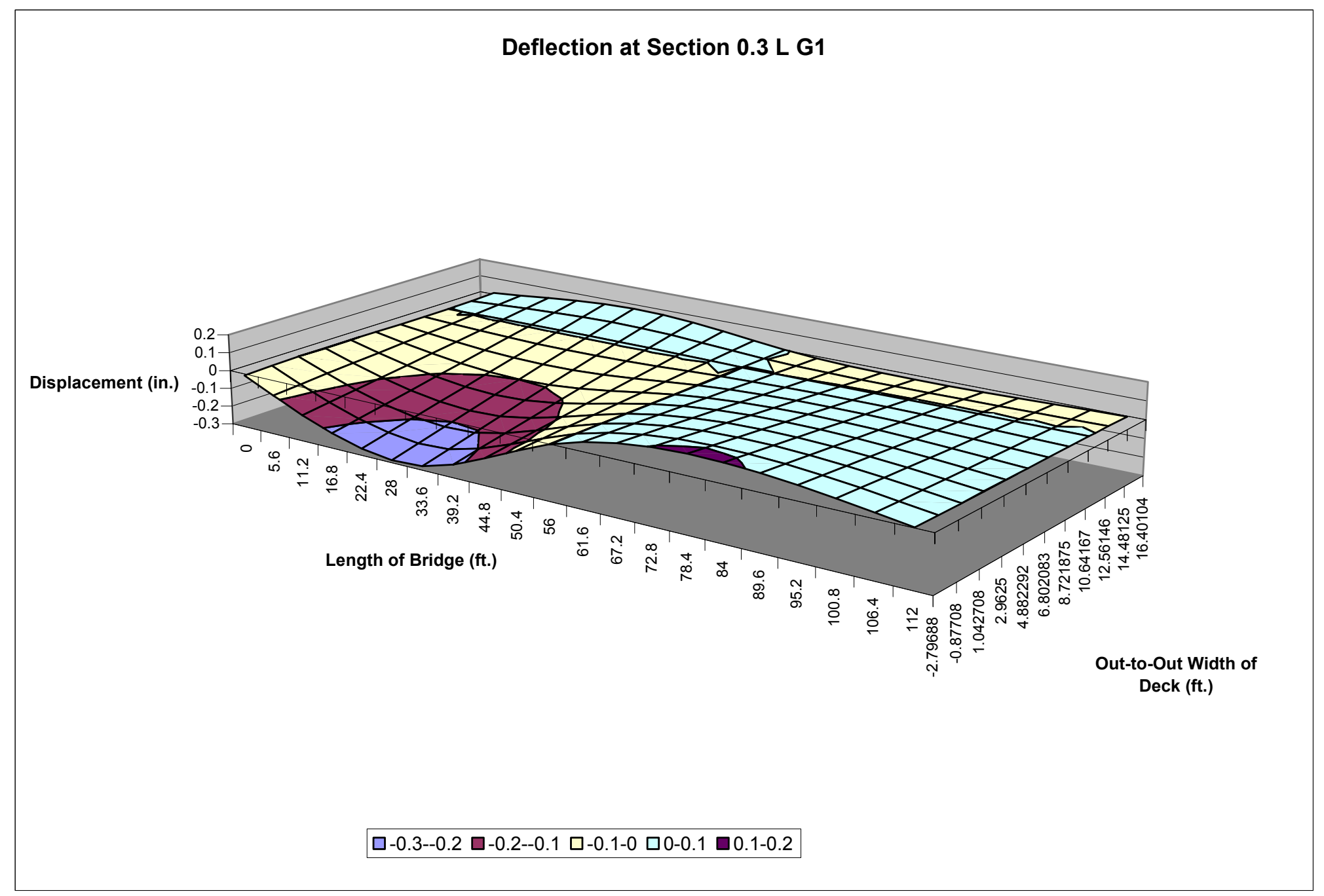

Figure B.25 Influence Surface for Deflection at Section 0.3 L G1 


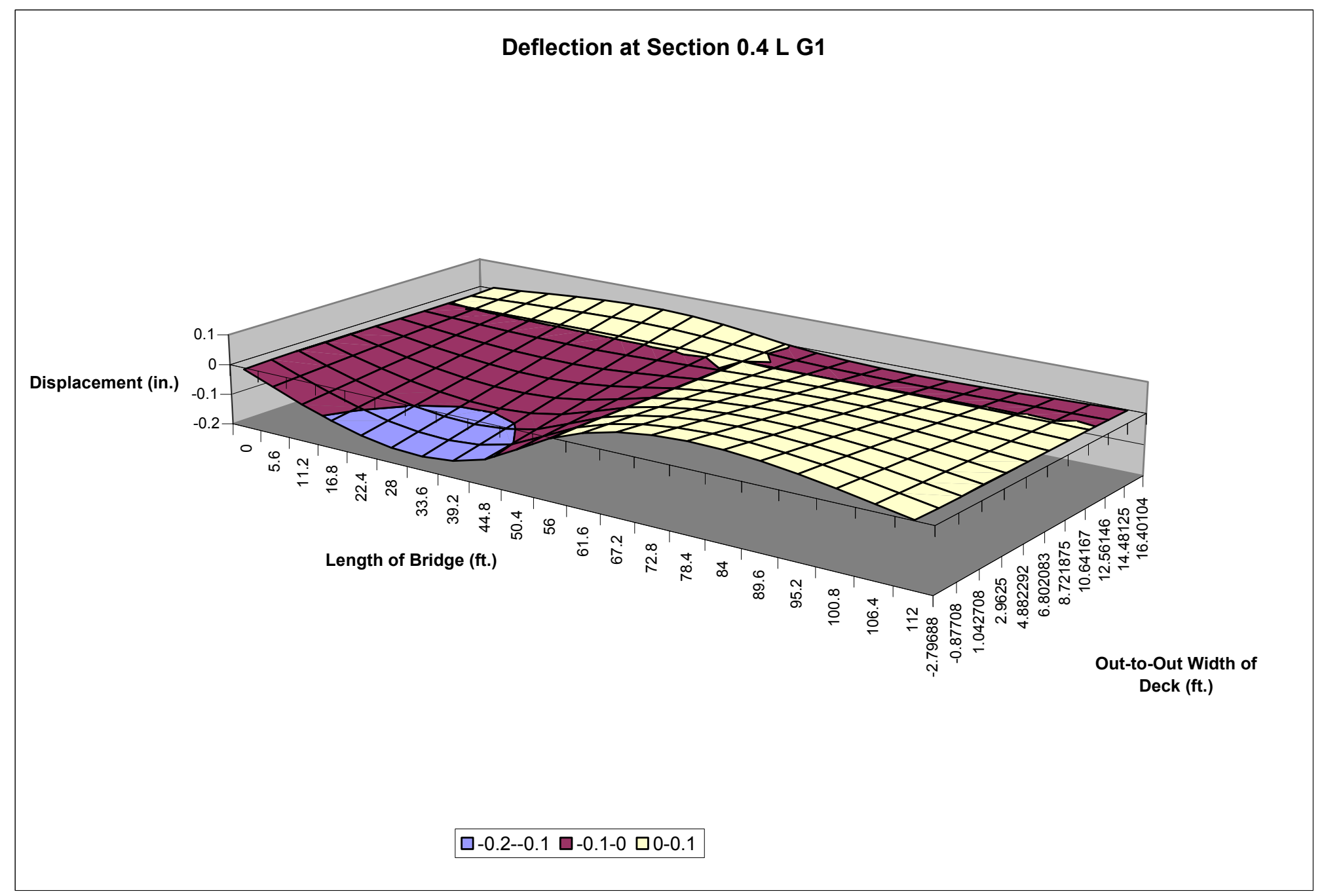

Figure B.26 Influence Surface for Deflection at Section 0.4 L G1 


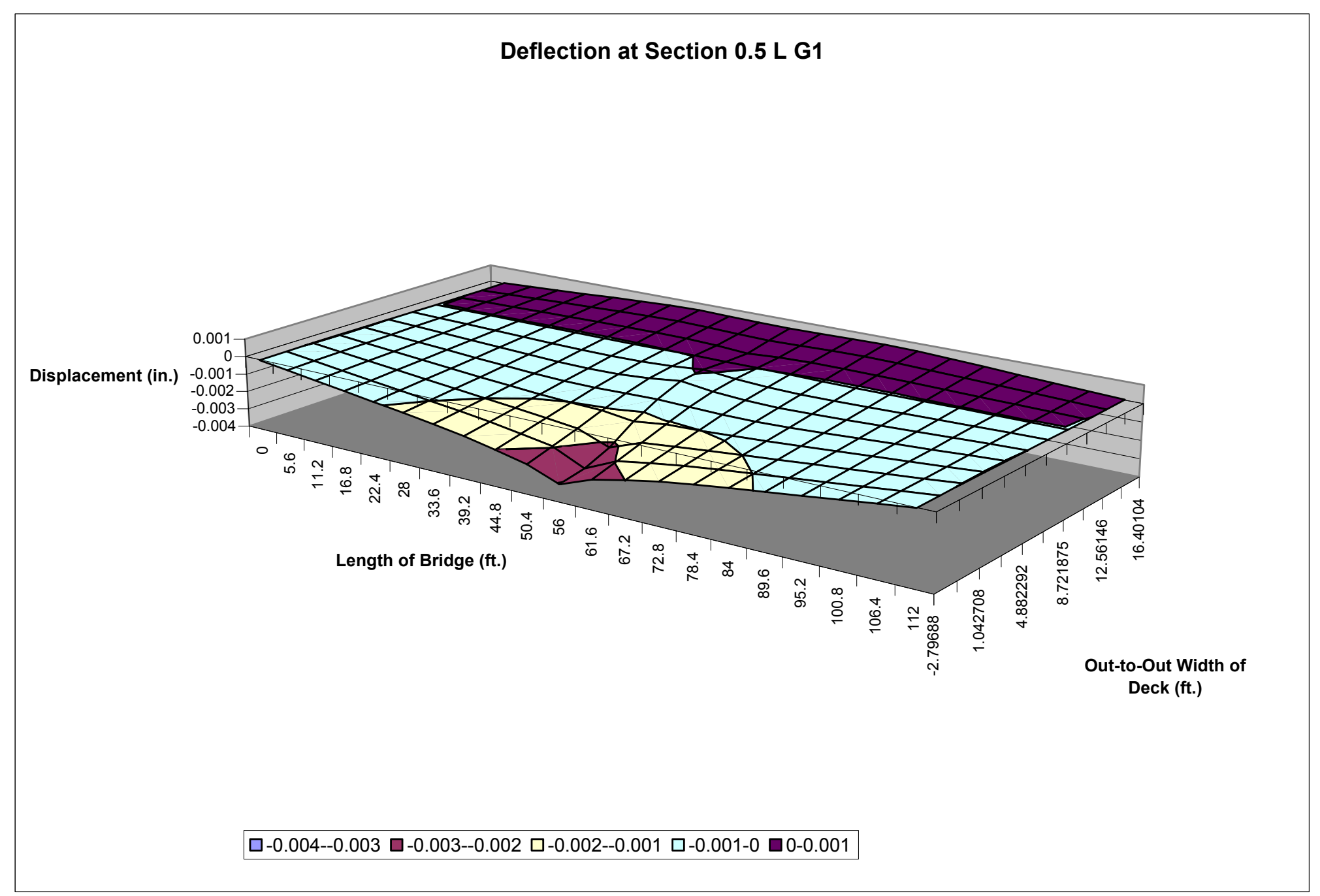

Figure B.27 Influence Surface for Deflection at Section 0.5 L G1 


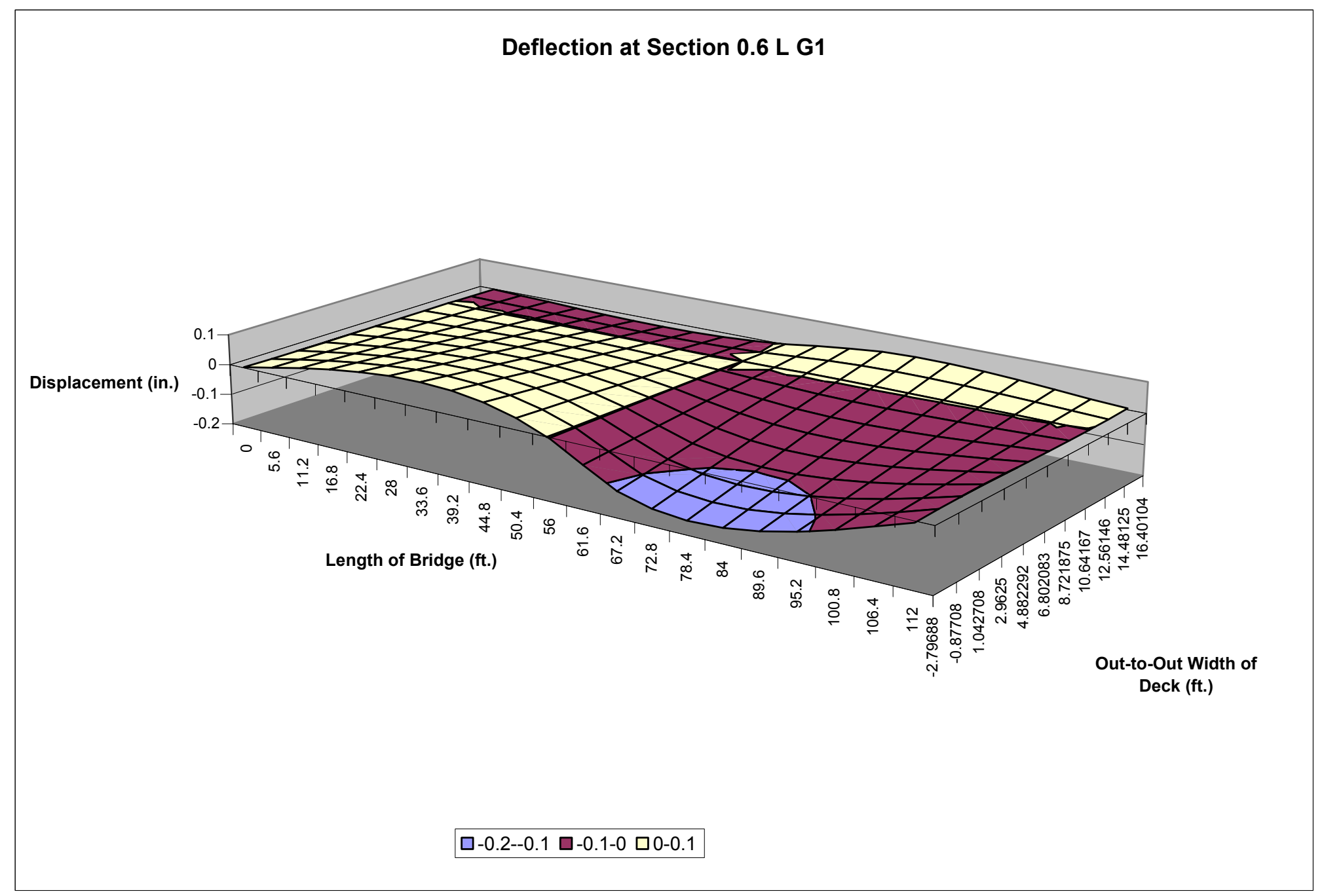

Figure B.28 Influence Surface for Deflection at Section 0.6 L G1 


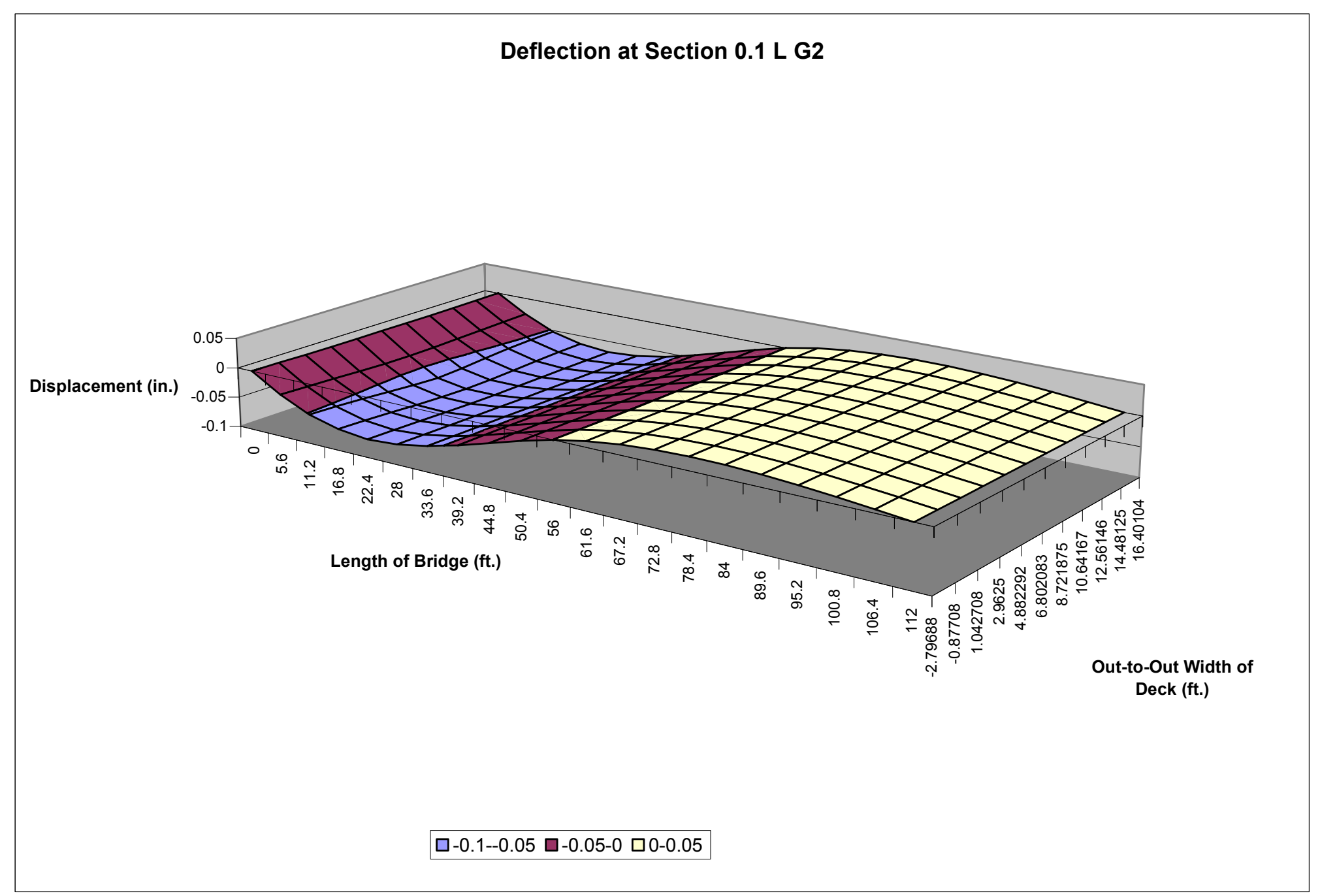

Figure B.29 Influence Surface for Deflection at Section 0.1 L G2 


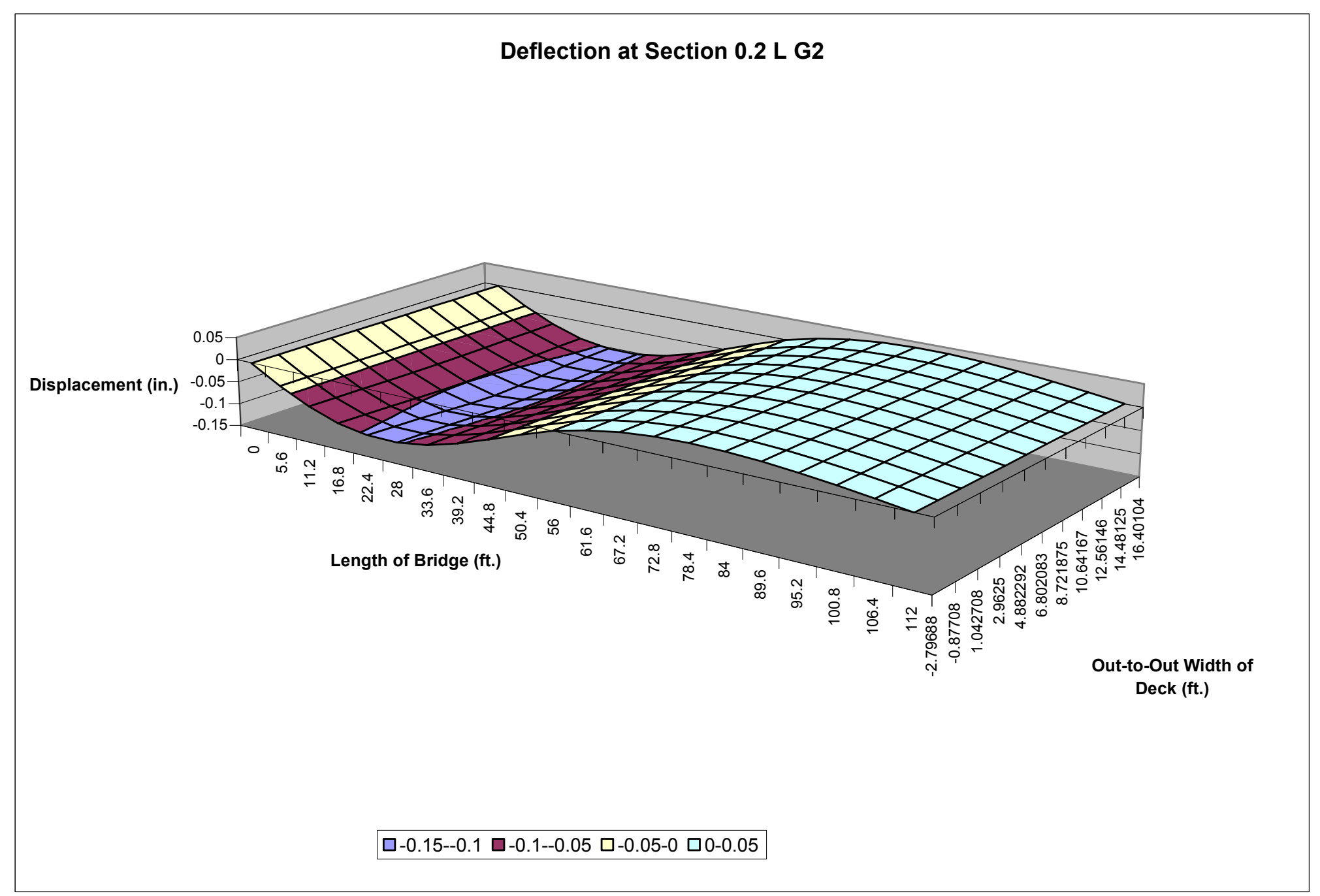

Figure B.30 Influence Surface for Deflection at Section 0.2 L G2 


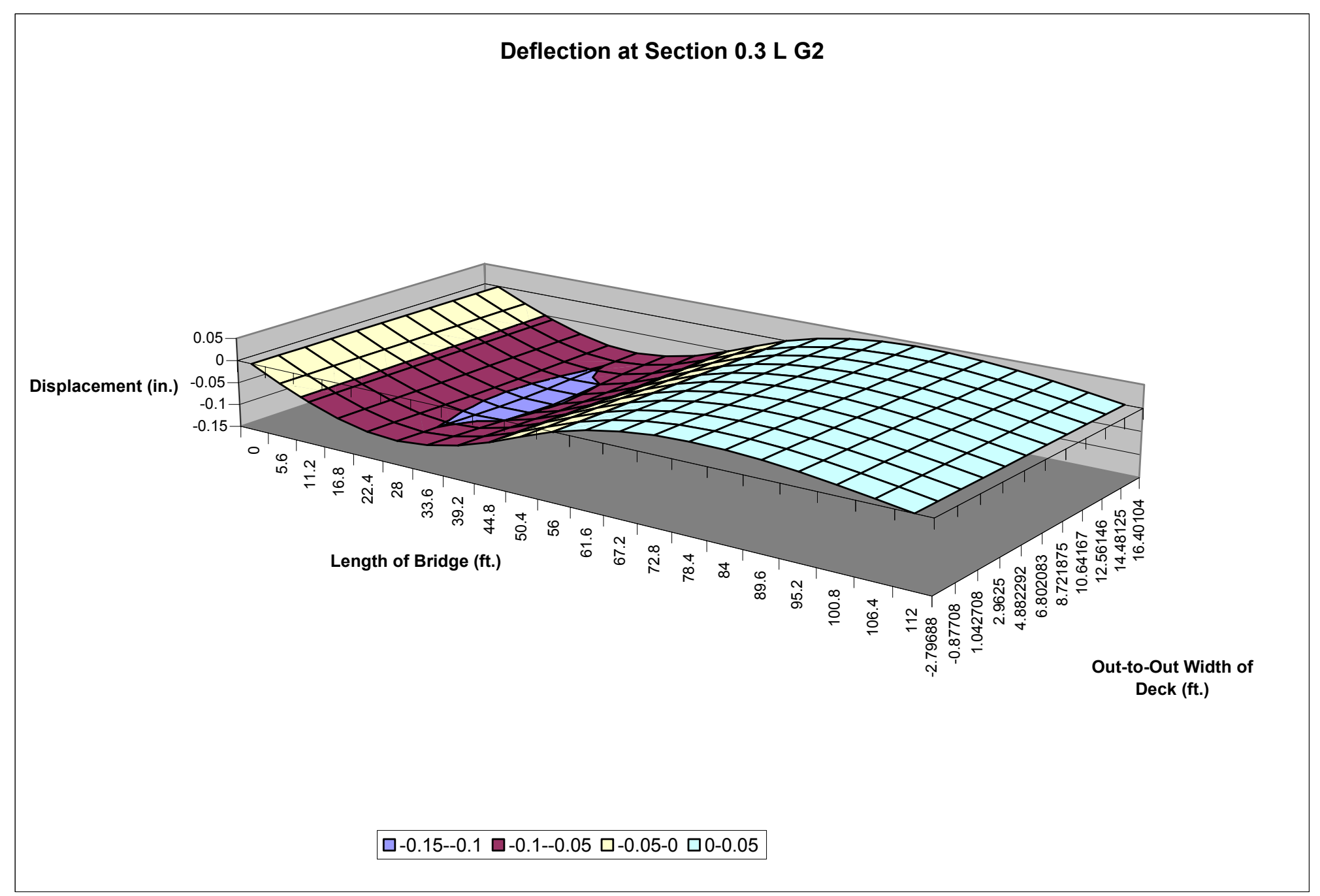

Figure B.31 Influence Surface for Deflection at Section 0.3 L G2 


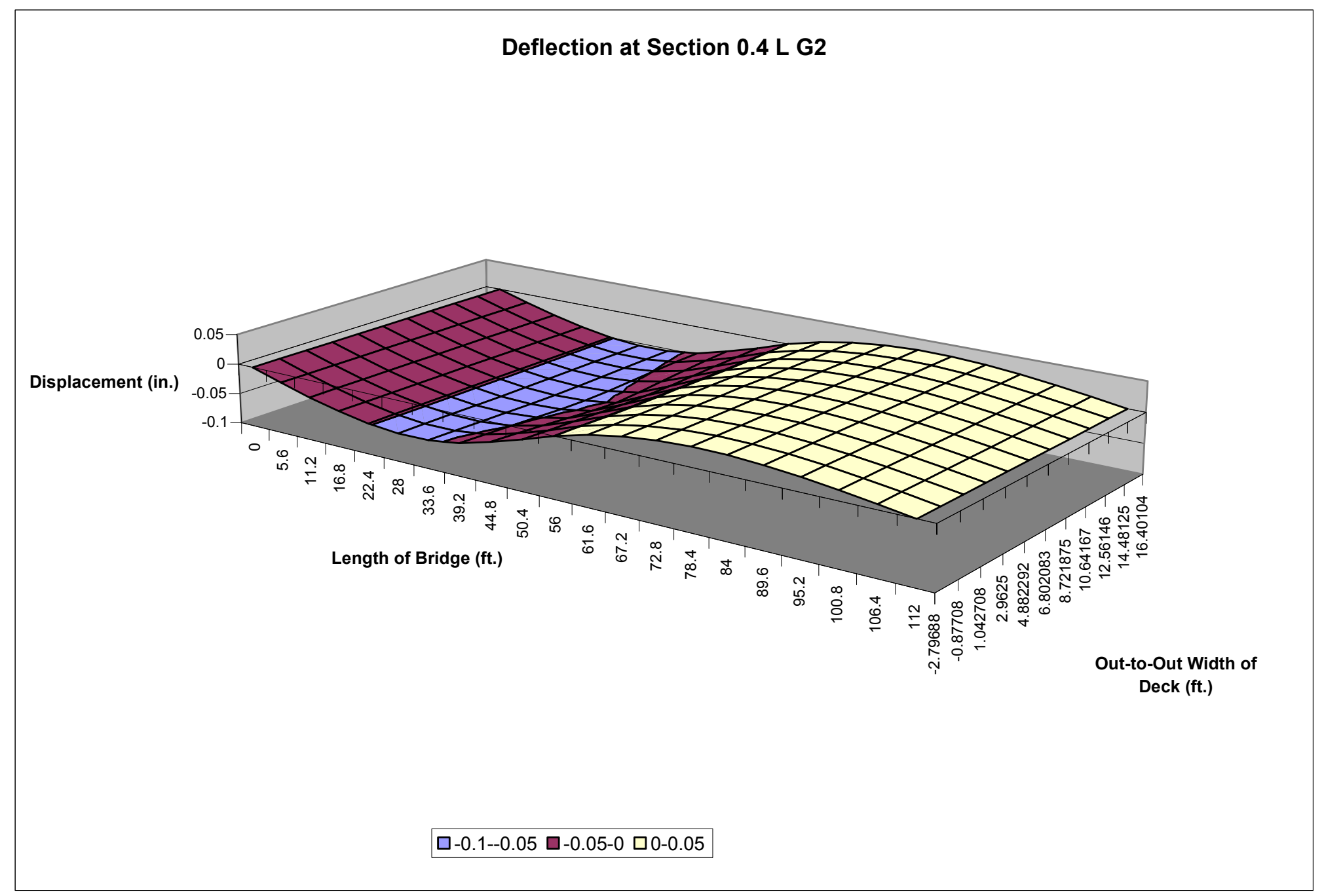

Figure B.32 Influence Surface for Deflection at Section 0.4 L G2 


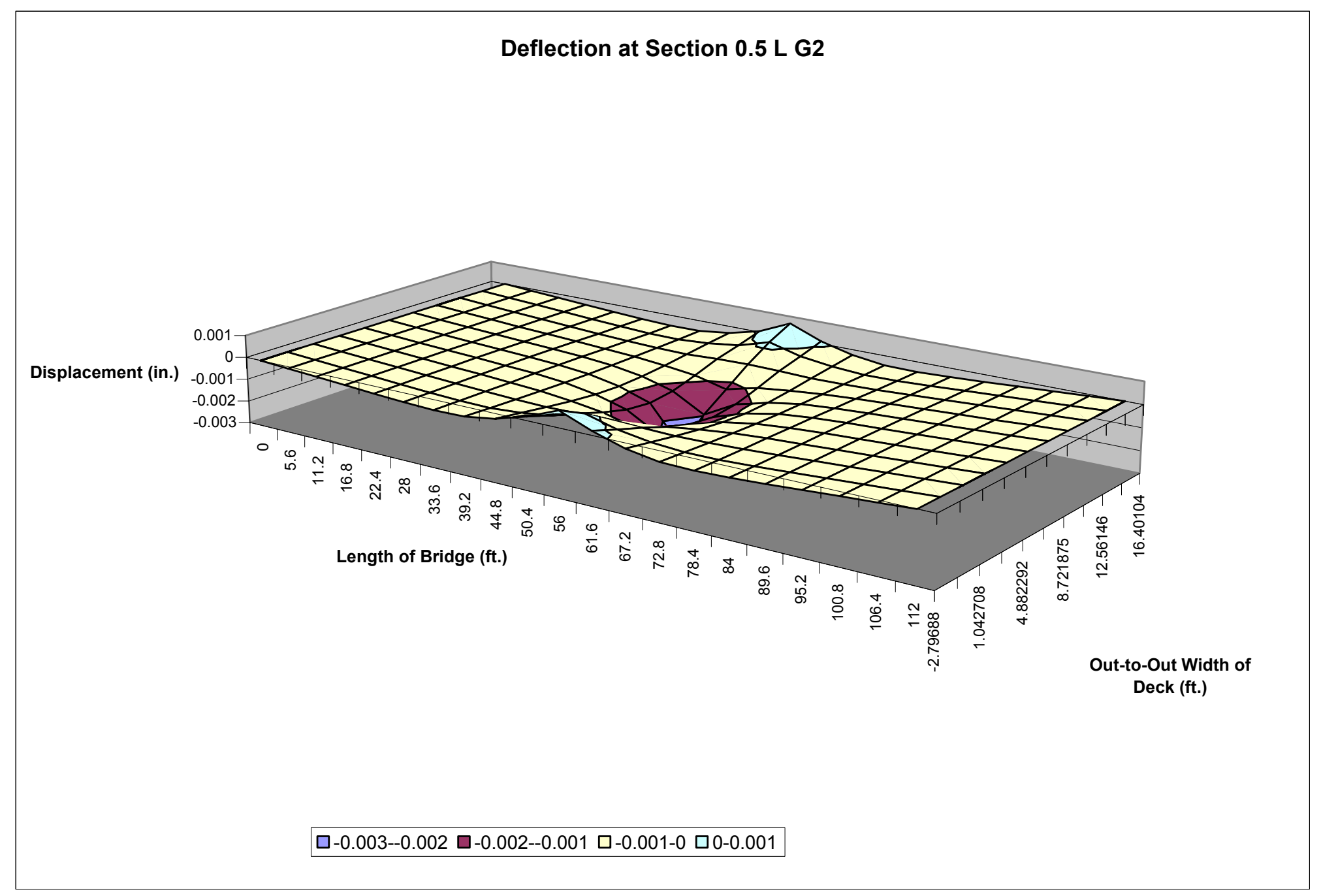

Figure B.33 Influence Surface for Deflection at Section 0.5 L G2 


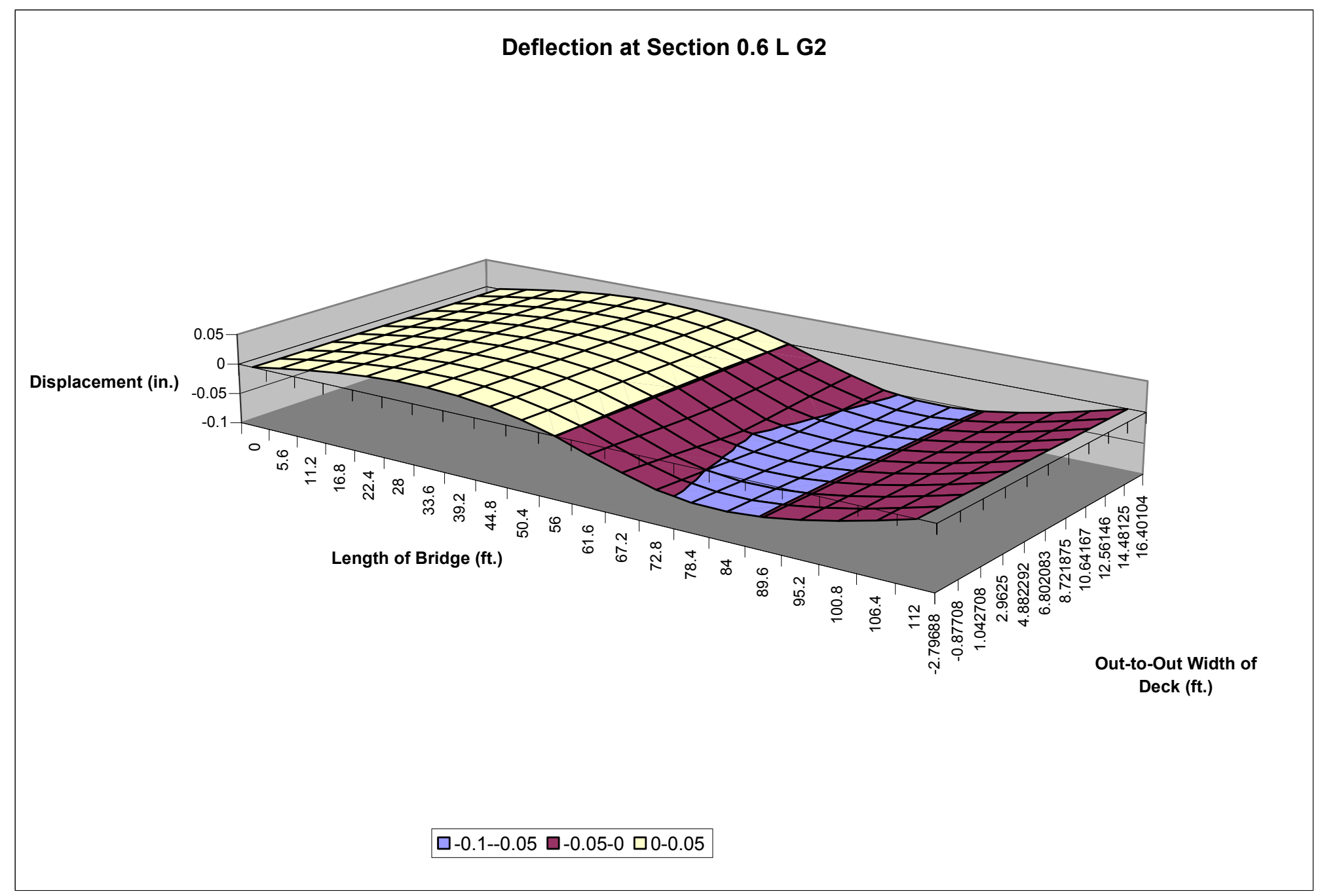

Figure B.34 Influence Surface for Deflection at Section 0.6 L G2 


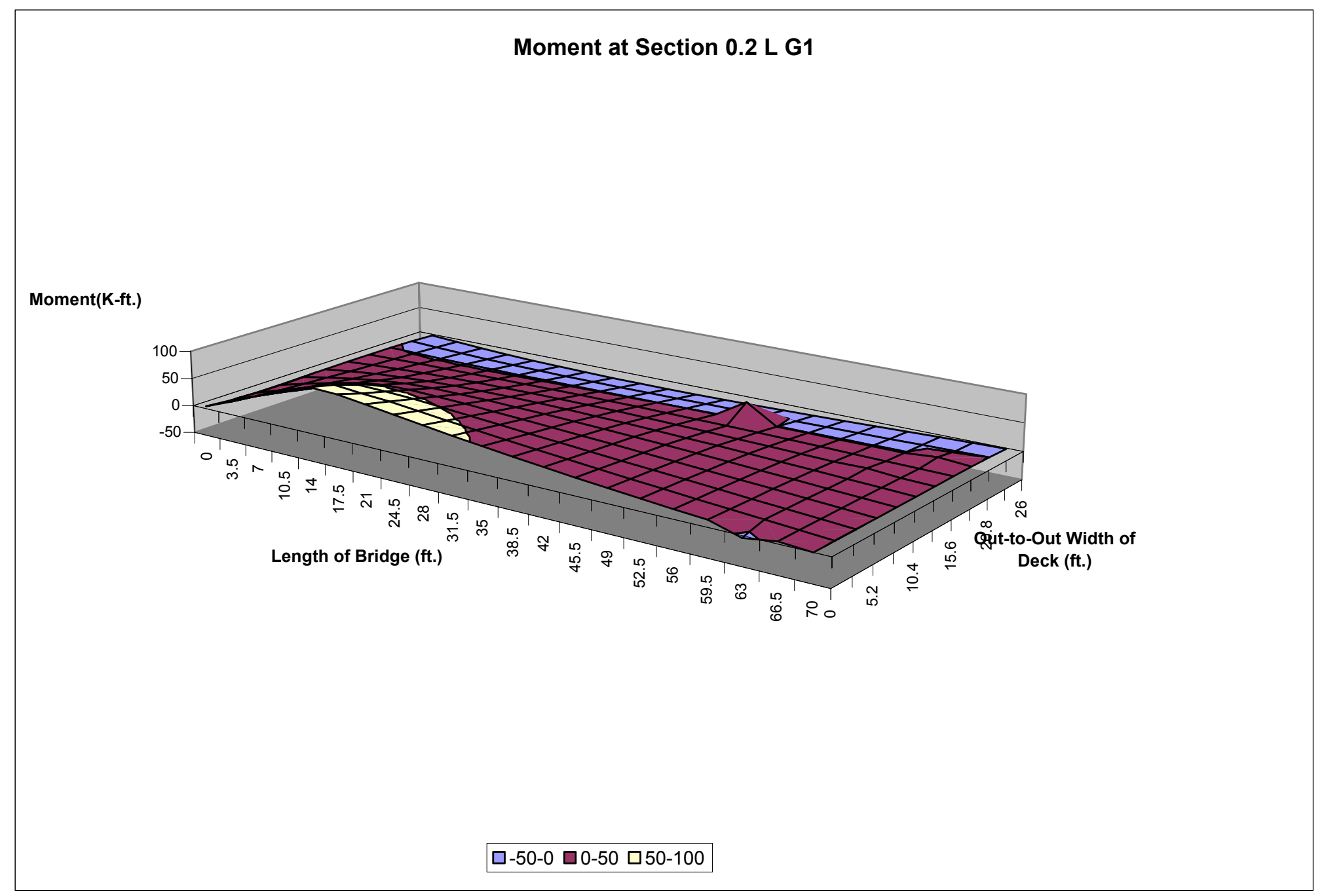

Figure B.35 Influence Surface for Moment at Section 0.2 L G1 


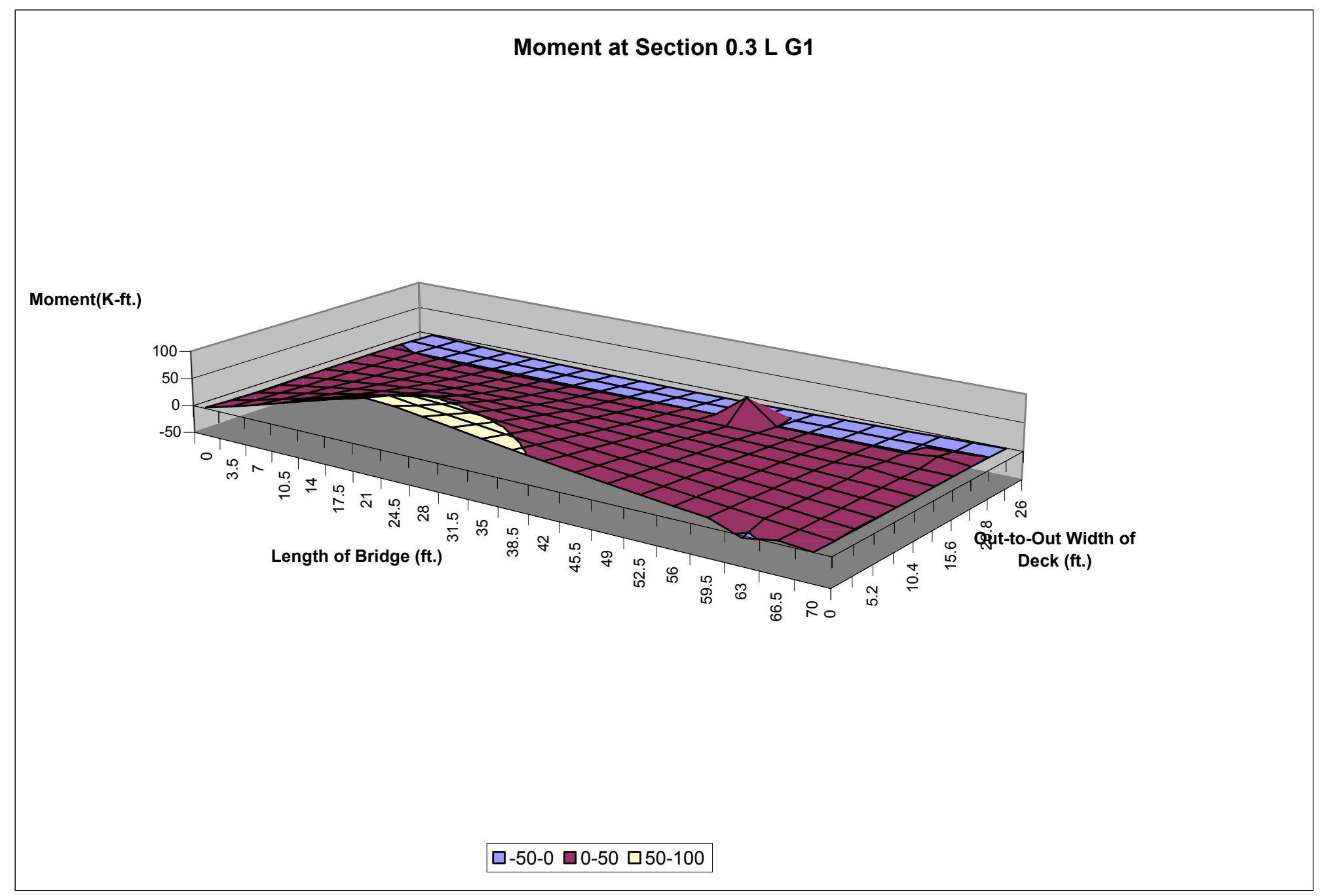

Figure B.36 Influence Surface for Moment at Section 0.3 L G1 


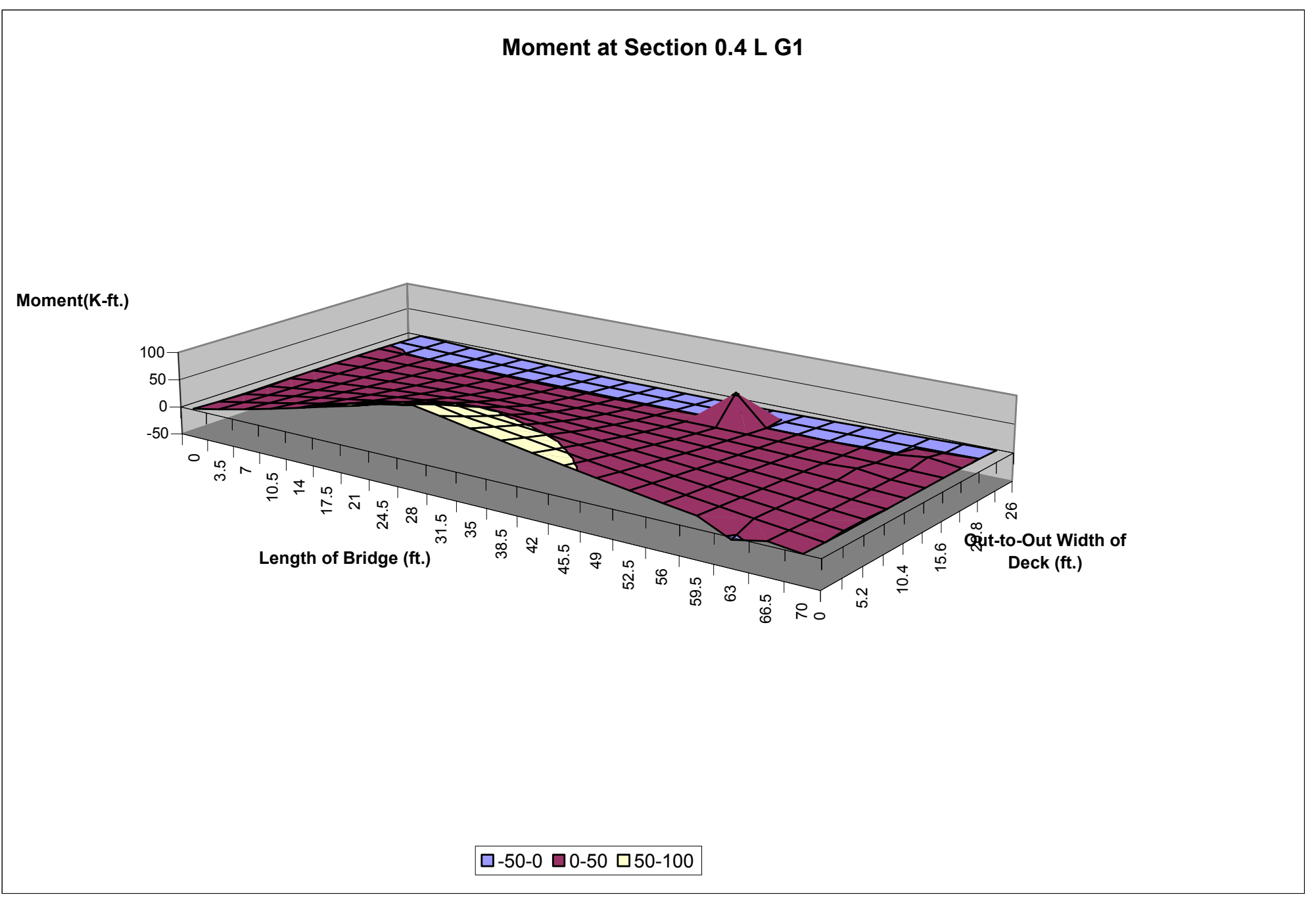

Figure B.37 Influence Surface for Moment at Section 0.4 L G1 


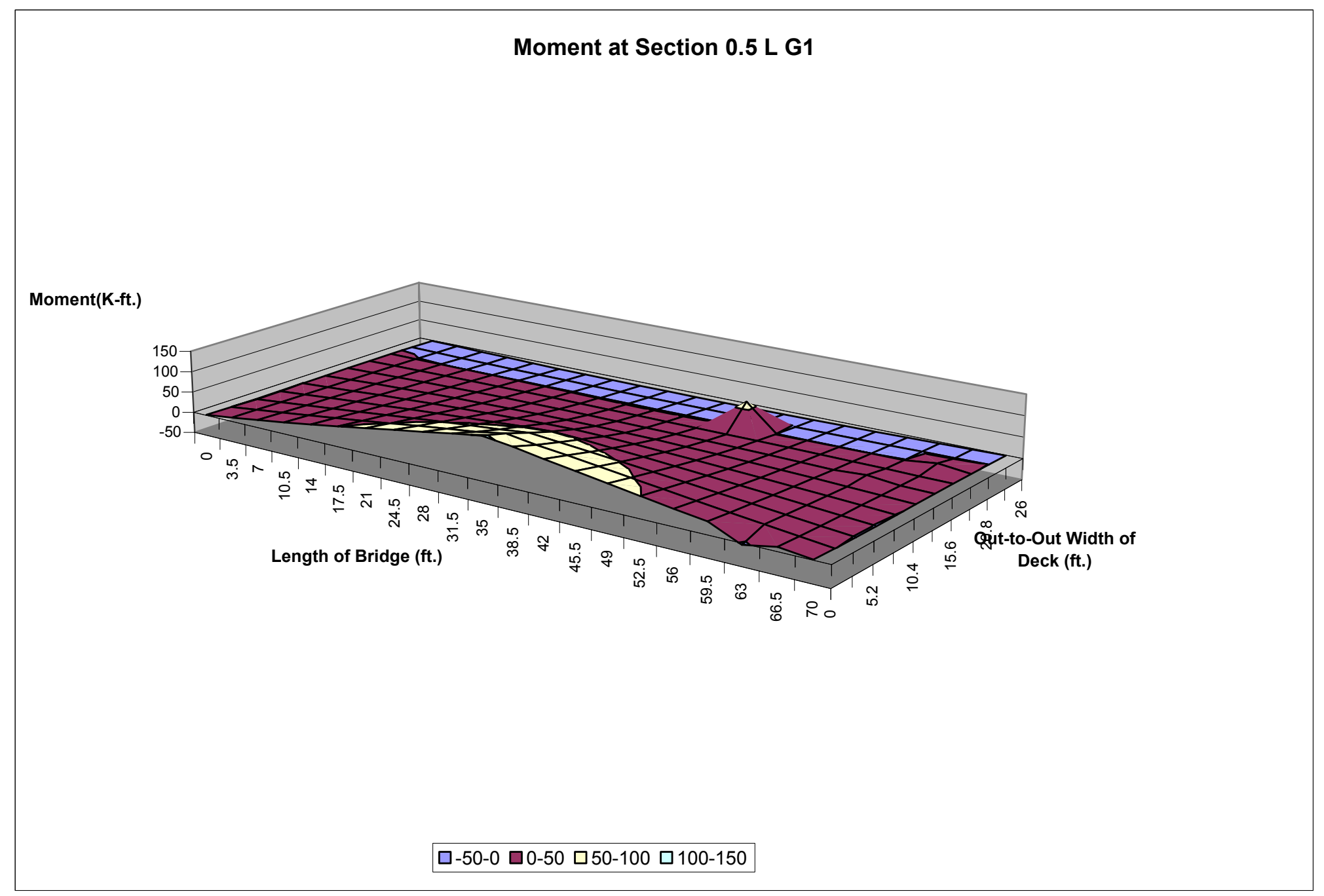

Figure B.38 Influence Surface for Moment at Section 0.5 L G1 


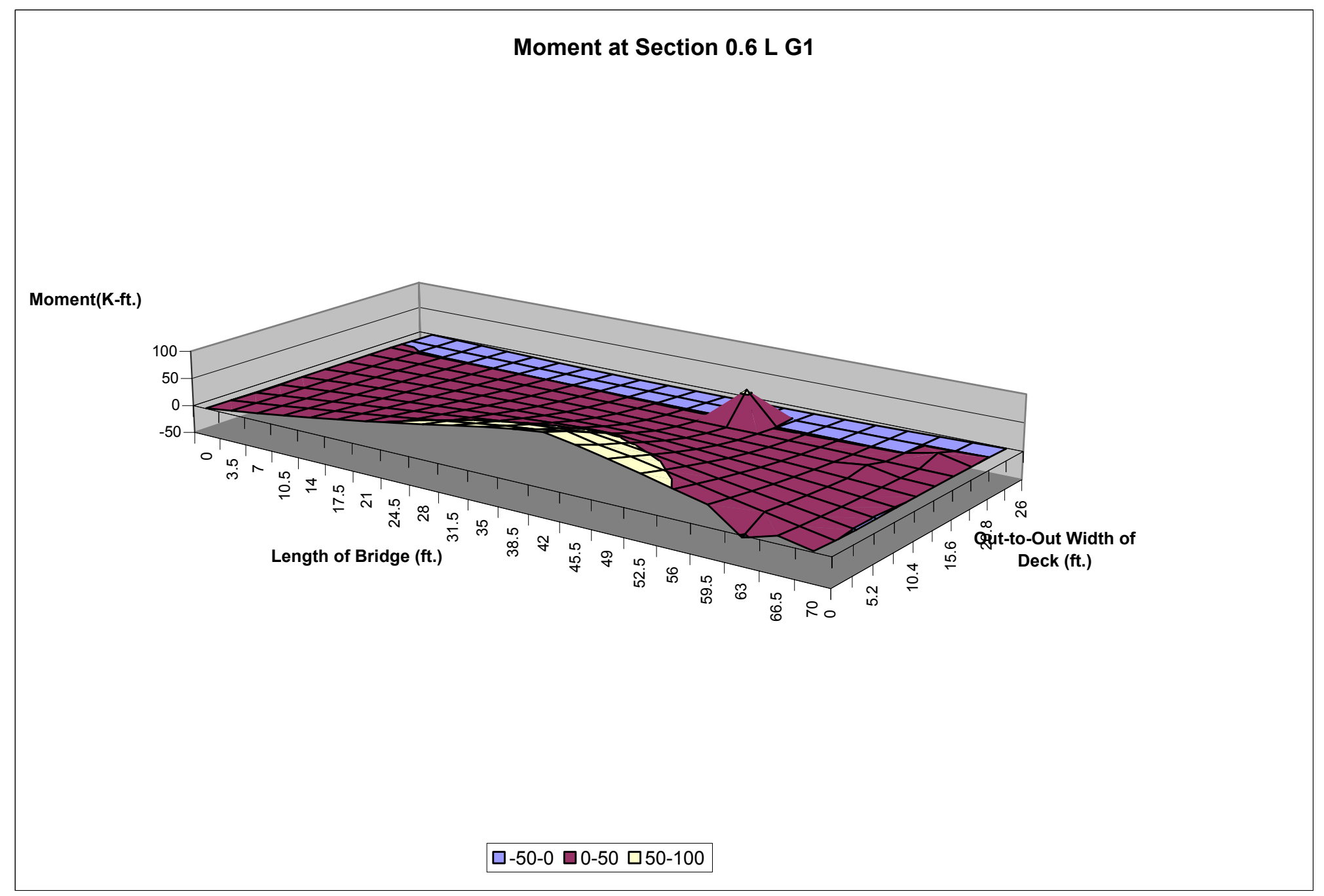

Figure B.39 Influence Surface for Moment at Section 0.6 L G1 


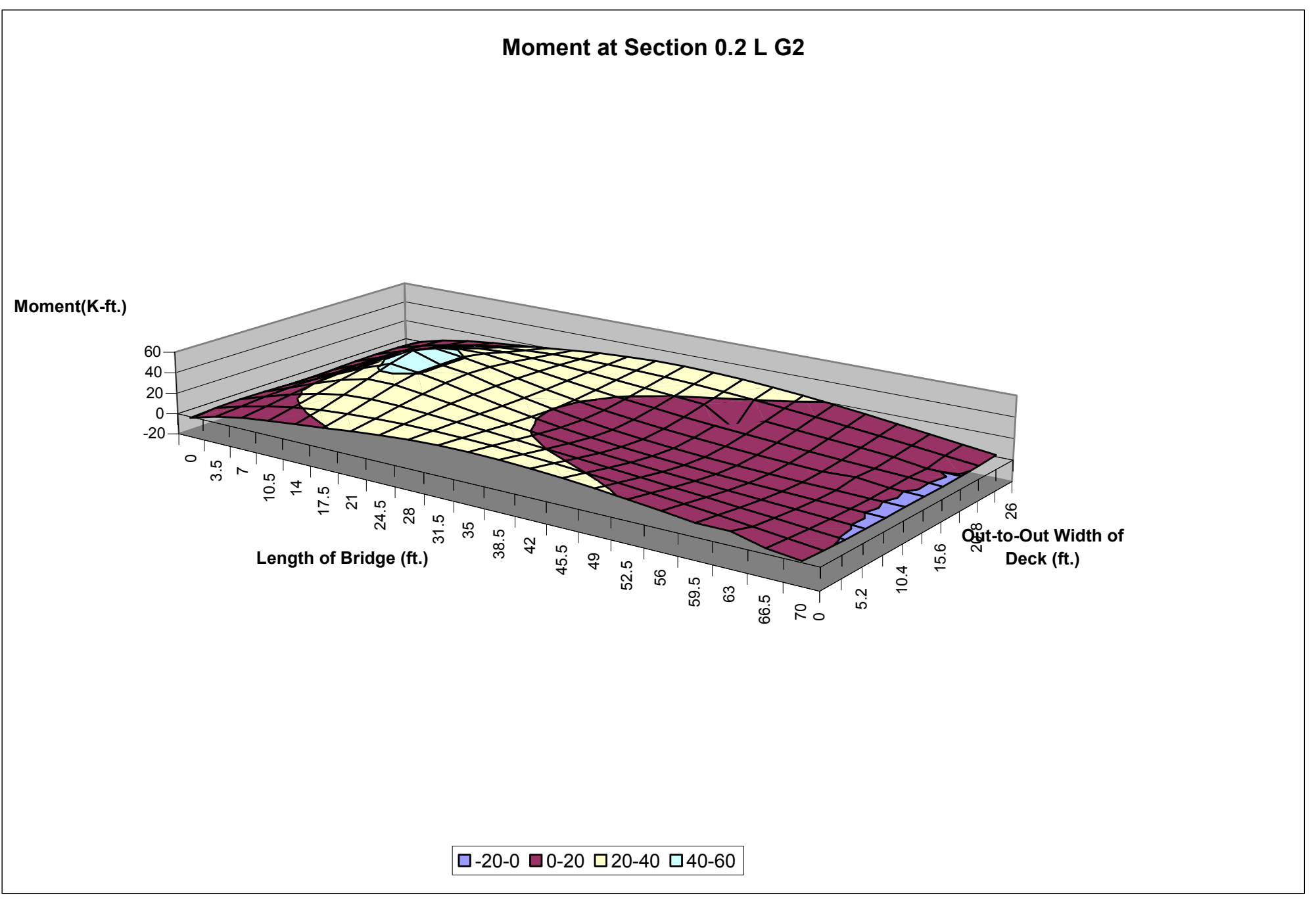

Figure B.40 Influence Surface for Moment at Section 0.2 L G2 


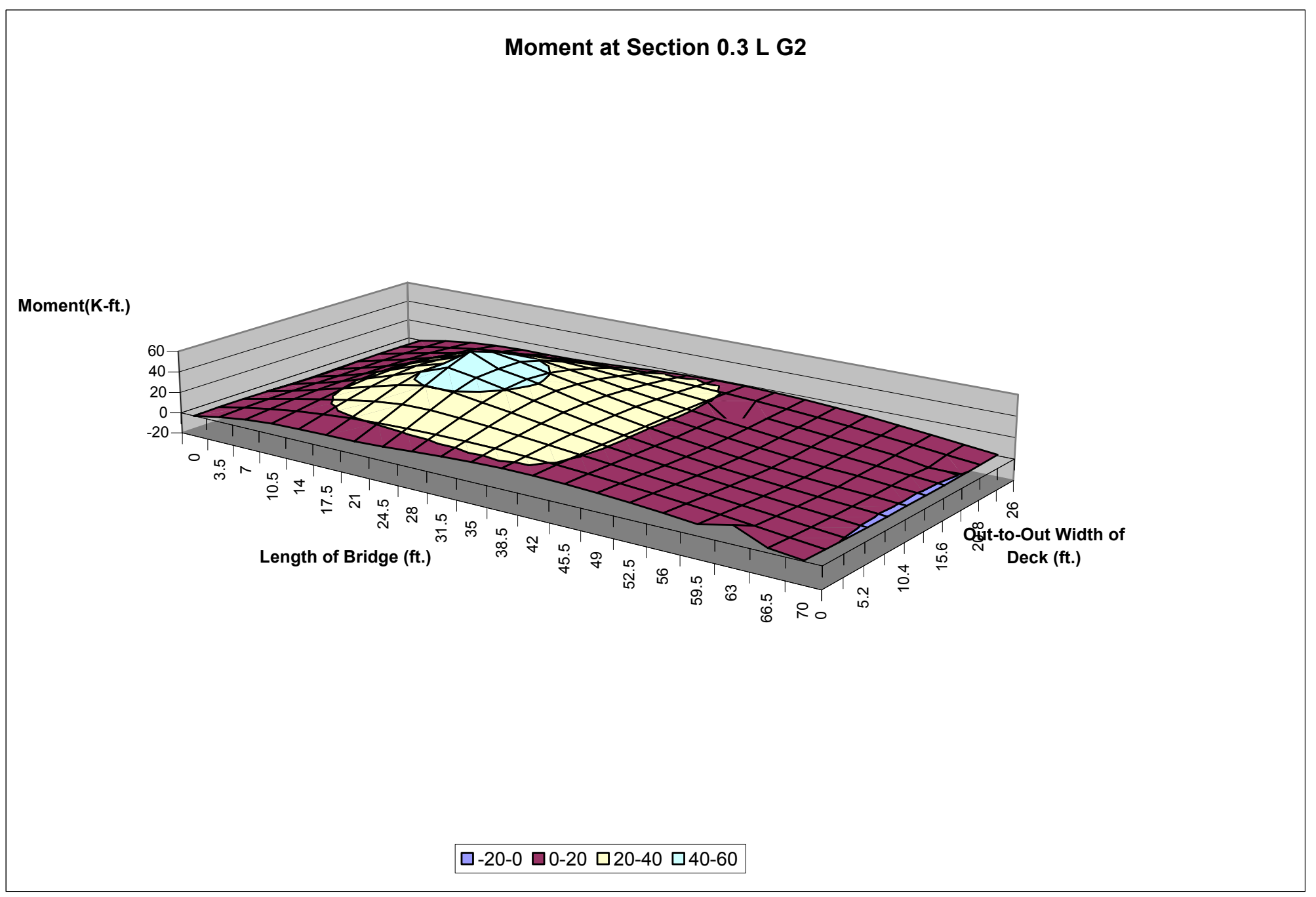

Figure B.41 Influence Surface for Moment at Section 0.3 L G2 


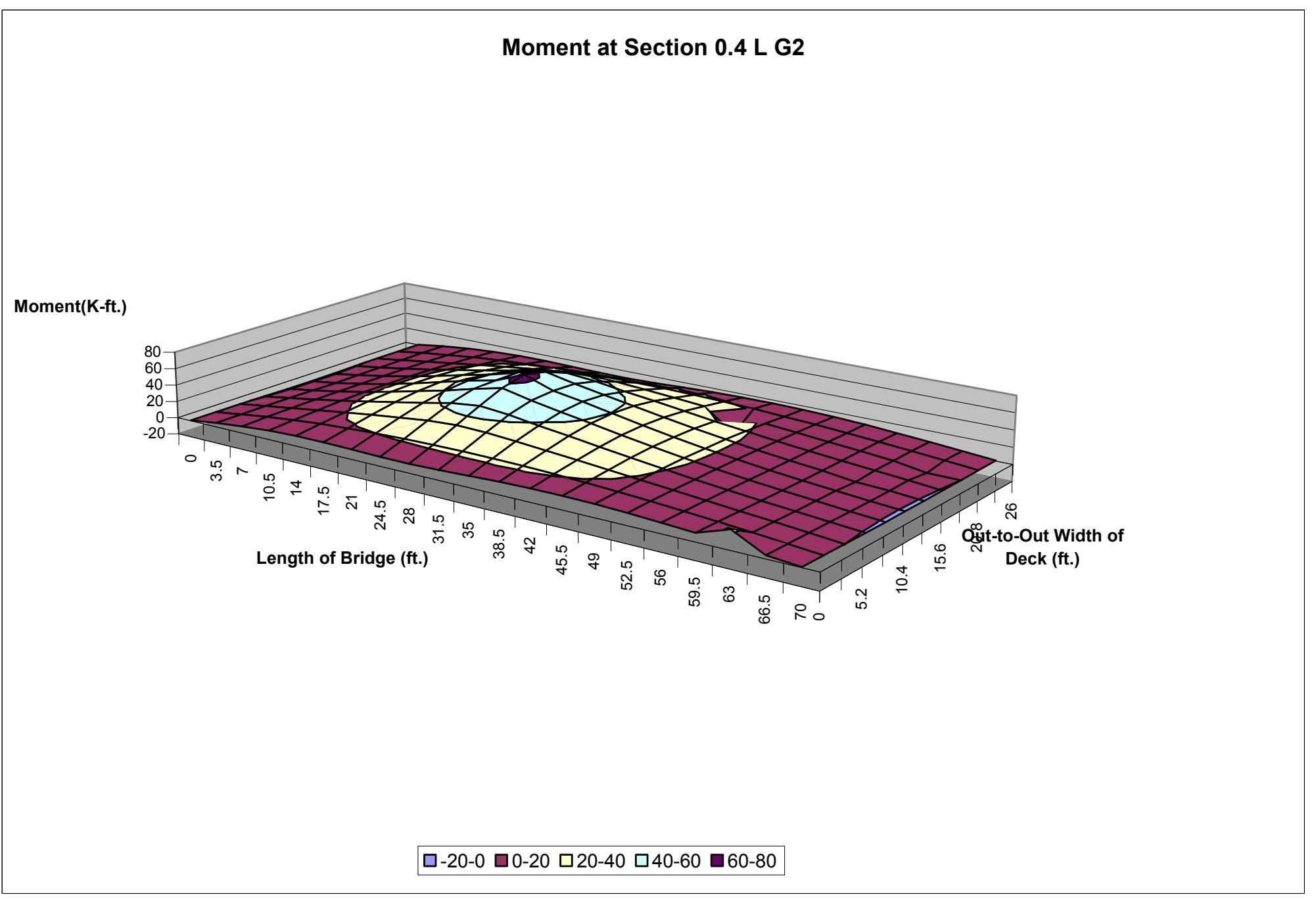

Figure B.42 Influence Surface for Moment at Section 0.4 L G2 


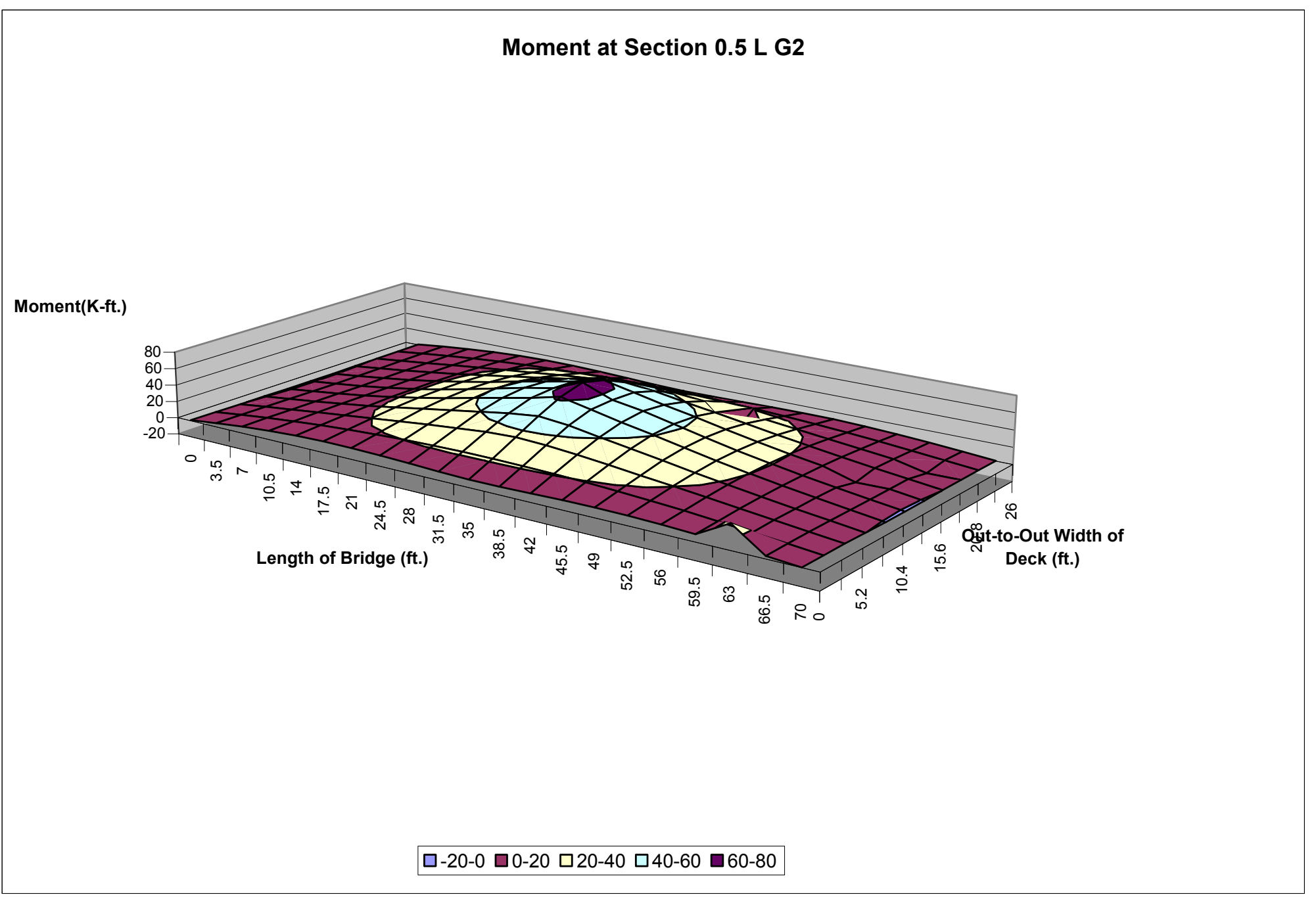

Figure B.43 Influence Surface for Moment at Section 0.5 L G2 


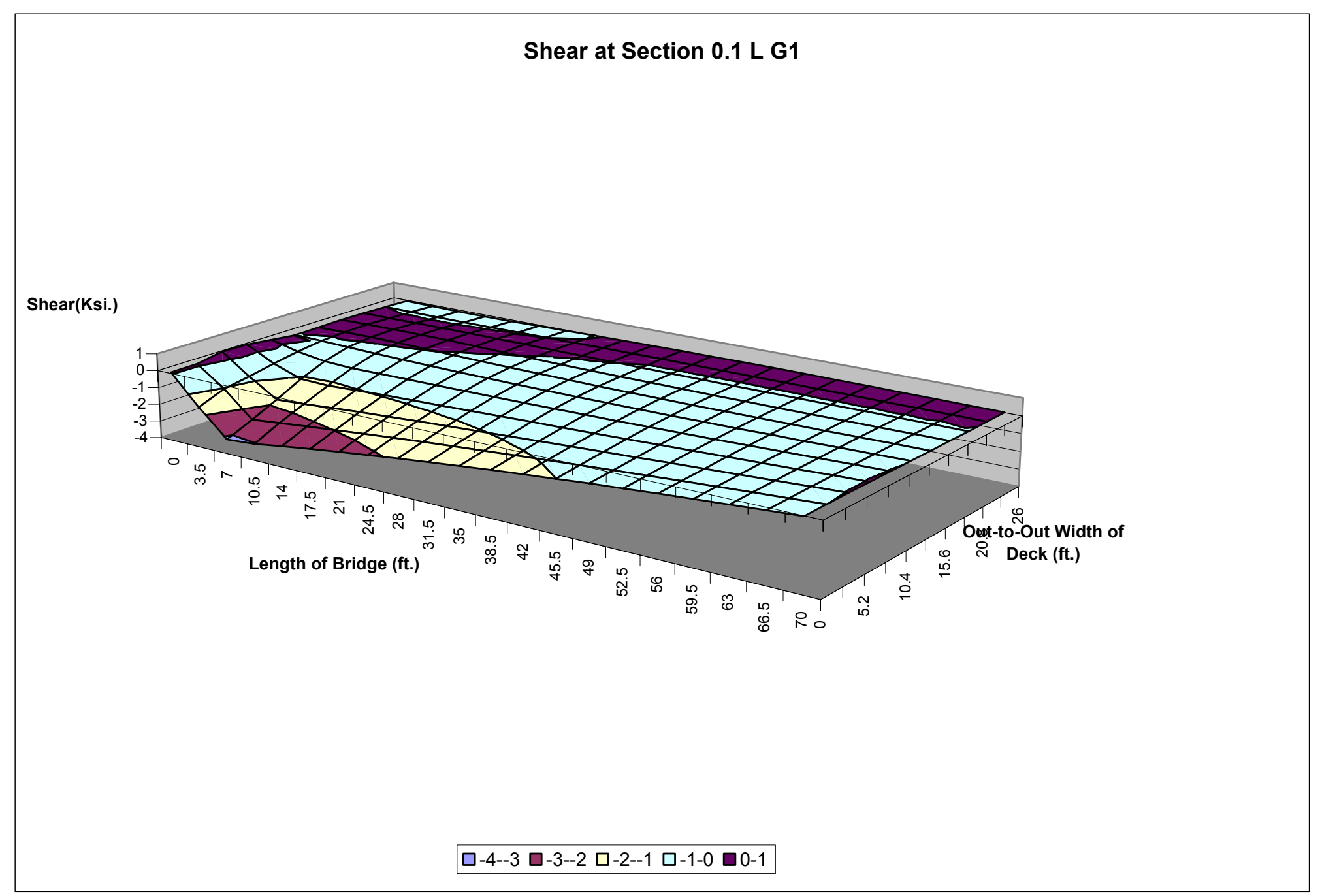

Figure B.44 Influence Surface for Shear at Section 0.1 L G1 


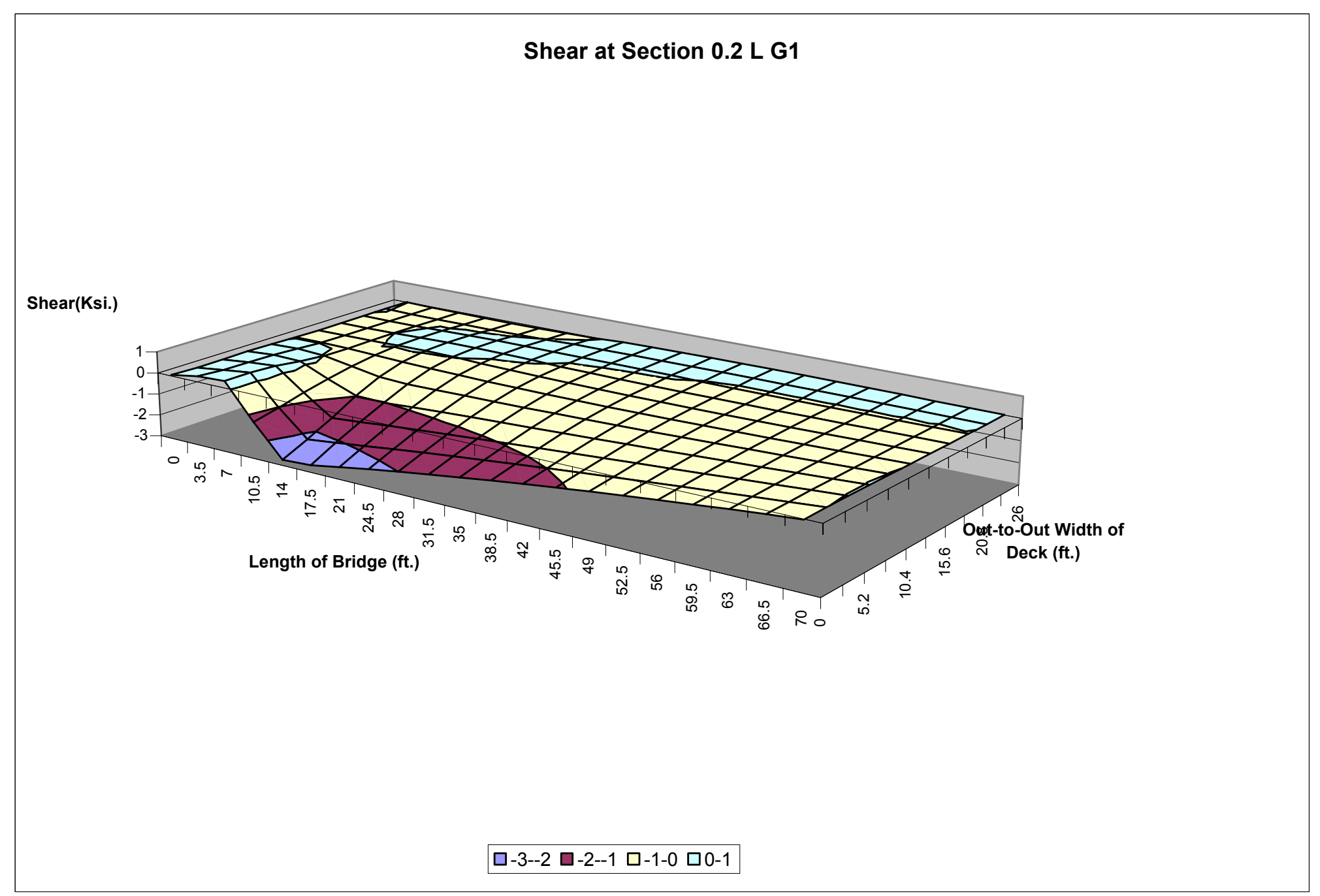

Figure B.45 Influence Surface for Shear at Section 0.2 L G1 


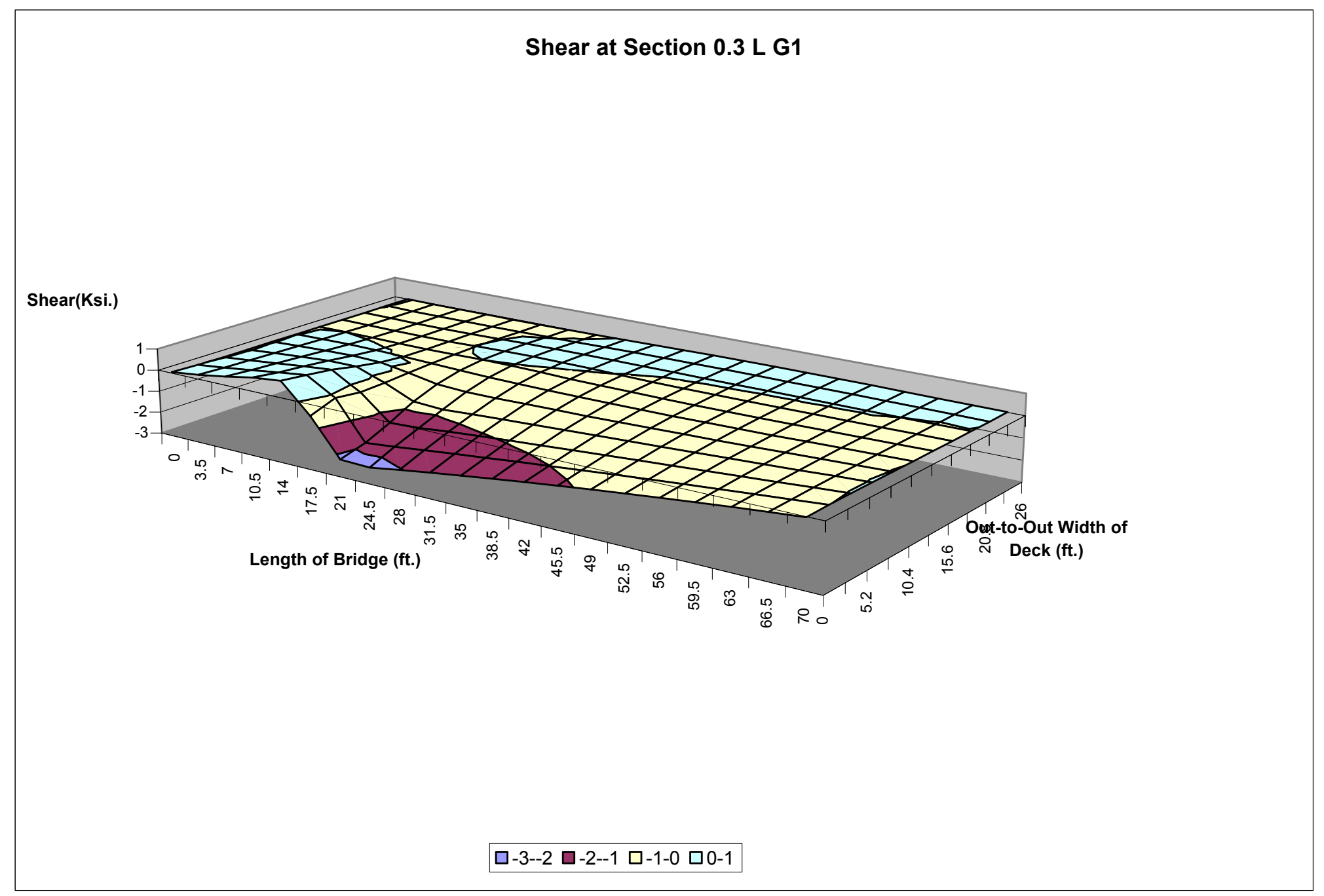

Figure B.46 Influence Surface for Shear at Section 0.3 L G1 


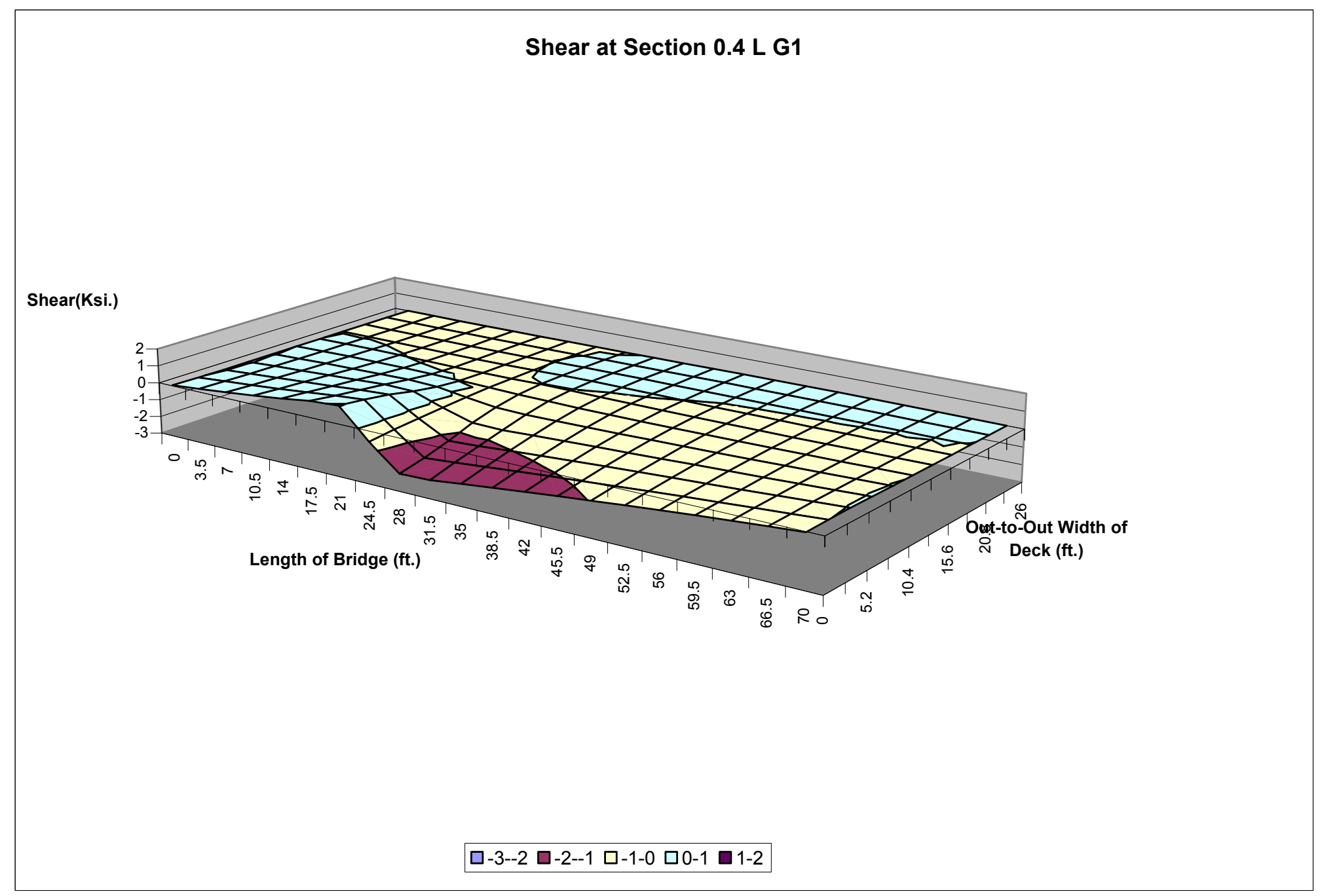

Figure B.47 Influence Surface for Shear at Section 0.4 L G1 


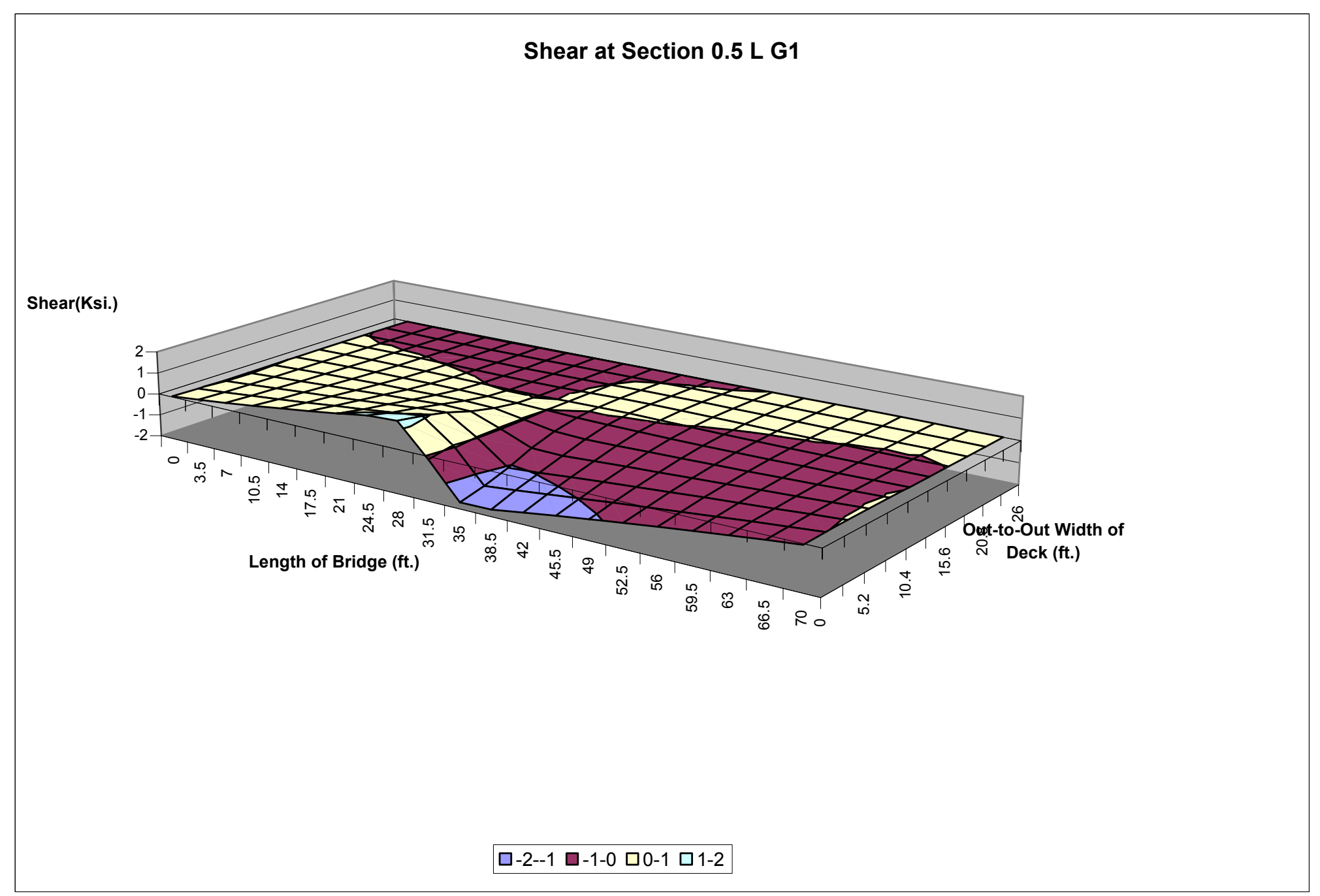

Figure B.48 Influence Surface for Shear at Section 0.5 L G1 


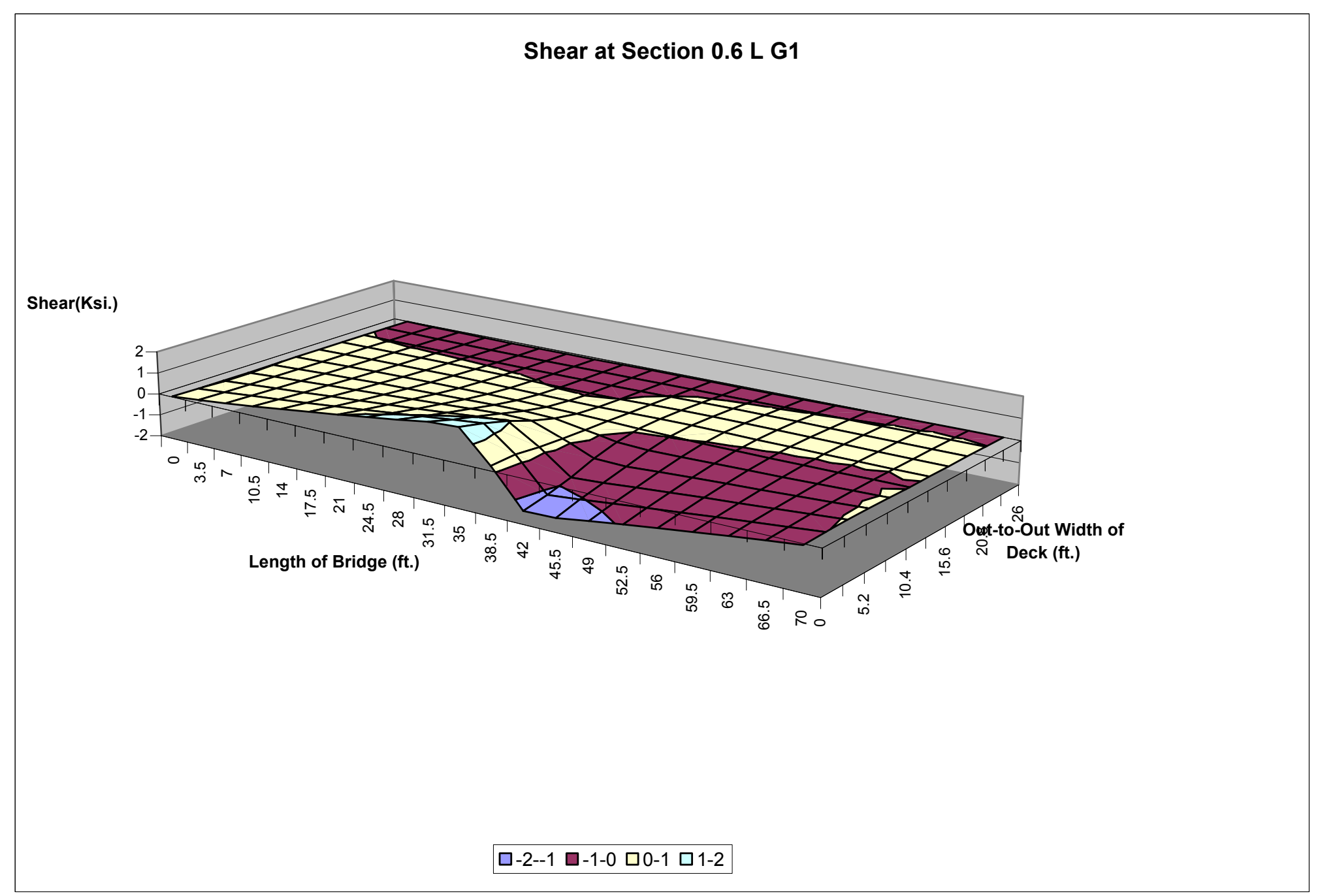

Figure B.49 Influence Surface for Shear at Section 0.6 L G1 


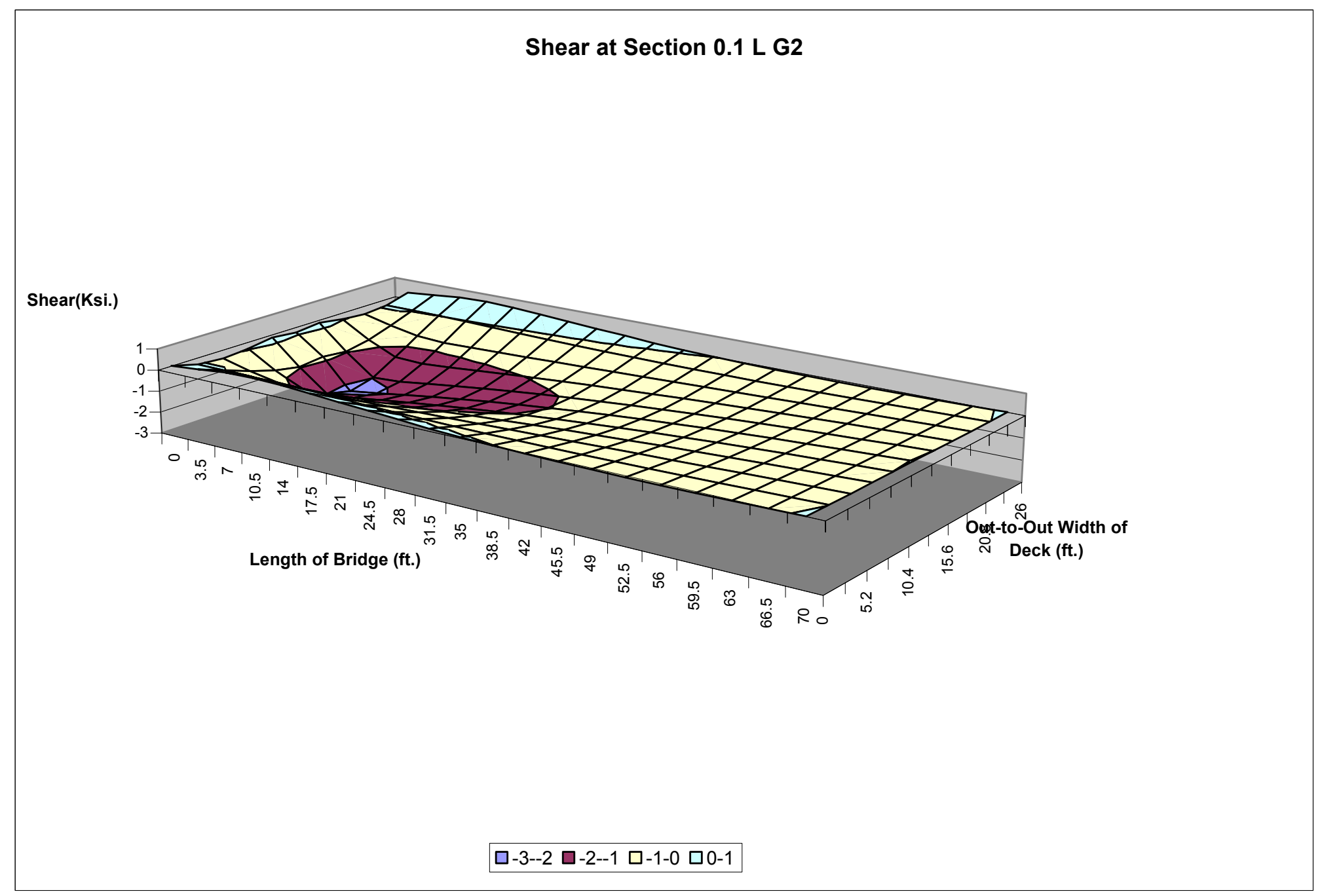

Figure B.50 Influence Surface for Shear at Section 0.1 L G2 


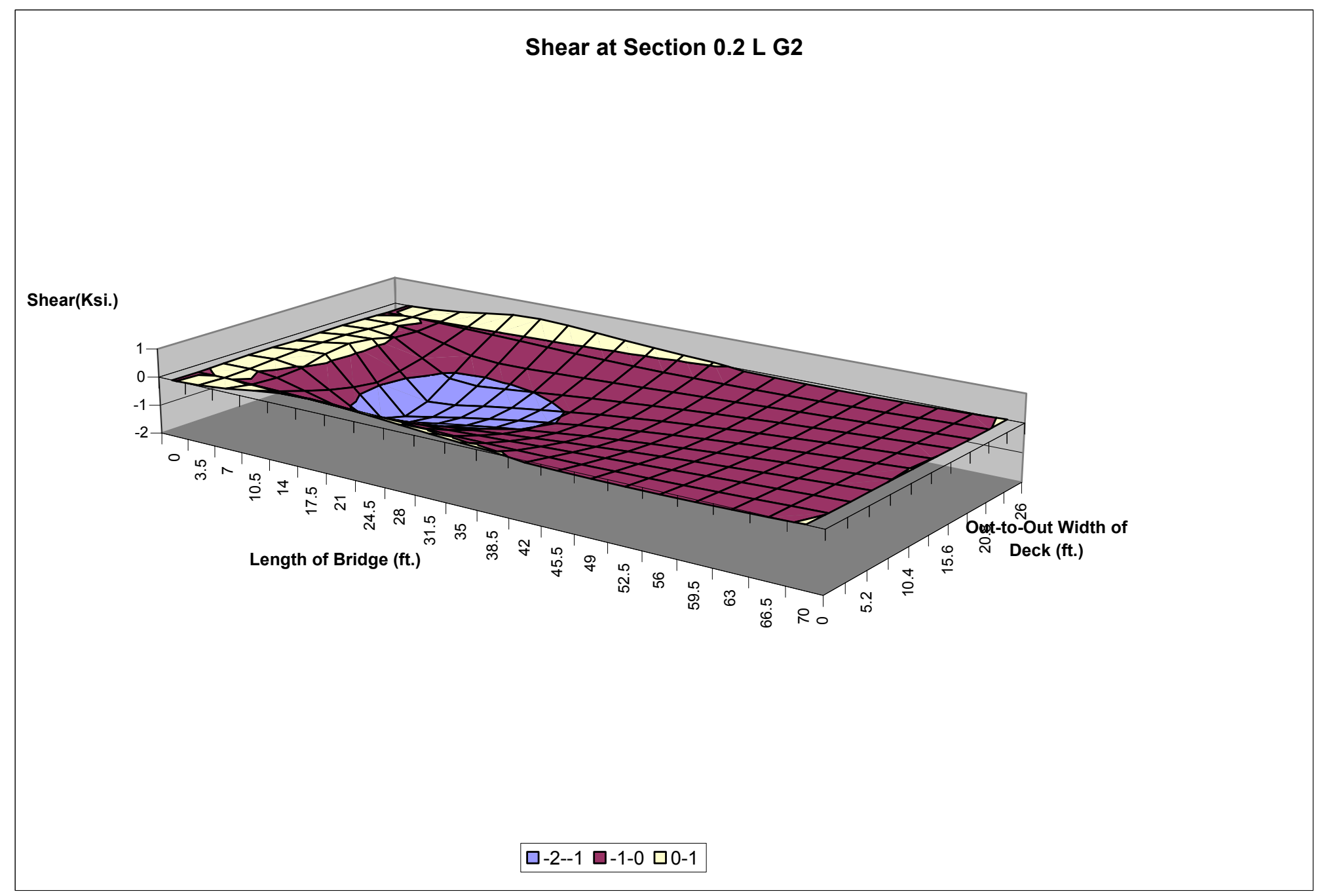

Figure B.51 Influence Surface for Shear at Section 0.2 L G2 


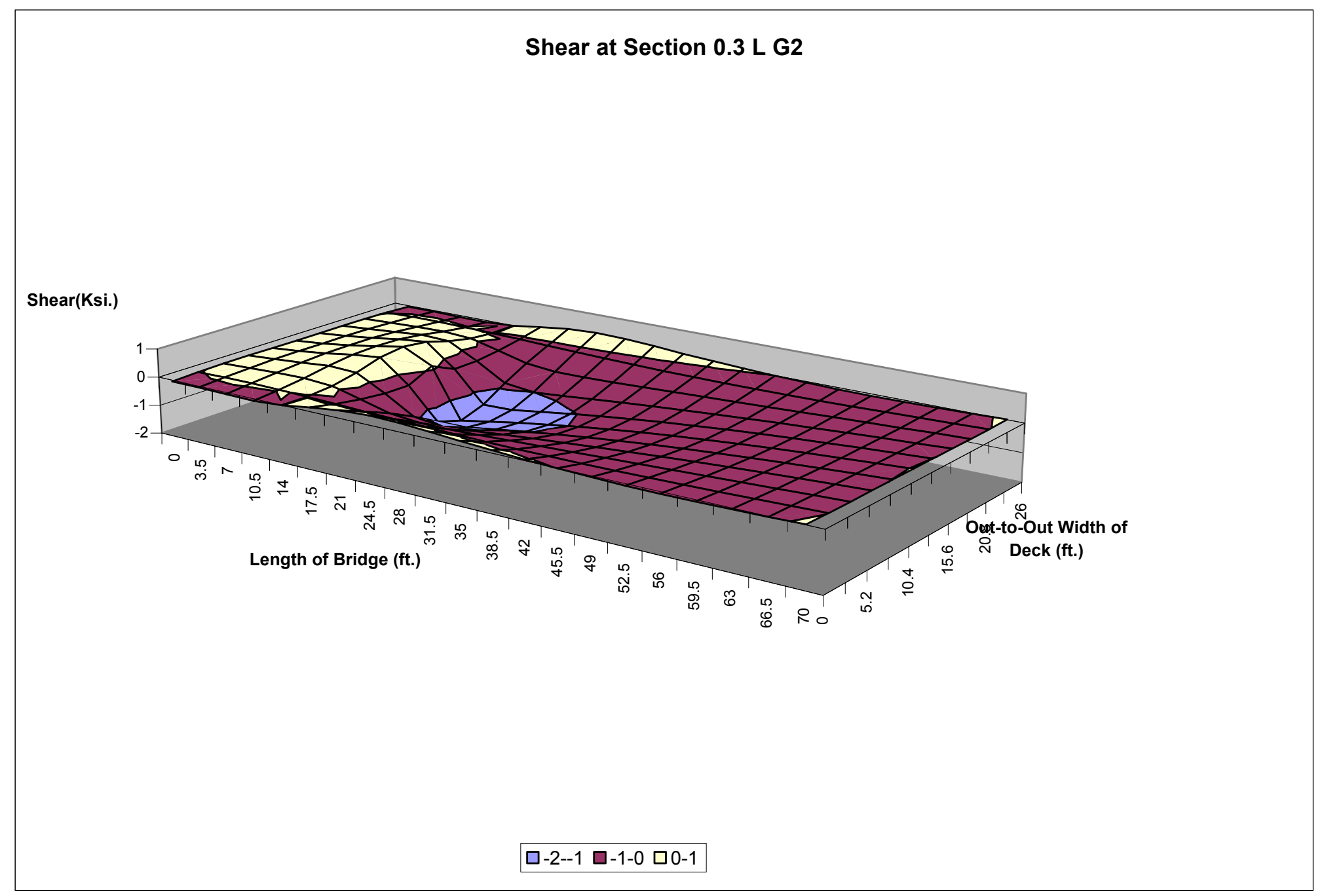

Figure B-52 Influence Surface for Shear at Section 0.3 L G2 


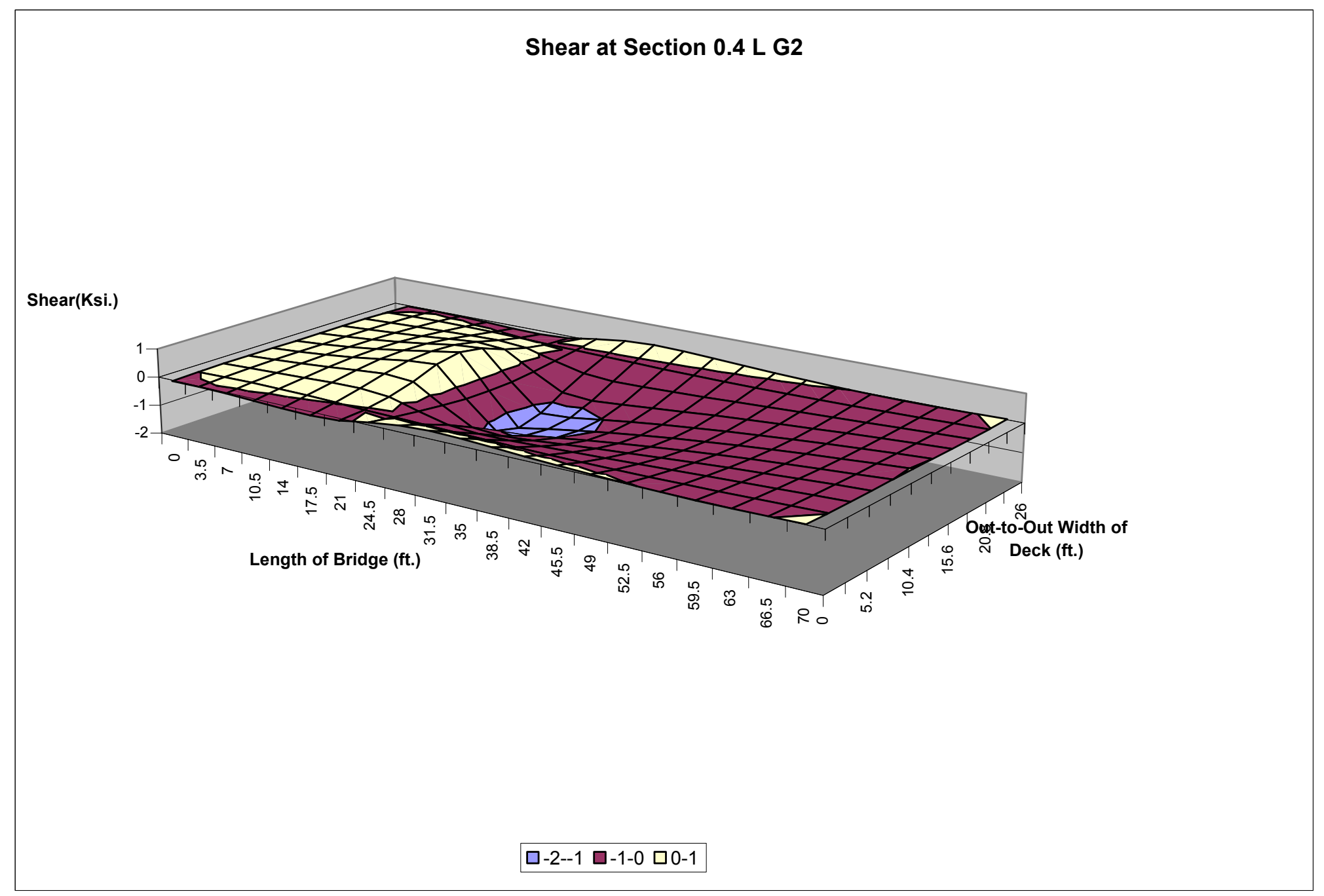

Figure B.53 Influence Surface for Shear at Section 0.4 L G2 


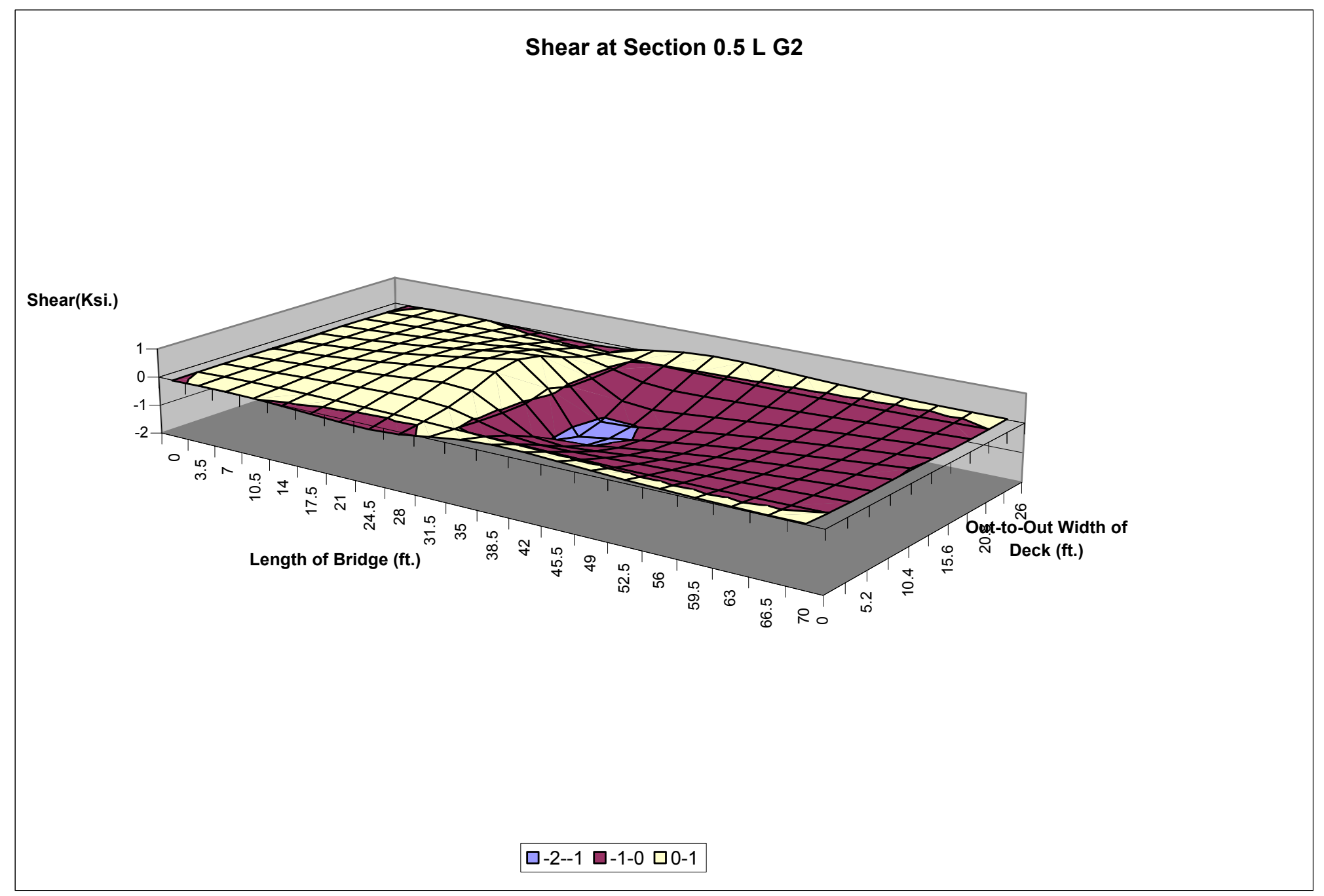

Figure B.54 Influence Surface for Shear at Section 0.5 L G2 


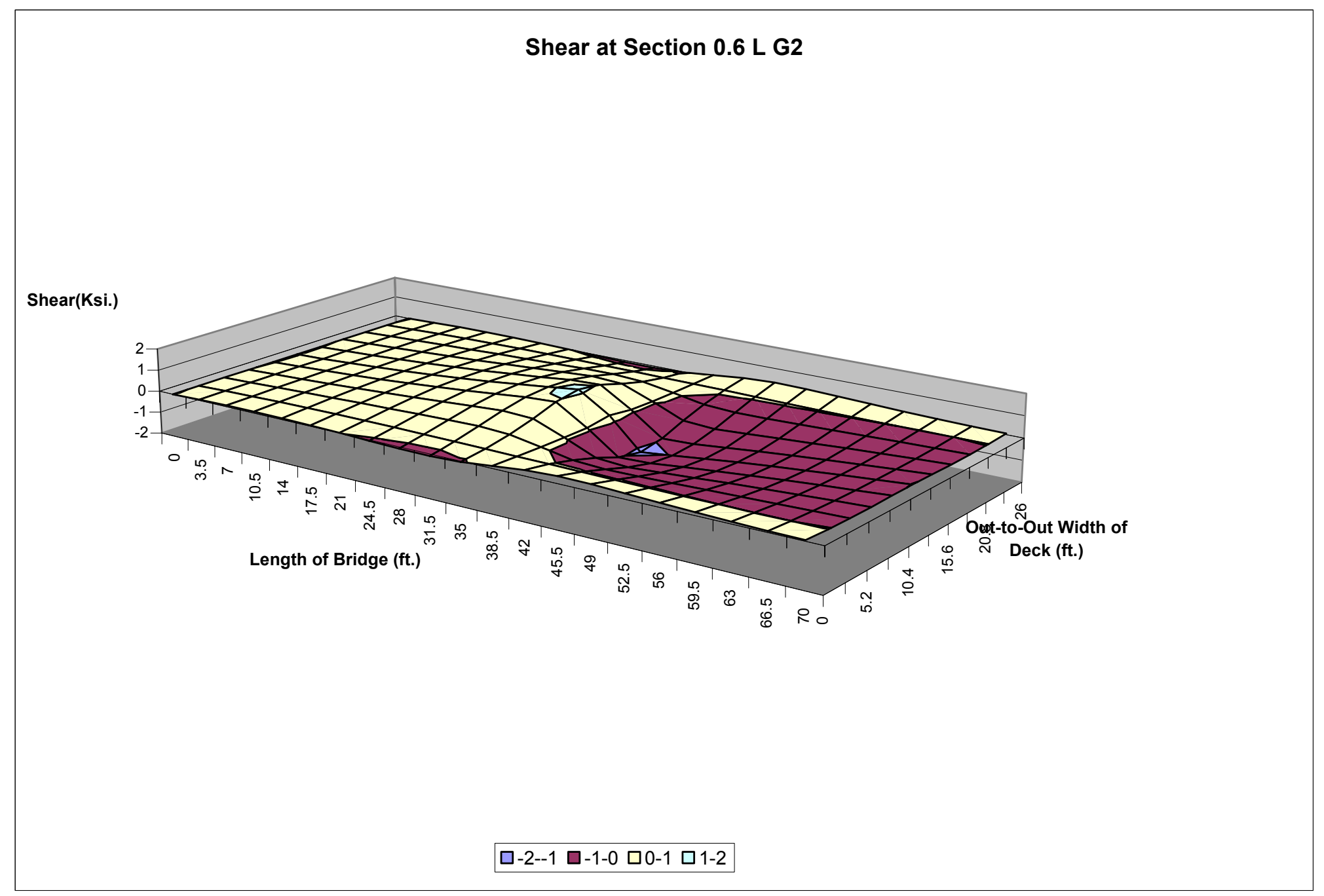

Figure B.55 Influence Surface for Shear at Section 0.6 L G2 


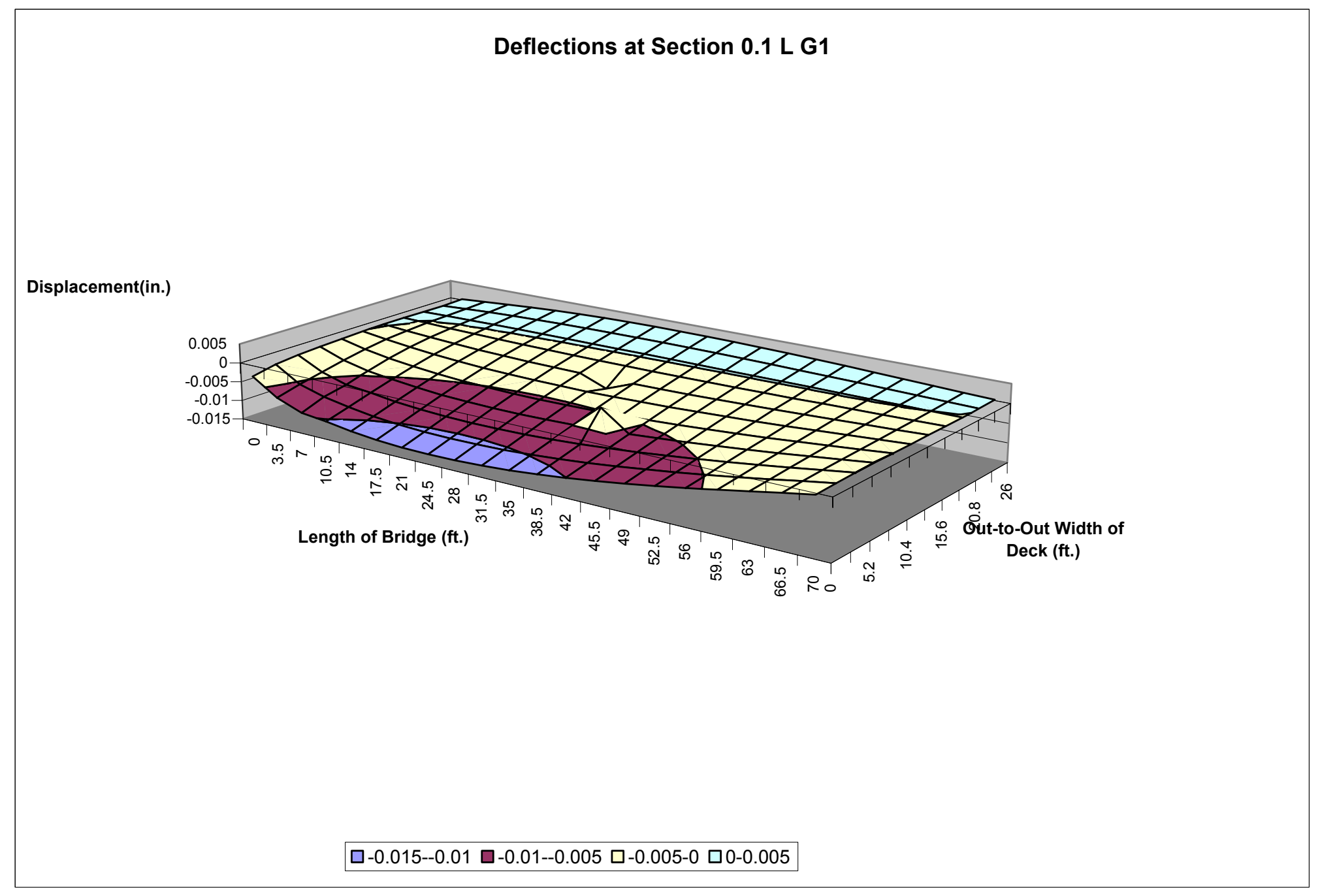

Figure B.56 Influence Surface for Deflection at Section 0.1 L G1 


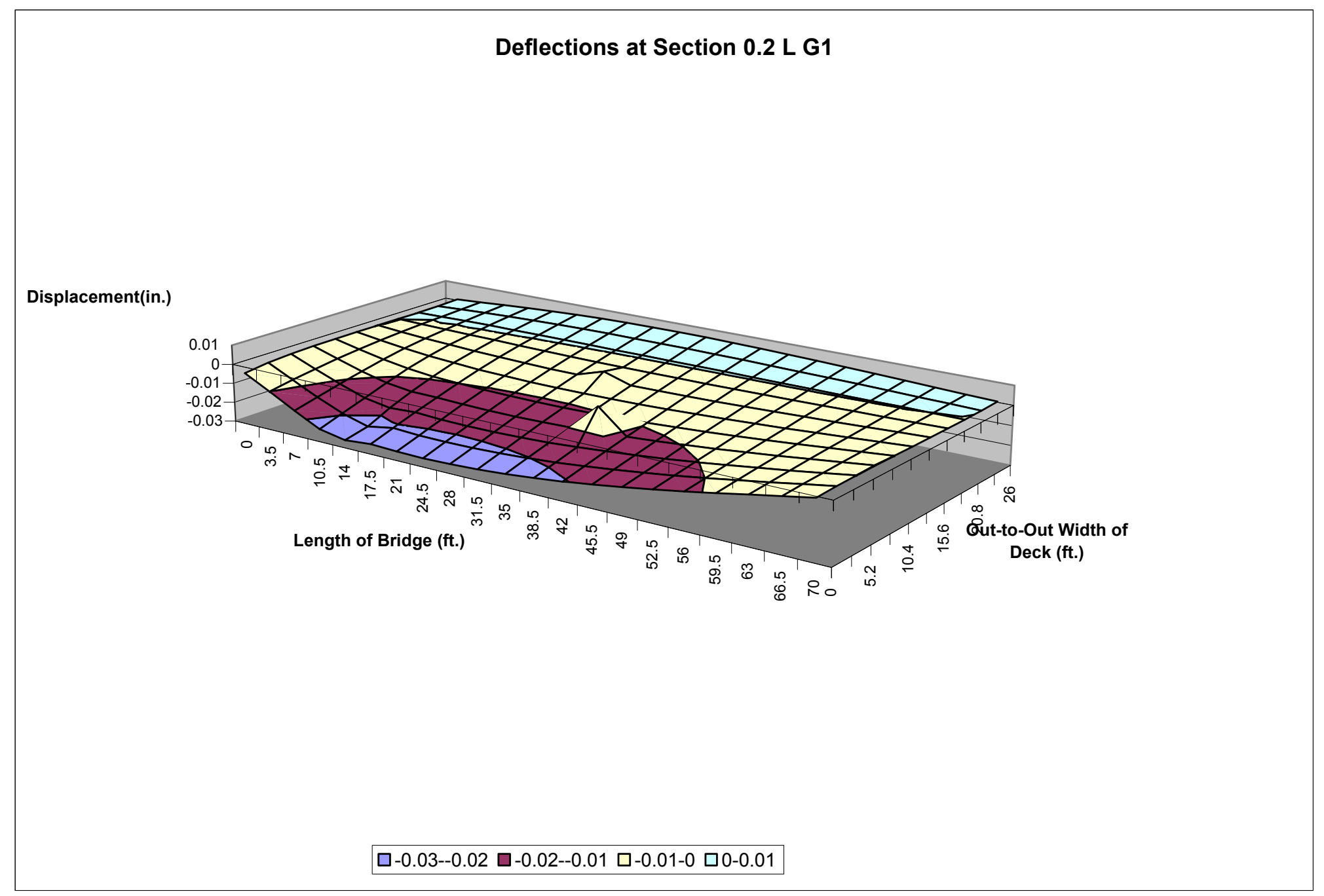

Figure B.57 Influence Surface for Deflection at Section 0.2 L G1 


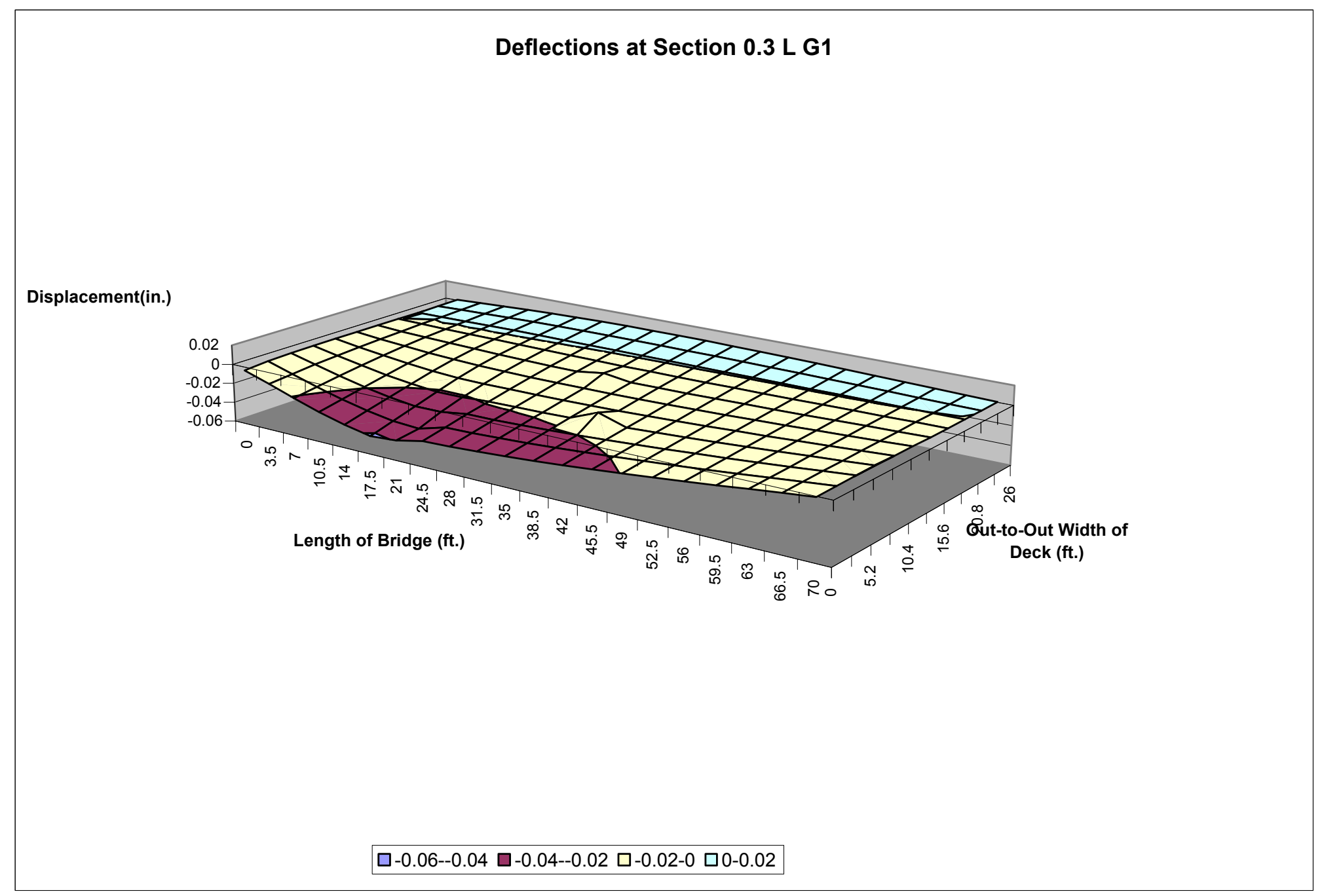

Figure B.58 Influence Surface for Deflection at Section 0.3 L G1 


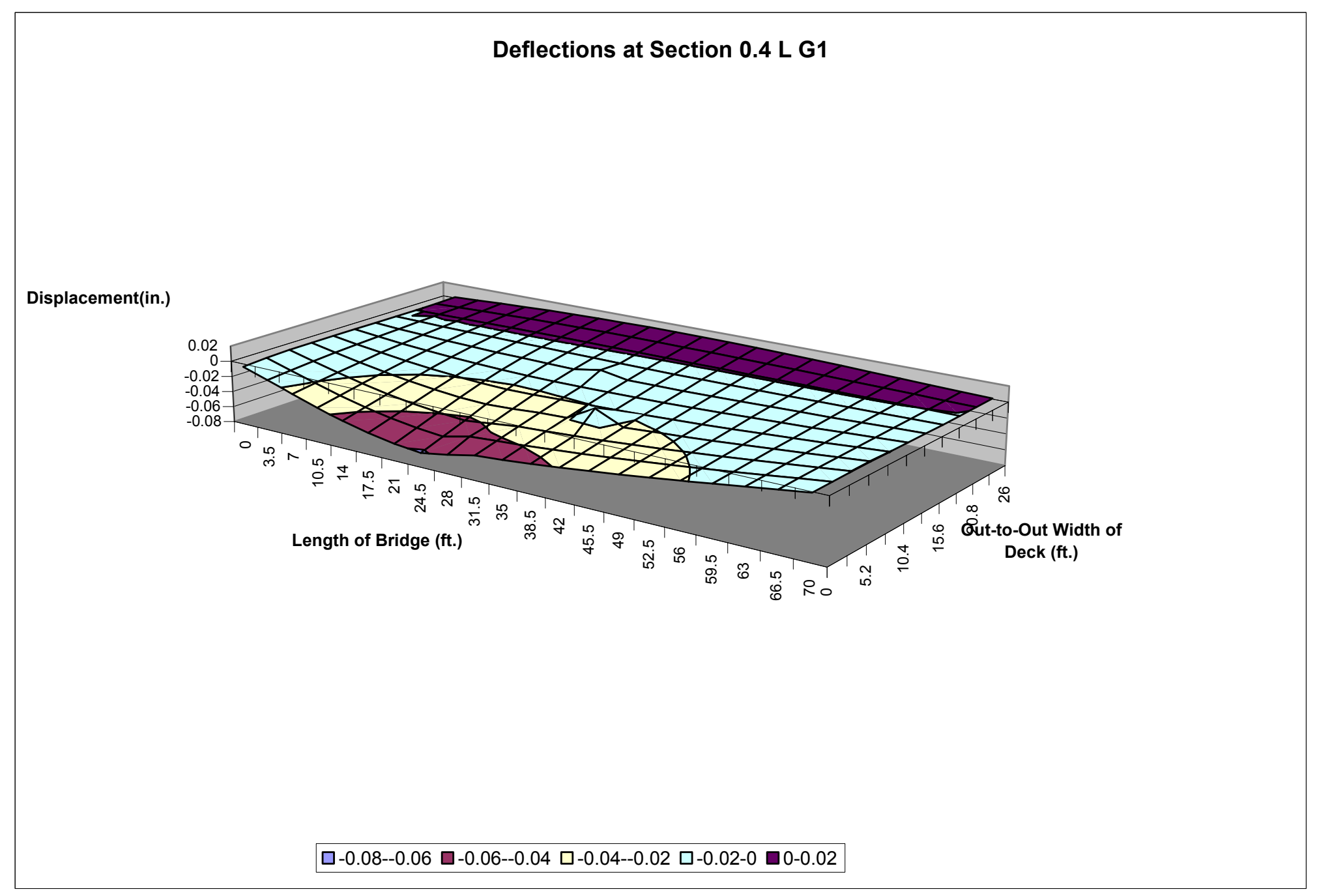

Figure B.59 Influence Surface for Deflection at Section 0.4 L G1 


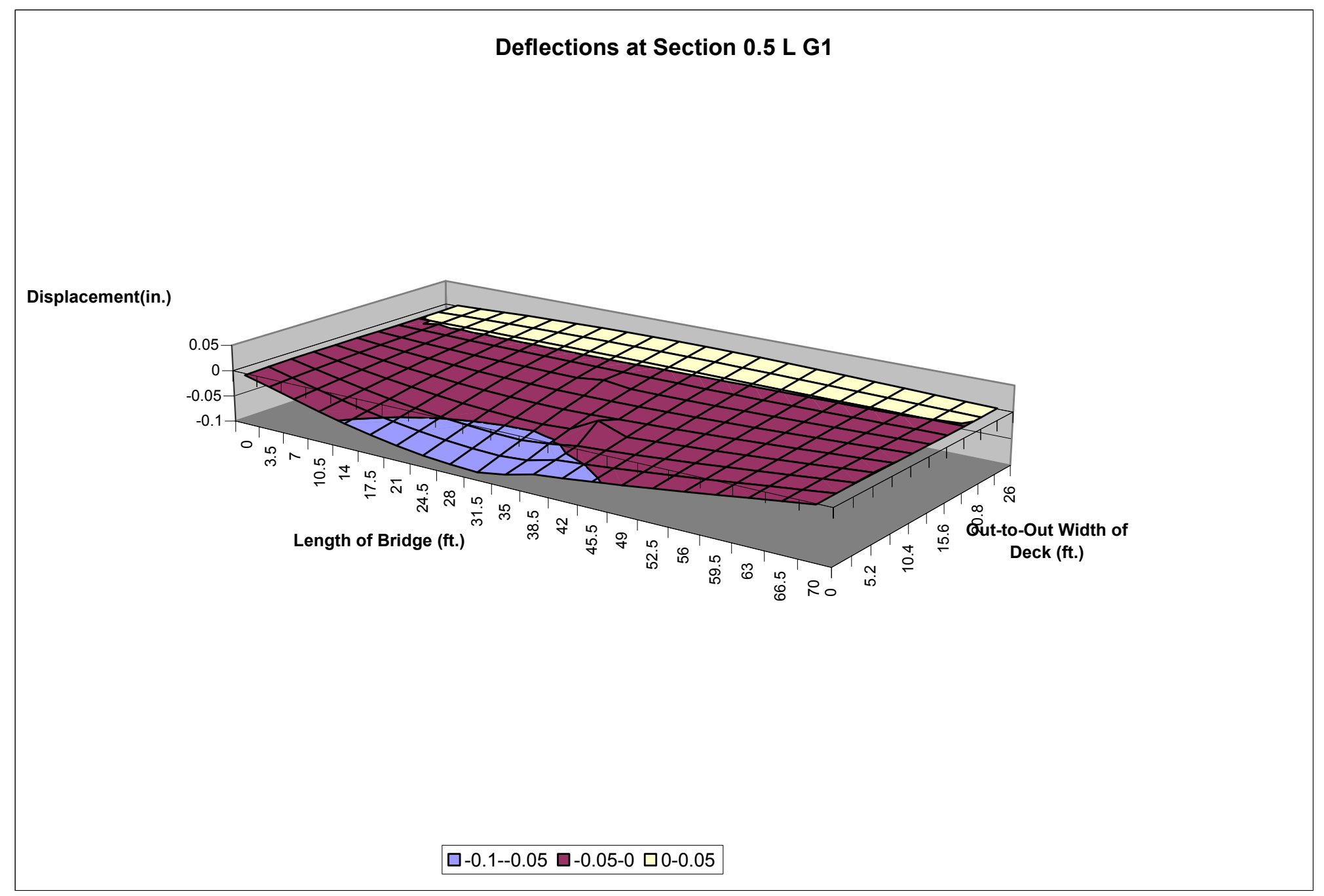

Figure B.60 Influence Surface for Deflection at Section 0.5 L G1 


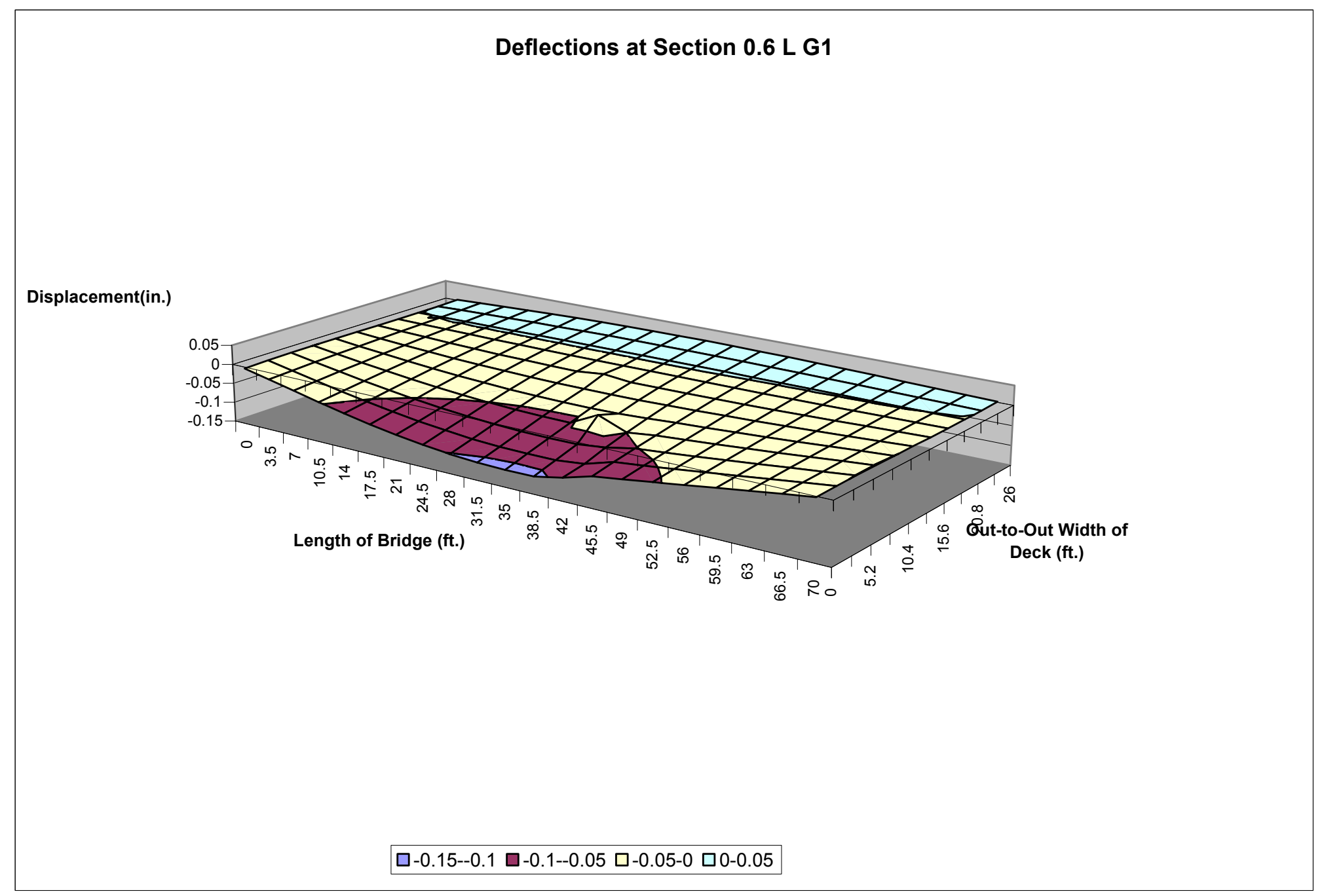

Figure B.61 Influence Surface for Deflection at Section 0.6 L G1 


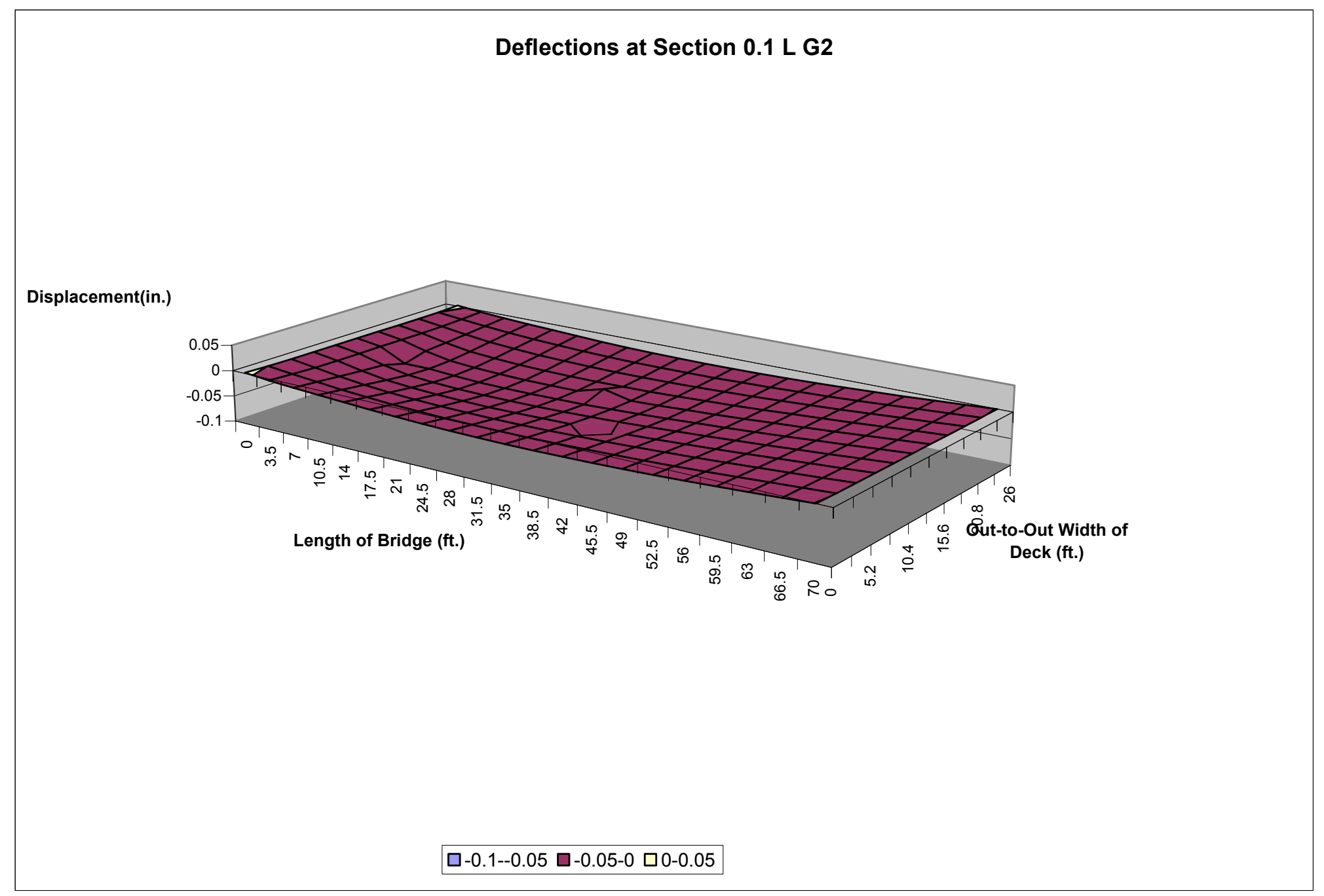

Figure B.62 Influence Surface for Deflection at Section 0.1 L G2 


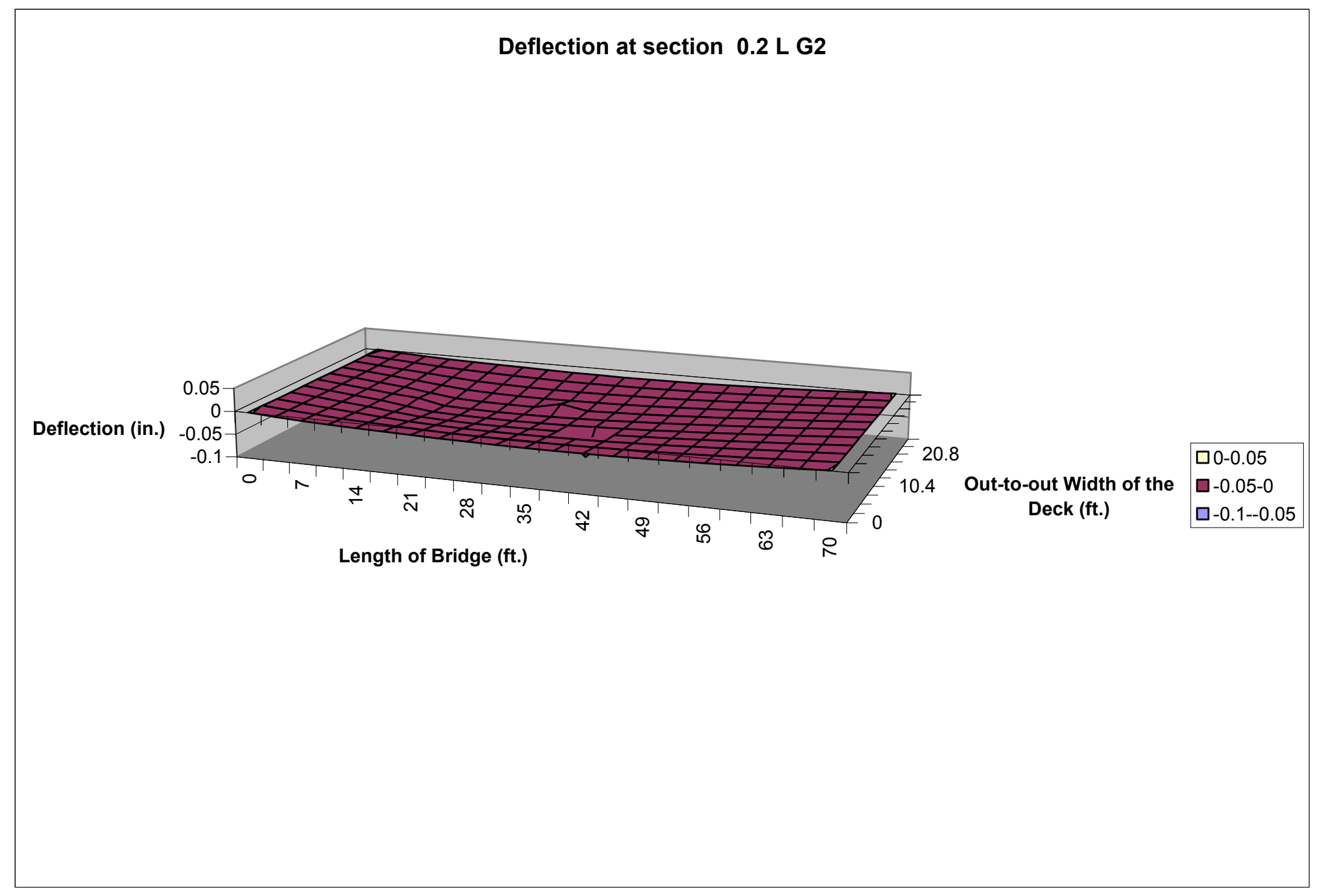

Figure B.63 Influence Surface for Deflection at Section 0.2 L G2 


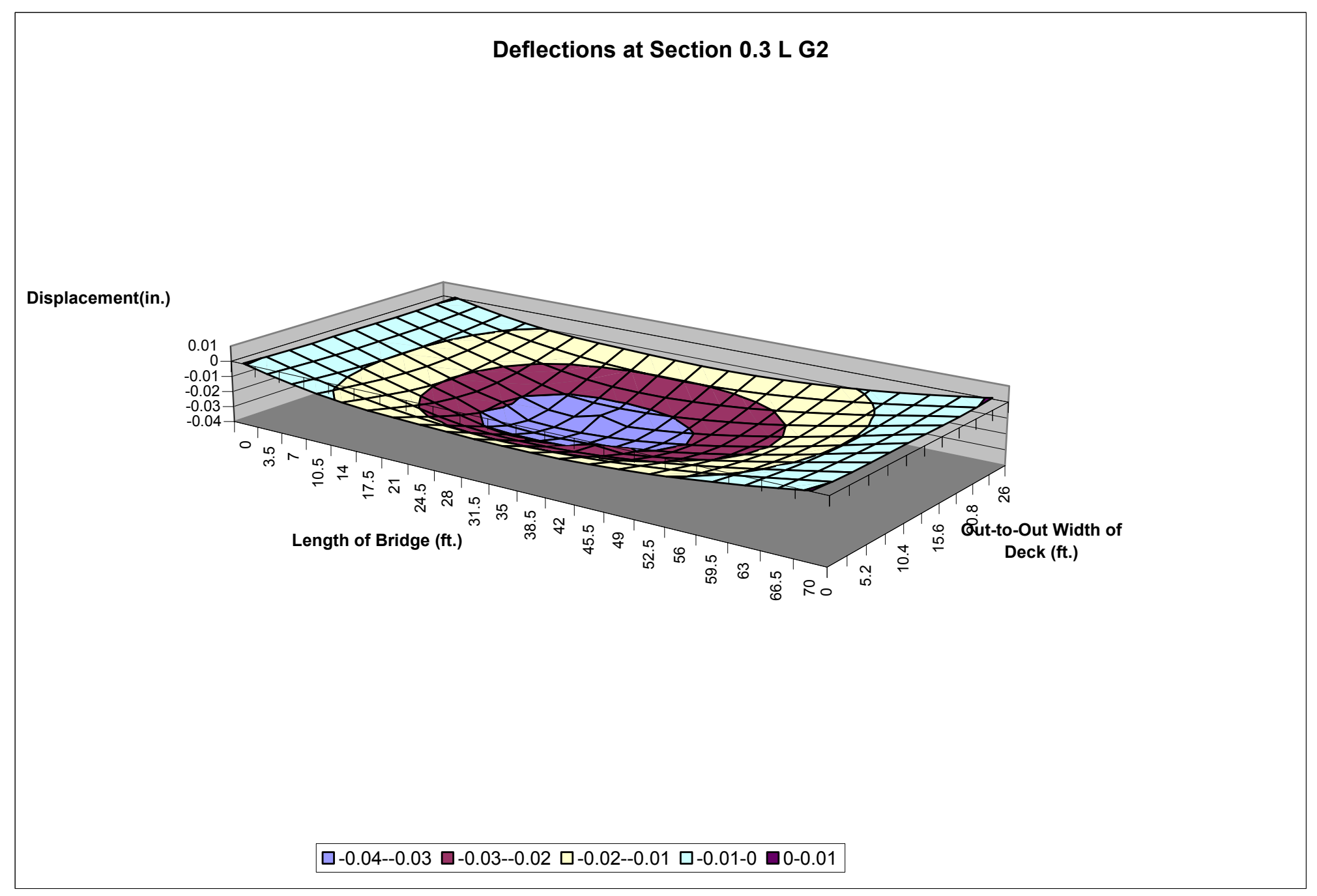

Figure B.64 Influence Surface for Deflection at Section 0.3 L G2 


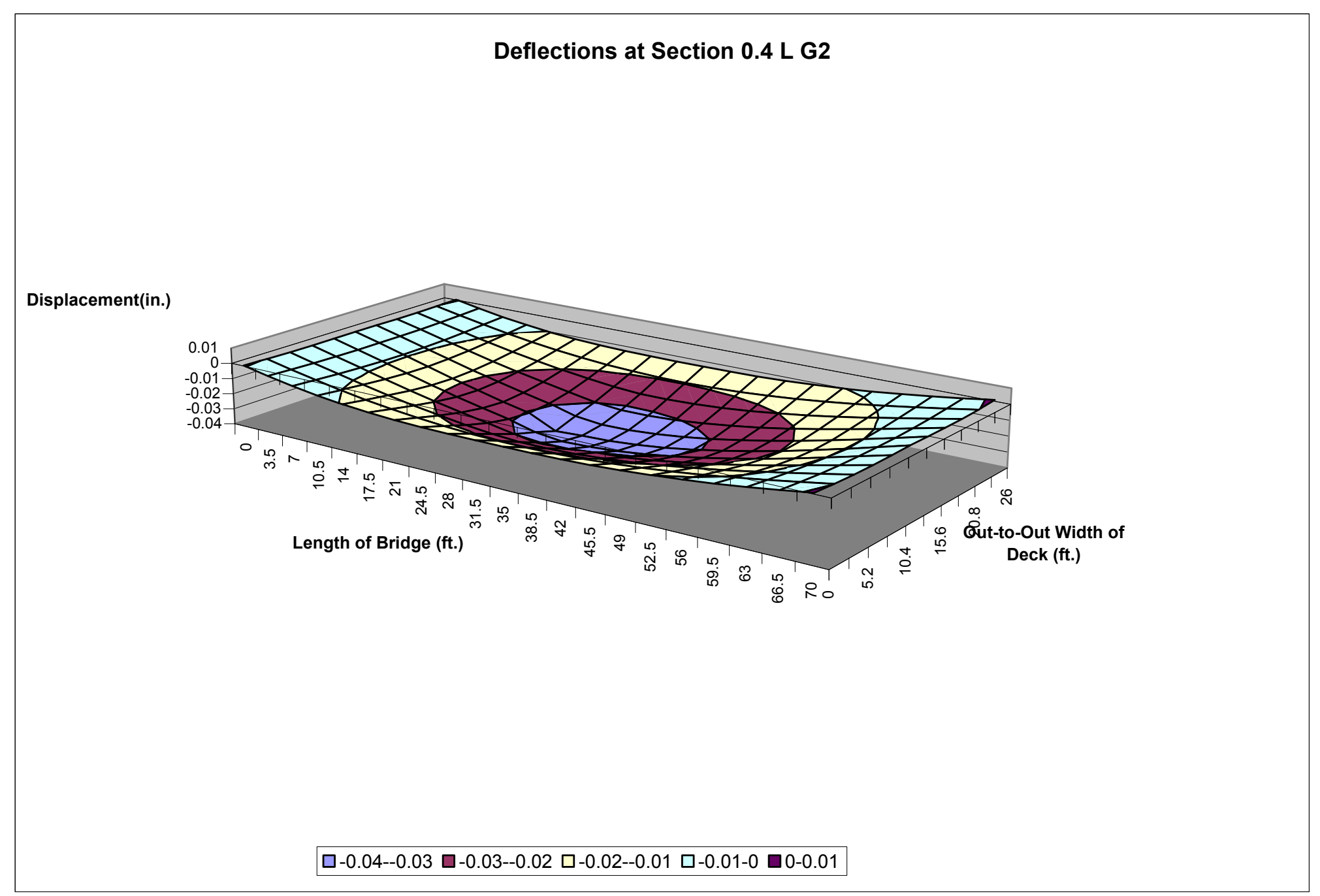

Figure B.65 Influence Surface for Deflection at Section 0.4 L G2 


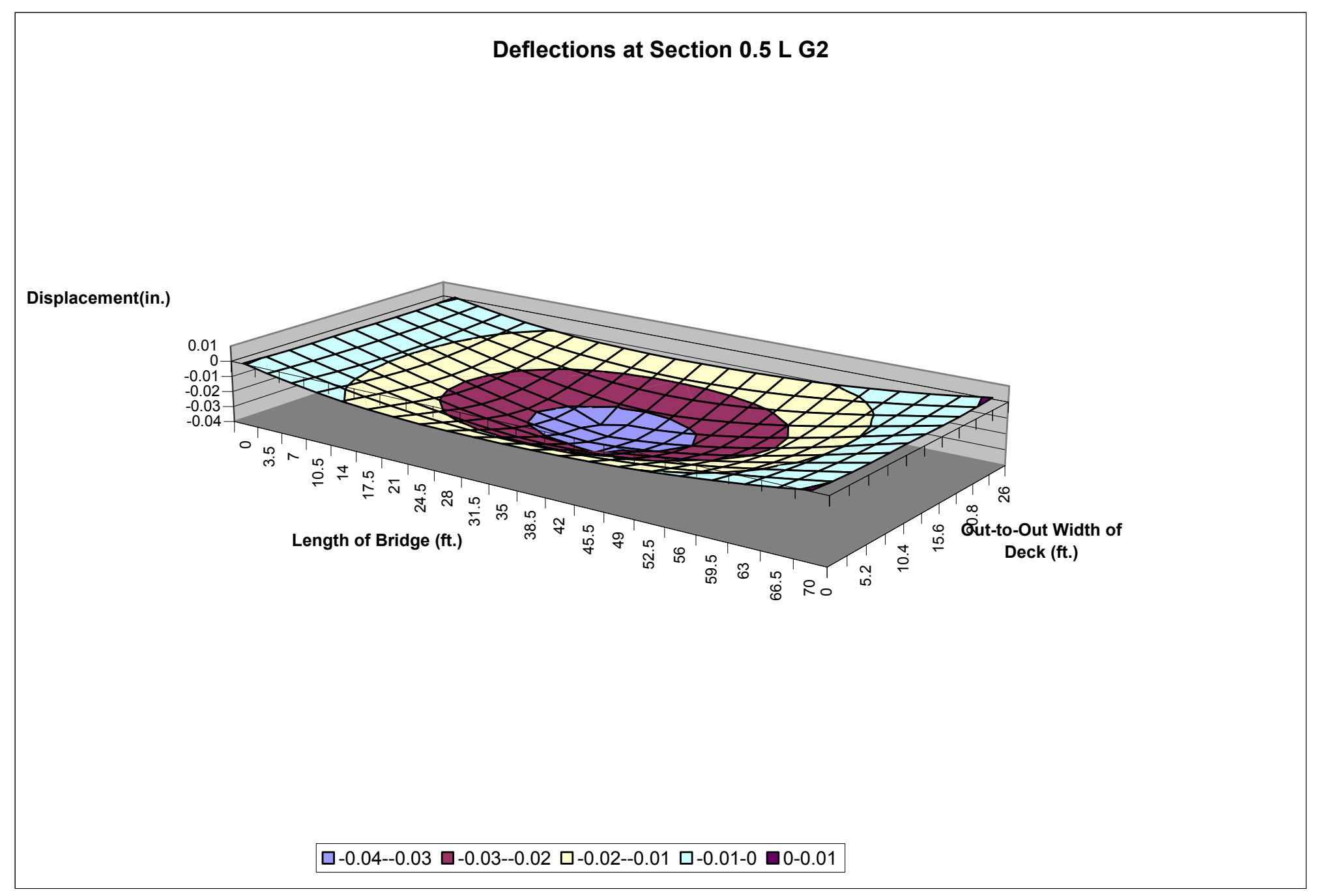

Figure B.66 Influence Surface for Deflection at Section 0.5 L G2 


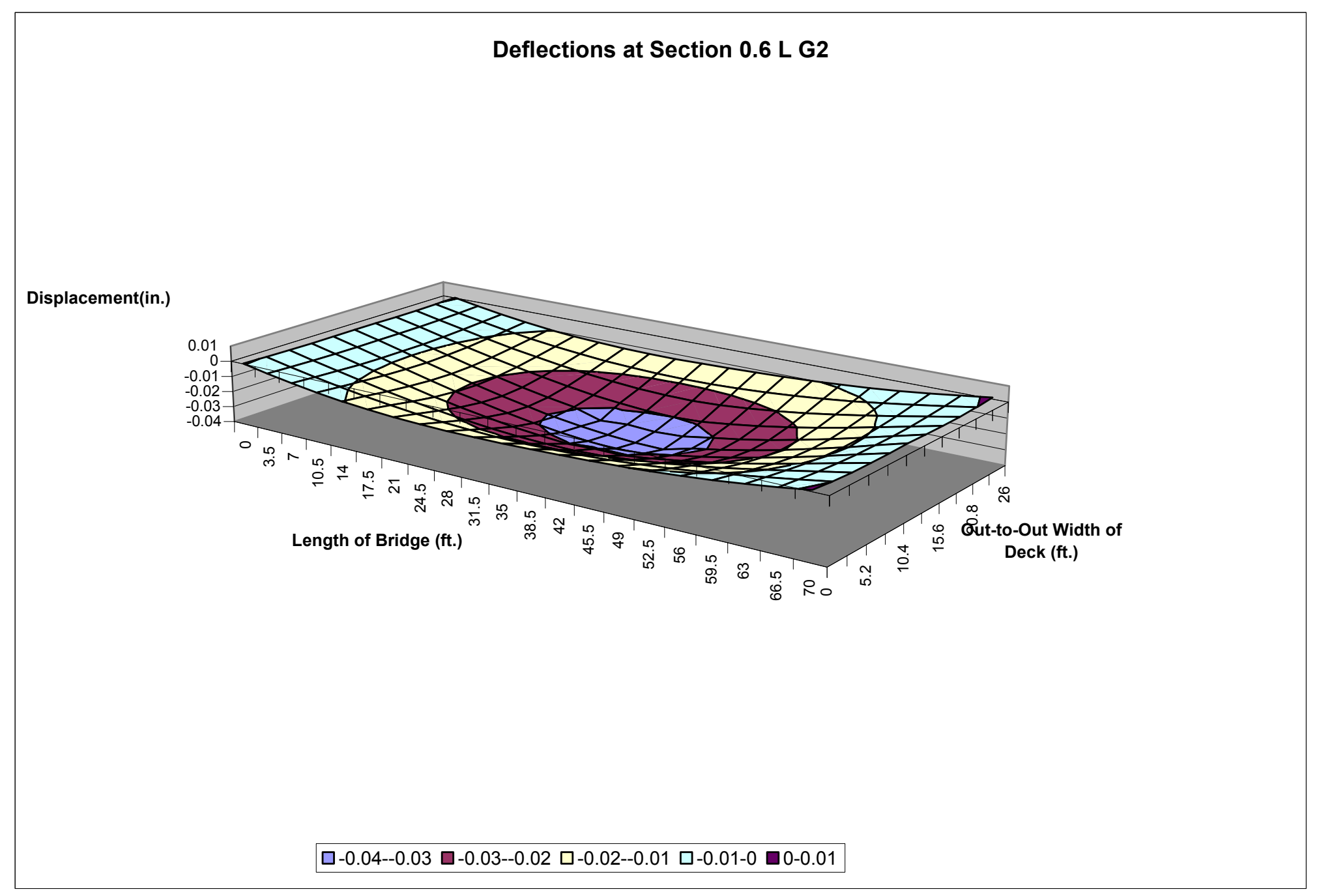

Figure B.67 Influence Surface for Deflection at Section 0.6 L G2 